\title{
LIVING WITH TENSIONS
}

Stories of Chinese early childhood teachers' teaching and learning experiences in the contemporary urban Chinese context

by

JING (JANE) ZHOU

A thesis submitted to the Victoria University of Wellington in fulfilment of the requirements for the degree of Doctor of Philosophy in Education

Victoria University of Wellington 



\section{Abstract}

This narrative inquiry explores 6 Chinese early childhood teachers' teaching and learning experiences in Shanghai and Beijing, where Chinese and Western educational ideas and practices co-exist. Interviews with teachers, kindergarten directors, and parents, and participatory observations and collected documents are analysed and interpreted to reveal the teachers' experiences of being both teacher and learner in the contemporary urban Chinese context.

The teachers' experiences and voices are at the centre of this study and are represented in poetic format. The themes emerging from the teachers' poems are discussed alongside relevant literature in order to gain in-depth understanding of each teacher's teaching and learning experience in specific kindergarten contexts. Emerging themes embody the reality of teaching and learning, professional learning in the embedded community of practice, and the teachers' professional and personal selves. Tensions and challenges the teachers faced in teaching and learning are identified. The enabling and constraining factors that may deskill, re-skill, or empower the teachers are discussed. The teachers' stories suggest that they experience tensions between the multiple and contradicting educational ideas; the embedded kindergarten community's interpretation of teaching and learning at multiple levels; the teachers' personal practical knowledge; and their life as a multifaceted human being. The research suggests the need for kindergarten directors, scholars and policymakers to pay attention to the dynamic relationships 
between a kindergarten's structure, curriculum, pedagogy, images of the child, teachers' personal practical knowledge, professional learning, and teachers' inner selves and agency. 


\section{Acknowledgements}

My first and biggest thank you goes to Linda, Angela, Selina, Cherry, Summer and Cecilia for opening their classrooms and sharing their stories with me. I also want to thank the children, the kindergarten directors, the parents and other teachers from the three participating kindergartens for their support of this study.

My supervisors $\mathrm{Dr}$ Judith Loveridge and $\mathrm{Dr}$ Alison Stephenson have accompanied me throughout this exciting and challenging journey. They have always been there for me, especially when I was experiencing great difficulty recruiting participants and doubting my ability as a researcher. Their professional knowledge, guidance, understanding and encouragement have been particularly important and valuable for a novice researcher like me.

I want to thank Dr Wei Li-Chan who has always been encouraging and shared her own observations and thoughts of early childhood education in different cultural contexts with me. I appreciate my friends Wendy and Angel's help in checking the bilingual letters and information sheets for me before sending them to the potential participants. I am also very grateful to have a group of fellow PhD students who have gone through a similar journey to mine, especially Linda Bonne who I have shared many critical discussions, laughter, and frustrations with.

This project is supported by the Victoria Doctoral Assistantship and PhD Submission Scholarship awarded by Victoria University of Wellington, and the research grant provided by the Faculty of Education. 
Special thanks go to Ms Colleen and Ms Cath who have taken me in as their family member in New Zealand. These two special ladies are also the most influential early childhood teachers in my teaching career and I respect and admire them greatly.

This thesis is dedicated to my family in China, especially my husband Bai Yu, my son Shiming, and my mum and dad. Without their unconditional love and ongoing support, this research project would not be possible. 


\section{Table of Contents}

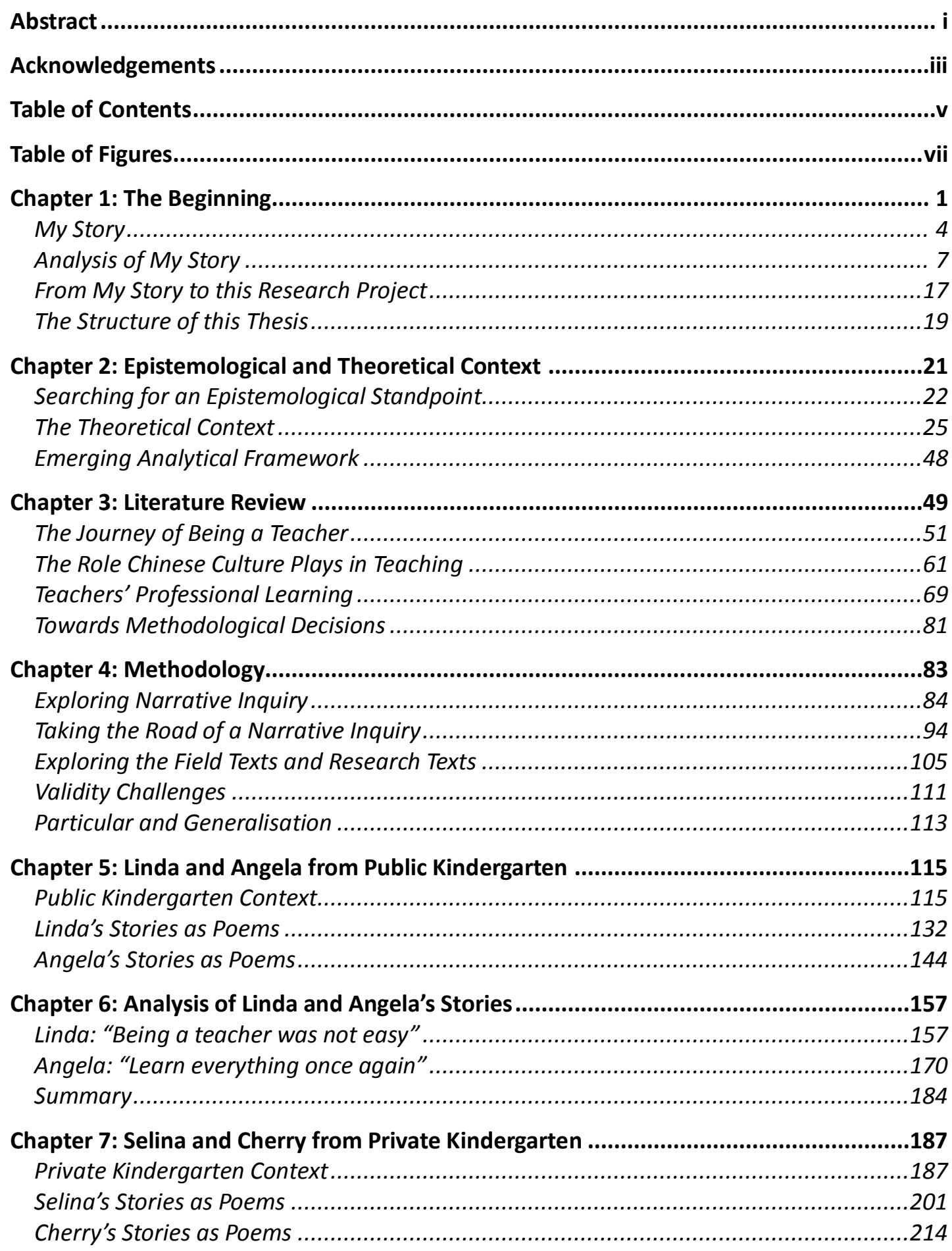


Chapter 8: Analysis of Selina and Cherry's Stories ..................................................227

Selina: "I have my thoughts of ideal teaching, however, ..."....................................227

Cherry: "I learn from children" ......................................................................... 240

Summary..................................................................................... 255

Chapter 9: Summer and Cecilia from International Kindergarten ...................................257

International Kindergarten Context ............................................................... 257

Summer's Stories as Poems ......................................................................... 268

Cecilia's Stories as Poems ..................................................................... 284

Chapter 10: Analysis of Summer and Cecilia's Stories ....................................................301

Summer: "Think back, I did not know how I taught before" .......................................301

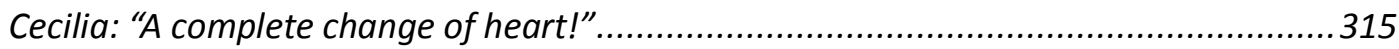

Summary........................................................................................ 330

Chapter 11: Conclusion ........................................................................................333

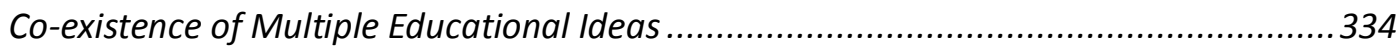

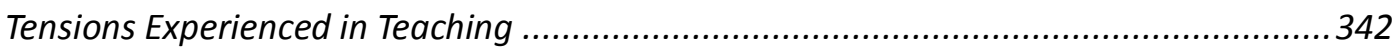

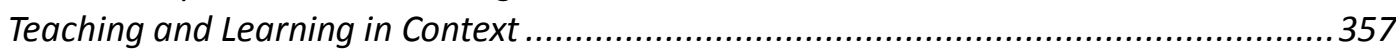

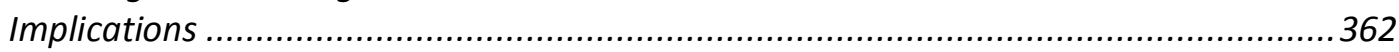

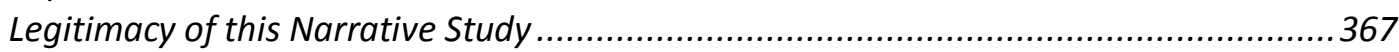

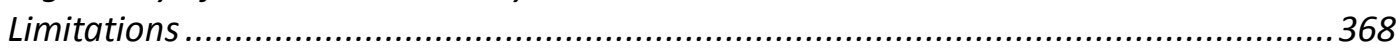

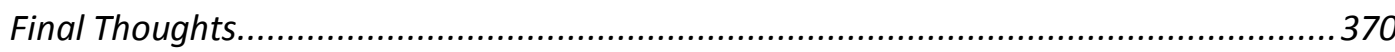

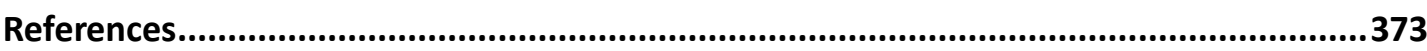

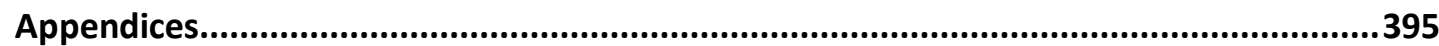

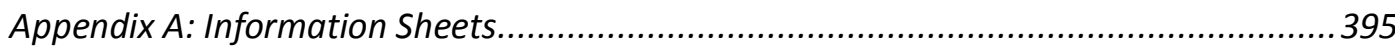

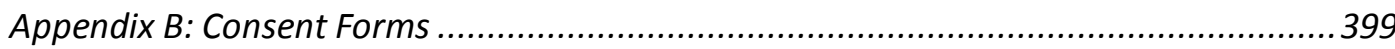

Appendix C: Consent Form for Parents .......................................................... 400

Appendix D: Sample of Observation Notes..........................................................401

Appendix E: Interview Schedules for Teachers ...............................................402

Appendix F: Interview Schedule for Kindergarten Directors .................................. 404

Appendix G: Interview Schedule for Parents................................................... 405

Appendix H: Simplified Letter and Consent Form for Public Kindergarten's Parents (in

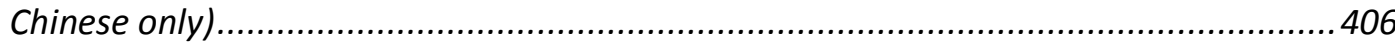

Appendix I: From interview transcripts to pomes ........................................... 408

Appendix J: Sample of Analytical Memo - Cecilia ............................................. 412 


\section{Table of Figures}

Figure 2.1 My integrated and interpretive approach to multiple educational ideas ...........24

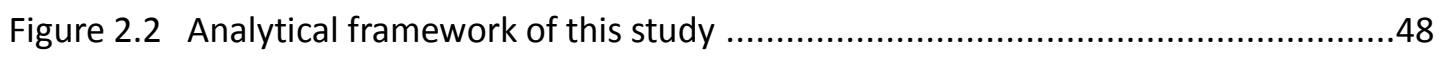

Figure 4.1 Three dimensional narrative inquiry space .................................................. 87

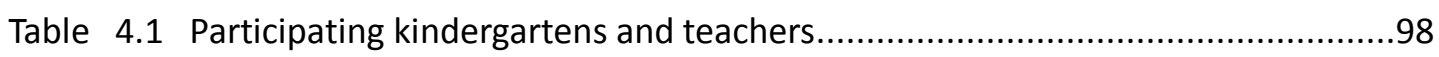

Figure 4.2 Data collection tasks and timeline ….....................................................99

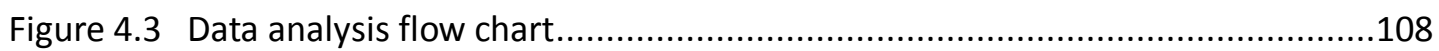

Figure 5.1 Representation of the concept of teacher-child-dual-subjectivity ...................118

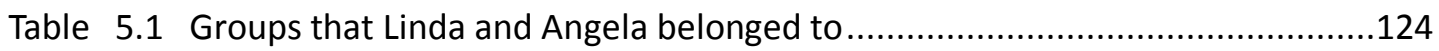

Table 5.2 Summary of professional learning activities over 16 days' observation ...........126

Table 5.3 Daily timetable of Linda and Angela's class (Autumn/Winter) .........................131

Table 7.1 Daily schedule for Selina and Cherry's class .................................................197

Table 7.2 Meetings Selina and Cherry attended over 16 days' observation .....................198

Table 9.1 The daily schedule of Summer and Cecilia's classes ......................................267

Figure 11.1 Context of Chinese early childhood teachers' teaching and learning................358 



\section{Chapter 1: The Beginning}

My research interest in Chinese early childhood (EC) teachers' teaching and learning experiences emerged from my own experiences of being a teacher and student in different kindergartens, and social and cultural contexts in Shanghai, Beijing, and Wellington. The differences, changes, uncertainties, and challenges I experienced when working with different educational ideas and practices in different contexts over time led me to wonder whether other Chinese early childhood teachers would face similar experiences to those I had encountered. I therefore proposed a research question at the beginning of my research journey: how do Chinese early childhood teachers work with the tension between traditional and modern early childhood educational discourses in contemporary China. I also wanted to place teachers at the centre of the study, enter their everyday teaching and learning, listen to their stories, and understand their feelings and perceptions of being a kindergarten teacher.

Clandinin and Connelly's (2000) book Narrative Inquiry: Experience and Story in Qualitative Research enlightened me when I was searching for an appropriate research method for my investigation. After reading some narrative studies of teachers' experiences (Connelly \& Clandinin, 1990; Craig, 1997, 2007; M. F. He, 2002a, 2002b, 2002c; X. Li, 2005; Scherff, 2008), I learnt that narrative inquiry would allow me to inquire into Chinese EC teachers' lives and experiences over time and in different contexts. Moreover, the process of telling-retelling-reading the participants' stories could be a way of communicating between the participants, the researchers, 
and the readers, which could be collaborative and non-judgemental. Therefore, I believed that narrative inquiry resonated well with what I wanted to achieve in this study.

To guide my investigation, I also proposed three sub-questions in my research proposal:

1. What are the dominant early childhood educational discourses in contemporary China?

2. a. How do Chinese early childhood teachers make sense of the curriculum in their kindergartens?

b. What knowledge or discourses do they draw on to help them interpret the curriculum and their practices?

3. What strategies do Chinese early childhood teachers use when dealing with uncertain and ambiguous teaching and learning situations?

At that time, the overarching research question and the sub-questions were very useful in guiding the data-collection process. As my understanding of narrative analysis deepened and as I interpreted the teachers' narratives, I found that the teachers focused more on multiple educational ideas they encountered, rather than on certain types of discourses that they worked with. Therefore, I changed the wording of the overarching research question from "work with" to "experience", and from "discourses" to "ideas and practices", and now this study's overarching research question is: "How do Chinese early childhood teachers experience the tension between traditional and modern early childhood educational ideas and practices in contemporary China?"

Moreover, during data analysis, I realised that the teachers' narratives had a life of their own. The teachers' narratives actually directed me to attend to the 
reality of teaching that each teacher experienced, their different professional learning experiences, and their feelings and identity, rather than what the proposed sub-questions were concerned with. In particular, various tensions emerged from the teachers' experiences at the personal and practical levels when they encountered uncertain and ambiguous moments concerning teacher-child relationships, planning and actual teaching, individual children's needs, and group needs. These tensions became very significant since they seemed to shape the teachers' experiences of (re)conceptualising teaching and learning, pedagogy, socialisation, and personal and professional self. Therefore, they led me to focus on why such tensions emerged and how the teachers experienced and responded to them rather than on the teachers' strategies when dealing with uncertain teaching situations. The analysis of these tensions also helped me understand the possible sources of the uncertainty and challenges I had experienced as a teacher myself. This realisation was exciting, as I started to gain in-depth understanding of my own experiences during this reflexive research journey. Based on these considerations, I decided to focus discussion of the findings around the themes emerging from individual teachers' stories on experienced tensions, rather than directly answering the proposed sub-questions in this thesis. However, my thematic analysis does eventually provide some answers to each of the proposed questions.

Narrative inquiry often starts from the researcher's own narrative of experience (Clandinin \& Connelly, 2000). Hence, my report of my narrative inquiry journey begins with the telling and retelling of my own story of being a student and Chinese early childhood teacher. As will become apparent in later sections, my own teaching and learning experience has influenced the direction and the design of this 
study. At the same time, what I have learnt from Chinese and Western literature, the participants, and different social and cultural contexts during this research journey has also shaped my own understanding of who I am as a teacher, PhD student, and researcher. Therefore, my understanding of my own experiences has been transformed by the experience of doing this research.

\section{My Story}

"We teach who we are."

(Palmer, 1998, p. 2)

\section{Late 1970s, Shanghai}

I only went to kindergarten for six months.

I often role played teacher and gave instructions to my younger brother. I would have loved to learn piano but my parents could not afford it!

\section{0s, Shanghai}

I was trying to be an "early bird" as my mum expected.

My entrance exam scores did not qualify me to study at the top middle schools. I believed that was because I did not study hard enough.

I disappointed mum and lost confidence.

I went to study at an average middle school.

I was doing well academically at the middle school.

My confidence was boosted!

Mum told me that was because I was the "taller" one among the "shorter" ones.

I needed to decide what to do after middle school.

I wanted to learn piano and music.

I wanted to be independent.

I wanted to avoid serious high school entrance exams. 
I decided to study at a residential preschool teacher's training college.

I was confident of passing the training college's entrance exams.

I felt a sense of control in my life.

I started my preschool teacher training at the age of 15.

I enjoyed the freedom and independence of boarding at the training college.

I got the teaching diploma after five years of training.

I was very comfortable to be an average student.

Like all future teachers in training, I received approximately CNY $¥ 30 / N Z D \$ 6$

grant each month from the government.

\section{Early 1990s, Shanghai}

I started my teaching career at a newly established state-run kindergarten. I worked there for three years and taught children from 4 to 6 years old. I had taught a class with forty-two 5 and 6-year-old children.

I won the second prize at a young kindergarten teachers' teaching contest.

I wanted to do the job well so I could meet other people's expectations.

I attended night time English and professional typing classes.

I thought these courses might help me find an office job in the future.

I went to classes after work, sat there listening or practising.

I passed tests and got the respective certificates.

\section{Late 1990s, Beijing}

I married a Beijing boy.

I decided to continue my teaching career after relocating to Beijing.

I got a job as a Chinese teacher at a newly established international school.

I started to work alongside foreign and English--speaking early childhood teachers for the first time.

I started to work with children who spoke different languages from all around the world.

But I had never spoken English to foreigners before.

I had to use English for communication, reading documents and writing reports.

I was ignorant of Western curriculum and teaching approaches.

I had to learn and work with foreign curriculum and approaches.

I could not teach according to my teaching plan on my first day.

I learnt that I needed to know the children before any planning.

I realised that my teaching diploma seemed not enough as a qualification.

I needed a degree.

I could not study at university since I did not have mainstream high school qualification.

Self-study Higher Education Examination was an alternative for me to get a 
degree.

I chose to study Chinese since I was teaching young children Chinese.

I needed to self-study all required textbooks and memorise all learning contents.

I needed to take the exams that were organised twice a year nationwide.

I could get a degree major in Chinese if I passed all the exams and wrote a

thesis.

But I did not!

I stopped this journey after two exams, I did one well and failed another.

\section{Early 2000s, Beijing ...}

I was promoted to a leadership role at the international school where I was teaching.

I was learning how to be a school leader while working alongside an

experienced Western principal.

I presented at the NAEYC ${ }^{1}$ annual conference in Chicago with a Western teacher.

I needed a degree desperately.

Online university emerged.

Its flexibility attracted me.

I enrolled in an education management programme.

I attended lectures with hundreds of other students every weekend on campus.

I listened to the tutor's presentation, noted down important passages in the textbooks, tried to memorise all the important content.

I needed to pass the exams as well as other assignments for each course.

I did very well in the educational psychology course.

I quit study after missing an advanced mathematic exam.

I was on a business trip and I knew I could not pass it.

I tried to balance my life as a new school leader, a student and a mother.

I failed to get a degree again.

I resigned from the school leadership role.

I went back to classroom teaching.

\section{Late 2000s, Wellington, New Zealand}

I considered my former New Zealand co-teacher's suggestion of furthering my study in New Zealand.

I passed IELTS ${ }^{2}$ test with an average score of 7.5/10 without attending any English courses.

My diploma and 14 years of teaching experience were recognised by Victoria University of Wellington.

I was accepted into the Master of Education programme.

I paid tuition fees approximately NZD\$20,000 per year.

\footnotetext{
${ }^{1}$ NAEYC stands for The National Association for the Education of Young Children.

${ }^{2}$ IELTS refers to the International English Language Testing System.
} 
I taught part time at a newly established preschool in Wellington while studying. I enjoyed reading, thinking, presenting, group discussions, writing assignments, and no exams.

I found learning could be meaningful, stimulating, exciting and satisfying. I started to reflect on my past passive and rote learning experience along with the current active and critical thinking focused learning.

I completed the master's programme with merit after two years of study. However, I still felt I only knew very little of early childhood education. I therefore carried on my study by undertaking this doctoral research project.

\section{Analysis of My Story}

Writing up the above snapshots is a process of reliving my life as a student and an early childhood teacher. In this section, I analyse these lived experiences by connecting myself with the landscape that constituted my learning and teaching journey (Greene, 1978). I also search for my own vantage point where I start my contact with the participants' world.

\section{A journey of finding paths to the future}

I have lived in a "good time era" according to my grandpa who had lived through war, famine, and the Cultural Revolution to mid-1990s. The era I have been living in is when Chinese society has experienced mass reform in political structure, economy and education. The forces behind the mass reform are the power of the centralised and autocratic political system through policies and regulations, the urge to be part of the global market, and the value of science and technology (Paine, 1986). As a result, Chinese people have enjoyed increasing wealth, possibilities and opportunities, and increasing interactions with the wider world. My story thus is 
constituted by a booming economy, modernisation of life styles, and integration into the global world. The "good time era" also comes with peculiar challenges, such as uneven distribution of capital and resources, decreasing number of family members in the younger generations, and fast developing technologies and access to an overwhelming amount of information. When facing these challenges and finding paths to the future, the Chinese government and people learn from Western approaches, adapt them to the Chinese context, propose new ideas and plans, test and try out the ideas at some institutions as models, reflect and evaluate, then promote the tested models nationwide.

My approach to finding paths to the future seems different to the government's approach since I cannot test my steps before moving, but must live with them. There were many good examples of students who succeeded in the Chinese education system, but I had experienced many failures, self-doubts and disappointments when finding my paths towards higher qualification in the same system. I did not have enough knowledge and skills to succeed in this particular context. However, I had instilled Chinese culture and my personal teaching and learning experiences accumulated over the years in different contexts. They are my personal knowledge gained through tacit knowing (Polanyi, 1962). They have sustained my learning, enabled me to study abroad, and became the genesis of this study.

\section{A journey of understanding teaching and learning}

Over the years, I have learnt to work with people who speak different languages and to teach children with diverse cultural backgrounds. This experience 
has given me insight into multiple ideas of teaching and learning. Through interacting with different external environments, I have gone through three phases when developing my understanding of teaching and learning: crossing the one-log bridge, finding my way in a maze, and driving on an open highway with maps.

During the crossing the one-log bridge phase, I studied the explicit knowledge written in the textbooks by modelling, mimicking and memorising. As a student, I experienced a culture of learning that was traditional and influenced by Confucian cultural heritage (Biggs \& Watkins, 1996; Clark \& Gieve, 2006; Jin \& Cortazzi, 2006). I was expected to listen carefully and to study hard. I had to pass gate-keeping exams (one-log bridges), which I was afraid of, in order to pursue higher education. I learnt to choose a log-bridge that was less popular and seemed a bit wider, so that I could keep myself in the learning journey.

The finding my way in a maze phase started right after working with Western teachers in the international school. The teaching and learning I was once familiar with was no longer relevant. I knew nothing about teaching foreign children. I could not understand the curriculum documents since they were all written in English. I planned the lessons and activities in the ways that I used to plan, but they did not work. I was lost and did not seem to know how to teach anymore. I tried to lean on my Western teaching partner. However, she was in a similar state as this was her first time teaching outside her own country. Prescriptive curriculum went out of the window because there were no early childhood curricula suitable for international schools in 1996. We were both lost. We had to turn to the children and to learn from them. There were many early childhood educational (ECE) ideas I encountered during that time, and many times I was confused. I was still trying to find a suitable 
log-bridge to cross for higher education in China, but I did not want to passively accept what was available for my learning. Sadly, there seemed to be no courses suited to my learning style and to meet my needs at that time.

Now I am on a journey of finding my next destination by driving on an open highway equipped with maps. There are many possible routes to get there, but I am confident I can find my way to the future. This metaphor expresses my current understanding of teaching and learning as an active, contextualised and wellequipped journey from the experienced past to the unknown future. Such understanding has been influenced by my first-hand learning experiences in different learning contexts: from a passive, quiet, rote learning experience in China, to an inquiry-based learning experience as a PhD student in New Zealand, encouraged and learning to be critical by drawing on both Chinese and Western ideas.

\section{A journey influenced by the conceptual worlds}

My journey is not only shaped by particular social and cultural contexts, but also conceptual contexts. Over time, traditional Chinese educational ideas, Western educational ideas, and co-influences of Chinese and Western ideas have created three different external conceptual worlds, shaping my understanding, actions, and feelings as a learner and a teacher. In the following discussion, I explore the three conceptual worlds as embodied, foreign, and chaotic to help me understand my "relations with the perceptual field that are given in experience" (Greene, 1978, p. 2). 


\section{The embodied conceptual world: traditional Chinese educational ideas}

My initial learning and teaching experiences were shaped by the traditional Chinese intellectual culture and most significantly influenced by Confucian thoughts (D. L. Hall \& Ames, 1995). At the centre of Chinese traditional education belief is that to know and to think are the selective processes of acquiring and comprehending the existing moral, principled, and authorised knowledge (D. Zhang, 2003). These views underpin the traditional Chinese culture of learning that values moral-centred knowing, knowledge-transmission emphasised teaching, selfcultivation and achievement-motivated learning (Hu, 2002; Shi, 2006). Some traditional Chinese educational ideas are still influencing teaching and learning nowadays. For instance:

- The purpose of education is to cultivate the ordinary child to the ideal child (Bai, 2005a).

- Teaching should be in accordance with student's aptitude (M. Gu, 2006).

- Learning and thinking are combined. To learn is to memorise, understand, reflect and question (W. O. Lee, 1996) in order to comprehend and acquire knowledge, but not to critique and challenge the knowledge which is known and taught.

- A view of "uniform teaching/learning" is valued, which "refers to education and instruction based on a uniform thought and value standard" (H. Zhang, 2006, p. 227). It emphasises "unify[ing], standardiz[ing] and stabiliz[ing] the thing being taught" (p. 228).

- Teaching and learning are closely monitored and controlled by teachers or more knowledgeable scholars who have absolute authority (Qi \& Tang, 2004). 
- Self-autonomy and individual development are subsidiary and they are subject to the interests of the society in order to maintain a harmonious human relationship and social order (G. Zhao, 2010).

- Play is not encouraged in young Chinese children's learning. Play is only encouraged when it has a purpose and when children can apply their minds to good things that may help them becoming sage or people of virtue (Bai, 2005a).

These educational beliefs and ideas have been practised at both the cultural and individual levels (Jin Li, 2009): in my parents' words, in my teachers' teaching, and in the Chinese education system. They are commonly accepted by the mass population. I grew up with these ideas and they were embodied in me until they were challenged by another set of educational ideas which seemed quite different.

\section{The foreign conceptual world: Western theories and ideas}

Western educational theories and ideas were foreign to me. Initially, I learnt some Western educational ideas as subject knowledge through developmental psychology courses, for instance, Piaget's, Vygotsky's, and Dewey's notions, selected and introduced by the Chinese scholars and my tutors at the training college. I learnt their theories by memorising what was written in the textbooks. I memorised Piaget's explanation of developmental stages. I used Vygotsky's notions to answer questions concerning the topic of nurture and nature in human development for exams, and I criticised the potential unbalanced teacher-child relationship if implementing Dewey's child-centred notions in practice according to my tutors' interpretations. My understanding of the Western theories had never gone beyond the exam papers. 
Then I met my first Western teaching partner who practised Western educational ideas in her teaching. She wanted to teach according to children's emergent interests. She did not do precise lesson/activity plans but would spend time observing children's play and discuss her observations with me. She posted a sign "Learning through Play" in the classroom. She questioned why children were led to recite a Chinese poem together several times during a day. She asked me "what is your educational philosophy?" without being aware how challenging this question was to me, since I had never thought about it. She did not formally transmit any Western educational ideas to me but demonstrated them in practice. Unlike my textbook-based learning at the training college that focused on the literal and given meanings of the Western ideas as a priori knowledge: this time I was learning the Western ideas as intentionally interpreted knowledge in practices and in everyday contexts.

I am now able to read and write in English and have taught in both Chinese and Western educational contexts. I am able to interpret and internalise Western theories by connecting them with my embodied cultural and personal knowledge, and my observations of the Chinese and Western contexts. With my growing ability in using English, conceptualising and making sense of multiple perspectives, I have learnt the importance of understanding Western ideas in relation to the wider Western and Chinese contexts. For example, I now see that Dewey's ideas, the guiding theoretical ideas informing this study, may be understood and interpreted differently in different cultural contexts.

In the early twentieth century, Dewey (1938) discussed characteristics of the traditional North American educational approach as: 
- Educational objectives emphasised future preparation and knowledge acquisition through practice and drilling.

- Students were expected to be docile, receptive and obedient.

- Teachers used books to represent the lore and wisdom of the past.

- Teachers were the agents of knowledge and skills, and enforced the rules of conduct.

What Dewey considered the traditional educational approach in the North American context a century ago is very similar to the Chinese traditional educational approach that still exists in Chinese ECE practices now. Dewey criticised this traditional educational approach as "imposition from above and from outside" ( $p$. 18). He advocated for democracy and freedom in education and promoted the notion of learning through experience. Dewey argued that an educational approach should value individuality, free activity, past experience, personal life and the changing world.

Like Dewey, the Chinese government and scholars nowadays also criticise the traditional educational approach and have been trying to make some changes through recent Chinese ECE reforms. In the edited book Interpreting Guidelines for Kindergarten Education (trial) (Basic Education Department of Ministry of Education, 2002), M. Zhu (2002), a government official from the Ministry of Education, uses terms such as "learn through experiences", "learn through activities" and "learn through the interaction with the environment" (p. 23, own translation) to illustrate the kind of learning that the Chinese ECE reforms intend to promote. These phrases echo Dewey's educational ideas. As my thesis will show, at times these terms can be interpreted differently through a Chinese traditional learning cultural lens, and may 
be nowhere near Dewey's ideas. X. Liu (2002) thus argues that it is important to gain in-depth understanding of the social and cultural context in which Dewey's ideas emerged while adopting or interpreting his notions.

What has become clearer to me now is that how Western ideas are introduced and learnt may influence teachers' understanding of them - for instance, whether the Western ideas are learnt through

- textbooks as I experienced at the training college

- being an apprentice to more experienced colleagues similar to my experience at the international school

- critically understanding ideas by connecting to underpinning values, social and cultural contexts, and multiple interpretations of them from different perspectives as I have been learning to do during this research journey.

\section{The chaotic conceptual world: coexistence of Chinese and Western ideas}

As a result of three waves of Chinese ECE reform since the 1980s (Yan Liu, Pan, \& Sun, 2007), the embodied Chinese educational beliefs and practices and the foreign Western theories coexist not only in my inner conceptual world but also in the external conceptual world in the contemporary Chinese ECE context. The first wave of reform occurred in the early 1980s when some Chinese ECE scholars initiated a bottom-up reform to experiment with the integrated theme teaching approach as a response to their critique of the existing subject-based ECE teaching practices at that time. In 1989, the Chinese government released the trial version of Kindergarten Work Regulation and Procedures Kindergartens (Ministry of Education in People's Republic of China, 1989). This marked the beginning of the second wave of reform, a top-down reform that reflected the government's intervention and 
guidance. The government wanted to change the teacher-centred, text-book centred and lesson-based approach, to a more holistic, active, and child-centred approach in ECE. Guidelines for Kindergarten Education (Ministry of Education in People's Republic of China, 2001) was released in 2001. It signified the third wave of ECE reform and reflected the government's determination to take further steps to deepen the reform. Some progressive educational ideas and practices derived from Western theorists such as Dewey, Piaget, Vygotsky, and Montessori were promoted and practised in kindergartens (J. Zhu \& Zhang, 2008).

Contemporary Chinese educational ideas have therefore been changed from being influenced solely by the Chinese traditional doctrine, to diverse ideologies and educational approaches (e.g., Montessori, Multiple Intelligence, Reggio Emilia, and English \& Chinese bilingual education). Chinese EC teachers are therefore teaching in a society experiencing huge ideological, cultural and structural changes. However, X. Liu (2007) argues the Chinese ECE sector has not found a theoretical framework to support the recent changes and development of Chinese ECE. Hua (2007) further states that the Western ECE philosophies and theories are mostly introduced or interpreted by Chinese scholars who often have no first-hand or practical experiences of applying these ideas in kindergarten settings. The theoretical explanation of Western educational ideas often goes beyond teachers' possible experiences at the practical level, which may make it difficult for teachers to understand and articulate them. Moreover, Chinese cultural traditions cannot be easily separated from Chinese EC teachers' teaching and learning. The co-influence of Chinese traditional and Western educational beliefs, theories, and approaches can thus be observed in all facets of ECE in contemporary China (H. Li, 2007). They 
are blended with Chinese teachers' knowledge system and their teaching practices (Rao, NG, \& Pearson, 2009). Some tensions have been identified in the mentioned scholars' - Hua, H. Li, Rao, NG and Pearson's - discussions, for instance:

- Chinese versus Western educational ideas

- Embodied Chinese cultural knowledge versus the promoted reform knowledge

- Theoretical versus practical knowledge.

These tensions present great challenges for Chinese EC teachers in terms of educational values, beliefs, practices, positions, and identities (Hsieh, 2004) since they may contradict and compete with each other. But how do Chinese EC teachers experience these tensions at the personal and practical levels in their everyday teaching?

\section{From My Story to this Research Project}

The telling and retelling of my own stories created a sense of who I am by "draw[ing] together human actions and the events that affect human beings" (Polkinghorne, 1988, p. 6). This particular biographical exploration of my past and inner self is important since it connects me with my inner world and the external world. In constructing this narrative I realised some of the vantage points that guided the design of this research and my interpretation of the participants' stories. 
Firstly, I realised that there were tensions and challenges accompanying the co-influence of diverse traditional Chinese and Western educational ideas in my teaching and learning because of their different cultural and social origins. Secondly, my understanding of the Chinese traditional and Western educational ideas and practices was developed from my first-hand learning experiences, puzzling and working with them over time in different cultural and kindergarten contexts. Thus I understood teaching and learning as an active and on-going meaning-seeking process through real life experience that was both personal and social, involving interaction in situations, continuously moving backwards and forwards from past to future, and associated with changes (Dewey, 1938). Thirdly, I felt that many Chinese EC teachers like myself were on their own journey of learning and working with both traditional Chinese and Western educational ideas, and of seeking the meaning of teaching and learning. They had much to say and to offer. However, there was little record of Chinese EC teachers' teaching and learning experiences, their frustration and satisfaction, their experiences of dealing with challenges and uncertainty, and their responses to the complex, dynamic, uncertain and rapidly changing era (J. Liu, Sun, \& Wang, 2007).

Therefore, in this study, I regarded teachers as people who "know more than they can say" (Schön, 1983/1991, p. viii). I positioned the teachers at the centre of my study, and attended to their personal knowledge and their relationships with self and the external environment. I explored the participants' teaching and learning in everyday contexts, and focused on the cultural and contextual influences, tensions and challenges the participants face, their professional learning experiences, and their feelings and professional identity. In short, teachers' teaching and learning 
experiences, culture and professional learning are three important aspects of this study.

\section{The Structure of this Thesis}

In this chapter, I told and re-told my own story as a student and teacher, discussed my contact with the wider world and my relationships with different social, cultural and conceptual contexts through a narrative meaning-making process (Clandinin et al., 2006). In later chapters I continue the narrative meaningmaking process to help me understand and present six Chinese EC teachers' stories from three different types of urban kindergartens - state-run, private, and international - in Shanghai and Beijing.

In Chapter 2, I describe the epistemological standpoint that orientates my approach of working with different knowledge claims from Western and Chinese contexts, and the selected theoretical ideas supporting the probing and analysis of the participants' stories in different kindergarten contexts.

In Chapter 3, I review related literature around three themes of teachers' experience: the journey of being a teacher, the role Chinese culture plays in teaching, and professional learning.

In Chapter 4, I discuss narrative inquiry as both a methodology and a method that have led me to the telling-retelling process of six Chinese EC teachers' teaching and learning stories. I explain the methods of recruiting participants, data collection and analysis, and justify my decisions to represent teachers' stories poetically. 
Chapter 5 is about two teachers' - Linda's and Angela's - stories from a state-run kindergarten (called Public Kindergarten) in Shanghai. I give readers a brief introduction to Public Kindergarten, and then tell Linda and Angela's stories individually as poems. In Chapter 6, I analyse their stories individually, then summarise my analysis by highlighting some common threads emerging from their stories. The process of analysis contextualises Linda and Angela's stories in the specific state-run kindergarten context, and connects them with my observations, the teachers' reflections, and the information gathered from the director and parents.

The telling-retelling process of four other teachers' stories follows the same structure and format as Linda's and Angela's. Chapter 7 and 8 are the tellingretelling of Selina and Cherry's stories from Private Kindergarten in Shanghai. Chapters 9 and 10 are about Summer and Cecilia's stories at International Kindergarten in Beijing. Readers are invited to make their own interpretations by relating their own experiences to the participants' stories.

In the concluding chapter, I return to the main research question and discuss how three main findings are reflected in the teachers' stories. I argue the situated teaching and professional learning context contributes greatly to how Chinese EC teachers conceptualise teaching and learning, how they define and construct their pedagogical positions and strategies, how they learn and develop appropriate repertoires of practices, how they feel about being a teacher, and how they understand who they are in children's life. Implications and future research needs are also discussed. 


\section{Chapter 2: Epistemological and Theoretical Context}

Reflecting on my discussions in Chapter 1, I realise the obvious influence of Western educational ideas in my current understanding of teaching and learning, and their relevance to teaching and learning in the contemporary Chinese context. As a Chinese researcher, I, therefore, often find myself battling with the questions:

- What is this study's theoretical context, Western or Chinese?

- Have I become the kind of Chinese researcher who uses Westernised ideas and language to understand Chinese teachers' experience, which $\mathrm{D}$. Wu (2009) believes is dangerous?

- Am I losing my identity and position as a Chinese researcher? But what should a Chinese researcher's identity and position be in the contemporary world?

My tension echoes the recent debate about how to localise Western educational ideas and approaches (D. Wu, 2009) in the Chinese context. Central to the debate is how to deal with multiple knowledge claims and from what epistemological viewpoint. It is therefore important to clarify my epistemological standpoint since it provides a specific intellectual context "in which to consider how [I] organize perceptions, responding to the world, and the conceptions of 'self'" (Popkewitz \& Brennan, 1998, p. 9) in particular ways. In this chapter, I discuss my particular epistemological viewpoint as well as the theoretical framework I construct by drawing on multiple theoretical ideas from three aspects of this study - 
experience, culture, and professional learning in education. Together, they constitute and inform my narrative inquiry of six Chinese EC teachers' teaching and learning experiences.

\section{Searching for an Epistemological Standpoint}

My epistemological tensions relate to the relationship I define between Chinese and Western ideas, the approach I take towards different ideas, and the socially and culturally bonded self when connecting with multiple ideas (Lyotard, 1984). Chen-Hafteck and Xu (2008) use the metaphor of bá hé/Pulling the River (tug-of-war in English) to illustrate Chinese people's internal struggles in finding the balance and position in the tug of war between the Chinese and Western worlds. $\mathrm{H}$. Li (2005) suggests Chinese EC teachers adopt the Zhongyong approach, a central Confucian epistemology and methodology, to gain appropriate balance between opposing Chinese and Western ideas such as teacher-directed and child-directed notions. Chinese and Western ideas in this sense are regarded as objects that can be collected and balanced, and they are opposed to, and distinguished from, each other. Moreover, H. Wang (2008) points out Chinese people tend to regard knowledge as "profound, coherent and self-consistent", and thus accept ideas with "reverence and trust" (p. 97). Chen-Hafteck, Xu, H. Li, and H. Wang's discussions provide insights into how Chinese people relate and respond to knowledge in general. However, when I work with multiple knowledge claims, I find a passive accepting and balancing approach is not very useful. The balance is hard to achieve 
because of the power struggle between Chinese and Western ideas, the authoritative interpretation of selected knowledge and my personal comprehension of them. Therefore, I want to take an active and integrated approach towards different knowledge claims when building this study's theoretical framework.

Instead of viewing Chinese and Western ideas as opposing parties in a tugof-war, I see them as different cords needed for making a Chinese knot. A knotmaker decides what cords are needed for the particular knot he/she is making. I view myself as a knot-maker, exploring different Chinese and Western ideas through an active process of selecting, reflecting on, and interpreting multiple ideas (different kinds of cords), deciding how these cords can be used for making a unique Chinese knot (this study) to represent my point of view (my argument). This is a careful thinking process that enables me to "thread everything together into one whole" (D. Zhang, 2003, p. 434) thus supporting the development of new understanding and knowledge. Moreover, different ideas are not considered as totally objective and waiting to be acquired and applied, but as subjective, partially true, and open to interpretation, reflection, and question. I interpret selected Chinese and Western ideas by connecting them with particular contexts, my personal knowledge, and academic scholarship to construct a knowledge base and theoretical context for this study.

According to D. Wu (2009), Chinese scholars often use a "comparative pedagogy" when working with Western theories and pedagogy, through direct and indirect translation, comparing, compilation, editing, commentary, and criticism. This pedagogy implies that Western and Chinese ideas can be viewed as objects and contextual free knowledge to be known and compared, rather than as knowledge 
that "lives in human acts of knowing" (Wenger, McDermott, \& Snyder, 2002, p. 8). It is an approach of introducing Western ideas to Chinese audiences, rather than recontexutalising them in the Chinese context.

Apple (1993) argues concepts can travel and be introduced in different places, that the context where the concept travels to defines the meaning of the concept, and that "[p]olitical accords and educational needs can radically alter the shape and organization of the knowledge". Apple asserts that the process of selecting certain knowledge claims, recontextualising agents who have the power to select and interpret different knowledge claims, and kindergartens' and teachers' personal responses to the ideas are important aspects in recontextualising educational ideas. Informed by Apple, I regard myself as a recontextualising agent who is trying to select and interpret Chinese traditional and Western educational ideas in the contemporary Chinese context. The recontextualising process emphasises the consideration of my personal standpoints, cultural and political contexts, and the selection, reflection, interpretation, and critique of multiple ideas in a contextualised and critical way (see Figure 2.1).

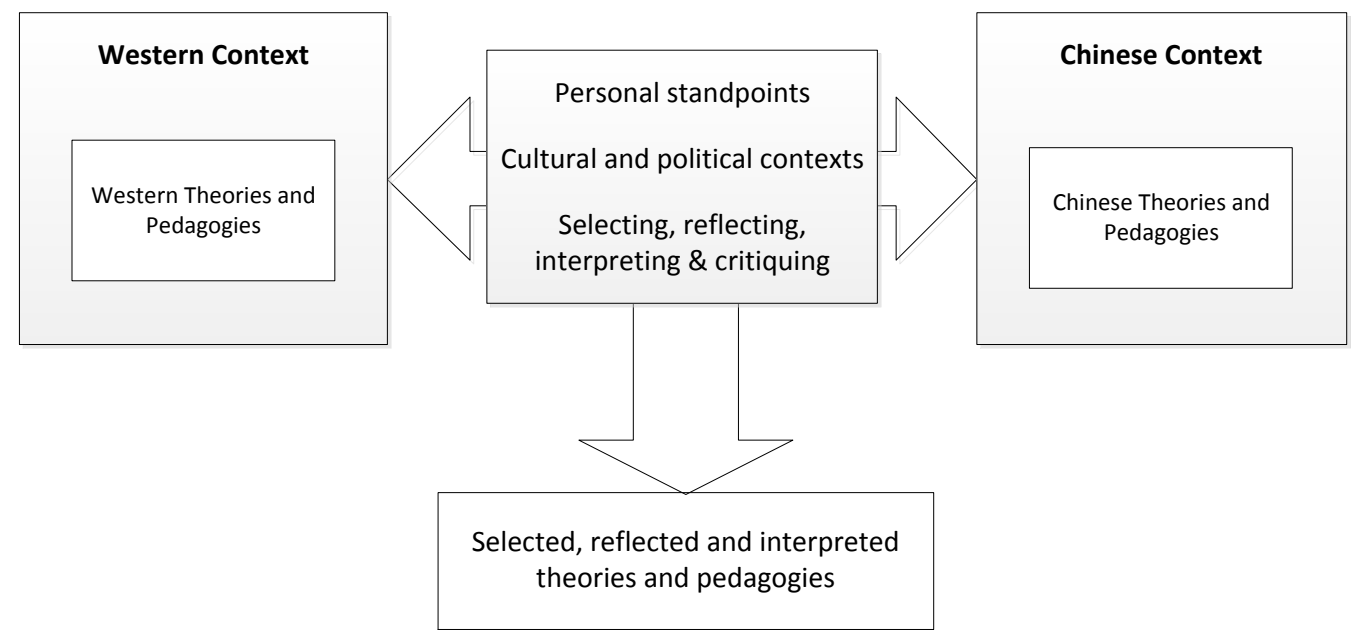

Figure 2.1 My integrated and interpretive approach to multiple educational ideas 


\section{The Theoretical Context}

This study emerged from my own vantage points focusing on teachers' experiences, cultural and contextual influences, and teachers' central position in teaching and professional learning. Therefore, I explore three main bodies of theoretical ideas when constructing a theoretical context for this study:

- understanding experience

- understanding culture in teaching and learning

- understanding teachers' professional learning.

My reflexive interpretations of the selected theoretical ideas support the probing and analysis of the participants' teaching and learning experiences in later chapters.

\section{Understanding experience}

The main focus of this study is to understand the teachers' experiences, so it is important to first define the term experience from both linguistic and theoretical perspectives.

\section{Linguistic definition of experience}

According to the online Oxford English Dictionary (http://www.oed.com), the English word experience as a noun means "the action of putting to the test; trial" and "proof by actual trial; practical demonstration". It also refers to a source of knowledge gained through direct observation or from lived-through events, and a 
state of one's condition in or affected by an event. As a transitive verb, the word experience means encountering or undergoing an event or occurrence. These definitions suggest experience concerns the action of seeing, hearing, and doing; time; event; the process of knowing; and the relationship between the subject (someone) and the object (something or event).

While the definition of experience in the English dictionaries considers the connection and interaction between the subject and the object, the direct Chinese translation of experience as a noun, jingyàn, has its main emphasis on the skill and objective knowledge gained through practices (Youqing Chen, 2006). Youqing Chen suggests translating the word experience as tǐyàn - a verbal phrase containing a meaning of internalisation, exploration or on-the-spot investigation through practical and personal experience, according to the Chinese dictionary (http://www.zdic.net). In this study, I use the word experience in a broad sense that can be referred to as both jingyàn and tǐyàn depending on the specific contexts of the teachers' narratives.

\section{Dewey's notion of experience}

In terms of a theoretical definition of experience, this study is largely influenced by Dewey's theory of experience in education. Dewey (1934) defined experience as "the result, the sign, and the reward of that interaction of organism and environment which, when it is carried to the full, is a transformation of interaction into participation and communication" (p. 22). Dewey (1938) placed the intellectual activity of knowing and thinking (perception) in social actions and human affairs (practice), rather than seeing it as a mental and cognitive function. 
Dewey's theory of experience unifies individual, environment, time, and space in the meaning-making process. According to Dewey (1934), experience is an endless movement towards the desire of fulfilment and consummation. Understanding experience in a broad sense, Dewey believes that education comes through continuous and interactive experience and promotes a learner-centred learning process based on the learner's life experience. As I discussed in Chapter 1, Dewey values a democratic and equal teaching and learning process for the learners. He prioritises learners' needs over societal agendas and learners' experiences over teachers' instructions or textbooks. In this sense, Dewey's notions resonate well with my desire to engage in teacher-centred research and prioritising teachers' own experiences. Moreover, Dewey's notions also connect me with narrative inquiry (Clandinin \& Connelly, 2000), an interpretive research method, since it uses a framework of three-dimensional narrative inquiry space that mirrors Dewey's theory of experience (see Chapter 4 for more detailed discussions).

My recent reading of Dewey provides me with an alternative cultural and theoretical view of experience beyond its linguistic meanings. This view is also quite different to my initial understanding at the training college of Dewey's notions being just around child-centeredness. My new understanding of Dewey's ideas has led me to choose Dewey's notion of experience as one of the theoretical pillars guiding this narrative study. Discussing Dewey's notion of experience alongside the linguistic definitions of experience in English and Chinese has also made me realise the complexity of introducing and interpreting a Western concept in the Chinese context. There are linguistic, intellectual, philosophical, and cultural aspects of interpreting a foreign concept. These aspects are a whole package; leaving out any 
of them may cause misunderstanding or one-sided interpretations. This has occurred to Dewey's notions in China (X. Liu, 2002).

\section{Understanding culture in education}

The second focus of this study is the cultural and contextual influences on the teachers' teaching and learning experience. In the material that follows, I discuss culture by creating a bricolage of different ideas to support my analysis of the teachers' teaching and learning experiences. Firstly, I focus on the concepts of culture (Hofstede, 1986, 1997; Stenhouse, 1967) generally at the national level. Then I discuss how Apple $(1993,1995,2004)$ uses the concept of culture in a sociological analysis of education with a focus on the relationship between school structure, work culture, and teachers' agency. Finally I draw on socio-culturalists' (Rogoff, 1995, 1998, 2003; Vygotsky, 1987, 1997) ideas around particular aspects of culture at the level of the individual acquiring culture. This bricolage of different ideas is used to support my analysis of the cultural influences on the teachers' teaching and learning experiences at the general/national, organisational, and personal levels. There are some links between my discussion about culture in this section and the material covered in the next section on professional learning.

\section{Defining culture}

In the West, the concept of culture has various definitions depending on the focus and form (Cohen, 2009; Kroeber \& Kluckhohn, 1952; Lawton, 1975). Stenhouse (1967) stated: "culture serves as a medium through which individual human minds interact with one another in communication", and "[i]t lies, as it were, 
between people and it is shared by them" (p. 13). Stenhouse asserted that there were common aspects among individuals' unique experiences if the individuals shared "a way of life and a language" (p. 14). Culture, in this sense, is rooted in common and shared experience, and is embodied in everyday lives and interactions of specific groups (Apple, 1995). It also forms the basis for understanding each other and co-operation between people. Furthermore, Hofstede (1997), through the lens of social anthropology, defined culture as "the collective programming of the mind which distinguishes the members of one group or category of people from another" (p. 5). In other words, the term culture refers to the unique "patterns of thinking, feeling and actions" (p. 4) of a group of people or a society with shared beliefs, values and practices.

In the Chinese linguistic context (Feng, He, Gui, \& Yan, 2001), the word culture (wénhuà) is the abbreviation of "rén wén jiào huà", which has three levels of meaning. Firstly, rén (people) indicates that culture is a word used to discuss only human society. Secondly, wén refers to language and/or characters and is the basis and tool of culture. Thirdly, culture emphasises jiàohuà (education/educate) that can be used as both a noun and a verb and refers to both the common rules of human activities, and the process and methods of generating, transmitting, disseminating, and accepting common rules.

In this study, I regard culture as common and shared experiences, as medium and tools, and as a process of developing, learning, and accepting common rules, values and practices. I also understand culture as learnt (Stenhouse, 1967) through interaction and communication with other members of a particular group. Culture may change over time since human communities sometimes face the need to adapt 
to new changes, new demands and new crises in order to survive and continue human society (Rochon, 1998). Culture, in this sense, is embodied, reciprocal, changeable and multi-dimensional.

\section{The model of cultural differences and Chinese culture of learning}

Chinese culture of learning has its "expectations, attitudes, beliefs, values, perceptions, preferences, experiences, and behaviours that are characteristic of Chinese society with regard to teaching and learning" (Hu, 2002, p. 96). Hofstede's (1980, 1997) five-dimensional model of cultural differences is useful in understanding Chinese culture in general and its influences on the Chinese culture of learning. Based on his influential cross-national survey conducted twice in $\mathbf{4 0}$ countries around 1968 and 1972, Hofstede found five elements of cultural characteristics that can be compared among different cultures: power distance, individualism versus collectivism, masculinity versus femininity, uncertainty avoidance, and long-term versus short-term orientation. Hofstede's (1986) data has shown, in the Chinese cultural context, that the large power distance between teachers and students supports a teacher-centred education in which the teacher holds the authority and power in teacher-student interactions. The collective society prioritises the group/society over individuals, and harmony over an individual's personality. The low uncertainty avoidance dimension reveals that Chinese teachers and learners are more comfortable with prescribed and structured learning situations. The masculine society dimension reflects male supremacist thinking that is competitive, goal orientated, and striving for material success; and the long-term vision values effort, thrift, and perseverance. These characteristics are reflected in 
my teaching and learning journey - some of them have enabled me to keep pursuing higher education after many failures, and others seem constraints, causing some frustration for me. For instance, as a Chinese researcher I find critiquing multiple theoretical ideas very challenging.

Although Hofstede's empirical data was collected three decades ago, his cultural model is still popular in the disciplines of business and psychology (Baskerville, 2003), and has been incorporated in much research worldwide (Kirkman, Lowe, \& Gibson, 2006; Taras, Kirkman, \& Steel, 2010). Hofstede's findings resonate with Hu's (2002) and Shi's (2006) descriptions of the traditional Chinese culture of learning. These areas are also made explicit in the Chinese cultural context by researchers like Dimmock and Walker (Dimmock, 1998; Dimmock \& Walker, 1998) who studied the policy of school restructuring that promotes a modern version of Chinese culture of learning in Hong Kong. They used Hofstede's five dimensions to compare the culture of Hong Kong with other cultures, and with the promoted school restructuring policy. Incompatible cultural understandings of teaching and learning were found between the general public and Western influenced policies. Cheng and Wong (1996) made a similar inquiry into school effectiveness in Zhejiang in mainland China. They identified values and factors that enabled the effective learning and high achievement of students, and traced them back to the Confucian origins of Chinese educational culture and concepts. They argued that the promoted "educational thoughts and systems have to be consistent with the general beliefs and social infrastructure of societies" for a "successful marriage of education values from the East and the West" (p. 47). This body of literature indicates the importance of studying the relationship between cultural 
system, values, and teaching and learning.

Hofstede's cultural model enables Chinese scholars to connect Chinese educational policy and practice to cultural values in a context of coexistent Chinese and Western ideas. For this reason, I chose Hofstede's model to help me interpret the participants' narratives, who share an identity as Chinese learners and teachers with Confucian heritage, cultural experiences of teaching and learning. However, I am aware that Hofstede's universal approach is criticised in terms of its theoretical foundation, equating a nation with culture, the quantifying method of studying cultural differences (Baskerville, 2003), and its cultural and philosophical relevance from specific cultural insiders' perspectives (Fang, 2003). Therefore, in this study, Hofstede's general characteristics of Chinese culture and values are used with considerations of particular kindergarten culture, teachers' inner-self, and my “being within" (Baskerville, 2003, p. 8) position as a Chinese researcher and an outsider as a graduate student of a Western university.

\section{Culture-structure-agency}

Although the participants of this study share a common cultural identity as Chinese teachers at the national level, they were members of three kindergartens which were different in their organisation, culture, and structure during data collection. Therefore, it is important to look at culture at the organisation level. After reading Apple's (1993, 1995, 2004) work, I was convinced that his sociological perspective of culture would help me understand teachers' teaching and learning within a particular kindergarten's social system and structure, as it connects culture, structure, and teacher's agency. 
Apple (2004) regarded education as "a site of conflict", and was particularly interested in "uncover[ing] the complicated connections among knowledge, teaching, and power in education" (p. vii). According to Apple (1993, 1995), knowledge was not neutral and was always cultural and political. It existed within certain power relations. The selection process of what to teach and how to teach was a cultural, political and economic decision that was controlled by curriculum forms, pedagogy, and techniques and the ideological vision of management. Teachers' responses to the concepts and official knowledge often accorded to "political and ideological discourse" (p. 10), the policies, the curriculum, the classroom teaching, and their personal understanding. Apple borrowed Benson's (1986) definition of work culture as "a relatively autonomous sphere of action on the job" (p. 228). He argued that work culture constituted "a realm of action that in part provides both strength and the possibility of transformative activities" (Apple, 1995, p. 70), and might have also defined teachers' multi-dimensional relationships within a specific education system and kindergarten structure. Moreover, he indicated that a teacher's position within the authoritative structure of a particular kindergarten and the control the kindergarten management exercises were two factors influencing teachers' teaching. Apple's notions remind me that it is important to attend to the underpinning values and power relations among the legitimate official ideologies presented in the curriculum, the roles of school structure and work culture, the control in teaching and learning, and the teacher's position and agency in the situated social, cultural, economic and political structure. Apple's notions were rooted in the American context and driven by values of democracy and equality, which are different to the traditional Chinese context. 
However, I still chose Apple's notions to inform my study in the contemporary Chinese context for the following reasons. First, to increase equality and democracy is a long-term goal for educational development and reform in contemporary China (M. Gu, 2010). Second, increasing Chinese EC teachers' voice, power and autonomy are topics that have been raised in recent years (C. Shu, Gao, \& Li, 2006) which echo Apple's arguments. Third, Apple's notions emerged in the debates between neoliberals and neo-conservatives (Apple, 2001). This context is similar to the contemporary Chinese context where Western liberal-influenced modern and traditional conservative-Chinese ways of teaching and learning coexist. Therefore, his notions may provide some insights into my analysis of Chinese EC teachers' experience of traditional Chinese and Western educational ideas and practices.

Informed by Apple, I started to reflect on the cultural value system, the power relations in curriculum, pedagogy, and teaching, and on the cultural and structural constraints of my learning. I no longer blame myself for not working hard enough to get a degree in the Chinese education system. I can understand why I felt I could not meet others' expectation during my first three years of teaching. My passive acquiescent position in the kindergarten structure, and the director's tight control of curriculum and pedagogy were clearly influential. However, I am also aware Apple's perspectives are from his own vantage point. From a vocational perspective, Lewis (1998) criticises Apple for not valuing forms of curriculum and knowledge other than the mandatory state curriculum. Null (2011) points out Apple's notions are based on a negative review of American education focusing on class, status quo, and power from a "left-lean" (p. 95) political position that may not be relevant to the Chinese political context. Therefore, I incorporated Apple's 
analysis of culture, structure, curriculum, and teacher agency in education rather than the political aspects of his notions. In particular, I paid attention to the official ideologies represented in curriculum, the lived work culture, the power relations, the process of control, and the teachers' agency when analysing the teachers' stories in specific kindergarten structures.

\section{Culture-learning-development}

Apple has studied education at both the macro level of system and social structure and the micro level of teacher agency. However, as a sociologist, his main foci are on the society and human social activities. Thus, I needed some theoretical ideas that could inform my analysis of cultural influences at the personal level, as this study is about six teachers' personal teaching and learning experiences. I find socio-cultural scholars' (Cole, 2000; Rogoff, 1995, 1998, 2003; Vygotsky, 1987, 1997; Wertsch, 1991; Zinchenko, 1985) discussions around learning and development helpful. They examine the interrelationship between mind and culture, and the individual's meaning-making process shaped by cultural artefacts, everyday practices, situated context, and individual agency (Cole, 2000). These ideas resonate well with the aims of this study.

Several key concepts which have informed this study are derived from the work of Vygotsky $(1987,1997)$. Firstly, according to Vygotsky, human functions appear on two planes - the social plane and the personal psychological plane. Individuals' learning and development is firstly understood in a social and cultural process, by engaging in culturally specific activities and through communicating, collaborating, and interacting with the social world, cultural artefacts and others. 
Then individuals go through a process of internalisation as they transform external knowledge and actions into internal psychological functions. The internalisation process can lead individuals to self-regulate and demonstrate appropriate behaviours and mental activities according to the accepted meanings and practices of a particular community. These views direct my attention to the participants' social relations and interactions with others around them, and how they understand and appropriate their own teaching by engaging in culturally organised activities at particular kindergartens.

Secondly, Vygotsky argued the physical and symbolic (psychological) tools, for instance, language, music, and arts etc., mediate an individual's higher mental functions such as voluntary attention, deliberate memory, concepts formation, and decision-making. The development and modification of physical and symbolic tools is closely related to specific cultural and historical contexts for meeting the particular needs of certain cultural groups and individuals. This notion directs me to attend to the cultural artefacts available in different kindergarten contexts that may mediate the participants' higher mental capacity, for instance "planning, logical thoughts and problem solving, learning ..." (Lantolf, 2000, p. 2).

Thirdly, Vygotsky highlighted the close relationship between thought and language. He argued both the meaning and the linguistic form of word/words should be attended to, as well as the mediated process that might enable thought to become verbal, and language to become intellectual. These views guide me to focus on the participants' narratives and the important role they may play in the construction of new knowledge and self-identity. However, Wertsch (1991) stated there are multiple layers of meaning conveyed in particular narratives, which may 
be determined by the position of the speechmaker, the dialogue between the speechmaker and others, and the authoritative discourses. Zinchenko (1985) also asserted that it is not only the words, but also the tool-mediated actions which are driven by certain motives and goals. The tool-mediated actions occur during the externalisation and internalisation process, including "external, material, practical action and internal, ideal and mental action" (p. 106). Informed by Wertsch and Zinchenko, I have realised the complexity of personal narrative, meaning and action in learning and development, and have decided to collect and analyse data from multiple sources - interview, observation, and documentation etc. - when studying the participants' teaching and learning experiences.

Among many socio-cultural scholars, I find Rogoff's (1995, 1998, 2003) participatory theory of learning is particularly insightful for this study as it positions learning in context and analyses it through multiple lenses. Rogoff's (2003) participatory theory of learning understands an individual's dynamic transformation process by analysing individuals' participation in social activities through three inseparable lenses - personal, interpersonal, and cultural/institutional. It is based on the overall assumption that "human development is a process of people's changing participation in sociocultural activities of their communities" (p. 52). From this perspective, the individual's development is not simply influenced by the external social and cultural environment. Rather, it is a process of active participation in cultural practices, collaborating with others, resulting in individual changes and development of the repertoires of practice (Gutierrez \& Rogoff, 2003; Rogoff, 1995). Repertoire of practice refers to "the ways of engaging in activities stemming from observing and otherwise participating in cultural practices" 
(Gutierrez \& Rogoff, 2003, p. 21). It considers the linguistic, cultural and historical specificity of certain types of cultural practice demonstrated by an individual in cultural activities. This cultural-historical approach of understanding an individual or a community's ways of acting, unlike Hofstede's universal model of cultural differences, may reveal the uniqueness of each participant's professional learning experience. These views suggest socio-cultural theory can guide this study as it allows me to contextualise individual teachers' teaching and learning experiences in a "shared endeavour" (Rogoff \& Toma, 1997, p. 474), and analyse them through multiple lenses.

Nevertheless, Sawyer (2002) reminds me that socio-culturalism's process ontology prioritises process and ignores entities and structure in learning and development. The assumption that the individual and the social are inseparable may be "theoretically problematic and empirically untenable" (p. 283). Therefore, individual subjectivity may be neglected in the analysis of action or event. Based on these views, Sawyer suggests an "analytic dualism" (p. 297) that views the individual and the social context as both analytically distinct as well as interrelated. This supports my decision to incorporate Apple's sociological and the socio-cultural perspectives when building a theoretical framework for this study. It led me to focus on individuals, contexts, and individuals in contexts. Moreover, my choice to use teachers' verbal and written narratives, and observed actions in specific contexts as analytical units may resolve the methodological challenge of studying the individual and the social world. 


\section{Understanding teachers' professional learning}

The third group of theoretical ideas are concerned with the topic of teachers' professional learning. In recent years, research into teachers' professional learning has focused mostly on three sub topics: learning to teach over time and in different contexts, learning how to learn, and learning to change and make changes (Avalos, 2011). This trend reflects a growing emphasis on lifelong learning and socio-cultural perspectives of learning (Kelly, 2006). Teachers' professional learning has also moved from emphasising learning "developmental and technical-rational models of practice, towards more complex ways of thinking about teaching young children" (Edwards \& Nuttall, 2009, p. 4). More specifically, teachers' professional growth and development is believed to be a cyclic (Shulman, 1987/2004), reflective (Schön, 1987), situated (Lave \& Wenger, 1991), and multifaceted process of participating in social activities in a specific teaching and learning community (Rogoff, Baker-Sennett, Lacasa, \& Goldsmith, 1995). The learning processes are influenced by politics (Lefstein \& Snell, 2011), contextual conditions (Blank, 2009), the model/approach of professional development programmes (Levine \& Marcus, 2010), teachers' beliefs and past experience (Weber, 2010), students' responses to teaching (Vescio, Ross, \& Adams, 2008), and so on. These views are different to the traditional knowledge transmission and acquisition learning that I once experienced as a Chinese student and teacher, and the "pragmatic, skill-based transmission models of 'professional development'" (Fleet \& Patterson, 2009, p. 16). They provide me with an alternative lens for understanding teachers' learning from a Western cultural and theoretical perspective. In this section, my discussion of theoretical ideas examines the four 
aspects of effective learning that Shulman (1996/2004) identifies: activity/agency, reflection, collaboration and community.

\section{Activity/Agency}

Some scholars have discussed the important role activity/agency plays in effective learning (Shulman, 1996/2004), the construction of agency (Davies, 1990), and the influence of emotion on teachers' experience and agency (Hargreaves, 2001). Shulman (1996/2004) saw the learner's active position during the learning process as the first important condition for effective learning. According to Davies (1990) who wrote from a post-structural feminist perspective, there were two important aspects of this view: learner's positioning and the learning actions or practices, which are also important for the construction of human agency. Davies argued that agency might be "constructed discursively as a positioning made available to some but not others" (p. 341). She asserted human agency does not necessarily depend on an individual's behaviour and action, but the position of the individual in the discursive practices of the particular collective environment. In this sense, the agency of a learner is not only constructed by what he/she does as a learner, but also by his/her positions and choices of certain actions constituted by the discursive practices made available in the learning environment. These discussions suggest I should pay attention to the social relationships and the positioning of the participants in particular kindergarten contexts, as well as the discursive practices that may provide opportunities for the participants to make different choices in their professional learning. Inspired by these views, I analysed the teachers' agency by exploring whether the participants had the power, personal, 
and social resources to enable them to take control of and interpret their learning. This exploration was integrated with Apple's (1993, 1995, 2004) sociological perspective of macro cultural and structural influences and control of teachers' teaching, learning, and agency. However, Davies did not discuss extensively personal resources in the construction of teachers' agency, for instance, the search of teachers' inner self (Palmer, 1998) - their perceptions, feelings and emotions of teaching and learning, and their relations with others and the wider world. I then find Hargreaves' (2001) notion of emotional geographies of teaching useful for understanding the emotional aspect of the participants' experience, since personal resources may influence the construction of teachers' active position and agency in their professional learning.

Hargreaves (2001) studied the teachers' emotions in relationships, and used the term "emotional geographies" to "describe the patterns of closeness and distance in human interactions that shape the emotions we experience about relationships to ourselves, each other, and the world around us" (p. 1056). Hargreaves argued that emotional geographies are not only shaped by structural and cultural conditions, but also the teachers' active making and remaking of "the emotional geographies of their interactions with others" (p. 1062) and themselves. The teachers' positive or negative emotions can be shaped by:

- the socio-cultural distance - which relates to the social and cultural backgrounds between the teacher and the others

- the moral distance - which is "closely bound up with and triggered by our purpose" (p. 1066), priorities and choices

- the professional distance - which is about whether the teachers' professional practices are understood or recognised 
- the physical distance - which refers to the "intensity, frequency, and continuity" (p. 1071) in teachers' interaction with themselves and others

- the political distance - which links to teachers" "experiences of power and powerlessness" in social relations and structures (p. 1072).

Hargreaves revealed the complexity of teachers' emotions from multiple aspects. His relational and contextualised approach to understanding teachers' emotions coheres with this study's sociological and socio-cultural stances. However, I am aware that there may be a potential dilemma around whether it is culturally appropriate to highlight and explore the self, agency, and emotion in the Chinese context where traditionally the hierarchical structure of authority defines the self, not vice versa (Lau, 1996). Therefore, I need to be culturally sensitive and respect the participants as individuals, culturally located in part by traditional values. In short, Hargreaves and Lau highlight the importance of the teaching self, the positioning of the teacher in the particular professional group, the teacher's social relations, interactions and emotions, as well as cultural and structural matters in teachers' professional learning. These aspects are at the centre of this study.

\section{Reflection}

Shulman (1987/2004) stated teaching and learning are inseparable in the cyclic process of

- learning and comprehending propositional knowledge

- transforming propositional knowledge into practice and instructions that build up teachers' case knowledge

- evaluating and reflecting on the case knowledge and strategic knowledge used in practice 
- thus reaching new understanding and comprehensions of teaching and learning.

Shulman regarded teachers" "pedagogical reasoning and action" (p. 233) and the wisdom of practice as "the maxims that guide the practices of able teachers" ( $p$. 232). Teachers' practical knowledge and experience could act as "ground of belief" (Dewey, 1933, p. 11) for teachers' reflective thinking, which might enable teachers to become conscious of how and why they were "learning particular things in particular ways" (Shulman, 1996/2004, p. 476). To value teachers' practical knowledge and their reflective thinking and reasoning process is inspiring because it no longer places teachers at the receiving end of theory-driven practice. It allows me to move teachers to the centre of the study and gain insights from their experiences of constructing their professional knowledge (Zeichner \& Liston, 1996).

According to Dewey (1933), reflective thinking has two phases: "a state of doubt, hesitation, perplexity, mental difficulty, in which thinking originates, and an act of searching, hunting, inquiring, to find material that will resolve the doubt, settle and dispose of the perplexity" (p. 12). Uncertainty and inquiry are important impelling aspects for reflective thinking grounded in cumulated and empirical experiences. Teachers often use certain repertoires to help them understand unique and uncertain circumstances through reflection-in-action, and therefore to develop their own responses to the embedded situation (Schön, 1983/1991). For Schön, repertoire can be images, examples, ideas, and actions that emerge from teachers' past experiences in similar or different situations. This view echoes Gutierrez and Rogoff's (2003) notion of repertoire of cultural practice as discussed earlier. However, the repertoires of practice may hinder the teachers' reflection in some 
cultures, as O'Sullivan (2002) found with Namibian teachers. This implies that reflection, as a cultural practice, may not be natural to teachers in a culture that values knowledge transmission and acquisition. In addition, van Manen (1991) stated some actions cannot be fully reflected since they are "instant thinking acting" during pedagogical situations that required "our immediate response and participation" (p. 118). This has brought the notion of tacit teaching and pedagogical thoughtfulness to my attention, leading me to attend to teachers' intuitive actions and what mediates these actions. Together, the cited scholars suggest I should connect thinking and practice, highlight a process of meaningmaking and theorising practice, value practical knowledge, and acknowledge uncertainty and tacit knowing in teachers' teaching and learning.

\section{Collaboration and community}

Shulman (1996/2004) identified collaboration and community as two important aspects of effective learning. Unlike activity/agency and reflection, which look at learning at the personal level, collaboration highlights the interpersonal interactions that may only happen when working or learning alongside others in a community. Therefore, I chose to discuss collaboration and community together. Shulman stated that, during effective learning, learners would engage in "collaboration, working together in ways that scaffold and support each other's learning, and in ways that supplement each other's knowledge" (p. 476) within a community that would support and enable such collaboration.

Like Shulman, Lave and Wenger (1991) also believe learning should be a situated activity and the learning mind cannot be separated from the social world, 
and context and participation are two important elements of learning. Lave (1993) discussed the contextual aspects of learning through the concept of community of practice. She explained that community of practice was everywhere and was defined through three dimensions: a joint enterprise which determined what the community was, mutual engagement that illustrated the function of the community, and a shared repertoire that enabled the community's capability of function. In terms of participation, Lave and Wenger (1991) proposed a concept of legitimate peripheral participation "as a descriptor of engagement in social practice that entails learning as an integral constituent" (p. 35). Legitimate peripheral participation was a social process by which a newcomer changed his/her position from being peripheral in the community of practice to being central and becoming "a full participant in a socio-cultural practice" (p. 29). Lave and Wenger's ideas acknowledge that teachers may participate and position themselves in multiple ways and various degrees in the community in which they are located. It allows time and space for teachers to learn and develop their own understanding of theory and practice at their own pace.

What Lave and Wenger present to me is a way of respecting Chinese EC teachers as individuals with unique personalities, knowledge, and cultural backgrounds while teaching and learning with others. They remind me to contextualise teachers' learning and development in the community within which they are located, pay attention to "the structure of social practice" (Lave \& Wenger, 1991, p. 103), and to study the culture of the organisation that unifies the teachers and their colleagues to work together (Goodman, Phillips, \& Boyacigiller, 2003). Lave and Wenger's ideas have provided an illustration of the teachers' social relations and positioning, which align well with Apple's (1995) discussions around the 
relationship between teacher's agency and school structure, and Rogoff's (1995) participatory theory of learning. Therefore, these ideas can be integrated with each other to deepen my understanding of teachers' professional learning experiences from multiple perspectives.

The reflective, participatory, and situated view of professional learning highlights the important role the community plays. In Wenger's (1998) later work, he developed a social theory of learning that connects individuals' meaning-making process, their practices, the embedded community, and identity formation. Based on this learning theory, he paid specific attention to the cultivation of communities of practice, "an ideal knowledge structure - a social structure that can assume responsibility for developing and sharing knowledge" (Wenger et al., 2002, p. 29). Wenger et al. stated that "a community of practice is a unique combination of three fundamental elements: a domain of knowledge, which defines a set of issues; a community of people who care about this domain; and the shared practice that they are developing to be effective in their domain" (р. 27). This definition led me to look at three aspects of a kindergarten community - knowledge or educational ideas within the community, social relations among the members, and routine and shared practice in everyday teaching. Wenger et al. further argued a community's knowledge strategy that was embodied in its operation and practice could show how the community views, manages, leverages and generates knowledge and the types of values that might connect the community and its members, the social relationship and ways of communicating. A community of practice thus provided spaces for members to develop and own its standards of practice if it: 
- took situated, integrated and dynamic approaches to knowledge

- created multiple types of value for both the members and the community

- supported trusting and collegial social relationships

- valued open dialogues so that new knowledge can emerge and be endorsed within the community "as accepted communal knowledge" (Wenger et al., 2002, p. 40)

- had multiple levels of participation.

However, potential disorders of community might be caused by imperialism in the knowledge structure domain, "the clique in the community", and "the dogmatism of practice" (Wenger et al., 2002, p. 150).

The value of Wenger et al.'s (2002) ideas is they not only provide a framework for me to understand the community's influence on teachers' experience, but they also suggest what may be done to develop an enabling and empowering environment for members of a specific community. However, Wenger's ideas are mostly discussed in a business context, based on research of newcomers' experiences (Cherrington, 2011), and were developed in the Western context. Moreover, Wenger's notion of community of practice pays less attention to teachers' prior knowledge, the process of generating innovative and spontaneous knowledge, external influences, as well as the complex life of the teachers (Hedges, 2007). Thus, it is important to integrate the ideas around community of practice with the other theoretical ideas that I have discussed in this chapter, as they provide a more holistic, multifaceted and contextualised picture of teachers' teaching and learning experiences. 


\section{Emerging Analytical Framework}

Based on the preceding discussions, I am now able to draw a diagram to represent the analytical framework of this study (see Figure 2.2). This framework has guided my investigation of six Chinese EC teachers' teaching and learning experiences.

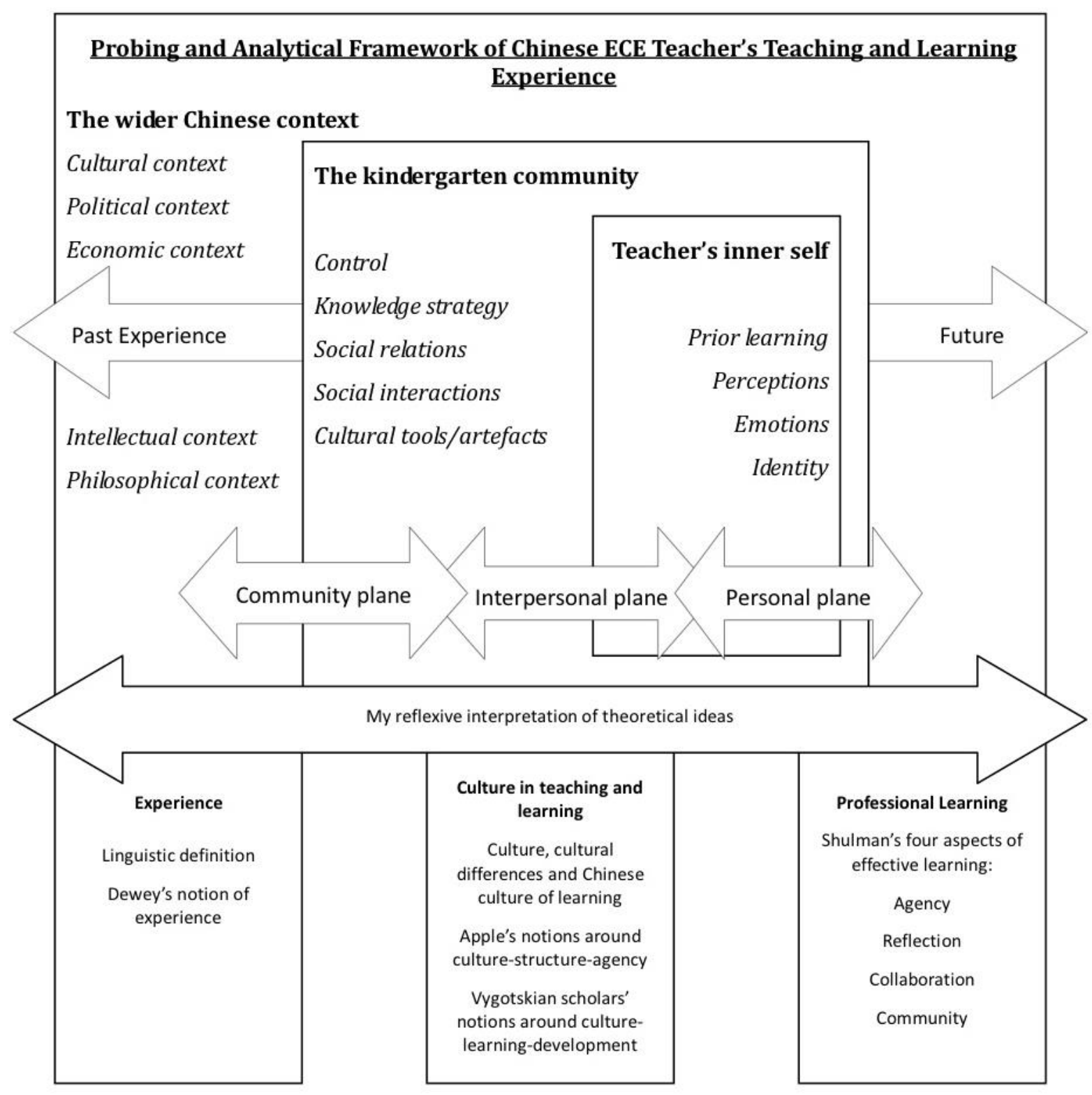

Figure 2.2 Analytical framework of this study 


\section{Chapter 3: Literature Review}

In this chapter, I review three areas of literature of the journey of being a teacher, the role Chinese culture plays in teaching, and teachers' professional learning. Three considerations were behind my decision to do a thematic literature review on the chosen topics. Firstly, the preceding discussion has foregrounded the influences of the external social, cultural, and educational contexts in my teaching and learning at various stages of my teaching career. This realisation has led me to review studies about teachers' teaching over time, their career phases, and the personal and external factors shaping teachers' teaching journey (Ayers, 1989; Burke, Christensen, Fessler, McDonnell, \& Price, 1987; R. Gu, Qin, Zheng, \& Cheng, 2007; Katz, 1972; Sikes, Measor, \& Woods, 1985; N. Zhao \& Qin, 2007). Secondly, some scholars (I.-F. Lee \& Tseng, 2008; H. Li, 2007; Rao et al., 2009; Tobin, Hsueh, \& Karasawa, 2009) have identified traditional Chinese culture as one important factor influencing Chinese EC teachers' implementation of Western educational ideas in practice. The need to consider the cultural contexts constituting traditional Chinese and Western educational ideas thus emerged, leading me to studies investigating cultural aspects in Chinese EC teachers' teaching and learning. Thirdly, professional learning is considered crucial if Chinese EC teachers are to learn the promoted modern educational ideas and transform their practices (Huo, 2010; Yan Liu \& Feng, 2005). Therefore, I have reviewed studies investigating teachers' professional learning and teachers' experience of different professional learning approaches to inform this study. 
Chinese EC teachers are at the centre of this study, so I started my search for relevant literature in Mainland China. However, I experienced great difficulty in accessing relevant Chinese research from a New Zealand university library database, especially lengthy research reports and full-length theses. There were two reasons for this difficulty: 1) there was a very limited amount of Chinese EC teacher-related research published in English, and 2) most of the Chinese ECE related research reports available to me on the Chinese Knowledge Resource Integrated Database (www.cnki.net) were brief two to six pages long articles. I then bought some Chinese books based on relevant research projects in Mainland China (R. Gu et al., 2007; X. Zhu, 2008). I also searched relevant studies conducted in Hong Kong and Taiwan (Huo, 2010; Yan Liu \& Feng, 2005; J. Shu, 2010), and on Chinese teachers who were teaching in the United States (S. Yang, 2008). Since Confucianism and traditional Chinese culture were part of Hong Kong, Taiwan, and part of the overseas Chinese people's cultural heritage too, these studies might provide some insight into understanding the cultural aspects of Chinese teachers' teaching and learning. A substantial amount of research about teachers' teaching and learning experience has also been conducted in other cultural contexts. Hence, I extended my search and included studies of Western teachers' teaching and learning experience (Craig, 2010b; Hargreaves, 1998; Jordan, 2003; Nuttall, Coxon, \& Read, 2009), as well as studies of teachers from other cultures like Namibia (O'Sullivan, 2002) and Lithuania (Jurasaite-Harbison \& Rex, 2010). Two important criteria for selecting relevant studies from other cultures were whether they investigated teachers' experience from multiple lenses over time, and whether cultural and contextual aspects were highlighted. 
When reviewing the relevant literature, I examined the strengths and weaknesses of the different methodologies. Narrative inquiry seemed an appropriate way to investigate my research question since it would allow me to access and dig deeper into the teachers' experiences in different contexts and over time. The literature review thus informed the direction and the design of this study in terms of its methodology, data analysis, and possible contributions to existing knowledge base.

\section{The Journey of Being a Teacher}

In order to understand teachers' complex and unique journeys, I reviewed literature on teachers' career phases, critical incidents that might influence their career choices, and what would make a good teacher. The studies highlighted the continuous, contextualised, cultural, and multifaceted nature of the teaching career.

\section{The career stages}

A number of scholars (Burke et al., 1987; Katz, 1972; Sikes et al., 1985) studied the stages/phases of teachers' careers. Katz (1972) identified four developmental stages that an EC teacher may go through:

- the survival stage when teachers experienced the discrepancy between anticipated successful teaching and the reality of classroom teaching

- the consolidation stage when teachers started to focus on children who are problematic and want to gain more knowledge and skills to help them 
- the renewal stage when teachers sought new ideas, materials and challenges to maintain or renew their interest in teaching

- the mature stage when teachers accepted their identity as a teacher and were able to explore deeper and more abstract questions for "insights perspectives and realism" (p. 53).

The characteristics of each stage Katz described are helpful in understanding how teachers may respond to teaching at the personal level with a particular focus on professional development.

Burke and his colleagues (Burke et al., 1987) took "a social system approach" (p. 3) to explore differences among 778 teachers at different career stages using a self-report survey in the United States. Fessler, a member of the research team, developed a dynamic career cycle that linked each of eight career stages with personal and organisational environmental influences. The identified career stages are: preservice, induction, competency building, enthusiastic and growing, career frustration, stable and stagnant, career wind-down, and career exit. Personal environment refers to family, positive and critical incidents, crisis, disposition, interests and life stages, while organisational environment includes regulations, management, public trust, societal expectations, professional organisations and union atmosphere. This is a dynamic career model, and the proposed career stages are not linear; rather, they reflect a teacher's "responses to the personal and organizational environmental factors" (p. 6). Unlike Katz's four-stage model focusing on the personal dimension of the teaching journey, Fessler's model contextualises teachers' career choice and journey in the wider social context, highlighting the influences of the personal and organisational environments. 
The Chinese researchers N. Zhao and Qin (2007) drew on Fessler and Katz's models when reporting their inquiry into teachers' job burnout after interviewing 12 and surveying 204 Chinese EC teachers. N. Zhao and Qin aligned the teachers' survey responses and the interview data with where the teachers were in their career. They identified a seven-stage career cycle - exciting and settling (0-2 years), developing and selecting (3-6 years), competent and steady (7-9 years), renewal and conflicting (10-12 years), steady and stagnating (13-18 years), recurring and crisis (19-25 years), exiting and fading (26+ years). They found that the Chinese EC teachers experienced job burnout at all stages of their career, but at different levels. Emotional and physical exhaustion, dissatisfaction, and lack of enthusiasm in teaching were identified as four contributing factors. N. Zhao and Qin reported some unique features of Chinese EC teachers' job burnout. For instance, physical exhaustion did not decline for the teachers who were at the competent and steady stage but tended to increase. Moreover, teachers' job dissatisfaction did not seem to decline at the exiting and fading stage, and it levelled out with the previous stage. Lack of enthusiasm in teaching reached a peak in the steady and stagnating stage, and it was at its lowest level in the renewal and conflicting stage.

N. Zhao and Qin's study prompts me to look at emotional aspects of teachers' teaching: for instance, burn out and job satisfaction. Their descriptions of Chinese EC teachers' career stages are similar to Fessler's (Burke et al., 1987), but the stages are presented linearly. However, the survey method and the cited brief report do not reveal how teachers experience these stages and why the identified features are unique to Chinese EC teachers. N. Zhao and Qin did not report how Katz and Fessler's models were used in their research. In the current study, both Katz and 
Fessler's models have informed my interpretation of the participants' journey and my analysis of personal and organisational influences on their teaching and learning experiences at different career stages.

\section{Critical incidents}

One of the factors making individual teachers' teaching and learning experience unique may be their different experiences and responses to critical events. Sikes, Measor and Woods (1985) used the concepts critical incidents and critical phases to explain the movement and progression of a teacher's career phases. Using participants' biographies, they identified three types of critical phases - extrinsic, intrinsic and personal - relating to events occurring in society, within career stages, and in family. Sikes et al. stated critical incidents are "key events in an individual's life, and around which pivotal decisions revolve" (p. 57) and are "occasioned by the conjuncture of particular sets of constraints" (p. 71). Critical incidents can provoke decision-making and are catalysts for thinking and change. Managing and coping with critical incidents and phases is a creative process and teachers respond to them differently. Some participants were found having no counter or negative responses, some changed commitment of teaching, and others tried to strategically compromise the situation to "allow room for their interests, while accepting some kind of modification of those interests" (p. 238).

In China, some researchers (R. Gu et al., 2007) studied critical events in retrospect among $32 \mathrm{EC}$ teachers (from novice to 20 plus years of teaching) from an exemplar kindergarten in Nanjing. Through life history interviews and document analysis, R. Gu et al. specified the critical events as events of success, setbacks, and 
inspirations that could influence a teacher's professional identity, self-efficacy, motivation, attitude, behaviour, knowledge, and philosophy in a variety of ways. In another study, Yun Liu and R. Gu (2008) used in-depth interviews to explore the impact of nurturing incidents on 10 female EC teachers. Nurturing incidents referred to teachers' experience of giving birth and bringing up their own children. Becoming and being a mother had negative influences on most participants' teaching careers because of the challenge of managing time and the energy required to cope with the demands of teaching, professional development, and family commitments. Yun Liu and R. Gu found that the teachers' personality, their gendered views of the teaching career, self-value, and the relationship between family and career influenced their career decisions. According to a survey of 30 "expert" teachers in Wuhan (B. Peng \& Xie, 2009), critical events, critical periods and critical persons were also identified as key external factors influencing Chinese EC teachers' professional growth. These scholars suggest it is important to explore the critical events and people mentioned in teachers' narratives to understand an individual teachers' unique journey of being a teacher.

\section{A destination: being a "good" teacher}

The concept of a "good" teacher can reflect and define what teachers do and what they are expected to do (Cortazzi \& Jin, 2001). L. Liu (2009) analysed 485 extracts from Chinese primary and secondary school teachers' autobiographies to search for their perspectives on being a good teacher. L. Liu found that from the teachers' perspectives, the disposition of being passionate was more important than having profound thoughts or extensive knowledge. A study of eight award winning 
Chinese EC teachers in Shanghai reflected the researchers' agenda of understanding "good teachers" by attending to explicit teaching behaviour (J. Huang, 1998; J. Huang, Du, Yang, Zhe, \& Wang, 1999). Through classroom observation and interviews, the researchers explored how good teachers got to know and worked with children, and demonstrated good and workable models of teaching to other teachers. Teaching techniques and teachers' planning processes were at the centre of the investigation. Caring, observing, and knowing the children were valued and practised by the good teachers but only for the purpose of curriculum delivery.

L. Liu (2009), J. Huang (1998) and J. Huang et al.'s (1999) studies reveal different understanding of what makes a "good teacher" from the teachers' and the researchers' perspectives. The different perspectives reflect different values and priorities of teaching that may result in diverse paths and approaches towards becoming a good teacher: whether to focus on the development of the desired dispositions according to the teachers' wishes, or to focus on the improvement of teaching techniques as the researchers hope.

In the West, Ayers' (1989) book The Good Preschool Teacher illustrated six good teachers' complex lives in the United States. Ayers indicated the experienced teachers constantly engaged in self-critique and self-reflection, and they all in some way struggled against what the government and the official curriculum demanded. Ayers' study has offered some methodological insights into how to study teachers' teaching experience in depth. He regarded teachers as people who had "a rich and worthy source of knowledge of teaching" (p. 1). He used narrative as a research method that prioritised teachers' voices over the demands of the curriculum. He also made teachers' work visible through participatory observations, interviews and 
analysis of observed teachers' practice. By developing the portraits for each teacher, Ayers demonstrated the value of taking a narrative approach as a way of accessing teachers' life stories to explore "how teachers understand themselves and how they locate themselves on their own particular pedagogical journeys" (p. 6). Ayers' study suggests that narrative is a useful approach to access the Chinese EC teachers' teaching and learning experience for investigating my research question.

In another book, Ayers (2001) described complex, emotional and discovery aspects of being a teacher by reflecting on his own teaching journey. According to Ayers, the fundamental challenge for teachers was "to embrace students as threedimensional creatures, as distinct human beings with hearts and minds and skills and dreams and capacities of their own, as people much like ourselves" (p.134). The relationship and the positioning of the teacher self and the external power, the individual children and the standardised curriculum were at the centre of the teachers' problem solving and decision-making. From their own humanistic perspective, Ayers and other scholars (Allender \& Allender, 2008) suggested teachers place children before curriculum, teach towards freedom and teach ethically with an inquiring and wondering mind, and understand pedagogy as relational rather than instructions and teaching techniques. To be humanistic and to teach towards freedom are underlying values of these Western scholars' notions, which is very different to the Chinese traditional value system valuing harmony and social order (M. Gu, 2006).

The different perspectives on "good teacher" imply that it is important to attend to teachers' personal values, visions, and the decisions they make during their teaching journey: in Palmer's (1998) words, to explore "the inner landscape of 
the teaching self" (p. 4). Therefore, the journey of being a teacher is not only about the educational reforms, curricular requirements, and teaching techniques, but also learning about one's past, beliefs, cultural values, emotions and changes of self through various career stages.

\section{Narrative studies of Chinese EC teachers' teaching experience}

Chinese scholars have used narrative inquiry to study Chinese EC teachers' professional growth over time. Based on interviews, C. Shu, Ke and Du (2006) told the story of one "good" Chinese EC teacher from her decision to be an EC teacher, through her teacher training, and to the different stages of her professional growth. C. Shu et al. identified the following factors shaping this teacher's professional development: personal history, organisational environment, active learning dispositions, public trust and expectations, and promotions. These findings echo Fessler's (1985) view that a teacher's professional career is shaped by personal and organisational environments.

Like C. Shu et al., X. Yang and Zhai (2006) studied one EC teacher who had 10 plus years teaching experience and gathered data from multiple sources interviews, participatory observation, and documents. X. Yang and Zhai focused on the teacher's professional identity at different stages of her teaching career by analysing the teacher's self-image, professional preparation, vocational motives, and teaching practice and prospects. In another study, Yani Zhang (2009) analysed interviews with one Chinese EC teacher about her becoming and being a teacher. She explored the internal subjective factors affecting the teacher's professional development. She argued that the teacher's enthusiasm, autonomy, and the 
teaching practices in the embedded contexts were major influences in her professional development. These three studies are valuable because they explore the teaching journeys of Chinese EC teachers and identify some influential factors on their experiences at the personal, organisational, and social levels. However, they do not dig deep enough to reveal how these factors have actually shaped the teachers' experiences. They only studied good or experienced teachers from public kindergartens, and so represent only one group of Chinese EC teachers. The reporting of the studies mainly quotes the teachers' stories around the identified influential factors, and pays less attention to the researchers' retelling of the teachers' stories that may lead to the construction of new meaning.

N. Zhao and Qin's (2007) study, discussed earlier, highlighted the emotional aspect of Chinese EC teaching experience. Hargreaves (1998) also stated that emotions were "at the heart of teaching" (p. 835), teachers were emotional labourers and their emotions were "inseparable from their moral purposes and their ability to achieve those purposes" (p. 838). Some researchers have used interpretive case studies to explore teachers' emotions (Mitchell, Riley, \& Loughran, 2010; O'Connor, 2008; Schmidt \& Datnow, 2005). Others (Rippon \& Martin, 2006; Scherff, 2008) used stories because they retained "the complexity of the situation in which an action was undertaken and the emotional and motivational meaning connected with it" (Polkinghorne, 1995, p. 11). However, Chinese EC teachers' emotions and related topics such as mental health, burnout, and wellbeing were mostly studied quantitatively through surveys and questionnaires (Lai, 2011b; Liang \& Feng, 2004; Lu, 2006; C. Zhang \& Zong, 2010; N. Zhao \& Qin, 2007). These quantitative findings are helpful in understanding teachers' emotional conditions 
and influential factors in general, but do not explain how such emotional conditions are reached and how these conditions affect teachers' teaching and learning in everyday practices.

Meng and Yu's (2007) study of a young Chinese EC teacher's thoughts of leaving teaching was the only research I found that used a narrative approach to explore the Chinese EC teacher's emotion. The participant was a teacher in her sixth year of teaching. Meng and Yu reported the participant's feelings towards teaching over time. The participant had no specific knowledge and career goals when making her initial career choice and during training. Now she thought that teaching was very important for children's development, but she personally did not want to be a teacher anymore if it was possible. Meng and Yu identified factors influencing her feelings of teaching as: the disconnection between her personal beliefs about teaching and the reality of working with children, lack of public understanding and recognition, intensity of everyday teaching, and pressure around professional development. However, the researchers only identified the influential factors, and left out the important question of how these factors impacted on the teacher's feelings as well as her daily practice as a teacher.

Here, I must acknowledge that these four cited narrative studies of Chinese EC teachers' teaching experiences are three to six pages long articles with two to eight references, published in Chinese academic journals. 


\section{The Role Chinese Culture Plays in Teaching}

In the contemporary Chinese ECE context, researchers have studied how traditional Chinese culture influences teachers and how they use cultural resources in their teaching and learning (Hsieh, 2004; Hsueh \& Tobin, 2003; Li-Chan, 2006; Y. L. Li, 2004; Tobin, Wu, \& Davidson, 1989; J. Wang, Elicker, McMullena, \& Mao, 2008). In this section I review some selected studies with a particular focus on the role Chinese culture plays in teaching.

\section{Implicit cultural beliefs and practices}

Studies have shown Chinese traditional culture influences EC teachers' teaching and learning implicitly in the contemporary Chinese context. Rao, $\mathrm{Ng}$ and Pearson (2009) reviewed four studies of pedagogy in Hong Kong kindergartens. Chinese cultural beliefs and values were reflected in the social milieu of the classroom environment and teachers' instructions, while Western ideas influenced pedagogy. The co-influence of Chinese and Western beliefs and ideas was also found in Mainland Chinese kindergartens by Tobin and his colleagues (Hsueh \& Tobin, 2003; Tobin et al., 2009) in a follow-up of their frequently cited research of three kindergartens from three countries in the 1980s: China, Japan, and the United States (Tobin et al., 1989). In the follow-up study, Tobin and his colleagues videotaped a day in each participating kindergarten. Then they showed the edited video clips to not only the teachers who were filmed, but also other teachers from the participating kindergartens and early childhood educators around the three 
countries. Teachers' discussions and reflections of the video clips were recorded. After analysing the data from the two Mainland Chinese kindergartens, one rural and one urban, the researchers found changes in facilities, ideology, and practice had occurred over the past two decades (Hsueh, Tobin, \& Karasawa, 2004; Tobin et al., 2009). They asserted that Western educational ideas had influenced Chinese teachers greatly and that "the call for respect for children, freedom and equality in preschool education [was] emerging as a powerful new perspective in Chinese ECE education" (Hsueh \& Tobin, 2003, p. 86).

Analysis of the cultural aspects of the kindergartens' everyday life by Tobin et al. (2009) showed Chinese EC educators were trying to balance the use of Western child-centred and creative education approaches with the essence of Chinese traditional education theories, pedagogy, and teaching practice. Tobin et al. (2009) argued an implicit cultural logic - the unmarked, unspoken (even denied) cultural beliefs, values and practices - may influence teachers' understanding of their relationships with children, and other teaching and learning-related topics. According to Tobin (2011), teachers' implicit cultural beliefs and practices are learnt in practice from more experienced teachers rather than from formal training, textbooks, and policies. However, the agendas of rationalisation, modernisation, globalisation and standardisation in early childhood education in the contemporary contexts, mean implicit cultural beliefs and practices seem less valued and thus are "endangered" (р. 6.). These discussions suggest a need to explore cultural meanings between the lines of teachers' narratives, and the assumptions, reasons, and thinking behind the observed teaching practices. However, much of Tobin et al.'s focus is on revealing the various practices, opinions and debates around ideological 
and pedagogical changes among the Chinese kindergarten teachers, directors, and scholars. The teachers' actual experience of various educational ideas and how the kindergarten context constitutes the teachers' experience of changing educational ideas are not thoroughly discussed.

\section{Cultural artefacts}

Research reveals that teachers from different cultures may share similar expressions of particular educational philosophies and ideas, but practise them differently. J. Wang et al. (2008) studied Chinese and American EC teachers' beliefs of curriculum. They surveyed 296 Chinese EC teachers and 146 American teachers, and had in-depth interviews with 10 teachers from each country. They found the teachers from the two countries emphasised similar beliefs "including integrated curriculum, child-initiated learning, teacher-directed learning and basic school skills" (p. 244), but endorsed these beliefs in contrasting ways. In general, Chinese teachers seemed to favour teacher-directed beliefs and American teachers were more likely to endorse "less formal, less structured and more child-initiated learning beliefs" ( $p$. 245). Cultural requirements and conditions of teaching such as the differences in learning how to write English letters (easier, less instruction and practice required) and Chinese characters (more complex, and required more instruction and practice) might result in different beliefs of what should be valued in learning. Chinese EC teachers also identified some cultural matters influencing their beliefs, such as government regulation and available resources, while American teachers' beliefs seemed to be influenced by common Western values like individuality. The Chinese teachers who taught at high-quality, urban kindergartens with high-level 
qualifications and professional training seemed more able to practise according to their beliefs than the rural teachers. The training programmes and kindergarten contexts emphasising child development theories and Western ideas were reported to be more likely to support the teachers' endorsement of child-initiated approaches. According to Cole (2000), secondary cultural artefacts like cultural values and beliefs about teaching, emphasis of training programme, and government regulations as identified by J. Wang et al. may shape teachers' understanding and interpretation of shared educational ideas at the personal level. J. Wang et al.'s findings resonate with Cole's arguments that secondary artefacts may "play a central role in preserving and transmitting modes of action and belief" ( $p$. 121), and culture can be regarded as a "control mechanism" (p. 123) mediating human action through artefacts.

Similar findings were reported in the Hong Kong context. Li-Chan (2006) observed and interviewed Chinese and Western teachers in a bilingual international kindergarten in Hong Kong. She found that although both Chinese and Western teachers expressed similar concepts of teaching and learning in ECE, they interpreted these concepts differently and sometimes in opposing ways. Teachers' cultural backgrounds were often referred to when the participants tried to articulate their own thoughts and practices. Teachers, in this sense, use their own cultural knowledge to help them explain their beliefs and practices.

J. Wang et al. (2008) and Li-Chan's (2006) studies highlight the importance of cultural artefacts and cultural knowledge in understanding, articulating and practising shared educational beliefs and ideas. However, the research methods that Li-Chan and J. Wang et al. used, the interview and the self-report survey, did 
not allow them to explore the link between teachers' beliefs, thoughts, and their actual practices.

\section{Culture as constraint on change}

Culture may be helpful and used as a tool when making sense of the world, but at the same time it may also be a constraining factor rather than an empowering force in the process of changing practice. In Taiwan, Hsieh (2004) used the document Developmentally Appropriate Practice in Early Childhood Programs (Bredekamp, 1997), an exemplar that took a child-centred approach, as a guideline when studying Taiwanese EC teachers' teaching practices in the classroom. Taiwanese teachers seemed to struggle to make practical decisions when implementing the Developmentally Appropriate Practice (DAP). Their struggles related to the following topics: viewing the child as an individual or part of a group, the tension between having intimate child-teacher relationships and maintaining their authority, the practicality of organising teaching around children's interests, whether to provide learning experiences that were hands-on and promoted problem solving or whether to transmit some scientifically-proven facts "without training [children's] high order thinking" (p. 326). Hsieh found that the teachers used Chinese culture as a source of knowledge and experience when learning how to teach in the child-centred ways DAP advocated. However, this seemed to hinder their practices from the DAP perspective since the Chinese culture of learning was rooted in teacher-directed practices.

In a case study involving nine teachers, Y. L. Li (2004) discovered that Hong Kong EC teachers were coping with "a triangle of potentially conflicting expectations 
and orientations: the vision of ECE, the Chinese culture and local constraints" (p. 330). By observing and interviewing the teachers, Y. L. Li identified three constraining factors affecting their professional development:

- lack of subject knowledge and professional knowledge required by modern day teaching and learning

- the tendency to "play it safe" when trying a new strategy

- the irrelevance of their personal learning experiences, influenced by the traditional Chinese culture of learning, to the contemporary view of teaching and learning.

Hsieh (2004) and Y. L. Li's (2004) studies highlight how embodied traditional Chinese cultural teaching practices may act as a constraining influence, and the tensions that teachers may experience as they try to adopt Western ideas. Their studies reveal the complex and challenging nature of working with both traditional Chinese and Western educational ideas and practice. Therefore, when studying cultural influences in everyday teaching and learning contexts, it is important to collect data from multiple sources in order to make the complexity and challenge explicit.

The preceding review suggests that traditional Chinese culture plays an important role in constructing Chinese EC teachers' teaching experience, but in diverse ways. The findings of the selected studies are mostly about Chinese EC teachers in Hong Kong and Taiwan where the political and economic contexts are different to Mainland China. Therefore, it is necessary to locate this study in urban Mainland China where the coexistence of Chinese and Western cultures is more obvious than in the rural areas. Moreover, the question of how culture and 
embedded context shape teachers' teaching and learning over time is still unclear due to some methodological limitations.

\section{Narrative studies of culture in Chinese teachers' teaching}

Researchers have used life history, educational autobiography and narrative inquiry to study Chinese teachers' professionalism (Goodson \& Choi, 2008), knowledge (L. Liu, 2009), and personal growth (Yani Zhang, 2009). But little has been done in the areas of cultural and contextual influences, and on teachers' "ongoing negotiation that seeks to authorize cultural hybridities that emerge in moments of historical transformation" (Bhabha, 1994, p. 2) between traditional and modern, Chinese and Western, personal and community cultures. Besides, culture often plays an implicit role in teachers' experience and the construction of their inner landscape, and sometimes it is hidden and difficult to access. However, some narrative inquirers (J. Shu, 2010; S. Yang, 2008) found narrative inquiry enabled researchers to access multiple perspectives from different knowledge bases and cultural backgrounds, and to make teachers' cultural practice explicit.

S. Yang (2008), a Chinese language teacher from Taiwan, used narrative inquiry to reflect on his experience of teaching Chinese as a second language to U.S. students. Narrative inquiry (Clandinin \& Connelly, 2000; Connelly \& Clandinin, 1999) enabled S. Yang to realise the relationship between his inner landscape and the outside world, and opened up possibilities for new understanding of teaching Chinese in the United States. His narratives focused on how the Chinese and Western theories of teaching and learning were used in his Chinese classes. He revealed some challenges he had encountered as a Taiwanese Chinese teacher 
teaching in the United States. These challenges related to his assumptions about students, the student-centred learning approach and the prescribed teaching procedures, and the teaching materials that included some negative stories of Chinese culture. In his narrative study, S. Yang brought together his personal practical knowledge influenced by both Chinese and Western culture, the professional knowledge landscape, and his identity as a teacher when teaching in the classroom.

J. Shu (2010) wrote narratives to reflect on his own teaching as a drama teacher and a researcher who worked with some Hong Kong schools to implement a drama programme. The three teaching episodes and J. Shu's reflections on them revealed the tension between the Chinese traditional teaching approach as "discipline first and then teach" (Ho, 2001, p. 109) and his attempt to teach according to the students' needs and curiosity. J. Shu demonstrated how he dealt with challenges caused by the differences between the embodied Chinese cultural stances in his teaching that were rooted in authoritarianism, and his alternative and desired approach of student-centred practice valuing democracy. The process of constructing the three narratives of his teaching led J. Shu to gain new understanding of teaching and learning. He made some changes to his teaching approach, and thus provided a more engaging learning experience for the students in his class. Narrative inquiry in this sense not only reveals the cultural struggles in his teaching, but also catalyses J. Shu's change process.

In short, narrative inquiry can access teachers' cultural experience, and reveal the tensions, challenges, and conflicts that emerge from their cultural interactions with the milieu through a narrative meaning-making process 
(Polkinghorne, 1988). However, narrative inquiry has not yet been used to explore in-depth cultural influences on Chinese EC teachers' teaching and learning in Mainland China. This study intends to start to fill this gap.

\section{Teachers' Professional Learning}

Teachers' professional learning and development has become a widely studied topic since the 1990s among Western scholars (Evans, 2002). This has happened about 10 years earlier than in China. After reviewing the research conducted by postgraduate students from three major Chinese normal universities between 1996 and 2006, Yan Liu, Sun, and Wang (2007) found only one study about Chinese EC teachers' professional development conducted before 2002. However, by 2006 the number increased to 19 . Eighteen of 20 studies found were Masters theses, and two were doctoral dissertations. Because of the limited number of relevant studies conducted in the Chinese ECE context, my review in this section was extended to the wider context including studies from overseas and among primary and secondary school teachers in China. I paid specific attention to studies exploring in-service teachers' professional learning, and to studies reflecting the recent trend of understanding professional learning as on-going, collaborative, situated, active and reflective as this resonates with the socio-cultural nature of this study. 


\section{Teachers' professional learning is on-going}

Feiman-Nemser (2001) used a continuum metaphor to describe the on-going learning process from pre-service preparation at training college or university to induction and in-service professional development in the workplace, and highlighted the need to provide different programmes for teachers at different chronological stages. By identifying the continuing threads of teachers' learning over time, Feiman-Nemser urged for a more connected and continuous system with collaboration between the university, schools, and other stakeholders to support teachers' learning all the way through their careers. Feiman-Nemser's ideas are very helpful in understanding teachers' learning needs. However, the chronological approach is problematic itself since teachers' learning and development are not as straightforward and linear as the continuum suggests - from immature to mature at the micro level (Britzman, 2007). The changing world and the changing relationship between teachers and the environment may bring uncertainty and unevenness to teachers' learning at various times through their career. Moreover, Feiman-Nemser mainly focuses on formal learning opportunities for teachers. A study that surveyed German teachers' choices of learning through questionnaires showed teachers also learned through informal learning opportunities such as reading books, observing others, mentoring and collaborating with colleagues and parents (Richter, Kunter, Klusmann, Ludtke, \& Baumert, 2011). These findings suggest teacher learning is continuous; it is not linear and step-by-step but extended and complex (Gravani, 2007). 
In China, the recent ECE reforms required on-going professional development and learning of new curriculum promoted by the recent reforms and/or imported curriculum models such as Montessori and project approach (Huo, 2010). Huo stated Chinese scholars accepted the ideal way of learning new curriculum through a three-stage process:

- the technique learning stage led by the experts

- the practical learning stage supported by experts and through reflective practice

- the liberated learning stage in which teachers master a certain type of curriculum by learning to reflect and evaluate curriculum implementation in a rational way.

Huo pointed out many Chinese kindergartens had not provided the learning environment for teachers to go through the three stages of learning, causing inefficient professional learning of the new curriculum and teaching approach. However, I have not been able to locate any empirical studies relating to this threestage professional development approach. I wonder whether there are approaches other than the linear three-stage model. How do teachers in different kindergarten contexts experience this model? How does a teacher's particular professional learning experience influence their teaching and learning?

\section{Community of practice}

Researchers have studied how to build up a community of practice during professional development courses to enhance teachers' learning from the sociocultural perspective. Morrell (2003) reported on a project that made a critical research community of practice available to the teachers. Students, teachers, and 
university researchers in an urban U.S. context formed the community. All participants explored the topic of social justice in schools as a research project but with different roles and responsibilities, and participated differently. Morrell found that teachers' professional learning required interaction with others and spaces for "legitimate peripheral participation" (Lave \& Wenger, 1991, p. 35), even for the veteran teachers when they were learning something new. The participants needed to feel included and have a sense of full membership in the community of practice.

The importance of being included was also reported by Yongcan Liu and $\mathrm{Xu}$ (2011) who studied a Chinese English language teacher's inclusion and exclusion experiences in a community of practice in a Chinese university. Hui, the teacher in Yongcan Liu and Xu's study, was once included in a new English Language Teaching reform community along with two other Chinese teachers and one Western teacher with full membership. However, Hui's personal view of teaching and learning, which was influenced by traditional Chinese culture, contradicted the promoted ideas within the community of practice. Hui did not have enough time to develop her indepth understanding of the reform views because of intense teaching responsibilities. Hence, she became a passive follower with a withdrawal attitude in the community. As a result, she was excluded from the community of practice. Interestingly, Hui rediscovered her freedom to teach in ways she believed in after she was excluded, and was able to explore more learning opportunities that were meaningful to her. Hui's story suggests that teachers' active agency is important in professional learning, and being excluded from one community does not always have negative influences on teaching and learning. In fact, it can expose teachers to different communities of practice in the wider world. 
Craig (2004) regarded the specially built community of practice for teachers' formal professional development as teachers' knowledge community where teachers might feel safer to talk and discuss, and to develop shared understanding of promoted knowledge. However, this special learning and teaching community that many researchers designed and organised (Gilrane, Russell, \& Roberts, 2008; Graven, 2004; McNaughton \& Krentz, 2007; Morrell, 2003) is different to the everyday teaching community in kindergartens and schools where teaching and learning is often shaped by "competing discourses and complex contexts" (Kable, 2001, p. 321).

\section{Informal professional learning and teacher agency}

Some researchers explored the types of school communities that might enable or constrain teachers' informal professional learning in everyday teaching contexts. Jurasaite-Harbison and Rex (2010) studied different informal learning experiences of teachers in three schools in the United States and Lithuania through a two-year ethnographic study. They found that the teachers' informal learning was supported if the school environment was stable, and management and policy promoted interpersonal interaction, collaboration and shared understanding, and informal learning. Teachers' experiences of professional learning therefore were different when working in the different communities of practice.

Elsewhere in the United States, through the case studies of mathematics and English teachers in two high schools, Little (2003) studied the positioning of teachers and their dynamic relations and interactions within the schools' teacher communities. She indicated that teachers' positioning and social relations and 
interactions with other colleagues were closely linked to the motivation and opportunities for teachers' learning. Dehli and Fumia (2008) also reported a study in Canada focusing on teachers' informal learning in everyday teaching contexts and the reconstruction of professional identity in the education reform context. By analysing the power relations between the government and the teachers in the reform context, Dehli and Fumia argued that teachers who took an active position in learning and implementing the reform initiatives were recognised as change agents. The studies cited in these paragraphs provide a broad view of professional learning. They draw connections between teachers' learning, the situated school's structure, and the teachers' social relations within the particular school communities. The importance of acknowledging teachers' agency also emerges from these studies.

Craig's (2010b) longitudinal study of one American middle-school teacher's experiences of different professional development programmes over 10 years showed the importance of teacher agency in professional learning. Using a narrative approach, she wrote up four exemplary stories that represented the teacher's experiences within four different learning contexts. The teacher's first story of participating in a "models of teaching reform" initiative was an unsatisfying story since the professional learning was directed, determined, monitored and evaluated by external agents. Thus, the teacher's agency, emotion and identity were discounted in the externally mandated professional development approach. However, the teacher eventually engaged in a more teacher-centred professional development programme that preserved his "identity and agency as a teacher and allowed him to simultaneously teach and learn" (p. 433). This experience led him to regain control and autonomy in his own teaching and learning. This study shows 
narrative inquiry can enable a researcher to access the teacher's learning activities, feelings and emotions as well as the teacher's relationship with the environment over a long period. New insights and understanding can be gained through the coconstructed stories from both the teacher and the researcher. Craig also demonstrated what narrative inquiry could achieve when studying teachers' professional learning experience, which supports the choice of taking a narrative study for this research.

Nuttall, Coxon and Read's (2009) report of two Australian EC teachers' experiences of learning about socio-culturally-informed teaching and learning suggested that teachers' agency was closely related to teachers' positive learning disposition and aspects of school structure, such as teacher-child ratio. The development of new pedagogical tools, for instance planning and assessment templates informed by socio-cultural theories of learning was also found to enhance two teachers' active exploration of new and meaningful educational ideas and practices. In this sense, the personal and structural factors, and the pedagogical tools/cultural artefacts may shape teacher's agency in their learning.

\section{Collaborative learning resources}

Research shows that being able to learn from experienced teachers in complex everyday teaching contexts, and co-constructing meanings with colleagues are very important for teachers' professional development. Bradley (2004) took an ethnographic approach to study five novice childcare teachers (including her) in an American childcare centre. Through participatory observations, videotaped visits and interviews, Bradley identified that a common experience among them was that 
they were all teaching in the classroom alone with groups of children, and it was not easy for them to see and hear how experienced teachers teach in an everyday context. Being isolated affected their understanding of the curriculum and required teaching practice, and generated negative feelings such as feeling "anxious, overwhelmed and afraid" (р. 357). This finding highlights the importance of enabling teachers to access all necessary resources that they need for their learning (Wenger, 1998). This includes both collaborative learning resources such as being able to observe and interact with experienced teachers in the classroom, and individual learning resources such as teachers' past experiences, creativity, learning by doing, and everyday interaction with children (Bradley, 2004).

In New Zealand, Jordan (2003) used action research to investigate how the teachers from four ECE centres explored the topic of developing authentic learning experiences for children by valuing children's voices. She argued that the development of new understandings of teaching and learning were constructed during teachers' interactions with themselves, their colleagues, and the professional development facilitator (the researcher). Again, Jordan's study draws attention to the collaborative learning resources and co-construction of new knowledge in professional learning.

In the Chinese ECE context, thorough investigations of how specific formal professional learning programmes and particular communities of practice shape Chinese EC teachers' professional learning are rare. However, J. Zhang (2008) studied the influence of experienced teachers and/or experts in the Chinese ECE context with the focus on explaining the roles experts might play in teachers' professional learning, and $\mathrm{Mu}$, Shen and Luo (2008) studied the effects of pairing 
experienced and new teachers in a master-apprentice relationship. The gap in understanding teachers' collaborative learning in everyday context is apparent.

\section{Reflection}

In China, school/kindergarten-based action research and writing up teacher narratives are strategies that have been used to help Chinese teachers become reflective, as also practised in the Western context (Conle, 2000; Marcos, Sanchez, \& Tillema, 2011). However, according to Shao and L. Gu's (2010) survey of 64 Chinese middle school teachers, reflection was not a voluntary everyday action for most of these teachers. Reflection was more of a requirement from the management, and the majority of the teachers did not feel writing up narratives was effective for their reflection. School culture and teachers' lack of theoretical knowledge were identified as constraining factors in teachers' reflection. However, Shao and L. Gu's study did not explore in depth how reflection was promoted to teachers, nor how the identified factors constrained teachers' reflection, and influenced their professional learning and brought changes to their practices.

For many Chinese EC teachers, reflection is a new skill. X. Zhu (2008), a kindergarten director, and her colleagues conducted a three-year multi-case study in Beijing, of how teachers reflect and cultivate their ability to reflect. They began by investigating teachers' existing understanding of reflection in order to identify problems in teacher reflection. They found that teachers often reflected through introspective writing and favoured the dialogue approach as a method of reflection. Teachers tended to reflect on technical aspects of teaching and learning rather than being critical about the fundamental values, norms, and methods. Similar findings 
were reported by Lin (2010) based on the analysis of 320 teachers' edu-care journals in Chongqing. X. Zhu and her team (2008) identified the need to extend teachers' perspectives and in-depth understanding of reflection. They also explored the theories, methods and approaches of reflection introduced through kindergarten-based training to inform their strategies for improving teachers' ability to reflect. Journal writing, open-class observation and guided group discussion within subject study groups were used to facilitate teachers' reflection of prior experience and practical cases. Reflection in this study was a learning subject for teachers, as well as a problem solving strategy for their practices. Teachers experienced both learning how to reflect and applying reflection in teaching at the same time. In this sense, learning how to reflect was situated in everyday contexts through interaction with others. This was made possible because the kindergarten director, who was also the leader of the research, had the power to change the kindergarten's policies and procedures, to make the time and resources available for the teachers to reflect. However, how teachers feel about the reflective way of understanding teaching, learning, and problem solving, and how the changed culture of this community shaped the teachers' experiences were not reported.

In Shanghai, Yan Chen, Jiang and H. Wang (2010) used action research to facilitate a kindergarten teacher's reflection over 18 months. Through classroom observations, interviews and questionnaires, they noticed the positive changes in this teacher after they changed the reflection approach from a teaching-problemfocused reflection to theme-based reflection in order to cater for the teacher's personality and habits. This move made the reflection and learning more meaningful to the teacher. However, the focus of the cited article was to report a 
workable model of facilitating one teacher's reflection as a new skill, rather than making explicit the teacher's actual learning.

\section{Narrative studies of Chinese EC teachers' professional learning}

The preceding review indicates that to understand teachers' learning requires researchers to adopt methodologies that connect learning to teachers' experience and practice over time in an intentional, systemic, collaborative, and contextualised way. Many researchers favoured qualitative research for understanding such phenomena since it used a variety of empirical materials and deployed "a wide range of interconnected interpretive practices" (Denzin \& Lincoln, 2008, p. 5) such as ethnography (Graven, 2004), action research (Goodnough, 2010; Jordan, 2003; O'Sullivan, 2002), and narrative inquiry (Craig, 2010b; Latta \& Kim, 2010). However, Chinese researchers tended to study EC teachers' learning strategies (R. He, 1998), their efficacy and attitudes of learning (Lai, 2011a; R. Li, 2010; Z. Wu, 2010), their knowledge types and management (C. Yang \& Pang, 2009; Yue, 2010) through surveys and questionnaires, which do not provide in-depth understanding of cultural, contextual and multifaceted influences in teachers' learning. Most studies intended to explore 'workable' models for Chinese EC teachers' learning rather than teachers' actual learning processes and experiences.

I found only two narrative studies about the Chinese EC teachers' understanding of teaching and learning in kindergarten. Yi and Pang (2005) interviewed one EC teacher to understand how she developed her personal educational concepts. They argued that she developed these concepts through a process of interacting with both theory and practice. They identified personal 
experience, important others, promoted educational ideas, and the specific kindergarten culture as the main influential factors on her construction of personal educational concepts. Similarly, Y. Peng (2009) studied the formation of three Chinese EC teachers' personal views of education - two classroom teachers, and one teacher-turned-kindergarten-director. Y. Peng shared the three teachers' voices around each of the identified factors that influenced their personal views. However, Y. Peng did not report how the narrative data were gathered and generated in the cited article. Yi and Pang's (2005) and Y. Peng's (2009) studies reflect the trend of studying Chinese EC teacher's change of educational philosophy. Yet, the two cited five-page long reports fail to make connections between the teachers' changing views, their particular professional learning experiences, and their practice.

Y. Wang (2010) urged Chinese researchers to take an ecological orientation and pay more attention to the cultural and contextual aspects of Chinese EC teachers' learning, and their experience of the reform-way of learning in the situated context. J. Liu et al. (2007) also identified the need to study teachers' learning from the teachers' perspectives. Informed by these researchers, I am assured that there is a need to study Chinese EC teachers' teaching and learning experiences in depth. Adopting a qualitative and narrative paradigm will allow me to access teachers' professional learning in particular communities of practice, and to explore how teachers' teaching and learning are mediated through different artefacts and cultural repertoires. 


\section{Towards Methodological Decisions}

The cited literature in this chapter tells small stories (Olson \& Craig, 2009) in the grand contemporary and globalised education context. Through these stories, I have learnt that to teach and learn becomes a fluid, multifaceted and complex phenomenon. In order to study Chinese EC teachers' teaching and learning experiences in the grand contemporary Chinese context, I need a methodology that allows me to place the teachers in the centre of the study, to listen to their voices and to access their experiences. In view of this and the socio-cultural view of teaching and learning that underpins this study, I have chosen narrative inquiry as the methodology to guide my exploration of Chinese EC teachers' teaching and learning experience.

C. Peng (2010) states that as a research method originally developed in Western culture, narrative inquiry is relatively new to Chinese educational researchers. C. Peng points out Chinese researchers may emphasise the procedure and form of narrative inquiry rather than the relationship and interaction between the researcher and the participants, and the in-depth description, interpretation, and reflection of the teachers' stories and the context. This may lead the researchers to a closed inquiry structure moving from process to result. These discussions highlight the importance of being reflexive, open, collaborative, and analytical when undertaking a narrative inquiry - a research method that contextualises personal experience in time and in milieu (Clandinin \& Connelly, 2000). In the next chapter, I will discuss in detail why and how narrative inquiry has 
helped me access six Chinese EC teachers' teaching and learning experiences at three kindergartens in Shanghai and Beijing. 


\title{
Chapter 4: Methodology
}

\author{
"Narrative inquiry is a way of understanding experience. It is a \\ collaboration between researcher and participants, over time, in a \\ place or series of places, and in social interaction with milieus."
}

(Clandinin \& Connelly, 2000, p. 20)

Narrative inquiry, a qualitative interpretive research methodology, is interested in "the nature of reality and our relationship with it" (Spector-Mersel, 2010, p. 204). In education, one approach to narrative inquiry, developed by Clandinin and Connelly (2000), explores teachers' embodied personal practical knowledge on the professional knowledge landscape through teachers' stories that are lived and told "in words as [people] reflect upon life and explain themselves to others" (Connelly \& Clandinin, 1990, p. 4). Clandinin (1985) defines personal practical knowledge as "knowledge which is imbued with all the experiences that make up a person's being. Its meaning is derived from, and understood in terms of, a person's experiential history, both professional and personal" (p. 362). Personal practical knowledge is embodied in practice, and shaped by situations, and contextualised in a professional knowledge landscape. These notions are the core methodological ideas supporting my view of teachers as knowledgeable, and providing me with a framework for conducting a teacher-centred research. In this chapter, I discuss my journey of exploring the qualitative and interpretive research 
paradigm that narrative inquiry has emerged within, and my choice and justification of using narrative inquiry as a research methodology for this study. I explain how narrative inquiry enables me to access and understand six Chinese EC teachers' teaching and learning experiences at three kindergartens in Shanghai and Beijing.

\section{Exploring Narrative Inquiry}

\section{Historical stances}

Over the past 40 years, narrative research has been increasingly popular as "a powerful tool" and "a method of analysis" (Bamberg, 2007, p. 1), across many disciplines, for understanding the multifaceted and complex nature of human lives and experiences. The narrative turn in social science can be traced back to the humanistic move in sociology and psychology after World War II and the development of contemporary social research in early 1970s (Andrews, Squire, \& Tamboukou, 2008). Turning from the traditional positivism objective approach to life and experience with an aim of developing universal principles, theories, and abstracted knowledge, narrative research attends to individuals and their particular actions, feelings, and thoughts constructed in social practices. Rather than aiming to produce knowledge that is generalised and can be applied universally, narrative research represents local knowledge with considerations of context, reflexivity, coconstruction, and multiple truths of life and experiences (Josselson, 2007b). This narrative turn has resulted in a collaborative relationship between researchers and 
participants, a broad understanding that research data can be both numbers and words, valuing particular experiences, and understanding the various ways of knowing (Clandinin \& Rosiek, 2007).

Narrative inquiry is part of the big narrative research family. Connelly and Clandinin (1990) introduced it as a research methodology in 1990. It is influenced by Dewey's theory of experience as temporal, continuous, and interactive (Dewey, 1938) and is based on the premise that an individual's experience is "a source of insights useful not only to the person himself or herself but also to the wider field of social science scholarship generally" (Clandinin \& Rosiek, 2007, p. 49). Narrative inquiry is also rooted in Bruner's (1986) narrative cognitive theory in which he distinguished two modes of thinking for "ordering experience and constructing reality" (p. 11) - the paradigmatic mode and the narrative mode. The paradigmatic mode functions in a logical scientific fashion. It helps people to understand the world by forming a descriptive and explanative system through categorisation and conceptualisation, and leads to the search for universal truth that is guided by hypotheses. In contrast, the narrative mode of thinking looks for verisimilitude instead of the truth, through "good stories, gripping drama, believable (though not necessarily 'true') historical accounts" (p. 13). It attends to human intentions and actions, and deals with uncertainty, change and consequences of the experiences over time and in different places. The development of narrative research in social science, and the influences from Dewey and Bruner make it possible for narrative researchers to undertake their studies based on the understanding of human experience as relational, temporal, and continuous. They seek knowledge of human experience that remains within the stream of human lives (Clandinin \& Rosiek, 2007, 
p. 35), which resonates with the core of this research project - to understand the Chinese EC teachers' personal teaching and learning experiences in their embedded social contexts over time and at different places.

\section{Narrative inquiry as a methodology}

Narrative inquiry connects theoretical ideas and human experience (Connelly \& Clandinin, 1990). Four assumptions underpin the claims to reliability, objectivity, generalisability and validity of narrative inquiry (Pinnegar \& Daynes, 2007):

- All research is based on language, either the language of numbers or discourse.

- The interaction between people in the research is "a relationship process that ultimately involves caring for, curiosity, interest, passion, and change" ( $p$. 29).

- The local and particular information and knowledge of what has been researched is important for understanding the complexity of human life and experiences.

- There are multiple ways of knowing the world, and the purpose of the research is to understand the world rather than to control and predict it.

Accordingly, narrative inquirers begin their inquiry by exploring human experiences as relational, temporal and continuous, and believe knowledge is embedded in the life that human beings live. They inquire into various events as happening over time in multiple contexts, are aware of the uncertainty and tentativeness within people's lives and the inquiry process, and use "plot" to organise "listing of events into a schematic whole" (Polkinghorne, 1988, p. 19) 
which is continuous and unified. Thus they continuously seek "other possibilities, interpretations and ways of explaining things that are possible" (Clandinin \& Rosiek, 2007, p. 46) through the stories that are lived and told (Clandinin \& Connelly, 2000).

Dewey's notion of experience has influenced Clandinin and Connelly's (2000) development of three dimensional narrative inquiry space (see Figure 4.1) for narrative analysis: 1) the personal and social dimension (interaction), 2) the temporality dimension (time), and 3) the place dimension (situation).

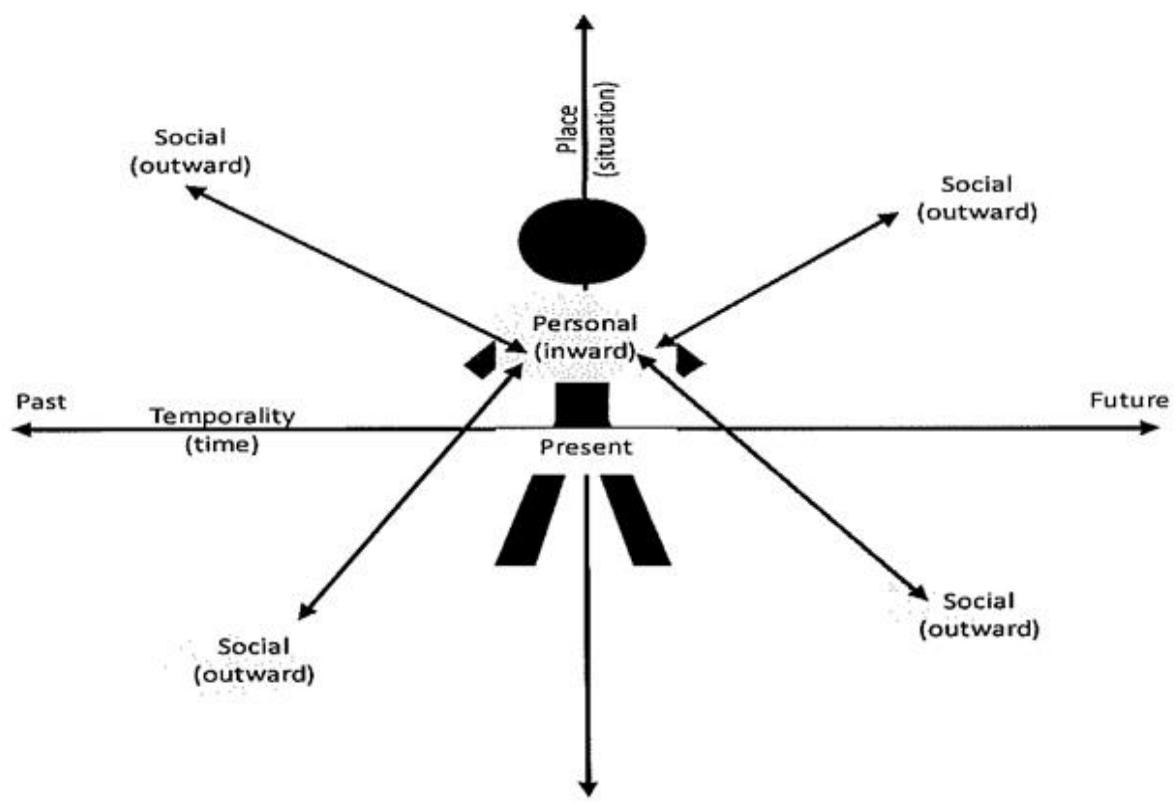

Figure 4.1 Three dimensional narrative inquiry space

Inquiry within the three dimensional narrative inquiry space means that narrative inquirers need to move freely and flexibly backwards and forwards from past to present and future when attending to their own and participants' lives and experiences. Narrative inquirers also need to move inward and outward to explore their and participants' internal "feelings, hopes, aesthetic reactions, and moral dispositions" (Clandinin \& Connelly, 2000, p. 50) and the interaction with the 
external contexts. Clandinin and Connelly (1996) propose the concept of professional knowledge landscape that is "at the interface of theory and practice in teachers' lives" (p. 24) to help "contextualize teachers' personal knowledge" (p. 25) both inside and outside classrooms in school contexts and to explore the influential forces from society. Craig (2007) adds another concept: teachers' knowledge communities, which refers to "the safe places within which teachers negotiate meaning for their stories of experiences on their professional knowledge landscape" (p. 175). These concepts lead narrative inquirers to explore and examine the dynamic relationship between teachers' practical and professional knowledge by unfolding teachers' stories on the landscape.

Narrative inquirers (Ayers, 1989; Craig, 2010b; J. Shu, 2010; S. Yang, 2008) use multiple data collection methods to access multiple perspectives and dig deep into participants' experiences through a process of broadening, burrowing and restorying (Connelly \& Clandinin, 1990) when analysing, interpreting and writing up research texts. Broadening is about making "a general comment of a person's character, values, way of life or, perhaps, about the social and intellectual climate of the times" (p. 11) that helps to set up a social and contextual backdrop for participants' stories. Burrowing is when a researcher focuses on the reconstruction of a specific event from the participant's point of view at a certain point of time and place, and tries to understand why the participant feels and experiences such events in particular ways. This leads to restorying when the researcher locates a specific event in the dimension of time and explores the meaning of such an event and how the participant may "create a new story of self which changes the meaning of the event, its description, and its significance for the larger life story the person may be 
trying to live" (ibid.). Restorying therefore captures changes in participants' experiences and in contexts over time and "makes the turbulence, tensions, and epistemological dilemmas that invariably appear in teachers' lives visible" (Craig, 2007 , p. 180). The interpretation of a participant's experience is a co-construction of new meaning and understanding because narrative researchers work not only with participants' stories but also their own stories as well as other relevant researched stories and theoretical works (Clandinin \& Connelly, 2000).

In short, narrative inquiry can make teachers' practical knowledge explicit in context over time. It seeks new knowledge and understanding through the inquiry process and can connect researchers and participants and thus co-constructs and deepens our understanding of our own teaching and learning experiences. In other words, narrative inquiry is "shared relational work" and "an evolving co-construction" (Clandinin et al., 2006, p. 20). A caring, equal, and mutually constructive research relationship between researchers and participants is crucial when undertaking narrative studies. These characteristics resonate well with this teacher-centred, experience-focused and contextualised study. I was thus convinced that narrative inquiry could be used both as a theoretical framework and as a method for my study. In particular, narrative inquiry allowed me to work with both the participating Chinese EC teachers and myself, to focus on their growth and transformation and my own, and to deeply understand our experiences and the interconnecting contexts that shaped our thinking and practices. I not only attended to the teachers' current teaching practices, but also the relationships between their experiences and the situated contexts. By analysing the teachers' experiences within the threedimensional narrative space through broadening, burrowing and restorying, I 
interpreted the teachers' stories from the micro perspective, focusing on how teachers negotiate meanings and construct their knowledge in everyday contexts through their social actions. Narrative inquiry also helped me explore teachers' experiences at the macro level to understand how social/contextual structures function and the possible structural conflicts that might impact on their experiences (Meighan \& Harber, 2007).

\section{Considering ethical issues: A relational inquiry}

Narrative inquiry emerges "in relation with our life experiences, of living, composing field texts and research texts in relation with participants, and of being attentive to ourselves as part of and under study in the inquiry" (Clandinin, Murphy, Huber, \& Orr, 2010, p. 81). Narrative inquirers therefore are researching with participants rather than on them (Schulz, Schoroeder, \& Brody, 1997). Ethics becomes a very complex topic and narrative inquirers have "an ethical duty to protect the privacy and dignity" (Josselson, 2007a, p. 537) of participants. "Respect for persons, beneficence, and justice" (Nolen \& Putten, 2007, p. 404) are three general ethical principles for research with humans that guide the ethical conduct of researchers in order to "protect the rights of individuals and groups who are the subject of research" (Victoria University of Wellington, 2007, p. 1). In particular, narrative inquirers need to consider the ethical issues relating to access, context, negotiation, privacy, confidentiality, anonymity, presenting participants' voices, and possible risks, dangers and abuses at every stage of the inquiry (Clandinin \& Connelly, 2000). 


\section{Role of the researcher}

One ethical dilemma narrative inquirers face is the positioning of the researcher in the participants' lives and stories over the course of the research (Clandinin \& Connelly, 2000). Josselson (2007a) states that narrative inquirers play dual roles when making their inquiry: a role as a researcher who builds intimate relationships with participating teachers, and a role as a professional who is responsible in the scholarly community. This dual role may cause role confusion when the researcher is developing a personal relationship with the participants (Kennedy, 2005). Informed by these scholars, when undertaking this study, I regarded myself as one of the Chinese EC teachers who had different learning and teaching experiences to the participants. I was cautious about my personal values, assumptions, biases and prejudices that might be harmful or overpower the participants' voices. This was because the researcher's voice was only part of the research; the participants, and the community/society's voices were equally important (Ebbs, 1996). Moreover, in the participants', parents' and kindergarten directors' eyes, I was a researcher who had more scholarly knowledge, skills, and experiences. Although I positioned myself as a teacher assistant in the class, there were still times that teachers, parents, and administrators tried to seek my advice, judgement or opinion on their teaching, parenting, and management issues. When this happened, I made my responses general, non-judgemental, was careful not to embarrass people, and ensured I kept the collected data confidential. In addition, I was aware that in the kindergarten contexts the relationship between the researcher and the participants was not the only relationship that exists. There were complex relationships and politics among teachers and kindergarten directors 
(Xuesong Gao, 2008) that the researcher needed to be alert to. In one case, Private Kindergarten's director asked to read my observation notes in order to help her review the curriculum in practice. Although the participants agreed to the director's request, I refused. I had promised the participants that I would keep the collected data confidential, and I sensed that in the Chinese cultural context, where the director has a lot of power over teachers, the teachers might find it hard to say no to her request.

\section{Participants' rights}

Victoria University of Wellington's (VUW) Human Ethics Policy (2007) indicates that participants have the right to be well informed about the research project and how their rights will be protected, for instance, privacy, confidentiality, anonymity and withdrawal from the project, before they agree to participate. Following this guideline, I sent information sheets (Appendix A) to kindergarten directors, teachers, and parents to introduce this study and to inform them about strategies to protect their rights. Consent forms (Appendix B, C) were used to obtain informed consent from the people involved in this study. I made all the information sheets and consent forms bilingual and had them checked by my bilingual friends who understood the Chinese and Western ECE contexts. They didn't advise me to make any changes to these documents, but provided some insights into how teachers and parents might perceive them while I was giving information and obtaining consent. Their feedback led me to produce some supporting documents in Chinese, such as FAQs for teachers used in the recruitment phase, to present the information in a more accessible way for the teachers. The purpose of these 
practices was to provide as much contextual information as possible.

The process of giving information and obtaining consent was very important for ensuring the participants took part voluntarily in the study and that their decision to participate was informed by accurate information. The participants were assured that they could withdraw from the project at any time during the datacollection process. All interviews were recorded with a digital tape recorder. Before each interview, I assured the participants - the teachers, directors/principals, and parents - that they did not have to answer all of the questions and I could stop recording the interview at any time they wished. All interview transcripts and the observation data collected from the first phase of data collection were returned to the participants for them to comment and to check accuracy. These strategies provided a basic research ground for a caring, collaborative, and relational inquiry.

In order to protect the participants' privacy, confidentiality and anonymity, I asked the participating teachers to choose "research names" for this study. I used the initials of children's names when taking observation notes, and I assigned "research names" to individual children used in the research texts. I drew up a code table to record the teachers' and children's real names, initials, and research names. The participants were also informed that only my supervisors and I had access to the original data and documents, as well as how the collected data were archived.

\section{Reporting}

The major ethical issues during report writing for narrative inquirers concern interpretive authority and the question of whose story it is in the research report (Josselson, 2007a). Depending on the nature of the research, different narrative 
inquirers take different positions when interpreting the stories that are told by the participants from the field work. In this study, I took the position suggested by Josselson and my research report rested "in the researcher's authority" (p. 549). From this point of view, the participants had the right and ownership of which experiences they chose to share during the data collection process. I had the authority and responsibility to determine how the teachers' experiences could be represented and interpreted, and this final report itself is my narrative understanding of Chinese EC teachers' experiences. However, the teachers' voices and honouring their own words were at the centre of representing and interpreting the teachers' "storied lives in storied ways" (Clandinin \& Connelly, 2000, p. 141). Therefore, I was constantly negotiating between my scholarly obligation to accuracy, authenticity, and interpretation, and my interpersonal responsibilities of being caring, empathic, and protective to the participants when writing up the research texts.

\section{Taking the Road of a Narrative Inquiry}

\section{Recruiting participants}

\section{A reality check}

The recruitment process started in Beijing in August 2009 after my ethics application (RM Code: 16767) was approved by the Victoria University of Wellington Faculty of Education Ethics Committee in late July 2009. The proposed research 
project was to recruit six Chinese teachers in Beijing from three different ECE centres: one state-run kindergarten, one private-run kindergarten, and one international kindergarten. I posted letters and research information sheets to the educational bureaux of two districts near my home. I made phone calls and sent letters via e-mail to 12 kindergartens including state-run kindergartens, local private kindergartens, and international kindergartens in Beijing to introduce my research project to them. I was invited to give a power-point presentation to the teachers in only one international kindergarten, and to meet with two kindergarten directors one from a state-run kindergarten and another from a local private kindergarten (all through personal networks and mutual friends). Most of the people I contacted expressed the belief that this study was valuable and necessary since Chinese teachers' teaching and learning experiences needed to be thoroughly understood in the contemporary Chinese context. But no one would commit to participating. Responses from the officers of local educational bureaux, kindergarten directors and teachers indicated the following reasons for their lack of interest in participating.

- It was at the end of August. Everyone was busy preparing for the new school year starting on 1 September. Hence, some kindergartens asked me to contact them one month later when children and teachers were settled into the new school year.

- H1N1 swine flu: It was the period when all kindergartens were told by the education bureaux to avoid any unnecessary events and visits, and to take strict measures to prevent the spread of the influenza pandemic. Even parents were not allowed to enter the kindergarten grounds. I was also asked to present a medical certificate to approve my health status which I obtained later from the authorised medical clinic. 
- Kindergartens' own research agenda: Some kindergartens had already planned their own research projects for the school year. They found it difficult to fit my research project in. The educational bureaux echoed this view and informed me they would only support government-funded research projects in kindergartens.

- My project was too personal and sensitive: The narrative inquiry method was regarded as being too sensitive and personal for teachers. Kindergartens would welcome a research project on children's learning and development, but not a narrative inquiry into the teachers' experiences by a researcher they didn't know. At one kindergarten, I was asked to change my research method if I wanted to undertake the research there.

- Some teachers thought my project was too big and were concerned they might not be able to cope, particularly with voluntary journal entry, because of their already busy teaching schedule.

- Staff turn-over: Some kindergartens (especially privately run kindergartens) were experiencing high rates of staff turn-over and they were concerned about potential changes in staff during my data collection period.

From these responses I understood that to the potential participants I was a stranger and an independent researcher who they didn't know and didn't have time and interest to know. My research project therefore might be an additional burden in the kindergartens' and the teachers' everyday life. As a result, while teachers and directors could see that it was valuable, they did not want to commit to the extra work involved in the project. Changes to the recruitment plan and strategy were necessary in order to generate interest in participation. 


\section{Change of plan}

I started to use my personal networks to promote my research project to change my status from being a total stranger to somebody the directors knew a little bit through trusted professional networks. Since I was trained in Shanghai and had more networks in the ECE field there, I decided, with my supervisors' permission, to extend the recruitment from Beijing to Shanghai. While Beijing is the capital, the cultural and political centre of China, Shanghai is known as the centre of finance and trade in mainland China. Although the two cities have their own unique cultural, political, social, and economic contexts, they both have had dynamic interactions with the wider world during the last thirty years and have become globally recognised cities. Beijing and Shanghai both have many different types of ECE services, for instance, public kindergartens, private kindergartens and international kindergartens that adopt various ECE approaches including Montessori, bilingual education, and the project approach and so on. This change of plan and strategy resulted in a positive outcome for the recruitment process.

I contacted three kindergartens from Beijing and Shanghai through personal contacts and mutual friends via e-mail and phone calls, and letters and information sheets were sent to them. I then met up with the directors and interested teachers face to face to answer any questions they had. An additional FAQ Sheet in Chinese was prepared and sent to the directors and teachers with the information sheets as an informal way of explaining my research. After some deliberation, all three kindergartens (one from Beijing, and two from Shanghai) agreed to participate in my research, and two teachers from each kindergarten (six teachers in total) opened up their classrooms to me (see Table 4.1). 
Table 4.1

Participating kindergartens and teachers

\begin{tabular}{|c|c|c|c|c|c|c|}
\hline Kindergartens & Types & Teachers & $\begin{array}{l}\text { Age of } \\
\text { starting } \\
\text { teacher } \\
\text { training }\end{array}$ & $\begin{array}{c}\text { Years of ECE } \\
\text { teaching } \\
\text { experience }\end{array}$ & Classes & $\begin{array}{c}\text { Number of } \\
\text { children in } \\
\text { the class }\end{array}$ \\
\hline \multirow{2}{*}{$\begin{array}{c}\text { Public } \\
\text { (Shanghai) }\end{array}$} & \multirow{2}{*}{ State-run } & Linda & 15 & 2nd year & \multirow{2}{*}{ 3-4-y-old } & \multirow{2}{*}{26} \\
\hline & & Angela & 15 & nearly 10 years & & \\
\hline \multirow{2}{*}{$\begin{array}{c}\text { Private } \\
\text { (Shanghai) }\end{array}$} & \multirow[b]{2}{*}{ Private-run } & Selina & 15 & 6 years & \multirow[b]{2}{*}{ 3-4-y-old } & \multirow[b]{2}{*}{26} \\
\hline & & Cherry & $\begin{array}{l}\text { Mid } \\
20 s\end{array}$ & 3 years & & \\
\hline \multirow{2}{*}{$\begin{array}{c}\text { International } \\
\text { (Beijing) }\end{array}$} & \multirow{2}{*}{$\begin{array}{l}\text { International } \\
\text { Private-run }\end{array}$} & Summer & 15 & $10+$ years & 2-3-y-old & 15 \\
\hline & & Cecilia & 15 & nearly 10 years & 3-4-y-old & 22 \\
\hline
\end{tabular}

(all names in the table pseudonyms)

\section{Collecting narrative data}

Connelly and Clandinin (1990) urge narrative inquirers to collect "a rich data source with a focus on the concrete particularities of life that create powerful narrative tellings" (p. 5). The rich and detailed field texts can be any forms of narrative texts or artefacts such as teacher stories, journal writing, conversations, interviews, field notes, documents etc. (Clandinin \& Connelly, 2000). In order to access Chinese EC teachers' daily teaching practices and build an intimate relationship with them to ensure the collected data were authentic and reliable, I entered their classrooms as a teacher assistant offering my help to them when needed, joining their planning meetings and other kindergarten functions with them. The multiple data resources were collected in a two-phase data collection process during one school year (September 2009 - June 2010) in Beijing and Shanghai. The data collection tasks and timeline are presented in Figure 4.2. 
Recruiting participants

August - October 2009

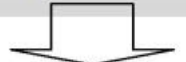

First phase of data collection - October 2009 - March 2010

International Kindergarten

(Beijing)

October - November 2009

Consenting

Participatory observation

Interview participants,

director/principal, parents

Collect documents

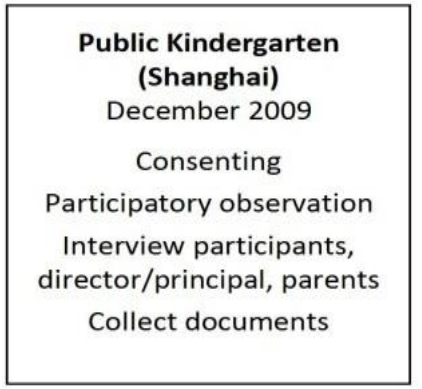

Private Kindergarten

(Shanghai)

March 2010

Consenting

Participatory observation

Interview participants, director/principal, parents

Collect documents

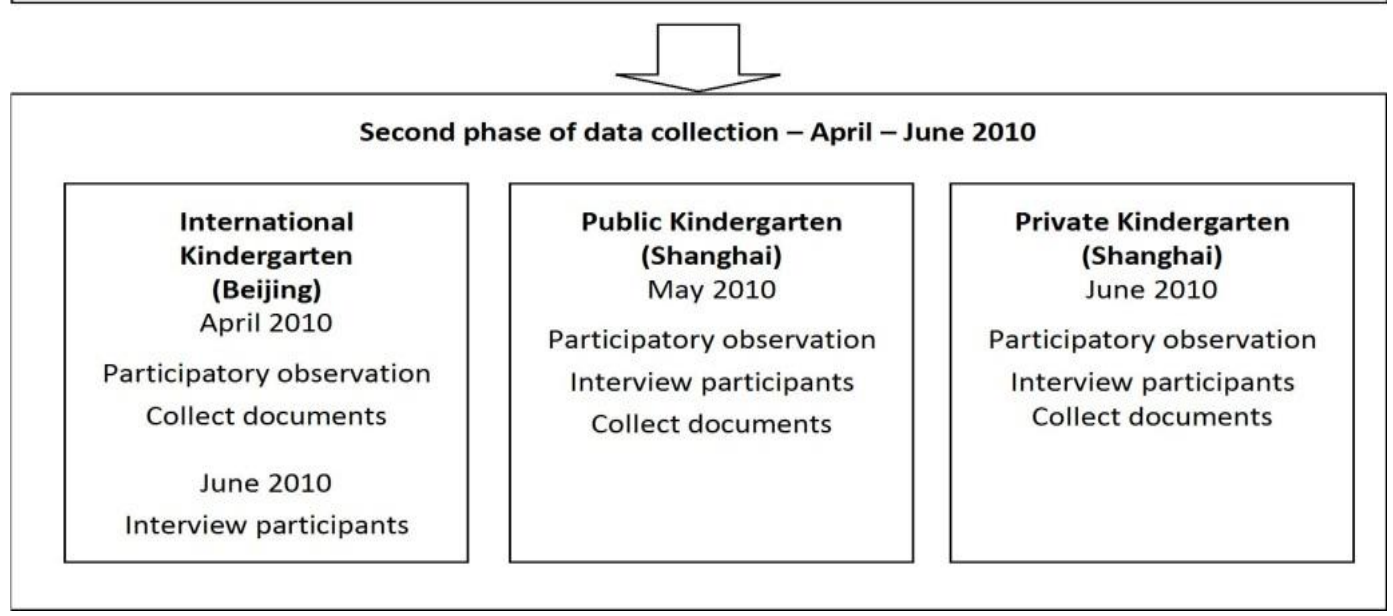

Figure 4.2 Data collection tasks and timeline

\section{Classroom observations}

The main task for the first phase of data collection (October 2009 - March 2010) was to build a trusting relationship with teachers and their kindergartens, and to get to know each other and the contexts. The participatory observation lasted eight days for each class over a two-week period. I recorded the classroom environments, the teacher-child interactions, and almost everything that happened in the class each day (see Appendix D for a sample of observation notes). Through these detailed observation notes, I was able to identify "narrative threads that pulse through every moment" (Clandinin \& Connelly, 2000, p. 77). This approach caused 
some stress to the teachers at the beginning, but the teachers and children quickly got used to my presence in their classrooms and regarded me as a "regular" class member during the observation period. This attitude enabled me to observe a more authentic and real classroom life than the show-off performance type of teaching. I took photos of each kindergarten's environment (no children and teachers in the photos) with verbal permission from the directors and teachers. These photos helped me to remember the environment of each kindergarten but they were not used as data for analysis. During the second phase of data collection (April $2010-$ June 2010), I continued with this practice and worked in each class for another eight-day period.

I was aware of how nerve-wracking and daunting it could be for the teachers who were observed closely over two eight-day periods by somebody they didn't know very well. Therefore, I offered to help the teachers set up the classroom and volunteered to make teaching materials they needed. However, most of the time I was an observer taking notes. I showed the teachers my observation notes and they could read them anytime they wanted. I made folders for each teacher storing all the printed-out observation notes and interview transcripts for their comments and feedback. I tried to initiate casual conversations to reassure them that I cared about their feelings and emotions, and I did my best to reduce the stress that might be caused by my presence in the classroom. Some teachers mentioned in their interviews that my observation notes and their conversations with me had helped them to know their children better and extended their thinking and reflection on their own practices. 


\section{Interviews}

With the teachers - Two or three semi-structured interviews with each teacher were conducted during the first round of data collection. I interviewed the teachers at their kindergartens during their non-contact time. The lengths of the interviews ranged from approximately 30 minutes to 1.5 hours. Most of the interviews ended when the scheduled interview questions were discussed and the teachers felt they had shared enough with me. Some were interrupted half-way through since the non-contact time finished and the teachers had to either go back teaching or to a staff meeting. In such cases, the teachers would pick another time to continue the interview at their convenience, often after school. Three sets of interview questions (Appendix E) were designed to get to know the teachers as an autobiographer, an EC teacher, and a whole person (Ayers, 1989). However, the questions were not set in concrete but were designed to invite the teachers to share their thoughts and stories with me. The teachers were interviewed again at the end of the data collection phase. The last interviews were to gain feedback from the teachers about participating in this study, and to discuss some common topics that emerged from the research data around rules and routines, children with challenging behaviours, group and individualised teaching, and working with parents.

With the kindergarten management - I had one-hour (approximately) long semi-structured interviews (Appendix F) with each of the three kindergartens' directors/principals: one director (both Chinese) each from the Public Kindergarten and the Private Kindergarten, and two from the International Kindergarten (the Western ECE director and the Chinese Principal). These interviews helped me to 
probe kindergarten directors' perspectives on ECE at both the personal and the institutional level; and their perspectives on teachers' teaching and learning in their kindergartens.

With the parents - I interviewed 14 parents across three kindergartens: six parents from the International Kindergarten, three from the Public Kindergarten, and five from the Private Kindergarten. The interviews were semi-structured (Appendix G) and encouraged parents to share their perspectives with me on child development and learning, kindergarten curriculum, and teachers' teaching.

\section{Documentation}

I collected information from the kindergartens' websites, planning documents, policy documents, curriculum booklets (hardcopies, electronic copies or my notes after reading the documents on site) that the teachers and the kindergartens had agreed to share with me. These documents were either given to the teachers or produced by the teachers. The collected documents helped me to construct the contextual background of each kindergarten that constituted the teachers' teaching and learning experiences.

\section{Voluntary journal entry}

Journal writing was voluntary and the teachers were asked to write only if they wanted. However, writing journals was not a popular idea among the teachers. Linda and Angela only provided me with the journal entries that they submitted to the directors every week. Selina and Cherry didn't write any journals for me. Summer and Cecilia expressed strong objection to the idea of writing journal as they shared, based on their prior experiences of journal writing: 


\section{Summer}

It felt like handing in homework every Friday. It wasn't active; it was a requirement, two writings per week. We didn't usually have that many things to write about.

\section{Cecilia}

You were forced to write these teaching journals.

There wasn't a certain guideline of what to write. They were random stories.

I was good at compiling the stories, some were true stories, and some were not. Most nicely written stories were not true, but the directors would grade them with " $A$ ". True stories sometimes were not nicely written, so sometimes they would get " $B$ ".

Summer and Cecilia's comments led me to reflect on my own experience of journal entry as it was once a required routine job for me when teaching at local Chinese kindergartens. We were asked to write "teaching and caring journals" once a week to submit to the kindergarten director. We were told that journal writing could help us reflect on our teaching and child-care practices; the director would read them and give feedback as a way of communicating with the teachers and scaffolding teachers' learning. I could understand Summer and Cecilia's objections and did not want to force them to get invalid and untruthful data. Instead, I collected other forms of teachers' writings such as children's portfolio entries and learning stories where they might communicate their thinking and perceptions too.

\section{Focus Group}

I could not organize any focus group as planned in the research proposal because of the reality that the participants were now from two cities, Beijing and Shanghai. 


\section{Working in the field ethically with care and respect}

Before the classroom observations, I talked to the directors and six teachers individually to introduce myself, the study, and the consent process. I gave the consent forms to the teachers and the directors, and they returned the completed forms. I also visited each class and introduced myself to the children. I was at the International Kindergarten's parent-teacher interview to talk to the parents, and most of the parents filled in the consent forms at that time. I sent the forms home for the parents who did not come for the parent-teacher interviews. The consent forms were sent home with children at Private Kindergarten and Public Kindergarten, and I was available during the drop-off and pick-up time to answer the parents' questions. Since gaining consent from parents for research was not a common practice in China, Public Kindergarten's director did not want me to send the detailed consent form home since it might overwhelm parents. In fact, she did not see that such a practice was necessary. With permission from my supervisors and the chairperson of the Faculty of Education's ethic committee through emails, I only sent a letter and a simplified version of the consent form in Chinese (Appendix $\mathrm{H}$ ) to the parents of Public Kindergarten children. Children returned the completed forms to their teachers. Most parents from the three kindergartens gave their consent for their children to be part of this study. I made sure I did not use any data relating to children for whom I didn't have consent.

The classroom observation began after all the consenting procedures had been carried out and the observation dates were negotiated with the kindergarten directors and the teachers at their convenience. 


\section{Exploring the Field Texts and Research Texts}

The field texts of narrative inquiries are always richly detailed and draw from various sources (Clandinin \& Connelly, 2000). To manage the large amount of field texts efficiently, I used the software NVivo 8 that was designed to assist qualitative data analysis. When writing up the narrative stories of the six Chinese EC teachers, my goals were making these stories clear, authentic, transferable, explanatory, inviting, and to aim for verisimilitude (Connelly \& Clandinin, 1990). In this section, I share how I achieved these goals when working with the raw data in Chinese and English, analysing them and representing them in this thesis.

\section{Translation and interpretation: English-Chinese, Chinese-English ...}

A big challenge of this study relates to language. This study is informed by both Chinese and Western theories and philosophies, and is situated in the Chinese context. Therefore, the use of language, whether Chinese or English, is a challenge. For instance, the research proposal and the final report were written in English. However, the study was of Chinese EC teachers who used Chinese as their first and working language. Hence the raw data was mostly in Chinese. The interviews were conducted and transcribed in Chinese (excluding the interviews with the Western ECE director and some parents from International Kindergarten), the observation notes were mostly in Chinese (only a small portion of data in English from International Kindergarten), and so were the collected documents. The field texts were then imported into the NVivo8 software that supported Chinese characters. I 
was working with the original Chinese version of the field texts when annotating, sorting, and coding them. This allowed me to dialogue with the teachers when analysing the "first-hand" field texts at the initial stage. Then I started to construct "second hand" field texts - the teachers' emerging stories - translating the selected field texts from Chinese to English in a more cohesive manner, following some identified plots in individual teachers' stories. A sample of this process can be found in Appendix I. My narrative responses to the teachers' stories and the discussions of the research findings were written in English. This process helped me move from field texts to create research texts that clearly distinguish the stories that were told by teachers, and the stories of the teachers that were retold by me. In doing so, the stories could be collaboratively and mutually constructed and were "created out of the lives of both researcher and participant" (Connelly \& Clandinin, 1990, p. 12).

Esposito (2001) reminds me that language translation is crucial for qualitative cross-cultural studies in terms of validity. She defines the concept of translation "as the transfer of meaning from a source language to a target language" (p.570). Therefore, to translate is also to communicate with the texts and words with consideration of situation and the overall context of the source language, and to re-express the interpreter's understanding of meaning into the target language in a way that can be understood by people from the target language's cultural context. In this sense, translation is more of a meaning-making process to understand the texts as accurately as possible rather than a word-for-word interpreting task. I say "as accurately as possible" here because, during my literature review process, I have noticed that many English educational terms don't have a particular Chinese word to match the exact meaning. Therefore, it is possible that one English term can be 
translated in different ways by Chinese writers, and vice versa. For instance, the word disposition has been translated as xìngxiàng and xīnzhìqingxiàng in Chinese. To deal with the possible dilemma of becoming lost in translation and of confusion, I included both Chinese pinyin ${ }^{3}$ and English phrases for some important concepts such as experience and play.

\section{Data analysis}

I analysed the collected data through a process of broadening, burrowing and restorying (Connelly \& Clandinin, 1990). Throughout the data analysis process, I positioned the field texts collected from each teacher in the wider contexts. I read, annotated and understood the field texts in relation to the research focus, the wider contexts and relevant literature. I dug deep down into individual teachers' data and explored plots displaying "the linkage among the data elements" (Polkinghorne, 1995, p. 15), and selected the sections of the texts that were significant and meaningful. Analytical memos (Appendix J) were developed to assist the analysis and writing up research texts. I then wrote up the teachers' stories as poems and my interpretations of these stories in order to "bring an order and meaningfulness that [was] not apparent in the data themselves" (Polkinghorne, 1995, p. 16). This data analysis process is represented in Figure 4.3.

\footnotetext{
${ }^{3}$ Pinyin is the official system to transcribe Chinese characters into phonetic symbols.
} 


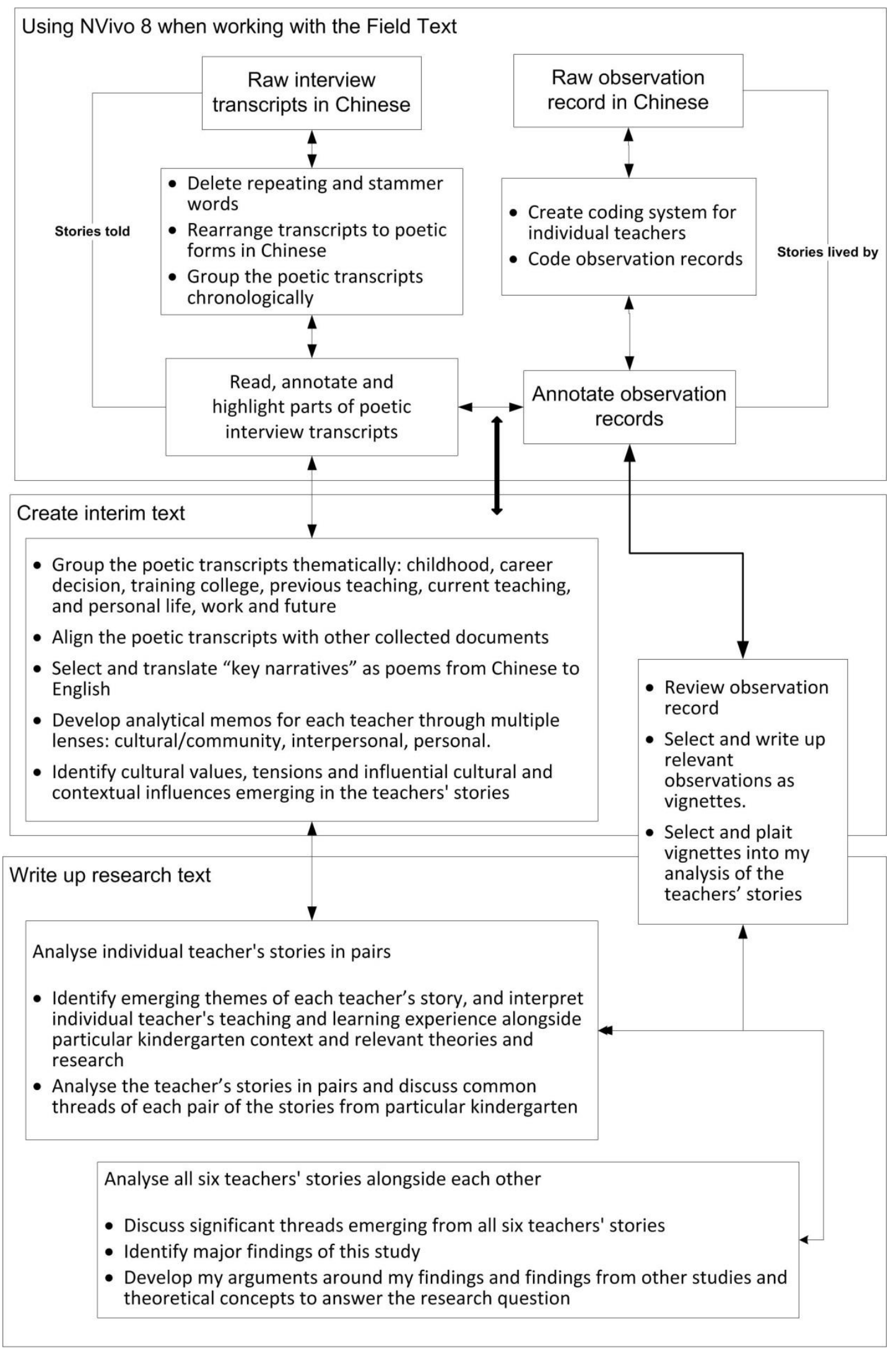

Figure 4.3 Data analysis flow chart 


\section{Representing the research texts}

\section{Interviews as poems}

When I was deciding how to represent teachers' stories, the idea of using poetic representation of the participants' lived experience as a gateway to understand their world (Mears, 2008) attracted me. Several researchers have discussed the use of poetic representations (Aultman, 2009; Glesne, 1997; Hopper \& Sanford, 2008; Richardson, 2000, 2003; Sparkes, Nilges, Swan, \& Dowling, 2003; Ward, 2007). They find that poetic representation can be a "creative analytic practice" (Richardson, 2000, p. 929) that shares and opens one's unique world to others with minimal words, and engages the readers to "see, feel, and analyse the familiar in new ways" (p. 933). Moreover, it has "the capability of reducing the distance between the ' $I$ ' and the 'Other,' and between the 'writing-l' and 'experiencing-l' of the writer" (Richardson, 2003, p. 197). It attends to participants' feelings, thoughts, inner and outer worlds, and metaphors they use, flows with identified themes; and leaves space for the audiences to interpret the poems reflexively. It also "tolerate[s] ambiguity, celebrate[s] process and openness, and avoid[s] premature closure" (Sparkes et al., 2003, p. 169). All of these advantages of poetic representation attracted me as I was concerned about the co-constructed nature of teachers' stories and representing the inter-subjectivity between researcher and participants. I had also been searching for an approach that had "the transformative powers of language and reflection to open, in some ways, all participants: researcher, researched, and readers" (Glesne, 1997, p. 218). Therefore, I choose to represent the teachers' stories in poetic format. 
Poems can be styled in ways to reveal how the researcher interprets the participants' experience (Holt, 2011). No matter how creative the form is, authenticity is always a key element of the poetic representation. Therefore, the poems of teachers' stories came from the teachers' words from the interviews and our conversations, not mine. In this sense, I firstly worked with the raw interview data in Chinese, reduced the repetitive words, and broke the sentences into short poetic formats. I then grouped the poetic interview texts chronologically and thematically. I selected and rearranged the order of the Chinese poems to illuminate the teachers' experience cohesively. The poems were then translated. Through this "narrative configuration" (Polkinghorne, 1995, p. 5) process, I constructed "poetic transcription" (Glesne, 1997, p. 203) that combined the teacher's voice and my choices of selecting and organising the teachers' narratives into poems. In doing so, I hoped to show the readers what the participants did, thought and felt.

\section{Observations as vignettes}

While the interviews provide information from participants' memory and reflection, the participatory observations offer insights into the "now" and "present" of participants' experiences. For this study, the selected observation notes were used as a source for reflection to support my interpretations of the teachers' lived experiences. Some specific observed teaching and learning moments were written as short vignettes, and some of my general observations of the kindergarten, the teacher or the teacher's interaction with others were written in a descriptive fashion. The narrated research texts therefore explored the connection between my observations of the teachers' personal practical knowledge in action within the local 
context, and the poems of the teachers' perceived knowledge and understanding that they had shared with me during the interviews.

\section{My analysis of the teachers' experiences}

My analyses of the teachers' stories were integrated with the teachers' narratives, my observations, and relevant literature. I identified the major themes that emerged from each teacher's stories. These themes were slightly different for each teacher, but were mainly around three broad topics: the reality of teaching, professional learning, and professional and personal self. I then wrote up my analysis of each teacher's story individually, and two teachers' stories from the same kindergarten were represented in pairs. This process enabled me to explore the uniqueness of each teacher's story, as well as some common threads of paired teachers' stories. After analysing six teacher's stories alongside each other, I identified three major findings of this study, which will be discussed in Chapter 11. By representing the teachers' stories and my interpretation in multiple levels, I hoped that I could reveal the complexity and multifaceted nature of Chinese EC teachers' teaching and learning experiences.

\section{Validity Challenges}

Narrative inquirers take the view that there are multiple versions of reality. Narrative inquirers and their participants interpret and represent reality through their construction of narratives that reflect "a subjective and relative reality" rather 
than "essential and objective reality" (Spector-Mersel, 2010, p. 208). In this sense, the issue of validity in narrative inquiry relates to the telling and retelling of multiple truths. The findings of the narrative research are the researchers' "situated interpretations" (Josselson, 2006, p. 6) of reality rather than abstract and generalised facts that the modernists desire. Thus, the subjective, relational and situated interpretation of the reality may lead to two main validity challenges for narrative inquirers.

The first challenge is that narrative study may become fictional. The researchers' interpretations of the participants' stories may also be shaped by their vantage point influenced by their "personal-cultural-context" (Conle, 2000, p. 57). Thus, I was alert to the assumptions, feelings and intentions, social appropriateness, truthful and comprehensive descriptions of the teachers' narratives and of my analysis, as suggested by Conle (2001).

The second validity challenge concerns the co-constructed narratives being used unreflectively and uncritically. This is because of the intention to have the stories speak for themselves, rather than analysing the stories' "rhetorical, persuasive properties, and their functions in constructing particular versions of events, justifications of actions, evaluations of others" (Atkinson \& Delamont, 2006, p. 167). To address this challenge, I systematically analysed the teachers' stories through multiple lenses - community, interpersonal and personal. I aligned the teachers' narratives with relevant theories and research when interpreting them. These strategies enabled me to attend to the embodiedness, the social, cultural, and philosophical influences, and the relationship between the power and knowledge within the told-retold stories (Peterson \& Langellier, 2006). 


\section{Particular and Generalisation}

Narrative inquirers value "the power of the particular" (Pinnegar \& Daynes, 2007, p. 21) over generalisation. This study intends to gain in-depth understanding of a particular group of people - urban Chinese EC teachers' teaching and learning experiences in contemporary China - rather than providing facts and truths for generalising the research findings across different contexts. The contextualised nature of this study means it lacks generalisability to teachers teaching in contexts other than contemporary urban China. The small sample of participants served this research purpose, as I have been able to know six participants and three kindergartens well over the period of a school year, which enabled me to gain rich and complex research data. The teachers were not representative of the whole Chinese EC teacher population; however, they were part of the population and their stories could form a base for understanding others' experiences. Clandinin (1993) argued reading researched stories can help readers to understand their own stories better by constructing new meanings. Hence, this study does not intend to offer any prescriptive plans or strategies for implementing into Chinese EC teachers' teaching and learning. Rather, it offers new possibilities for understanding and empowering teachers' teaching and learning through the dialogue between the researched stories and the readers' own experiences. 


\section{Chapter 5: Linda and Angela from Public Kindergarten}

\section{Public Kindergarten Context}

Linda and Angela were teaching partners of a 4 and 5-year-old class at Public Kindergarten, a state-run kindergarten in Shanghai. Linda was a second year teacher in her early twenties. Angela, almost 30 years old, had 10 years previous teaching experience at another state-run kindergarten in Shanghai before joining Public Kindergarten in mid-2009. Angela was the team leader of the 4 and 5-year-old class teaching team (two parallel classes with four teachers). Linda and Angela split the teaching load and took turns at teaching in the mornings and afternoons (7:30 a.m. - 12:00 p.m. and 11:30 a.m. - 5:00 p.m.), and switched daily. There were 24 children on Linda and Angela's class roll.

Public Kindergarten had only been in operation for 18 months when I started data collection in December 2009. It was a branch campus of a well-known exemplar kindergarten ${ }^{4}$ that had established its own curriculum and management structure over a 15-year period. The director of Public Kindergarten was an awardwinning teacher from the exemplar kindergarten, and was promoted to the leadership role in 2008. The teaching team was made up mostly of novice teachers,

\footnotetext{
${ }^{4}$ There are four different grades of kindergartens in Shanghai. The exemplar kindergartens are the top graded (Shanghai Municipal Education Commission, 1999) kindergartens in Shanghai. There were 41 exemplar kindergartens (out of approximately 1000 kindergartens in total in Shanghai) listed on the Shanghai Education Bureau's website (http://www.shmec.gov.cn/web/glxx/listInfo.php?id=37754) in 2007, retrieved on January $3^{\text {rd }}$ 2011.
} 
plus a few teachers transferred from the exemplar kindergarten and other local kindergartens. According to the director, Public Kindergarten's educational philosophy, curriculum and planning, ways of teaching etc. were expected to maintain a high degree of consistency with its affiliated exemplar kindergarten. According to Public Kindergarten's curriculum guide, the kindergarten's aspiration for children was: "to be healthy and civilised; curious and adventurous; sociable, open-minded and positive; confident and intelligent" (own translation).

\section{Funding}

Shanghai Municipal Education Commission funded and took centralised control of all state-run kindergartens. The funds came from the public expenditure of education. Public Kindergarten's director was expected to follow all the policies and procedures set by Shanghai Municipal Education Commission and run the kindergarten accordingly.

Public Kindergarten had a three-storey building accommodating the classes, an on-site kitchen providing meals and snacks to all children, a multifunction dance studio, an art-room, a library area and a small indoor gym area. It had a big outdoor play area with a sand pit, water play pool, outdoor play equipment, rock climbing wall etc. Each class had air-conditioners/heat-pumps installed and was equipped with multi-media devices such as flat-screen TV, laptop computer, CD/DVD player and piano. Public Kindergarten was well equipped in terms of space and facilities.

Public Kindergarten was serving 2 to 6 -year-old children mainly from the nearby residential areas. During the school year of 2009-2010, Public Kindergarten had five classes and approximately 120 children. Each class had two teachers and 
one caregiver. Shanghai Municipal Education Commission developed fee policies that all state-run kindergartens were required to follow. The state-run kindergartens' official grades and ratings given by Shanghai Municipal Education Commission determined the fees each kindergarten was allowed to charge. Public Kindergarten's parents paid approximately CNY $¥ 1000 / N Z D \$ 192$ each month. This was at the top end of Shanghai state-run kindergartens' fee range, but was the lowest of the three participating kindergartens.

\section{Curriculum}

Shanghai's ECE experienced two education reform initiatives that could be seen as the local interpretation of the Chinese government's nation-wide reform efforts over the recent decades (see Chapter 1, pp. 15-16). The first reform started in 1993 with an intention to change the primary-like early childhood education, to change the teacher-centred teaching and learning, and to establish scientific concepts of child development (Y. He, 2005). The release of the Shanghai Early Childhood Education Framework (Shanghai Municipal Education Commission, 1999) in 1999 marked the beginning of the second education reform. The reform promoted a child-development-orientated education recognising the teacher-childdual-subjectivity (jiàoshī yòuér shuāng zhǔtī) in teaching and learning. This meant teacher and child could both be at the centre of teaching and learning, and be the subject/executor and the object/recipient of actual teaching and learning activities (see Figure 5.1). 


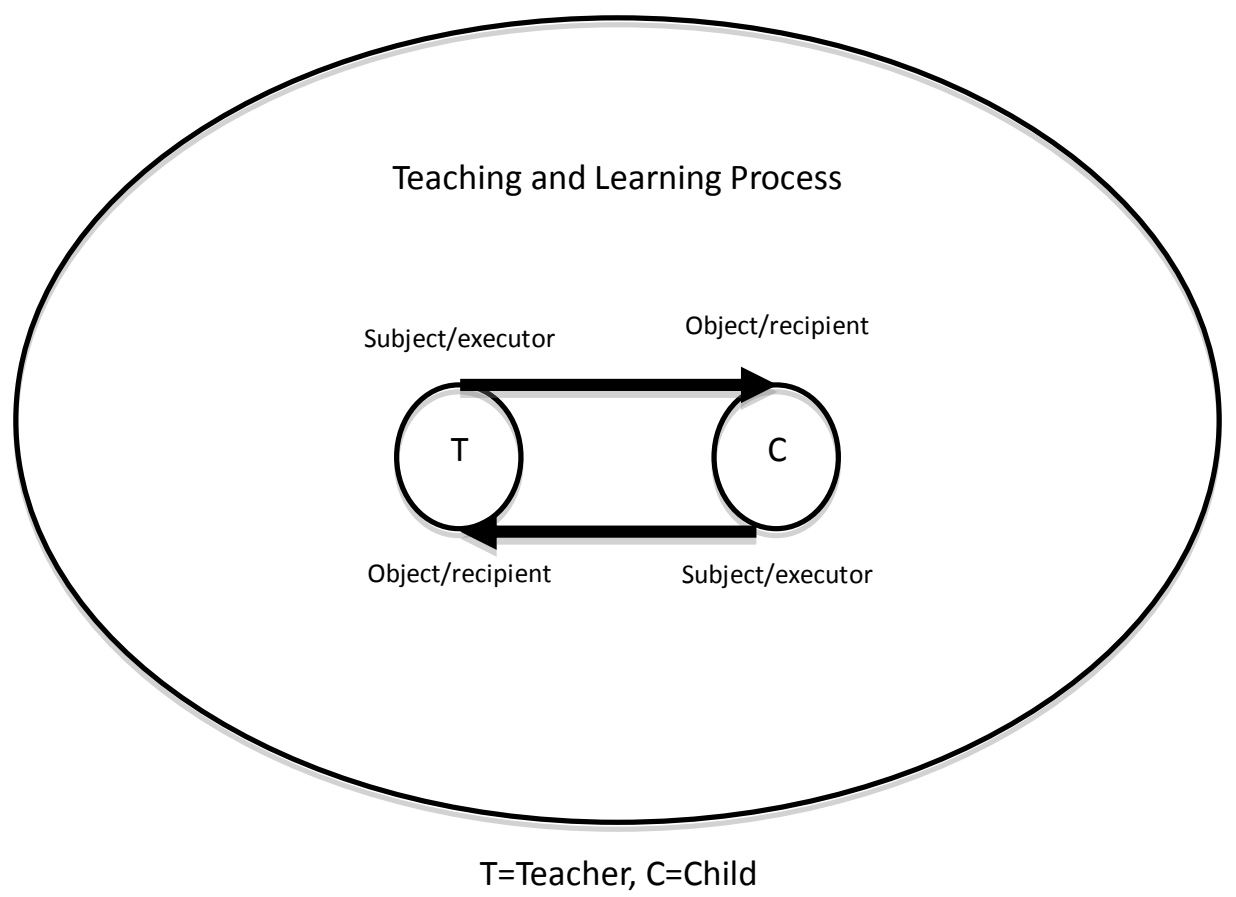

Figure 5.1 Representation of the concept of teacher-child-dual-subjectivity

H. Li (2005) argues that the concept of teacher-child-dual-subjectivity reflects the dynamic nature of teaching and learning due to the inter-subjectivity of teacher and child in teaching and learning, and the desire to balance teacher-led and child-led teaching and learning. Teachers were required to have children in their eyes, to have developmental goals in their mind, and to educate children at any time. These requirements valued children's subjectivity, holistic development, and emergent learning. In 2011 (after my field work), Shanghai Municipal Education Commission reinforced these reform ideas and required kindergartens to reduce group teaching and learning activity time to once per day: 15-20 minutes for 3 and 4-year-old classes, 20-25 minutes for 4 and 5-year-old classes, and 25-30 minutes for 5 and 6-year-old classes (Q. Huang, 2012). Kindergartens and teachers were expected to implement the government's new requirements accordingly. 
Shanghai Municipal Education Commission (2004) also released Shanghai Early Childhood Education Curriculum Guidance to guide kindergartens' implementation of Shanghai Early Childhood Curriculum Framework. It required each kindergarten to have a common curriculum and selective curricula allowing children to access three kinds of experiences: Living together (gòngtóng shēnghuó), Exploring the World (tànsuǒ shijiè), Expressing and Performing (biăodá biǎoxiàn). The common curriculum was made up of four kinds of activities (huódòng).

- Everyday Life Activities (shēnghuó) - self-care, manners and etiquette, selfprotection, hygiene, rules and routines etc.

- Sports Activities (yùndòng) - which should support children's physical development.

- Learning Activities (yuéxi) - where children could discuss, read, listen and appreciate, make things, perform, visit places, and collect information etc.

- Play (yóuxi) - child-initiated, active, and free activities. Teachers' tasks during yóuxì were to understand children by observing their play, and to create a learning environment for intervening and supporting children's play appropriately.

Shanghai Municipal Education Commission developed resource books for each of the four kinds of activities, and the purpose of implementing the common curriculum was to guarantee children's minimum development (Shanghaishi jiaoweijiaoxueyanjiushi youjiaozu, 2001). Kindergartens were also expected to develop their unique selective curriculum, known as kindergarten-based curriculum, for extending children's experiences, meeting children's interests and particular needs, highlighting the kindergarten's autonomy and children's choices. Public Kindergarten's kindergarten-based curriculum was developed by the affiliated 
exemplar kindergarten's teachers and included:

- Theme-based English Programme: group lessons taught by the class teachers who were Chinese.

- Learning Centre Activity: teachers provided materials and activities for children to manipulate and engage with, individually or with peers. For instance, the paper folding centre had origami paper and step-by-step diagrammatic instructions for children to learn how to fold specific objects by themselves; different maths activities such as making patterns out of different colour/size lids and laminated maze worksheets; blocks and openended art activity materials; etc.

- Experience Exchange Activity: a kind of facilitated group discussion around teacher-selected topics intended to foster children's critical thinking and language development.

According to the director, Public Kindergarten's teaching content came from both the common curriculum (70\%) and the kindergarten-based curriculum (30\%).

\section{Child in teaching and learning}

Public Kindergarten's director always made reference to the kindergarten's childdevelopment-orientated philosophy when asked about curriculum, planning, pedagogy, and assessment. She believed that "teachers' understanding of this philosophy and how they interpreted it in their interactions with children were crucial for the success of the curriculum" (interview, December 23, 2009). She shared:

Although teachers need to pre-plan more for group learning we still hope the teachers can pre-plan based on children's reality 
children's life experience.

Not only pre-plan

from the teachers' perspective.

We were doing

the teaching plans before.

Now

we need to focus more

on the learning plans.

To predict

what problems children would encounter

in my planned teaching

from children's perspective.

Individualised learning

is a process of

children's active construction.

Teachers act as

a spectator to observe

how children use the material.

How she manipulates the material.

If she would use other resources

when interacting with the material.

If she is able to ask for help.

Based on these observation

teachers then intervene

and discuss with children.

Our emphasis is to

provide space and time

for children to actively construct.

The director's poem revealed two different images of the child:

- The individual child teachers needed to "observe"

- The universal child illustrated by the characteristics of developmental stages to help teachers "pre-plan" learning activities, "predict" and set up learning goals for planned activities.

The universal image of the child seemed more visible than the individual child at Public Kindergarten, and it was used as a benchmark to help teachers understand and assess children's ability, so that they could teach according to children's aptitude as the reform's goal-orientated teaching and learning expected. 


\section{Kindergarten structure}

The director described her ideal kindergarten as "children's world" and articulated

the difficulties of making Public Kindergarten her ideal kindergarten. She shared:

If considering

the kindergarten

is the children's world

then children

should be allowed to

draw wherever they want

as long as

they have their own

ideas and thoughts.

But

from the management's perspective

it would be considered too messy.

Tidy and orderly environment

is still very important.

It should be ok

for the teachers

to have a designated area

in the classroom

to meet children's such needs

(of scribbling and creative drawing)

But in fact

many teachers still like

unified

pretty

nice displays

in the classroom.

They do not think much about

children's interaction

with the environment.

The restriction comes from

both the management and the teachers.

Our teachers came from

the traditional education system.

They dare not

follow the management's rules.

Their own creativity and teaching approach

have not been cultivated yet either. 
Also the external forces.

Inspections from the higher level.

They would come and see

the environment first.

They wanted to see children's work

that represents children's learning.

However

Some kindergartens' environments

were over the top

it made me wonder

how they created them

how children were going to

interact with them.

But nobody has asked me

how has the environment been created?

how have children been involved in the process?

This poem vividly illustrates the hierarchical social structure of Public Kindergarten and the different roles of each party:

- the Chinese government's education reform and overarching educational philosophy at the top

- Shanghai Municipal Education Commission guides and bridges the reform ideas between government documents to kindergarten practices

- the kindergarten-based curriculum, policies and procedures as the director interprets the reform ideas to the kindergarten context

- the teachers are expected to effectively execute the curriculum and procedures

- children's development as a product or outcome to assess the effectiveness of such policy, curriculum and practice.

In this structure, individual children were placed at the product end despite the kindergarten's guiding philosophy, which was child-development orientated. This might be why "children's world" could only be the ideal, not the reality. Teachers were the least powerful group in the decision-making process, not only 
because of the hierarchical structure, as will be seen in the analysis that follows; their personal understanding of the curriculum, social relations and agency also made them passive in the process. The management, Shanghai Municipal Education Commission and the Chinese government's agendas were prioritised and their focus was on how to regulate and supervise teaching by developing and reinforcing policies, procedures, and provisions for curriculum implementation. The director seemed a key person who bridged the two groups of "they", the teachers and the external power forces, in the Public Kindergarten context. Moreover, parents were not mentioned and they seemed invisible in this social structure.

\section{Professional learning}

Since Public Kindergarten's teaching team was relatively new, the director saw an urgent need to help teachers understand the curriculum, its philosophy and core values. Therefore, the director set up several subgroups for different professional learning and administrative purposes (see Table 5.1).

\section{Table 5.1}

Groups that Linda and Angela belonged to

\begin{tabular}{|c|c|c|}
\hline & Linda & Angela \\
\hline $\begin{array}{l}\text { 4-5-year-old class } \\
\text { teaching team }\end{array}$ & Member & Team leader \\
\hline Subject groups & $\begin{array}{c}\text { English } \\
\text { children's English language } \\
\text { development }\end{array}$ & $\begin{array}{l}\text { Experience Exchange Activity } \\
\text { children's language and } \\
\text { communication development in } \\
\text { Chinese }\end{array}$ \\
\hline $\begin{array}{l}\text { Young teachers' } \\
\text { learning group }\end{array}$ & $\begin{array}{c}\text { Member } \\
\text { led by the director }\end{array}$ & N/A \\
\hline $\begin{array}{c}\text { Senior } \\
\text { management team }\end{array}$ & N/A & $\begin{array}{c}\text { Represent the 4-5-year-old } \\
\text { teaching team }\end{array}$ \\
\hline
\end{tabular}


Linda and Angela were members of the 4 and 5-year-old class teaching team and Angela was the team leader. Along with two other teachers of a parallel class, they met regularly for planning, discussions, and organising special events. They also belonged to two different subject groups led by group leaders who were experienced in teaching the assigned subjects. The professional learning activities for all the teachers were held in the afternoons while children were napping (caregivers supervised). Subject group and small group professional learning activities were arranged during the teachers' non-contact time either in the mornings or in the afternoons.

The director intended to "build a learning platform and provide opportunities for the teachers to see others' teaching, to show others their teaching, to analyse teaching with teachers, to guide their thinking" (interview, December 23, 2009). She believed "teachers' active learning should be the result of a good combination of external support and teacher's internal motive" (ibid.), so that they could reach the professional level that the Public Kindergarten's curriculum required. During my 16 days of observation, there were nine days that teachers participated in 11 organised professional learning activities with different topics and foci (see Table 5.2). 
Table 5.2

\section{Summary of professional learning activities over 16 days' observation}

\section{(excluding administrative meetings)}

\begin{tabular}{|c|c|c|c|c|}
\hline No. & Name & Main tasks & $\begin{array}{l}\text { Teachers' discussion } \\
\text { points }\end{array}$ & The director's thoughts \\
\hline 1 & $\begin{array}{l}\text { Experience } \\
\text { Exchange } \\
\text { Subject-Group } \\
\text { (EESG) Meeting } \\
\text { Angela and } \\
\text { four other } \\
\text { teachers } \\
\text { The director } \\
\text { joined half way } \\
\text { of the meeting }\end{array}$ & $\begin{array}{l}\text { Activity preparation - } \\
\text { Topic: Finding mistakes: } \\
\text { Identify and discuss what } \\
\text { people did wrong that } \\
\text { might damage the } \\
\text { environment in the given } \\
\text { pictures } \\
\text { Goal: To help Angela } \\
\text { understand, design and } \\
\text { plan for the open-class } \\
\text { teaching - activity plans } \\
\text { and the pictures were } \\
\text { given to Angela before } \\
\text { the meeting. }\end{array}$ & $\begin{array}{l}\text { Identify and set up learning } \\
\text { goals } \\
\text { Decide the focus of the } \\
\text { teaching activity } \\
\text { Difficulties children may } \\
\text { encounter } \\
\text { Process of the activity } \\
\text { The relationship between } \\
\text { the learning content and } \\
\text { children's existing } \\
\text { experience and knowledge } \\
\text { Predict children's responses }\end{array}$ & $\begin{array}{l}\text { Are the goals achievable? } \\
\text { Why use this activity to } \\
\text { develop children's } \\
\text { awareness of environment? } \\
\text { Are the contents for } \\
\text { children to explore } \\
\text { valuable? } \\
\text { How do you respond to } \\
\text { children's discussions? } \\
\text { What could children's } \\
\text { thinking process and } \\
\text { responses possibly be? }\end{array}$ \\
\hline 2 & $\begin{array}{l}\text { EESG } \\
\text { Open-class } \\
\text { teaching }\end{array}$ & $\begin{array}{l}\text { Angela teach "Finding } \\
\text { mistakes" } \\
\text { EESG group members } \\
\text { and the director observe }\end{array}$ & & \\
\hline 3 & $\begin{array}{l}\text { EESG Group } \\
\text { reflection }\end{array}$ & $\begin{array}{l}\text { Analyse and reflect on } \\
\text { Angela's teaching }\end{array}$ & $\begin{array}{l}\text { Angela's self-reflection: } \\
\text { My problems: commenting, } \\
\text { catching the main } \\
\text { discussion points, minding } \\
\text { the sequence and logic in } \\
\text { discussion, left out some } \\
\text { pre-planned questions, } \\
\text { underestimating the } \\
\text { possible debate and } \\
\text { disagreement among } \\
\text { children thus failed to guide } \\
\text { the debate / discussion } \\
\text { effectively. } \\
\text { Main reason for the } \\
\text { problems: } \\
\text { I did not pre-plan well. }\end{array}$ & $\begin{array}{l}\text { Through questioning and } \\
\text { commenting on the activity } \\
\text { step by step, the director } \\
\text { urged the teachers to } \\
\text { change their thoughts of } \\
\text { changing children's } \\
\text { perception by just telling } \\
\text { them what was right and } \\
\text { what was wrong } \\
\text { The teachers should pay } \\
\text { attention to the 'bridge' } \\
\text { between the end result and } \\
\text { the cognitive knowing } \\
\text { process that emphasises } \\
\text { understanding and } \\
\text { internalisation rather than } \\
\text { imparting knowledge } \\
\text { directly } \\
\text { Teachers needed to study } \\
\text { the topic of 'how to teach } \\
\text { by focusing on how children } \\
\text { learn... }\end{array}$ \\
\hline 4 & $\begin{array}{l}\text { Professional } \\
\text { learning } \\
\text { session } \\
\text { All teachers }\end{array}$ & $\begin{array}{l}\text { Topic: Teacher's Love } \\
\text { Presentation by an } \\
\text { award-winning teacher } \\
\text { from the exemplar } \\
\text { kindergarten }\end{array}$ & $\begin{array}{l}\text { Stories of loving children } \\
\text { Do you love children? } \\
\text { How do you know? } \\
\text { How do you love children? } \\
\text { Examples of activities }\end{array}$ & $\begin{array}{l}\text { Think about "who the } \\
\text { teachers are in children's } \\
\text { life?" }\end{array}$ \\
\hline
\end{tabular}




\begin{tabular}{|c|c|c|c|c|}
\hline 5 & $\begin{array}{l}\text { English Subject } \\
\text { Group (ESG) } \\
\text { Open-class } \\
\text { teaching }\end{array}$ & $\begin{array}{l}\text { Linda teaching a group } \\
\text { English lesson } \\
\text { ESG group members and } \\
\text { the director observe }\end{array}$ & $\begin{array}{l}\text { Linda pre-planned the } \\
\text { lesson with the ESG leader } \\
\text { Her lesson plans were } \\
\text { rejected twice }\end{array}$ & \\
\hline 6 & $\begin{array}{l}\text { ESG Group } \\
\text { reflection }\end{array}$ & $\begin{array}{l}\text { Analyse and reflect on } \\
\text { Linda's teaching } \\
\text { Linda wrote a reflective } \\
\text { journal afterwards, listed } \\
\text { four self-identified } \\
\text { problems of her teaching } \\
\text { despite everybody else } \\
\text { thinking the activity was } \\
\text { a success. }\end{array}$ & $\begin{array}{l}\text { Analysed the lesson plan } \\
\text { and design, and overall } \\
\text { effectiveness of the lesson } \\
\text { Emerging question: "how to } \\
\text { judge if the lesson is } \\
\text { effective - children happily } \\
\text { participated in the planned } \\
\text { activities, or they are able } \\
\text { to memorise the pre- } \\
\text { targeted key words } \\
\text { according to the learning } \\
\text { goals" }\end{array}$ & $\begin{array}{l}\text { Asking teachers to think: } \\
\text { What do you value the } \\
\text { most? } \\
\text { What is the English lesson } \\
\text { for? How to handle learning } \\
\text { process and learning } \\
\text { outcome? } \\
\text { Director's position: to } \\
\text { pursue result, to optimise } \\
\text { process, children develop in } \\
\text { the process of learning. }\end{array}$ \\
\hline 7 & $\begin{array}{l}4 \text { and 5-year- } \\
\text { old class } \\
\text { teaching team } \\
\text { meeting } \\
\text { Angela, Linda } \\
\text { and two } \\
\text { teachers from } \\
\text { a parallel class }\end{array}$ & $\begin{array}{l}\text { Angela chaired the group } \\
\text { discussion around to the } \\
\text { prepared meeting } \\
\text { agenda }\end{array}$ & $\begin{array}{l}\text { Sharing what was } \\
\text { happening in each class } \\
\text { Discussing the measures of } \\
\text { caring for children } \\
\text { Learning centre activity - } \\
\text { Angela shared the photos } \\
\text { she took at other } \\
\text { kindergartens, discussed } \\
\text { some challenges and } \\
\text { dilemmas }\end{array}$ & \\
\hline 8 & $\begin{array}{l}4 \text { and 5-year- } \\
\text { old class } \\
\text { teaching team } \\
\text { meeting } \\
\text { Angela, Linda } \\
\text { and two } \\
\text { teachers from } \\
\text { a parallel class }\end{array}$ & $\begin{array}{l}\text { Angela chaired the group } \\
\text { discussion } \\
\text { The discussion was } \\
\text { around the prepared } \\
\text { meeting agenda }\end{array}$ & $\begin{array}{l}\text { Team study topic- } \\
\text { Cultivate children's listening } \\
\text { habit (continue with } \\
\text { previous discussions) } \\
\text { Plan for May - class theme } \\
\text { "people around us" } \\
\text { Activities for the late pick } \\
\text { up children }\end{array}$ & \\
\hline 9 & $\begin{array}{l}\text { Lesson } \\
\text { observation }\end{array}$ & $\begin{array}{l}\text { The director observed } \\
\text { Angela's teaching }\end{array}$ & $\begin{array}{l}\text { Experience Exchange } \\
\text { Activity - Topic: Shanghai } \\
\text { World Expo. } 2010\end{array}$ & \\
\hline 10 & $\begin{array}{l}\text { Reflection / } \\
\text { Coaching } \\
\text { Director, } \\
\text { Angela and a } \\
\text { teacher from } \\
\text { the parallel } \\
\text { class }\end{array}$ & $\begin{array}{l}\text { Analyse Angela's } \\
\text { teaching } \\
\text { Design activities }\end{array}$ & $\begin{array}{l}\text { Both teachers planned } \\
\text { together and used the } \\
\text { same lesson plan } \\
\text { They shared their rationales } \\
\text { of such planning to answer } \\
\text { the director's questions: } \\
\text { "why this topic is chosen } \\
\text { and why design the activity } \\
\text { like this". }\end{array}$ & $\begin{array}{l}\text { Director guided teachers' } \\
\text { thinking step by step so } \\
\text { they could learn "How to } \\
\text { turn the interesting topic } \\
\text { into valuable teaching } \\
\text { practices?" } \\
\text { Teachers need to think } \\
\text { about children's interests, } \\
\text { children's developmental } \\
\text { and cognitive } \\
\text { characteristics, and } \\
\text { children's experience }\end{array}$ \\
\hline
\end{tabular}




\begin{tabular}{|c|c|c|c|}
\hline 11 & $\begin{array}{l}\text { Professional } \\
\text { Learning } \\
\text { Session } \\
\text { PowerPoint } \\
\text { presentation by } \\
\text { the director } \\
\text { All teachers } \\
\text { participated }\end{array}$ & $\begin{array}{l}\text { Create environment to } \\
\text { support individualised } \\
\text { learning centre activities } \\
\text { The } 4^{\text {th }} \text { training session } \\
\text { on the same topic by the } \\
\text { director }\end{array}$ & $\begin{array}{l}\text { Choose, create and make } \\
\text { different levels of learning } \\
\text { materials, and set up } \\
\text { learning centres } \\
\text { Value and characteristics of } \\
\text { learning centre activities. }\end{array}$ \\
\hline
\end{tabular}

Table 5.2 shows the director and teachers were very committed to professional development. Through diverse professional learning activities such as open-class teaching and observation, group evaluation and reflection, presentations and seminars, one-to-one consultation between more experienced teacher and novice, the director anticipated a professional community that would be "open, sharing, collaborative, harmonious where teachers would help each other and be allowed to discuss and question for the sake of children and teaching" (interview, December 23, 2009). The director prioritised the topic of group teaching for professional learning, and how to understand individual children and support their individual learning were not on the agenda.

Shulman's (1996/2004) framework of effective learning is helpful in considering teachers' agency, thinking, collaboration, and the culture of Public Kindergarten's professional learning programme. Public Kindergarten's professional learning activities covered many areas that might imply there were many things teachers did not know and needed to learn. The director, the subject group leaders, and the given curriculum documents represented the official knowledge of teaching and learning that needed to be passed on to and acquired by the teachers and children. The more knowledgeable people identified the teachers' learning needs by finding the gaps in their teaching, then scheduled, planned, and guided their 
professional learning activities accordingly. During the group discussions, I noticed the teachers' reflection and discussion were focusing more on actions and behaviours, while the director tried to encourage the teachers to reflect more deeply by questioning and guiding their thinking step by step. Often, the teachers could not respond to the director's questions well. They then tended to be quiet and expected the director to give them the answers. The director always made her ideas very clear. Therefore, the director and the more experienced teachers became the knowledge-givers, and the teachers seemed to be followers, receivers and acquirers of the knowledge and skills required for effective teaching.

However, how to help teachers understand their own actions, thinking processes and the consequences of what they did and thought were not on the learning agenda. In this sense, what may be missing from Public Kindergarten's wellintentioned and hard-working professional learning approach are the acknowledgement and recognition of teachers' agency, personal practical knowledge, and their initiative and agenda for their own learning. Some traditional educational ideas can also be identified in Public Kindergarten's professional learning programme such as valuing more knowledgeable people, authorised knowledge, and external agendas in teaching and learning.

Public Kindergarten's professional learning approach assumed that teachers could gain more control in their practice by mastering the child-developmentorientated curriculum through purposeful pre-planning and accurate prediction of children's responses. This assumption places teachers in a position of conforming to the curriculum and prescribed planning that may disconnect them from their inner self and from children in their classes (Ayers, 2004; Palmer, 1998). Moreover, 
believing the power of prescribed planning and accurate prediction of what would happen seems unrealistic in actual teaching practice since, as Shulman (1996/2004) argues, uncertainty and unpredictability are important features of teaching and there are always chances of the "plan [being] interrupted by a surprise, . . ., by the unexpected" (p. 473).

\section{Linda and Angela's daily routine}

Linda and Angela taught in the classroom alone in the mornings or in the afternoons, except for the scheduled small group learning once a week, and during the transition time after lunch (See Table 5.3). They taught different subjects: Chinese (including Experience Exchange Activity), music and general knowledge for Angela; and English, math and art-craft for Linda. They were both responsible for each child's individual learning at learning centres and their physical development. They shared the workload of communicating with parents through activities such as the class' online blog, individual home-kindergarten communication book, phone calls, and home visits. They spent either mornings or afternoons outside the classroom preparing for their teaching and participating in the professional learning activities. They would discuss the class term plan and monthly plan together, but plan their own everyday teaching individually. 
Table 5.3

Daily timetable of Linda and Angela's class (Autumn/Winter)

\begin{tabular}{|c|c|c|c|c|c|}
\hline & Monday & Tuesday & Wednesday & Thursday & Friday \\
\hline $\begin{array}{l}7: 45-8: 45 \\
\text { Play }\end{array}$ & $\begin{array}{l}\text { Little Society } \\
\text { Social and } \\
\text { dramatic play in } \\
\text { the role play } \\
\text { room }\end{array}$ & $\begin{array}{l}\text { Learning } \\
\text { Centre Activity } \\
\text { In the classroom }\end{array}$ & $\begin{array}{l}\text { Learning } \\
\text { Centre Activity } \\
\text { In the classroom }\end{array}$ & $\begin{array}{l}\text { Book Reading } \\
\text { In the library area } \\
\text { outside the } \\
\text { classroom }\end{array}$ & $\begin{array}{c}\text { Construction / } \\
\text { Lego and Block } \\
\text { Play } \\
\text { In the classroom }\end{array}$ \\
\hline $\begin{array}{l}\text { 8:45-9:00 } \\
\text { Everyday Life }\end{array}$ & \multicolumn{5}{|c|}{$\begin{array}{l}\text { Morning tea, Tuck children's shirts in } \\
\text { Other preparation for PE }\end{array}$} \\
\hline $\begin{array}{l}\text { 9:00-10:00 } \\
\text { Physical } \\
\text { Education }\end{array}$ & \multicolumn{5}{|c|}{ Group P.E. activities, Free choice P.E. time (outdoor if the weather permits) } \\
\hline $\begin{array}{l}\text { 10:00-10:25 } \\
\text { Learning }\end{array}$ & $\begin{array}{c}\text { Experience } \\
\text { Language } \\
\text { or } \\
\text { English }\end{array}$ & $\begin{array}{c}\text { Music } \\
\text { or } \\
\text { General } \\
\text { Knowledge }\end{array}$ & $\begin{array}{c}\text { Literature } \\
\text { Appreciation } \\
\text { or } \\
\text { English }\end{array}$ & $\begin{array}{l}\text { Experience } \\
\text { Exchange and } \\
\text { Math } \\
\text { (two small } \\
\text { groups) } \\
\end{array}$ & $\begin{array}{l}\text { Music } \\
\text { or } \\
\text { Art }\end{array}$ \\
\hline $\begin{array}{l}\text { 10:25-11:00 } \\
\text { Free Activity }\end{array}$ & \multicolumn{5}{|c|}{$\begin{array}{c}\text { Sand and water (not available in the classrooms), walk, story time, free choice, lunch } \\
\text { preparation }\end{array}$} \\
\hline $\begin{array}{l}\text { 11:00-12:00 } \\
\text { Everyday Life }\end{array}$ & \multicolumn{5}{|c|}{ Lunch, free play } \\
\hline $\begin{array}{l}\text { 12:00-2:30 } \\
\text { Everyday Life }\end{array}$ & \multicolumn{5}{|c|}{ Nap time } \\
\hline $\begin{array}{l}2: 30-3: 30 \\
\text { Everyday Life } \\
\& \quad \text { Physical } \\
\text { Education }\end{array}$ & \multicolumn{5}{|c|}{$\begin{array}{l}\text { Get up, afternoon tea, tuck children's shirts in and other preparation for PE } \\
\text { Group P.E. activities and free choice P. E. time }\end{array}$} \\
\hline $\begin{array}{l}\text { 3:45-4:15 } \\
\text { Learning } \\
\text { Activity }\end{array}$ & $\begin{array}{c}\text { English } \\
\text { or } \\
\text { Experience } \\
\text { Exchange } \\
\end{array}$ & $\begin{array}{l}\text { Art } \\
\text { or } \\
\text { Music }\end{array}$ & $\begin{array}{c}\text { English } \\
\text { or } \\
\text { Literature } \\
\text { Appreciation } \\
\end{array}$ & $\begin{array}{c}\text { English } \\
\text { or } \\
\text { Experience } \\
\text { Exchange } \\
\end{array}$ & $\begin{array}{l}\text { Art } \\
\text { or } \\
\text { Music }\end{array}$ \\
\hline $\begin{array}{l}\text { 4:00-5:00 } \\
\text { Play }\end{array}$ & $\begin{array}{l}\text { Learning } \\
\text { Centre Activity } \\
\text { In the classroom }\end{array}$ & $\begin{array}{c}\text { Construction / } \\
\text { Lego and Block } \\
\text { Play } \\
\text { In the classroom }\end{array}$ & $\begin{array}{l}\text { Little Society } \\
\text { Social and } \\
\text { dramatic play in } \\
\text { the role play room }\end{array}$ & $\begin{array}{l}\text { Learning } \\
\text { Centre Activity } \\
\text { In the classroom }\end{array}$ & $\begin{array}{l}\text { Sand and } \\
\text { Water Play }\end{array}$ \\
\hline
\end{tabular}

Apple (1995) asserts that schools' everyday routine activities have more influence and impact on the teachers' and students' development than the ideas and materials found in the related documents and plans. Therefore, it is worthwhile to understand the finer details of Linda and Angela's everyday routine. Most mornings the director would inspect each classroom, and the individual teacher's planning folder was expected to be with them every day, preferably placed on top of the piano in the classroom as a regular teaching routine. The director or team 
leaders' feedback on the pre-planning forms had to be considered. In Linda's mind, it would be disrespectful if she did not take on their recommendations. One-to-one interactions with the children were required as part of the daily routine: checking or tucking in individual children's shirts three times a day (before morning and afternoon PE times in winter and before going home); checking individual children's sweat and reminding them to have a rest when necessary during PE time; making sure children had eaten well at lunch; tucking individual children into bed before nap time; combing the girls' hair after nap; and so on. The kindergarten nurse would check up on these measures during the day.

Linda and Angela seemed to have all the resources they needed for effective teaching: time for preparation, great facilities, comprehensive curriculum booklets, detailed daily routines and procedures, and close teaching supervision. However, they were left to teach alone in the classroom most of the time. This intensified their teaching with the most obvious symptoms I observed, and also illustrated by Apple (1986), as having no time to go to bathroom for the whole morning, and feeling the anxiety of losing control in teaching, especially when facing multiple tasks and children's different needs at the same time.

\section{Linda's Stories as Poems}

\section{My kindergarten}

The kindergarten was on an island 
(a suburb of Shanghai).

It did not have

learning centre activities.

The things we had the most were

toys for playing on the table.

We did not have

teacher-made toys.

Today's children

have more activities.

Children today

are quite smart.

We were obedient

and well behaved.

Listened to the teachers' words.

I do not think

I saw

extremely disruptive children.

There is a gap in

how to view children

by the teachers

then and now.

The teachers then

would display

who were their favourite children

obviously.

I was not the teachers'

most favoured child.

It is quite difficult

to love every child.

But you need to tell yourself

to work towards this.

\section{Choice of being a kindergarten teacher}

My mum said

there was a shortage of

kindergarten teachers.

I wanted to learn piano ${ }^{5}$.

The decision was then made!

I did not really know

what a kindergarten teacher was.

\footnotetext{
${ }^{5}$ Piano is a subject taught at Chinese preschool teacher training colleges.
} 
No idea!

I felt it was a happy thing

to sing and dance with children.

\title{
Initial training
}

We learnt

subjects for learning specific skills

subjects for theories.

Theoretical lessons

were not practical.

Listened to what teachers said

then forgot.

Skills-learning lessons

were better.

The teaching at the training college

and actual kindergarten teaching

were out of touch.

\section{Internship and induction}

\author{
During internship \\ I realised \\ being a teacher was not easy. \\ The relationship with children \\ was not easy to handle. \\ It was not \\ as rosy \\ as I imagined.
}

When I first started teaching here

we were

at another kindergarten ${ }^{6}$.

We needed to

take care of everything.

Eating

Drinking

Toileting.

But it was ok.

We were not required

to do learning centre activities there.

\footnotetext{
${ }^{6}$ Linda refers to the first two months of Public Kindergarten's operation when they borrowed classrooms from a nearby kindergarten. It was because of the parents' demand to have longer time to air the newly built and furbished classrooms to reduce potential health risks to children.
} 
After moving back to our own kindergarten

everything built up.

It became too much trouble.

I had to think about everything

by myself.

How to decorate the classroom?

How to set up learning centre activities?

I needed to

make teaching materials.

We did not have anything

passed on to us.

The pressure was great!

\section{Curriculum}

I teach

Math, Art and English.

Each week

I have

Math small group teaching on Thursday.

Two Art lessons.

Two English lessons.

Besides lessons is play!

Games.

Inside

Learning centre activities.

Construction games.

Little Society's ${ }^{7}$ role-play.

Outside

Sports games.

\section{Planning}

Planning includes

Term plan and month plan.

Everyday plan

involves four areas

Everyday Life

Sport/P.E.

Learning

Play.

The good thing

\footnotetext{
${ }^{7}$ Little Society was a special room where all classes go for imaginative play. During data collection, there were family corner, bakery, hospital, hairdresser, restaurant and bank set up in the room.
} 
about these plans is

knowing what to do every day.

However

I am a new teacher

in many areas I cannot write well.

If there were experienced teachers

offering some suggestions to you

you would grasp it better.

Our daily planning form

half is for the plan

half is for reflection.

We hand in our plan.

Team leaders or the director

review and comment on them.

Just like checking homework.

Then return them to you.

I read the comments.

I would

make some changes in teaching

if I feel their suggestions

are appropriate.

If not I would still do it my way.

\section{Learning content}

Children in our class

would be interested in

a Pirate theme.

We seem quite traditional

we will not go to a topic like that.

Our themes are like ...

spring is coming.

Summer is so hot.

Cars on the road.

These seem normal.

It's closely interrelated to their life emphasises

the relevant life experience.

Pirate

has nothing to do with your life

can only be seen

in the movies or stories.

Children may be interested

since it is a mystery 
then they want to explore

know who/what they are.

How can we

change the summer theme to pirate?

Do you not teach

the regular lesson you have planned?

Talk about pirates

would take some time.

It may not be possible.

They will not agree if I do this!

After all

there is the learning plan

there are the themes

required to be done!

I feel it is interesting

Angela may not feel this way.

I only think

what I can do at art lesson.

What can she teach at language lesson?

Pirate stories?

Make up stories?

It would be

a difficult topic for her.

It is impossible to do this

at state-run kindergarten.

The topics

are set for each term.

The programme

emphasises

life experience.

You cannot change

as you wish.

\section{Group teaching and learning}

What is pre-set in the plan

is much less than

what may emerge

from children

during the actual teaching.

You may not be able to catch

children's answers.

It is very possible that

the topic may digress 
far away from the plan.

Sometimes I would realise

children had led me off the topic

then I tried to get back on track.

I have to achieve

the goals of the lesson.

Digressing too far from the plan

would affect the activity afterwards.

I need to achieve the goals!

\section{Transition between activities}

Afternoon-tea time.

Some children may be eating.

Some may be playing.

I may be

doing children's hair.

I would feel like ...

The eating children

talked too much.

The playing children

got too excited.

I could not mind all of them.

If children talk too much

they would eat very slowly

delay the following activities.

It' $d$ be better

to sit down to play.

Otherwise

it would be chaos.

Must do the girls' hair.

Parents can easily spot

if you do not.

Parents cannot see you

play, learn, interact

with children.

They only see

the most visible stuff!

\section{Teacher-child relationship}

Teacher-child relationship

is established through

living together

playing together 
sitting down

having one-to-one chats.

No matter what kinds

of children working with

the ideal teacher has

all sorts of strategies.

Serious when serious

Happy when happy.

Children are not afraid of you.

Hold a degree of

tightness or looseness.

But

it is difficult for me.

Children in our class are

quite assertive

like to express their thoughts

like to show themselves

quite warm

think actively.

But lacking in

discipline and routine!

I think

teacher and children

should have a relationship like

friends.

But sometimes

friends may

play jokes with each other

and not listen to you.

The distance

between children and the teacher

is something very difficult to grasp.

If it is too close

they may not

take you seriously.

If it is far

they may feel

teacher does not like them.

\section{Teaching English}

I do not know

why children need to learn English 
at kindergarten!

Some children already

mix up English with Pinyin.

I felt it was not appropriate.

I told the director

I did not want to teach English.

But she did not agree.

We are Chinese.

We cannot guarantee

our grammar is always correct.

Children are so young

especially for the three year olds

it is impossible

to teach them

singular and plural.

It is the kindergarten-based curriculum.

They have decided the themes

and which words need to be taught.

You cannot jump out of it

to teach other things.

I do not know

whether English should

follow the themes.

If it follows

it gets very messy.

English is better to have

some systematic and unified

teaching material.

Like learning Chinese

starts with Pinyin.

Some kindergartens have that.

\section{How could teaching be this beautiful?}

Two experienced teachers

(from the exemplar kindergarten)

were invited to share their stories with us

about how to love children.

Not about professional teaching.

I meant the teaching skills.

I thought it was good.

In fact

everything can be that beautiful!

How could it be this beautiful?

I cannot feel it yet. 
When will I feel it?

If they (children) could listen to me

I think

it would be very beautiful!

I cannot think of

any beautiful stories.

All I thought of was the mess.

Always something that I could not grasp.

Discipline and routine

is the area

I need to work on.

If this area is better

other problems

would be solved neatly.

It may need two teachers

to work together

set up same goals.

We (Linda and Angela) work

quite well as partners

but

we have not had time

to discuss this matter.

I cannot imagine an ideal kindergarten!

The kindergarten I want to work

is somewhere

I can pay close attention to

individual children's thoughts.

Would not always be a big group.

It' $\mathrm{d}$ be better

not tightly scheduled.

not to expect everything done perfectly.

Do one thing well at a time.

I really want to know

if there are kindergartens

that do not teach like we do.

I do not know

really what Montessori approach is.

What and how they teach?

What foreign kindergartens look like?

How do kindergartens operate

at different places?

Do not just tell us

we teach like this in China! 
I did not tell the director

my thoughts.

Because I feel

I have not done my current job well

and have no energy

to pay attention to these things.

However

I would like to know.

The director

not only teaches you

how to be a teacher

but also

the attitude towards work

and socialisation with others.

She is like our form teacher.

Sometimes

we are like naughty children

she would

criticise us

talk to us

teach us.

She is very strict.

We accept it.

We know she is right.

She is a good boss

hard to come by.

Other employers

would not have time

to teach you individually

the details.

They leave you

to figure things out

by yourself.

\section{Teaching profession, life and future}

The relationship among the colleagues

is really good.

In the office

I do not feel

anything bad about my job.

But

when entering the classroom

seeing the noisy class

I cannot stand it. 
When Angela was with me

I felt at ease

because someone could help me.

I could learn from her.

We could

learn from each other

solve identified problems together.

Kindergarten has

many trivial matters

all matters of livelihood

need to be

taken scrupulous care of.

But

I am a careless girl.

In my imagination

I just

play with them

teach them knowledge and skills.

I do not like to

manage every little thing.

But

it seems impossible.

My work

takes most of my time.

Teaching lessons.

Planning.

Preparing teaching aids.

Decorating classroom.

Decorating kindergarten for Christmas.

Open class teaching.

Going to (evening) classes

(at a normal university).

I cannot cope with all of these!

When many things come

at the same time

I cannot even do one thing well.

I feel defeated.

I have thought about

quitting teaching.

But it seems

the first three years

always the toughest

no matter what job you do

as people say. 


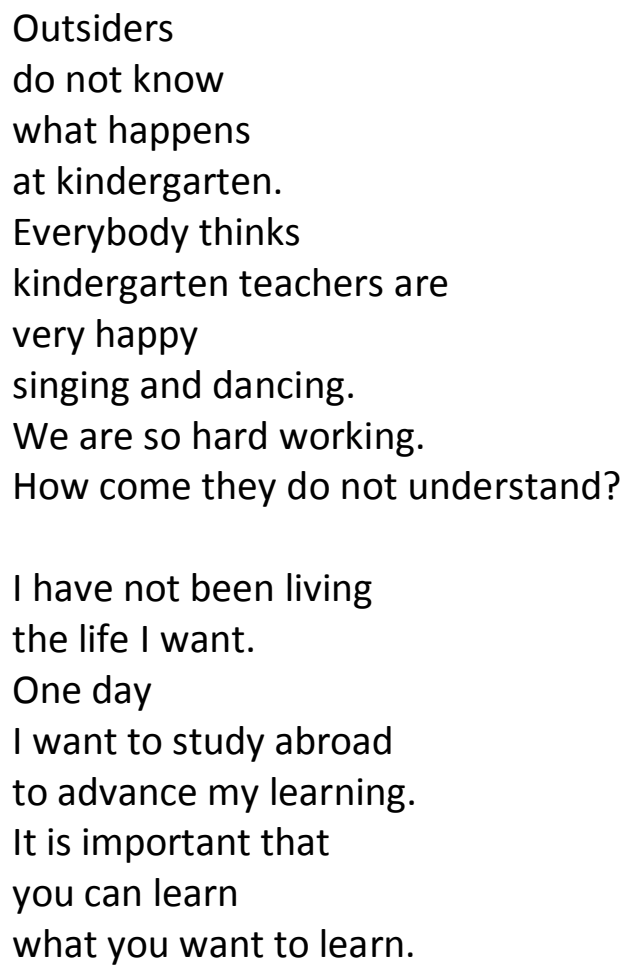

\title{
Angela's Stories as Poems
}

\section{From Heilongjiang to Shanghai}

\author{
I grew up in Heilongjiang ${ }^{8}$. \\ I attended kindergarten \\ but not for long. \\ The kindergarten \\ was not that different \\ to a primary school. \\ I could not remember \\ what the teachers had taught. \\ Most of my childhood \\ was spent at home. \\ It was fun. \\ Playing string games \\ with grandma.
}

\footnotetext{
${ }^{8}$ Heilongjiang is a province located at the far north of China.
} 


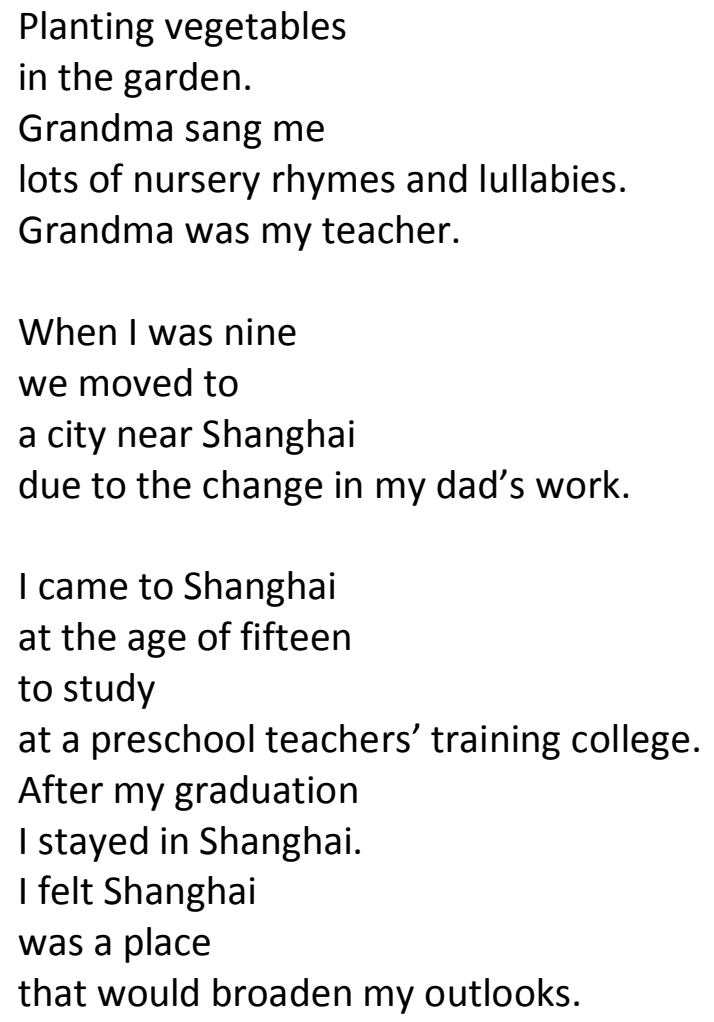

\section{Choice of being a kindergarten teacher}

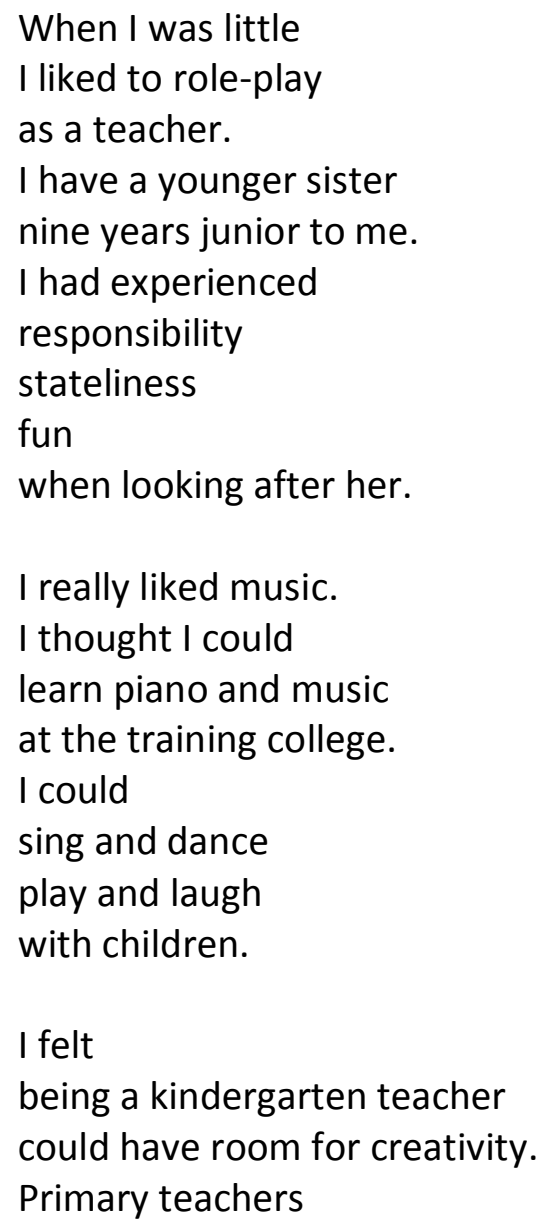


were just

echoing the textbooks.

\section{Initial training}

Learning at the training college

had prepared me

for teaching in kindergarten.

The teachers

took us to the kindergartens

to observe and analyse teaching

on the spot.

We then would be asked

to prepare our own teaching plan

and try out it

at an assigned kindergarten.

I felt

it was a way of connecting

the theory to the practice.

When I first started teaching

I did not feel gaps

between the training college

and the kindergarten.

Even when I was on practicum

I felt very happy

since I could do the job well.

I got many positive feedbacks.

Maybe because

I could use what I learnt

with high proficiency.

\section{It was easy to manage children}

At the beginning

I felt

it was easy

to manage children.

The teachers

set up all the rules and routines

then told children.

The teachers sometimes

would let children

play some games

to practice the routines.

Practice was a kind of routine too. 


\title{
First teaching partner
}

She influenced me the most.

She had a great work ethic

took care of children well.

Although she was old

she did exercise and play with children

enthusiastically.

Most importantly

she could manage the class

with order.

She was very experienced.

Her discipline methods were

quite traditional

threaten children

too fierce.

\section{Music education}

\author{
I learnt a lot \\ at the previous kindergarten. \\ Especially in music education \\ from a professor \\ for eight years. \\ She guided us through \\ workshops \\ observations \\ discussions. \\ She taught us \\ how to choose teaching materials \\ how to design teaching plan \\ how to implement the plan \\ according to \\ the characteristics of children \\ in the class \\ in music lessons. \\ She told us \\ the most important thing for teachers \\ was teaching the lessons. \\ At that time \\ I agreed with her. \\ We (also) had \\ a music education study group. \\ We observed each other's lessons \\ evaluated
}


analysed

discussed lessons

and set up

a music activity resource bank

together.

\section{Leaving the previous kindergarten}

I moved to this district.

Public Kindergarten

had very high reputation.

I felt

if I came to a better kindergarten

it could make up

what I had not learnt previously.

\section{Learn everything once again}

Initially I thought

the transition would be easy.

I believed in my capacity to

adapt to a new environment.

However

the ten years of teaching

at the previous kindergarten

their approach

the ways of thinking

were difficult to change

in a short period of time.

I was used to the old approach.

I felt it was quite handy.

Learning from

the teachers and the director here

now I know

everything should be the focus

not just teaching lessons.

There are

many aspects of a good class.

Ethos of the class.

Development of children's personality.

How to be with children.

How to guide them

in their life

study

and socialisation. 


\title{
Curriculum
}

is everything in everyday life.

It can be divided into

several areas.

It includes the contents

the model (of teaching/instruction)

teachers choose.

The change of approach

requires a process of adaptation.

I need to

learn everything once again.

I had found problems

in my practice.

But up to now

I still do not know

how to adjust my teaching.

\section{Experience Exchange Activity}

\author{
I had led \\ Conversational Language Activity \\ before. \\ There were various methods \\ we could use \\ for language activities. \\ They included \\ using drawing \\ or other ways of representation \\ at the end of the language activity. \\ It is called \\ Experience Exchange Activity \\ here. \\ It is different. \\ I do not know \\ what are the intrinsic differences \\ between Experience Exchange Activity \\ and Conversational Language Activity. \\ Or maybe \\ they are the same. \\ I have not grasped \\ the ways of teaching \\ Experience Exchange Activity. \\ Can it be integrated? \\ How to?
}


Can I add other elements into it?

I am not sure.

She (the director)

gave me opportunities

to observe others.

I saw other teachers

using many different forms of activities.

Maybe

the lesson plan we are given

has many things in it.

These plans are

in the kindergarten-based curriculum

done by the experienced teachers.

They are quite simple.

They only have main points.

Some good teaching methods

cannot be shown on the plan.

I cannot really understand

the beauty

and the meaning of the plans.

It is quite difficult to teach it.

\section{Learning Centre Activity}

Learning centre activity

emphasises

individualised learning.

Other kindergartens

have learning centre activity too.

But they do not study it

as deeply as

Public Kindergarten has done.

I have read

the kindergarten-based curriculum book.

It talks about

the individualised learning

from theory to practice.

It has many good examples.

By copying the examples

I now start to know ...

How to create learning centres.

How to provide materials.

How many materials are needed.

How to divide the learning centres.

How to present the learning centres. 
However

in terms of guiding the play

the current problems are ...

How to let children enjoy the play?

How to guide them when tidying up the materials?

How to establish good habits for playing?

\section{Pay attention to children}

My guiding educational philosophy is

children foremost

teacher after.

Children and teacher are

double subjects

in teaching and learning.

Before

we focused on

teacher's leading role.

Now is about

paying attention to children.

Sometimes I feel

I am following the plan

every day.

I do not know

some children's personality well.

I wish

I can have more

interaction with children.

But with many activities planned

time rushes by

very quickly.

Especially during some

challenging group teaching time.

When children were very noisy

it would take more time

for the teachers

to use different methods

to achieve the pre-set learning outcomes.

When working with children

the most difficult thing is

Change-Place-Reflect.

It is difficult

to think from 
children's perspective.

Sometimes

so many things happen

at the same time.

You get anxious.

You cannot really dig into

what is hidden behind.

In terms of individualised education

how to take account of all children

while focusing on individuals?

We have so many individuals

that require different ways of interaction.

In our class

some children have

very strong personalities.

Sometimes

I told myself

I needed to be more tolerant.

I think

it is children's inborn nature

to be naughty

to be a little crazy.

But

we are a collective group.

We need to establish

rules and routines/discipline.

Otherwise

children may be

blundering

noisy.

This would affect

classroom environment

the running of normal programme

increasing unsafe factor.

I need to

think more ideas of

how to help children to

manage their behaviour

cultivate good habits.

I am still exploring

the scale of this matter.

How to moderate it?

My main confusion is about

the moderating of 
children's autonomy

the freedom of children

to what extent and how?

Although we say

teachers need to

respect children in every aspect

but sometimes

you still need to

build ladders for children.

Like the Zone of Proximal Development.

We need to

act with a well-defined objective in mind

and think

to what extent the child can develop.

\section{Being a teacher and a learner}

I am suitable for teaching.

I am concerned about

whether I can do the job well.

I have quite high expectations

of myself.

I want to feel good

when doing my job.

If I do not reach that condition

I would feel sad and uncomfortable.

I would ask myself ...

Why can other teachers

interact well with children?

Why cannot I do that well?

In such a case

I feel I am really clumsy.

As a learner

I am a bird wanting to fly

and fly fast.

But

it is a big clumsy bird.

A clumsy bird

shall start flying early!

Maybe I need to

be more active in learning

think carefully about

how to teach the given lesson plans

think if the activities

are interesting enough

ask others 
to clarify my questions

learn more about

the kindergarten-based-curriculum.

At the different stages of my teaching

I would

observe how others do

listen to what others say

take up the experts' comments

of how to deal with particular situation.

They provided guidance

to help me understand

what I did right

what I did wrong.

But sometimes

it was hard to tell

what was right

what was wrong.

One situation might have

multiple ways

to deal with it.

However

I would still regard

the experts' comments as

fine examples and models

to learn

to follow.

It was like

do as the teacher said.

This was

the power of

the role models.

I am

in an erratic state now.

There is not

a single set of

criteria or standards.

We can choose to do things

in this way

or that way.

Sometimes I felt

I wanted to have

my own thoughts.

But

I find it is difficult

to decide what to do. 
I have been thinking about

quitting teaching

recently.

My teaching journey

had been so smooth.

With all the setbacks

and frustrations now

I feel very it difficult

to change the current situation.

I want to find

a good direction.

When I am getting lost

I would lose heart as well.

\section{Personal life, work and future}

(My life) is fast paced.

There are many things

waiting to be done.

Work and personal life

are melting together.

I take work home.

I have less time

to read books now.

The ideal state for me is

a little bit looser

than now.

It will give me

more time

and space

allow me to adapt to

the new environment

slowly.

I find myself

not able to keep up

the pace of this new environment.

I may be an older teacher

five or ten years later.

Enthusiasm would still be there.

Passion would have some degradation. 


\section{Chapter 6: Analysis of Linda and Angela's Stories}

In this chapter, and Chapters 8 and 10, I analyse the teachers' stories in pairs around three main themes emerging from all six teachers' narratives: the reality of teaching, professional learning, and teachers' feeling and professional identity. However, for each teacher, the dilemmas, challenges and uncertainties the teachers experienced in their teaching, learning and the construction of their professional identities were slightly different. And these nuances of the teachers' experiences are highlighted at the beginning of my analysis of each teacher's stories. The nuances are then made explicit in my discussion of particular teachers' narratives by linking them with relevant literature, the career stages the teacher was at, the particular kindergarten structure and professional learning programme she was embedded in, and the wider reform contexts along with Chinese cultural background. The first paired analysis shared in this chapter is the stories of Linda and Angela from Public Kindergarten.

\section{Linda: "Being a teacher was not easy"}

Linda, a beginning teacher, shared the "difficult" and "not easy" feeling of being a kindergarten teacher in her stories. Her narratives, "I cannot cope with all of these" and "I feel defeated" further suggested a painful beginning to her teaching career, as other teachers have experienced (Huberman, Grounauer, \& Marti, 1993). 
In fact, she tried to resign twice at the end of both her first and second years (after my data collection) of teaching. It seems Linda was still unsure whether she could cope with the hardships of teaching, although she realised the first three years of any career would be tough. This uncertainty appears to be different to many second year teachers who would have decided that they could survive the teaching life and were ready "to consolidate the gains made during the first stage and to differentiate tasks and skills to be mastered next" (Katz, 1972, p. 51). Instead, Linda was still in the process of inducting herself into the teaching profession, learning the Public Kindergarten culture, and trying to survive and endure the reality of classroom teaching.

My analysis of Linda's stories is constructed around:

- How Linda coped with the reality of teaching, which included multiple tasks, discipline and classroom management, and developing an appropriate teacher-child relationship.

- How Linda learned to teach from more experienced teachers and the director, and how did she understand the curriculum.

- How Linda constructed her professional identity, which was closely related to her feelings about teaching, and her positioning and social relations with others in the kindergarten context.

Linda's narratives and my interpretation of them may therefore provide some insights into a beginning teacher's understanding, practices, and feelings about teaching and learning in a curriculum context that is quite structured, controlled, and prescribed, and in a formal and director-led professional learning programme. 


\section{Coping with the reality of teaching}

\section{Multiple tasks, "trivial matters" and work pressure}

Linda was facing multiple tasks, including teaching, caring, planning, making resources and other tasks assigned to her. "The pressure is great" was how Linda felt about the busy work schedule stuffed with "many trivial matters" and the expectations of doing them perfectly. This heavy workload is not unusual for Chinese EC teachers. Lai's (2011b) survey of more than 5000 kindergarten teachers in Beijing reported their average working time as 13.5 hours per day, and that overall $48.15 \%$ of them wanted to reduce the workload outside classroom teaching.

In Linda's case, certain jobs caused "too much trouble" for her, for instance, she did not like to manage the caring routines of eating, drinking, and toileting. Linda viewed the task of taking care of "all matters of livelihood" as an addition to her jobs of to "play with them" (children) and to "teach them knowledge and skills". However, I did not observe Linda joining children as playmate in their games or free play. Teaching children knowledge and skills seemed more important and relevant to Linda's teacher status than playing with children and carrying out caring routines. This may reflect the long-term influence of the traditional masculine images of the teacher in China being the well-respected (Hofstede, 1986) knowledge-master and knowledge-transmitter ( $\mathrm{Hu}, 2002)$, which oppose the feminine caring and nurturing role (Noddings, 1988). Linda thought her frustrations over the caring routines were because she was a "careless" person. The director considered it to be Linda's lack of ability for and understanding of the kindergarten's caring measures. Therefore, the director organised a new teacher care-giving knowledge and skills competition 
(outside my classroom observations) to enhance new teachers' awareness and practice of caring for children. Public Kindergarten's emphasis on the caring routines suggested to Linda that caring for young children was her duty rather than an opportunity to develop relationships with children (Goldstein, 1999; Noddings, 1988) that she could enjoy. In this sense, Linda was carrying out the required caring duties without understanding the deeper moral dimension and the pedagogies of them. In short, Linda's difficulty in coping with the heavy workload and her lack of understanding of the jobs she was required to do contributed to the work pressure she experienced.

Linda's words "I had to think about everything by myself" hinted that feeling lonely and unsupported in the classroom may be another source of work pressure. However, Linda's feelings did not match up with Public Kindergarten's intention of developing a collaborative community. Linda's wish of "I would like Angela to be with me and help me" revealed what Linda needed most was collaboration with Angela inside the classroom to support her informal learning day by day. Some researchers argue informal learning is equally important to formal professional learning for beginning teachers (Dehli \& Fumia, 2008; Jurasaite-Harbison \& Rex, 2010; Williams, 2003). Recent research suggests being able to practise in a peripheral position with the support of experienced teachers (Labmson, 2010; Le Maistre \& Pare, 2010) can help beginning teachers to survive the first few years of their teaching career. Nevertheless, because of the shortage of experienced teachers onsite to mentor Linda and the reality of solitary teaching in class, the director could only organise as many formal learning activities as possible to make up for the lack of opportunity for informal learning at her workplace. 


\section{Children's discipline as "Iacking" and the class as "noisy"}

Linda experienced challenges when working with different agendas. She realised as a teacher she needed to maintain order in the class, keep up with the structured daily schedule, achieve pre-set learning goals, and keep the parents happy. Tensions arose when she felt:

- Children's emergent interests could cause her teaching to digress "far away from the plan" - in fact, pre-set plan versus emergent interest was a tension Linda experienced when learning to teach, and I discuss this in a later section.

- The classroom might become "chaotic" because of the lack of order in class, especially during transition time when children were following their own agendas.

- Children would not happily listen to her because she could not relate to them from an appropriate "distance".

Linda saw children's lack of discipline and her lack of classroom management strategies as two reasons causing the "noisy class" and her losing control. These narratives suggest Linda experienced pedagogical tensions when disciplining children, managing the class and building appropriate teacher-child relationships in the class.

Discipline and classroom management seemed the top concern for Linda, as well as for many other beginning teachers (Dollase, 1992; Veenman, 1984). In Linda's case, the high teacher-child ratio, the demand of group and structured teaching, and the cultural and personal views of discipline were factors influencing Linda's perceptions and experiences of discipline and classroom management. Linda taught in a class where she had to face 24 children alone most of the time and work with a group-activity-dominated daily schedule. However, the 24-child class was 
smaller than the government's maximum number of 30 for 3 and 4-years-old classes (Ministry of Education in People's Republic of China, 1996). Linda regarded discipline as a prerequisite of effective teaching, which echoed Chinese traditional understandings of discipline (Ho, 2001), and to her, classroom management was separate from other teaching activities, requiring techniques and strategies to shape children's behaviour. These views were commonly accepted at Public Kindergarten and resonated with Ayers' (2001) discussions about common understandings of discipline and classroom management concerning its "linearity" and "insularity" (p. 11). However, Ayers argues, alternatively, teachers can change their focus from seeking "techniques to shape behavior" (ibid.) for immediate results, to building authentic teaching relationships as a context for working out discipline and classroom management issues with children.

\section{Teacher-child relationship as "not easy to handle"}

Linda's statements, "it was difficult to love every child" and "the relationship with children was not easy to handle", indicated teacher-child relationships concerned her. Two images of the child emerged in Linda's story:

- an "obedient" and "well-behaved" image of the child revealed in Linda's descriptions of children when recalling her childhood

- a "smart" and "assertive" image of the child who would "like to show themselves" and "think actively" but "lacking in discipline" based on her observations of children in her class.

The formation of child images are influenced not only by "the values, beliefs and experiences of individuals" (Ebbeck \& Warrier, 2008, p. 247), but also by the external cultural and societal opinions of children and childhood. The two images of 
the child therefore may reflect:

- Confucian thinking, whereby Chinese children were defined "within the social context" and "in the hierarchy of relationships" (Lau, 1996, p. 360)

- the increasing recognition of self and personality of children influenced by Western psychology and reflected in "the call for respect for children, freedom and equality in preschool education" (Hsueh \& Tobin, 2003, p. 86) that the ECE reform tried to promote (Yan Liu et al., 2007).

The Chinese ECE reforms made Western ideas official and authoritative. At the personal level, the "disciplined" child image seemed to be the ideal for Linda compared to the other personal qualities she observed in children. This may reflect the strong influence of the traditional ideal Chinese child image (Bai, 2005b). The "disciplined" child may also be easier for Linda to love than the "disruptive" child.

Linda thus experienced conceptual tensions when working with the multiple images of the child: whether to view the child according to the needs of communal life or children's individual needs and thoughts, and whether to understand children based on a hierarchical teacher-child relationship or the "friend-like" equal relationship that Linda imagined. Linda's attention to discipline and classroom management signifies that the cultural norms of teachers to maintain authority and take control in the classroom still have stronger sway than the close and equal teacher-child relationship in her practice. Linda's dilemma also reflects a major concern of many Chinese EC teachers: the fear of losing teacher authority in the recent reform context where teachers are expected to change their roles from knower and knowledge-giver to supporter, collaborator and guide (Yi \& Pang, 2003). 


\section{Learning to teach}

\section{Making sense of curriculum}

Linda understood curriculum as the subjects "I teach", planning what she wrote on the planning forms to inform her "what to do every day" and to reflect on what she did. Linda's conception of teaching and learning was most strongly a teacher-led one, a one-sided learning model (Rogoff, Matusov, \& White, 1996). This reflected the long-term domination of understanding curriculum as subjects, goals, plans, and activities in China (Z. Li, Yang, \& Yin, 2009). However, the reforms promoted a different understanding of curriculum as "purposefully selected and organized learning experience" (p. 26) and as emergent events during teacherchildren interaction that value children's voice and subjectivity. Yet predesigned purposeful planning for both teacher-led and emergent learning activities were still believed crucial in effective teaching. Therefore, both teacher-led and child-led teaching and learning were equally important in the reform contexts.

A set of dual concepts - teaching and learning, teacher and children, prescribed plan and emergent interest, group and individuals - was elaborated in Linda's narratives. The reforms required teachers to recognise both teacher's and child's subjectivities when working with these concepts, and to find a balance of teacher-led and child-led teaching and learning in practice. However, this balance seemed easier to achieve in the curriculum and daily schedule by inserting child-led activities, as Public Kindergarten did, than in the pedagogy of classroom teaching. Linda's practical decisions reflect more of teachers' planning and group needs than children's voices. In the group learning situations, Linda prioritised the execution of 
the prescribed plan and the pre-set learning goals ahead of individual children's learning interests. According to Xiaoyi Gao and Pang (2006a), many Chinese kindergarten teachers tend to give children closed-ended responses in order to redirect children's interests and questions back to the planned lesson. Linda's discussion of the pirate theme shows that she believed learning content should be chosen from the curriculum booklets according to Public Kindergarten's activity selection criteria, not children's interests. Curriculum in this sense is seen as prepackaged and legitimated (Apple, 1995) and is placed before children's interests. As much as she would like not to, Linda still chose to orientate her teaching to the curriculum rather than children's emerging interests because of constraints such as time, and pre-set themes and plans that she "could not change". A sense of powerlessness was conveyed in Linda's narratives, which indicates both Linda and the children lack agency in the kindergarten structure, planning process, and actual classroom teaching.

\section{Learning from more experienced teachers and the director}

Linda desired a "beautiful" feeling when working with children as was demonstrated by the experienced teachers, but it was not felt in her everyday practices. Linda struggled when wanting to:

- attend to every child, but feeling constrained

- have more discussions with her teaching partner, but having no time to do so

- manage multiple tasks, but feeling she could not meet others' expectations

- learn more, but not able to because her and children's learning interests did not match with the kindergarten's training agenda. 
The preceding analysis indicates Linda's struggles were caused by her beginning teacher status as well as structural constraints such as the 1:24 teacherchild ratio, the group learning and pre-set teaching plan, teaching and learning oriented to teacher-led developmental goals, and a structured daily routine. However, such structural constraints also existed for the experienced teachers but did not seem to trouble them as much. Experienced teachers' successful experiences suggested to Linda that she should be able to overcome those constraints. Therefore, the "beautiful" teaching experience modelled by the experienced teachers could be an active motivation (Huberman et al., 1993) for Linda's future professional learning. But comparing her errors with the success of more experienced teachers also reinforced Linda's "defeated" feeling. Moreover, Linda's narratives imply that she seemed unaware that the "beautiful" teaching experience was not a result of learning different strategies and techniques; rather it was the development of pedagogical thoughtfulness learnt through reflection and experience (van Manen, 1991).

The director tried to help Linda realise the beauty of teaching by setting up policies, procedures, standards, expectations, and multiple professional learning activities. Linda described the director as "a form teacher" who was "very strict" and would teach her many things. Linda's narrative painted an image of the director as a skilful, responsible and authoritative knowledge-giver. In her strict-teacher and naughty-child relationship with the director, Linda was passive. The poem Teaching English made explicit Linda's passive position in professional learning. There were many training opportunities to inform Linda how to teach English in the Public Kindergarten's ways. However, Linda's doubts and questioning around English 
teaching were not part of the kindergarten's professional learning agenda. Despite her wonderings, according to the director Linda's English teaching still improved. The improvement was a result of a closely monitored planning process carried out by the director and the English Subject Group leader, numerous opportunities to observe other teachers and be observed, and collective reflection on planning and practice. Linda was learning how to teach English by passively assimilating and conforming to Public Kindergarten's ways of practice without mutual understanding of the shared endeavour. This can be seen as transmission and acquisition of required practice (Rogoff et al., 1996) rather than transforming teaching by connecting teaching with teacher's beliefs and expertise (Kose \& Lim, 2010). It seems there was a disconnection between Linda's personal passive professional learning experience and the active learning Linda was expected to deliver in the class. Shulman (1988/2004) argues that it is important to connect teachers' own learning with the learning they are required to support in their class; "the requirements for student learning shall be also requirements for teacher development" (p. 314).

\section{Constructing professional identity}

\section{A feeling of "could not"}

Linda frequently used the phrase "could not" when talking about her teaching. This illustrates a negative self-image with a strong sense of dissatisfaction and self-doubt, which is often found among beginning teachers (Huberman et al., 1993). Linda's feelings may be caused by the differences between her optimistic vision of teaching and the dynamic reality, for new teachers, of teaching in the 
classroom (Dollase, 1992). Linda's narrative reveals her ideal vision of teaching and the reality were far apart:

- Ideal "beautiful" vision of teaching that means children would willingly listen to Linda versus Linda's class as "messy" and "chaotic" in reality

- Ideal close relationship with children and having fewer everyday tasks might allow Linda to "pay close attention to individual children's thoughts" versus the "big group" dominated and "tightly scheduled" everyday teaching routine in reality

- Ideal professional learning to meet Linda's needs of learning different teaching approaches such as Montessori and foreign kindergartens where teachers "do not teach like we do" versus learning the particular Public Kindergarten/reform way of teaching in reality.

Linda desired a child/learner-centred teaching and learning approach. However, the curriculum requirements and the kindergarten's agenda dominated her actual everyday teaching and learning. Therefore, Linda's negative and doubting self-image may be a result of dealing with the mismatch between the ideal and the real; the different agendas between children, the teachers, the curriculum and the kindergarten; and Linda's low self-evaluation of her actual teaching and her negative emotions about her everyday practices.

\section{A sense of otherness}

Linda's stories echo Hargreaves et al.'s (2001) argument that teacher's emotions and self-identity are closely linked with school structure, pedagogy, planning and social relations. Linda shared the good and bad of being a kindergarten teacher by reflecting on her social relations, perceptions of teaching, current personal and professional self. As an insider, Linda realised the rude reality of 
teaching (Veenman, 1984) as intensified and multitasking with high expectations from others. Linda was anxious about her ability to cope with the reality, which is common for new teachers (Renard, 2003). Linda identified herself as a hardworking teacher, which is an important value in the Chinese early childhood community (Tobin et al., 2009), and she was trying hard to do everything well. However, she struggled with the issues of devaluing of kindergarten teaching by the general public (outsiders), the "defeated" feeling of not being able to meet the director's expectations, the curricular requirements, and parents' expectations. She also struggled with the imbalance between her work and her personal life, and her relationships with children in her class, the Public Kindergarten's curriculum, and herself as a teacher.

There was a sense of otherness in Linda's social relations with others throughout her poems:

- "they review and comment on them" when talking about the monitored planning process

- "they will not agree if I do like this" when predicting the possibility of exploring the pirate theme

- "they only see the most visible stuff" when understanding the parents' expectations

- "they have decided the themes and which words need to be taught" when questioning and reflecting the way English was taught

- "they also have pain and joy" when admiring the teachers from the exemplar kindergarten"

- "how come they do not understand" when her effort and hard work are devalued and misunderstood. 
The word "they" represents the people with power in the kindergarten contexts, the role models Linda looked up to, the parents she served, and societal expectations. The sense of otherness may imply the social, moral, professional, and political distances between Linda and the people around her in the kindergarten and a wider context, which according to Hargreaves (2001) may configure teachers' emotions in particular ways. Linda's stories also show she was positioned as:

- a follower, less powerful and less knowledgeable in her relations with the director, the team leader and the given curriculum

- a lower performer compared to the experienced teachers

- a manager or controller in the classroom

- a professional in front of the parents

- misunderstood by the wider society.

In this sense, Linda's positioning at Public Kindergarten is constituted by multiple and contradictory discursive practices when interacting and socialising with others. Linda's multiple images and positions in different social relationships at Public Kindergarten may have caused personal tensions when defining who she is and what her position can be in the life of children, others, the kindergarten, and herself as a teacher.

\section{Angela: "Learn everything once again"}

Angela came to Public Kindergarten as an experienced teacher, confident and not anticipating big changes in her teaching. However, "I need to learn 
everything once again" suggests that the Public Kindergarten's "culture of practice" (Lave \& Wenger, 1991, p. 95) may be quite different to her previous kindergarten's, despite the fact that they were both state-run kindergartens and guided by Shanghai's ECE reform initiatives. Angela was coping with the tough reality of teaching in a new teaching community, and learning how to teach the Public Kindergarten's ways was her top priority. She also experienced a shift of professional identity when redefining herself as a teacher at Public Kindergarten. These three aspects, emerging from Angela's poems, were parallel to Linda's. But their narratives about them were quite different.

- Angela talked about how she coped with the reality of teaching by focusing on the impact of this new teaching community on her ways of working with children and the need to grasp the Public Kindergarten's ways of teaching, rather than the day-to-day reality of being in the class.

- Angela's narrative of learning to teach at Public Kindergarten was about the disconnections between her previous and current experiences of learning, the multiple truths of teaching and learning, and the experts' influences.

- Angela shared how her professional identity had shifted, and her contrasting feelings and self-images of being a teacher at her previous and current kindergartens.

Taking a socio-cultural and narrative inquiry stance (Clandinin \& Connelly, 2000; Rogoff, 2003), I understand this difference reflects Angela's unique past teaching and learning experience and her particular position at Public Kindergarten. In the discussion that follows, I analyse Angela's stories by attending to the continuities and disconnections emerging from her teaching and learning experiences over time. Angela's narratives and my analysis thus may therefore illustrate possible challenges and tensions that some experienced Chinese EC 
teachers may confront when becoming enculturated in new kindergarten communities, and how the change of teaching community may shape teachers' feelings and professional identity.

\section{Coping with the reality of teaching}

\section{Work with children: "I do not know some children's personality well"}

"Easy to manage" was how Angela described her experience of working with children as a beginning teacher at the previous kindergarten. This is unlike many beginning teachers' who identify classroom management as the first problem in their teaching (Veenman, 1984). Angela's "easy" feeling came from tell-and-be-told teacher-child relationship where teachers "set up all the rules and routines" and "let children play some games to practice some routines". Those games were playlike activities that teachers arranged to train children to follow rules and instructions. The easiness was also because Angela had an experienced teaching partner who could "manage the class with order" using traditional discipline methods that might "threaten children" and be "too fierce". The hierarchical teacher-child relationship in Angela's class and the traditional discipline methods valued teacher-dictated rules and routines, rather than "children's hearts, souls, minds" (Ayers, 2001, p. 11). In short, a teacher-led model of teaching guided Angela's work with children at the previous kindergarten where she had had power and authority in her relationships with children, which matched with the "stately" image of teacher in young Angela's mind. 
Working with children at Public Kindergarten seemed a different story. Angela experienced a change of teaching focus from "lessons" to "everything in everyday life". This suggests a change of curriculum orientation from valuing subject-based teaching and a teacher-led teacher-child relationship, to children's active learning and an equal teacher-child relationship acknowledging both teacher's and child's subjectivities in everyday contexts. Children and their learning were placed at the centre of Public Kindergarten's curriculum, which directed Angela to value "children's personality", "children's perspective", "children's autonomy and freedom". The need to find a balance between teacher-led and childcentred teaching and learning is a task confronting many Chinese kindergarten teachers (H. Li, 2005). Angela's narrative, "my main confusion is about the moderateness of children's autonomy, the freedom of children, to what extent and how", may imply she experienced pedagogical tensions when finding the desired balance in her teaching.

- Is learning one-sided or dual centred? - When and how should the teacher "build ladders for children" and when should children be "respected in every aspect" in everyday contexts? How should the collective group's need of "establishing rules and routines" be balanced with individual children's "inborn nature" as "being naughty" and "being a little bit crazy"?

- Is learning an active discovery process or achieving developmental goals? What were the criteria that could help Angela make decisions between achieving "well defined learning goals" and respecting individual children's interests and needs?

- Is learning based on accepting individual children and celebrating who they are, or identifying their developmental gaps and then filling those gaps? Which children Angela should acknowledge first - the ideal children that the 
collective group needed who "could manage their behaviour" with "good habits", the developmental children who were climbing "the ladders" to reach the height teachers set for them, or children who came through Angela's classroom door every day with "inborn nature" and "strong personality"?

- Does good teaching mean responsive interactions with children or executing approved plans? -When could Angela find time to get to "know some children's personality well" every day in between "many activities"?

The busy daily schedule, the prescribed curriculum, the 1:24 teacherchildren ratio, Angela's gap-finding and-filling approach to child development, and her focus on teaching strategies seemed to prevent her from "knowing some children's personality well". Many Chinese kindergarten teachers experience similar uncertainty and ambiguity when trying to redefine and develop an appropriate teacher-child-relationship (Yi \& Pang, 2003), and to reconceptualise teaching and learning in the reform contexts (H. Dai \& Zheng, 2009; Xiaoyi Gao \& Pang, 2009).

\section{Teaching practice: "found problems" but "do not know how to adjust"}

Angela found problems in her teaching, more specifically when teaching the kindergarten-based curriculum, which she had not yet "grasped how to teach". At the conceptual level, Angela was unsure about "the intrinsic differences" between Conversational Language Activities that she taught at her previous kindergarten and Public Kindergarten's Experience Exchange Activity. The director's narratives suggested Experience Exchange Activity is a unique feature of Public Kindergarten's curriculum, and teachers should focus on children and children's active construction of new knowledge when planning and teaching Experience Exchange Activity. However, when comparing Experience Exchange Activity and Conversational 
Language Activity, Angela's focus was on the differences in the forms of activities and teaching strategies, rather than the values of each approach and children's roles in the different learning process. The conflicting Public Kindergarten's children orientated script and Angela's teaching strategy orientated script may have caused tensions for Angela when understanding the new teaching approach, and therefore may hinder the transformation of her practice (Blank, 2009).

At the practical level, Angela's reflection on an open-class Experience Exchange Activity (see Table 5.2, No. 3) revealed that she struggled with planning, responding, and interacting with children, and guiding the discussion. Angela understood her practical struggles as being a result of not learning the curriculum well enough, and that not planning sufficiently; while the director believed it was because Angela did not really understand children and "how children learn". Angela seemed to reflect on her own practice from a teacher-led mind-set, focusing on her role as a teacher rather than attending to children as the director did. The influence of a traditional teacher-led way of learning is obvious in Angela's reflection, which seems a constraint for Angela, preventing her from grasping the Experience Exchange Activity, an approach that requires teachers to place children at the centre of their thinking. Similar findings are reported in the studies done among Chinese EC teachers in Taiwan and Hong Kong (Hsieh, 2004; Y. L. Li, 2004).

According to the director, one of the key ideas of Public Kindergarten's curriculum was to let children actively construct new knowledge by themselves. However, this child-centred learning process was not made explicit in the curriculum resource books that Angela heavily relied on as she would often "copy the examples" from the books. In fact, the curriculum resource books presented a teacher-led 
model of teaching and learning. Experience Exchange Activity resources available to Angela were mainly tested plans written by experienced teachers in a prescriptive manner. The tested plans provided technical ideas for her, but not the experienced teachers' active higher-level thinking process, conceptual understanding and "pedagogical thoughtfulness" (van Manen, 1991, p. 8). This may be why Angela felt she did not "really understand the beauty and meaning of the plans" and the lessons she observed. Disconnection once again can be identified, as the prescriptive plans imply a passive learning process for both Angela's and the children's learning, while the purpose of these plans is to facilitate children's active learning. Learning centre activities resources were similar. They explained the theoretical background of this approach, focused on the material and technical aspects of the learning centre activities, and included experienced teachers' reflections of how they made the approach work in their classrooms. But, the question of "how children learn" during learning centre activities was not addressed. In short, the multiple but disconnected educational ideas in Angela's mind and practice, in her past and current teaching experience, in the director's expectations and Public Kindergarten's philosophy, and in the curriculum resource books may have contributed to some conceptual and pedagogical tensions Angela experienced when trying to grasp Public Kindergarten's ways of teaching in everyday practices. 


\section{Learning to teach at Public Kindergarten}

\section{Making sense of curriculum}

Angela's current understanding of curriculum was "everything in everyday life", which is "a broad view of curriculum" (Shanghaishi jiaoweijiaoxueyanjiushi youjiaozu, 2001, p. 32) the recent reforms have been promoting. It contrasts with Angela's previous kindergarten's lesson-focused practices. It seems the influence and implementation of reform ideas varies in different kindergartens. This finding resonates with Tobin et al.'s (2009) argument that some Chinese kindergartens may have progressed further in changing educational ideas, and have "already figured out how to put new paradigm into practice" (p. 78) while the majority of urban kindergartens struggle in the reform contexts. Pan and Yan Liu's (2008) study of 26 kindergartens in Shanxi province has reported similar findings. Therefore, the change of kindergartens is not only a change of location for Angela, but also a change of educational ideas and practices.

The disconnection of educational ideas and practices between Angela's previous and current experiences is apparent. Angela found the previous lessonfocused teaching and learning approach "quite handy", and felt it difficult to "adjust" her practice to meet Public Kindergarten's curriculum requirements. The need "to learn everything once again" implies what Angela knew about teaching previously was neither relevant nor valuable, and should be abandoned. However, scholars argue that teachers' irrelevant past experience should also be valued since it may provide personal knowledge (Connelly \& Clandinin, 1988), cultural tools (Cole, 2000), and self-knowledge (Palmer, 1998) to help them comprehend new educational ideas 
and develop new teaching repertoires. Greene (1978) states devaluing and dismissing the knowledge learnt from the past may disconnect teachers from "their personal histories, their lived lives" (p. 2) where teachers' new learning and their own transcendence are grounded.

There is another disconnection. Angela's broad definition of curriculum extended her attention from lessons to "children's personality" and ways of "being with children" when teaching at Public Kindergarten. However, her descriptions of curriculum in practice referred to the segregated activities according to the daily schedule, learning content and teaching approach representing teachers' agenda, and the tasks teachers were required to do. Children seemed invisible in everyday practices. Curriculum therefore was a tool for choosing learning content and teaching strategies (H. Dai \& Zheng, 2009), instead of everything in children's life. This analysis indicates that Angela was quite clear in her mind that the reform ideas were meant to focus on children and their everyday life, but not in her practice. Yet holding a broad view of curriculum in theory but not in actual practice is not just the case for Angela, but also for many other Chinese EC teachers (Xiaoyi Gao \& Pang, 2006a; Yan Liu et al., 2007).

\section{Multiple images of teaching and learning}

Multiple images of teaching and learning emerged in Angela's poetic stories. In contrast to Angela's casual, playful and informal early childhood home-care in a rural village, her primary-like kindergarten reflects a so-called traditional image of kindergarten as a place where "subject-based, teacher-centred and classroom/[lesson]-focused" (Yan Liu et al., 2007, p. 20, own translation) learning 
should take place. It is interesting that Angela regarded her grandma as her teacher, as it raises a question of what a kindergarten/early childhood teacher is in a child's life. Conflicting images of early teaching and learning thus emerged:

- play versus formal learning

- close bonding through shared experience versus teach-be-taught adult-child relationship.

Angela's memories of her home-care and grandma suggest that from an ordinary child's perspective, play and a close relationship with her caregiver seemed more important than being taught. This may reflect the playful nature of the ordinary child, which is in contrast to the neo-Confucian image of an ideal child as disliking play and showing intellectual superiority (Bai, 2005a).

The conceptual and pedagogical tensions can be clearly identified in Angela's current teaching. This may be because Angela was required to take a child-centred view of teaching and learning at Public Kindergarten and this requirement raised the questions of whether to value:

- children's play or formal learning

- close or authoritative teacher-child relationship

- children's “inborn nature" or the group needs.

Interestingly, these tensions were not revealed in Angela's narratives of her previous teaching experience in a teacher-led teaching and learning context where children seemed invisible; a situation the recent reforms were intended to change. This finding reflects a shift of curriculum orientation from being society-orientated to child-orientated in the reform contexts, which have challenged many Chinese kindergarten teachers in practice ( $H$. Dai \& Zheng, 2009). However, how to 
understand and attend to children were neither on the top of Angela's immediate learning list, nor on the agenda of Public Kindergarten's professional learning.

\section{Multiple truths and following "the experts' comments"}

The multiple images of teaching and learning in the traditional and reform ECE contexts created multiple truths for Angela and make it "hard to tell what was right, what was wrong". Multiple truths of teaching and learning thus placed Angela "in an erratic state". Reflecting on her teacher-led, professor-led, and director-led professional learning experiences at training college, and at the previous and current kindergartens, it is not surprising Angela found it difficult to "decide what to do" by herself when there were more than "a single set of criteria and standards" in everyday practices.

Angela highlighted the importance of connecting theory and practice when talking about her initial training. Her teachers guided her learning step by step through a teacher-led model of teaching and learning (Rogoff et al., 1996). Angela's confidence was boosted due to her ability to make use of the knowledge that was transmitted to her, and meeting others' expectations by following teachers' guidance. At the previous kindergarten, Angela's professional learning was through guided participation (Rogoff, 1995) by more experienced and knowledgeable others, including the professor. Angela was happy to be a follower in the professor-led model of professional learning and accepted the professor's truths of teaching and learning.

Influenced by her previous learning, Angela automatically placed herself as a follower at Public Kindergarten. However, unlike her previous learning only following 
one professor's ideas, the preceding analysis indicated that there were multiple and conflicting truths of teaching and learning at Public Kindergarten. Angela regarded the director and the more experienced teachers' ideas as "fine examples and models to learn and to follow". Angela wanted clear guidance and authoritative answers to inform her own decisions. She tended to rely on "the experts' comments", rather than her own "judgement, analyse and synthesize ideas and information, and draw [her] own conclusions" (Marton \& EDB Chinese Language Research Team, 2009, p. 134). "To be more active in learning" was what Angela thought she should do. But Public Kindergarten's director-led professional learning approach placed Angela in a passive position. Moreover, Public Kindergarten's lack of attention paid to facilitating teachers' critical thinking, flexibility, and creativity may have hindered Angela's understanding and reflection of multiple truths.

The preceding analysis suggests, as a learner, Angela believed in the importance of effort and recognising the hardship in learning and self-sacrifice to do a better job, which were commonly valued among Chinese EC teachers (Tobin et al., 2009). She valued more knowledgeable others, official and authoritative knowledge rather than her own ideas and judgements. Angela took the official and authoritative knowledge as the right way of teaching and learning at the surface level, instead of accepting multiple interpretations of teaching and learning when constructing her own response to the knowledge (Apple, 1993). Angela's experience implies that the context of professional learning has become complex and diverse for Chinese kindergarten teachers. This may require a change of professional learning approach from the traditional "learning by being taught" to "learning how to learn", which is an emphasis of the recent Chinese educational reforms (Marton 
\& EDB Chinese Language Research Team, 2009). Shulman (1998/2004) argued, professional learning should help teachers "to transform, adapt, merge and synthesize, criticize, and invent" and facilitate teachers' "exercise of judgement" ( $p$. 534); these were what Angela struggled with.

\section{Shifting professional identity}

The teaching journey: from "smooth" to "setbacks and frustrations"

Angela's use of opposites, "easy" and "difficult", implies the dramatic change in her teaching career due to the change of teaching community. "Easy" was associated with her "smooth" teaching experience in the past, and "difficult" reflected her current "frustrated" feeling. It seems Angela moved from the enthusiasm and growth stage of her career at the previous kindergarten to the career frustration stage at Public Kindergarten where she experienced "a lack of job satisfaction" (Lynn, 2002, p. 181). This supports Lynn's argument that teachers' career stages are not linear but dynamically shaped by "personal and organizational environmental factors" (p. 179).

\section{Self-image: from "could do the job well" to "clumsy bird"}

Angela had high self-expectations and often questioned why she could not do things well after observing or comparing her teaching with other teachers. Angela's "uncomfortable" feeling and fear of underachieving at Public Kindergarten are often found among beginning teachers (Cherubini, 2009), not among experienced teachers. In contrast with Angela's initial "happy" and "could do the job well" self-image as a teacher, Angela redefined herself as "a clumsy bird" who was 
unsure about her ability to teach. These narratives imply Angela was losing her confidence, self-efficacy and power in teaching. Angela's different experiences of working in two different kindergartens, and the ideological shift from traditional teacher-led to child-centred teaching and learning may have shaped her changing feelings of being a teacher. Angela knew the traditional ways of teaching and learning very well but not the child-centred ways. Sikes et al. (1985) assert that being able to do what is required may give teachers "a sense of security" (p. 152) in a particular teaching and learning context. Therefore, not being able to do what was required at Public Kindergarten may be the main source of Angela's negative feelings and self-doubt. Moreover, Angela's overt concentration on "experts' comments", and meeting the external requirements and tasks may disconnect her from gaining deeper understanding of herself and children (Apple, 1986; Ayers, 2001; Palmer, 1998).

Like Linda, Angela positioned herself as a passive follower, less powerful and less knowledgeable at Public Kindergarten. But she was employed as an experienced teacher with an expectation of providing help and guidance to her teaching partner Linda and was given a responsibility of leading the 4 and 5 -year-old class teaching team. In this sense, Linda and other teachers may view Angela as an experienced, knowledgeable and powerful member of the Public Kindergarten community. The contrasting images and positions of Angela from her own perspective and other teachers' opinions may cause tensions for Angela when becoming enculturated into the kindergarten community, when socialising with the colleagues, and when understanding the teaching self in children's life and in the wider community. 


\section{Summary}

Public Kindergarten's curriculum closely followed the government's reform ideas. Modern educational ideas such as valuing children's central position in teaching and learning, individualised teaching and learning, and a broad view of curriculum were promoted at Public Kindergarten. Understanding children is fundamental for implementing child-centred modern educational ideas; but it was not on Public Kindergarten's professional learning agenda. Moreover, Public Kindergarten maintained a traditional centralised control process for managing the kindergarten's operation, curriculum implementation and professional learning. Structured daily routines, prescriptive curriculum documents and planning processes, and director-led formal professional learning were some key aspects of its management strategies. The traditional ideas were embodied in the kindergarten structure as well as Linda and Angela's cultural repertoires of practice (Gutierrez \& Rogoff, 2003), i.e. their actual teaching. Conflicting scripts about teaching and learning thus co-existed at Public Kindergarten.

Several common threads have emerged from Linda and Angela's stories. Firstly, Linda and Angela both seemed to find it difficult to promote children's central position in their teaching, and experienced intellectual tensions when making sense of Public Kindergarten's curriculum and practices. Secondly, Linda and Angela both desired a close relationship with children. But they experienced pedagogical tensions due to the multiple images of child they encountered, the fear of losing their authority in the class, and the struggle of managing the needs and requirements of all parties - individual child, the class, the teacher, the kindergarten, 
and the parents. Thirdly, Linda and Angela both mentioned the influences of more experienced teachers/the director/the experts in their professional learning. However, they found it difficult to match their own teaching with the exemplified and required teaching. Fourthly, negative emotions such as frustration, fear, confusion and self-doubt were strongly communicated in Linda and Angela's stories, despite Public Kindergarten's well-intentioned professional learning programme led by a very proactive director in order to support the beginning teachers' and the newcomers' teaching and learning. Hargreaves (1994) points out that even wellintentioned provisions or systems may also be "self-defeating because they are squeezed into mechanistic models or suffocated through stifling supervision" (p. 3).

Public Kindergarten's particular professional learning approach and kindergarten structure seem important influences on Linda and Angela's teaching and learning. Public Kindergarten's director-led, structured and formal professional learning programme reflects a de-contextualised view of learning that may underestimate the complexity and uncertainty of teaching and learning, and the dynamic relationships among the four common places of teaching: teacher, curriculum, children, and milieu (Schwab, 1983). It may also cause a disjunction between Linda and Angela's personal passive professional learning experiences and the active learning they were required to support in the classroom.

Reflecting on my own teaching experiences of teaching at a state-run kindergarten 20 years ago, I noticed some changes in the daily schedule and planning between what happened in Public Kindergarten and my previous kindergarten. For instance, Public Kindergarten had individualised learning centre activities, small group learning activities, and extended pre-planning from bring only 
for big group lessons to all four kinds of activities; but they were not part of my previous kindergarten's practice. These changes may reflect the shift of underpinning educational philosophy and promoting a holistic and child-centred approach to teaching and learning. However, Chapters 5 and 6 showed that Linda and Angela were teaching alone most of the time in the classroom, and this was the same as what I had experienced 20 years ago. Other similarities between my own experience and what I observed in Linda and Angela's class are:

- the daily schedule and the teaching plans determine class activities

- teachers' teaching practices are controlled, supervised, and guided

- teachers' professional learning consists of being told and becoming aware of what is acceptable and appropriate according to the curriculum, the kindergarten policies, the more experienced others and the local education authorities.

This comparison may suggest the guiding philosophy of Chinese ECE has changed dramatically over the years, but kindergarten structure, management, everyday routine, and professional learning approach have not changed as much. This finding echoes Yan Liu, Pan and Sun's (2007) observations of the Chinese ECE reforms. They argue, "the tendency of emphasizing the change in philosophy but neglecting the system/kindergarten restructuring may constrain the promoted reform ideas being realized and pursued in reality" (p. 36). Therefore, the changing philosophy and the unchanging kindergarten structure, the disconnections between the promoted educational ideas in theory and in practice are other factors shaping Linda and Angela's teaching and learning experiences. 


\title{
Chapter 7: Selina and Cherry from
}

\author{
Private Kindergarten
}

\section{Private Kindergarten Context}

Selina and Cherry were teaching partners of a 4 and 5-year-old "international" ${ }^{9}$ class from Private Kindergarten in Shanghai. Selina had been teaching at Private Kindergarten for six years and was the master teacher ${ }^{10}$ of the class, and the team leader of the 4 and 5-year-old class teaching team (three parallel classes and six Chinese teachers). Cherry was the class teacher and in her third year of teaching. Both Selina and Cherry were in their early thirties. There were 27 children in Selina and Cherry's class, and they co-taught in the classroom most of the time.

Private Kindergarten was privately funded and managed by an educational organisation that ran several chained kindergartens in China. It mainly served local Chinese families. A three-storey building, a multi-function hall and a big grassy outdoor play area accommodated 15 classes of more than 300 children aged from 2 to 6 years old. Private Kindergarten's website stated that its educational philosophy

\footnotetext{
${ }^{9}$ Private Kindergarten had two streams of classes: International and Mainstream. The difference was international classes had English teachers teaching in the class half a day, while mainstream classes only offered English lessons. The fees for international and mainstream classes differed.

${ }^{10}$ The master teacher took the leading role in the class.
} 
emphasised holistic and harmonious development, independent thinking, environmental conservation, and international awareness. These emphases were believed to be important aspects of constructing a solid foundation for children's lifelong learning and sustainable development.

\section{Funding}

The school fee for Private Kindergarten's international class was approximately CNY $¥ 3000 / N Z D \$ 577$ per month. Because Private Kindergarten did not receive any government funding, school fees paid by the parents were its main income. The parents and the market played important roles in Private Kindergarten's decisionmaking process. Having an attractive educational philosophy and curriculum that the parents would accept and buy into was the key to success in holding a place in the ECE market. In Private Kindergarten's case, the uniqueness of its curriculum was the idea of international education and child-centred learning as opposed to the traditional academic-focused and teacher-directed education.

Private Kindergarten was regulated by the government's kindergarten work regulations (Ministry of Education in People's Republic of China, 1996), and guidance (Ministry of Education in People's Republic of China, 2001). As will become apparent in later discussions, Private Kindergarten chose some Western approaches to support "children's holistic and harmonious development" promoted by the government. The director shared:

Our curriculum

has learnt from

Early Years Foundation Stage

a curriculum from England. 
Our curriculum aligns with

the government's regulations of

early childhood education

to promote children's

holistic and harmonious development.

The difference

(between our kindergarten and other kindergarten)

is the implementation methods.

Our curriculum is quite integrated!

We have

structured teaching and learning

learning centres

project approach

daily life activities.

These four approaches

are integrated

not fragmented.

There is a process

for the parents

to accept our curriculum.

In Shanghai

many parents

value early children education.

They are willing to

try out new approaches.

Up to now

all parents who enrol their children here

accept our philosophy and approach.

Next year

we will face

the education authority's inspection

to give us an official grade.

They will mainly inspect

the kindergarten's management.

We cannot change our curriculum

but we can develop

a better awareness of

quality control

through this process

to make our management more

standardised

detailed

and better quality. 
According to the director, to be accepted by the parents and to be recognised by the local education authority were equally important for Private Kindergarten. The five parents I interviewed all stated they liked Private Kindergarten's philosophy, curriculum, and teaching approach. However, while the parents were largely happy with the active learning approach, they still had some concerns. For instance, their children might recognise fewer Chinese characters or recite fewer ancient Chinese poems or be slower in doing addition and subtraction than their friends' children who attended academic-focused kindergartens. Therefore, supporting children's active learning by following their interests and meeting some parents' demands to teach certain academic knowledge and skills might cause tensions for teachers, as Selina's poems will show.

In short, the market/parents and the government co-influenced the construction of Private Kindergarten's identity, philosophy, curriculum, and operation. Western child-centred educational ideas and approaches were valued by both the market/parents and the government's reform ideas. They became the focus of the kindergarten's marketing strategy, professional learning, and teachers' reflections. Meanwhile, the traditional structured teacher-directed teaching also held an important position in the curriculum; in the parents' expectations and according to the director it was supposed to be integrated with other aspects of the curriculum.

\section{Dual curriculum}

Private Kindergarten offered a mixture of Western and Chinese educational approaches, for instance: 
- Western approaches: the project approach (Katz \& Chard, 2000), multiple intelligence theory (Gardner, 1983) informed learning centres (each class set up eight learning centres corresponding to eight intelligences), learning stories (Carr, 2001) for formative assessment.

- Chinese approaches: structured group learning based on the subjects, the use of Shanghai's early childhood Common Curriculum so that teachers might choose some teaching and learning contents from it, according to Cherry, and the summative learning report.

These approaches may be categorised as child-centred and observationbased learning according to children's emergent interests, and teacher-directed structured learning that was subject-based. This dual-curriculum context shaped Selina and Cherry's teaching and learning experiences, as my analysis will reveal in Chapter 8.

Private Kindergarten was committed to integrating Chinese and Western educational ideas and approaches into everyday teaching and learning. According to the director, the kindergarten was still exploring how to integrate these approaches with a vision of "providing appropriate early childhood education that best suited children's development" (interview, March 19, 2010). However, "appropriate education" could be understood and interpreted differently in different socio-cultural contexts shaped by different underpinning values and priorities. For instance, should it be a teaching and learning process that would "address the full scope of [children's] growing minds as [children] strive to make better and fuller sense of their experiences" (Katz \& Chard, 2000, p. 6); or a sober, formal process of educating an ordinary child towards the ideal child as Confucian scholars believed (Bai, 2005a). Private Kindergarten's dual-curriculum indicated both Western and 
Chinese concepts of appropriate education and values were acknowledged and practised.

\section{Children foremost philosophy}

“Children foremost" was Private Kindergarten' guiding philosophy. The director claimed understanding children and children's development were at the heart of its teaching and learning:

Children Foremost.

This philosophy

we totally agree to.

If you lift the veil

you can see

what is the essence of

early childhood education

It is children's development.

This is the very basic.

We encourage teachers

to talk about children

to deepen the understanding of children

to reflect on practice.

It was part of

our kindergarten culture.

We use Learning Story

as a way of

capturing children's development.

Through

on-going analysis

on-going sharing

teachers become passionate of

observing children.

"Observing children" was widely practised at Private Kindergarten for both structured learning and child-centred learning during planning, documentation and assessment: 
- The monthly planning forms had a column called "analysis of children's existing experience" for each subject.

- The daily planning forms had a column called "guide point for observation".

- Teachers were required to plan and document children's project activities with photos and narratives.

- Teachers were required to use observation-based formative assessment tools, learning stories, and child's portfolio to assess individual children's learning and development in different areas.

As will become apparent later, these observation-based planning and assessment processes may be seen as pedagogical tools that helped Selina and Cherry make sense of Private Kindergarten's children foremost philosophy and directed their attention to individual children.

\section{Professional learning system}

Professional learning was an important aspect of Private Kindergarten's operation; there were different programmes for new employees, interns and all teachers. I observed open-class teaching, a maths-teaching workshop, an intern assigned to Selina and Cherry's class, and a 4 and 5-year-old class team's group meeting led by Selina to reflect on the implementation of the learning stories and the project approaches. Like Public Kindergarten, Private Kindergarten provided different kinds of training for different groups of teachers, and used similar training methods. However, there were some differences in how these training methods were practised, for instance: 
- Open-class teaching of subject-based structured learning - during a designated week, the teachers could choose what class they would like to open to others, and which teachers' teaching they wanted to observe. Teachers were required to complete a reflection after observing another's teaching. In Public Kindergarten, the director assigned open-class teaching and observation sessions.

- Workshop - the maths-teaching workshop I observed was run by an experienced teacher at Private Kindergarten. Selina gathered teachers' questions regarding teaching maths to help the experienced teacher prepare for the workshop. At Public Kindergarten, I only observed training seminars and presentations run by the director or by experienced teachers from the exemplary kindergarten.

- Group discussion and reflection - I observed two 4 and 5-year-old class teaching team's group discussions. The topics were strategies for supporting children's learning after observation, and teacher-child interaction strategies. I did not observe discussions focused on teacher-child interactions at Public Kindergarten.

The teachers at Private Kindergarten seemed to have a degree of agency in deciding what they needed for their professional learning; they could select professional learning activities and ask questions. There was also a sense of collaboration among the teachers at Private Kindergarten that they would "scaffold and support each other's learning" (Shulman, 1996/2004, p. 476), for example when interns became apprentices of experienced teachers in the classroom, and when teachers' own questions were discussed during workshops and group discussions.

\section{Kindergarten management}

The expert team of the educational organisation was in charge of developing 
teaching standards, practice guidance, all kinds of curriculum documents and forms etc. The director took responsibility for the kindergarten's operation, management, and curriculum implementation. The team leaders of each year level supported the director with curriculum management. The director had the power to make final decisions and interpret the curriculum ideas when there were disagreements.

Two kinds of control were embodied in the physical structure and social relations of Private Kindergarten: technical and bureaucratic (Apple, 1995). Firstly, Private Kindergarten used a fingerprint roll machine to control teachers' attendance, but only "late-arrival warnings" were issued to teachers. The extra time teachers spent at kindergarten for planning and weekend events were not officially acknowledged. Secondly, there were impersonal and bureaucratic rules set by the expert team and the kindergarten management through officially approved policy, curriculum, planning forms, and assessment instruments that teachers were required to follow. The expert team developed different sets of forms to guide the teachers' practice, and the director monitored the use of these forms in practice:

- A set of monthly planning forms - including class monthly planning form; month planning form for structured teaching; activity planning forms for math, literacy, music, art and craft, and physical development; monthly planning form for setting up learning centres and activities; planning for parents' involvement

- A set of project planning forms (two projects per term) - project predicting planning forms covered three phases of project approach; forms for documenting significant project activities and process

- Daily planning forms

- Daily School-Family diary 
- Individual structured teaching activity plans - two or three sessions per week

- Learning Story forms - one story per child per month

- Individual Child's Learning Support Forms - voluntary, 4 to 5 children per term

- Individual child's learning report - once a term

- One-to-one-parent-teacher interview forms - discussion points and reflection - twice a term

- Yearly and termly class planning forms, as well as the summary report of the class work at the end of each term and school year

- Personal self-report once a term.

The teachers were required to complete these forms along the way during the school year as part of their regular routine and submit them to the team leader for supervision and documentation purposes. In the poems, Selina and Cherry share their concerns about these written tasks.

The preceding discussions suggest Private Kindergarten's management expected and supported teachers' active role in their own professional learning, but they viewed teachers as passive followers in the kindergarten structure where the director and the experts had the power to direct teachers' teaching and learning.

\section{Selina and Cherry's daily routine}

Selina and Cherry shared most of the teaching responsibilities. They worked with a foreign English teacher who taught half a day (8:15-11:30 a.m. or 2:30-4:15 p.m., rotating every day) in the class (see Table 7.1). Selina and Cherry's daily planning was normally done one day ahead, and was displayed outside the 
classroom for the parents. Selina and Cherry would plan projects following a threephase process (Katz \& Chard, 2000). A monthly plan was done among the 4 and 5year-old class teaching team by filling out respective planning forms for learning centres, structured teaching, maths, art, music, physical education, reading and literacy, parent assistance, and an overall monthly plan for the class. Since some children used school buses, Selina and Cherry were required to use School-Family diaries to communicate with their parents on a daily basis. Other parents would receive teachers' written messages in the diary once a week. Selina and Cherry also shared the workload of writing up learning stories for individual children, parentteacher interviews and other kindergarten events.

Table 7.1

Daily schedule for Selina and Cherry's class

\begin{tabular}{|c|c|c|c|c|c|}
\hline & Monday & Tuesday & Wednesday & Thursday & Friday \\
\hline $7: 45-8: 30$ & \multicolumn{5}{|c|}{ Learning centre activities } \\
\hline $8: 30-9: 30$ & \multicolumn{5}{|c|}{ Physical development activities: Group games, free choice and group exercise } \\
\hline 9:30-10:00 & \multicolumn{5}{|c|}{$\begin{array}{c}\text { Morning tea } \\
\text { Class morning assembly }\end{array}$} \\
\hline 10:00-11:00 & \multicolumn{5}{|c|}{ Group learning: English or Math; English or Chinese; English or project discussion } \\
\hline 11:00-12:00 & \multicolumn{5}{|c|}{$\begin{array}{l}\text { Pre-lunch group activity: sharing, discussion, poems, art appreciation, stories etc. } \\
\text { Lunch, Free reading (books from home), After-lunch walk }\end{array}$} \\
\hline $12: 00-2: 30$ & \multicolumn{5}{|c|}{ Nap time } \\
\hline $2: 30-3: 30$ & \multicolumn{5}{|c|}{ Get up, Outdoor play } \\
\hline $3: 30-4: 15$ & & $\begin{array}{r}\text { Learning cen } \\
\text { Review }\end{array}$ & $\begin{array}{l}\text { Afternoon tea } \\
\text { or project learn } \\
\text { ne time prepara } \\
\text { nglish and Englis }\end{array}$ & $\begin{array}{l}\text { or music time } \\
\text { tory time }\end{array}$ & \\
\hline $4: 15-5: 00$ & \multicolumn{5}{|c|}{ Home time } \\
\hline
\end{tabular}

Group planning, training and meetings were important components of Selina and Cherry's daily routine. I observed 11 meetings they both attended during my 16 days' observation (Table 7.2). Most meetings were conducted after lunch during 
children's nap-time (care-givers to supervise). According to the director, these meetings were to help teachers cope with the demands of teaching, communicating with the parents, and learning both Chinese and Western approaches.

Table 7.2

Meetings Selina and Cherry attended over 16 days' observation

(excluding the team leaders' meeting which only Selina attended)

\begin{tabular}{|c|c|c|c|c|}
\hline No. & Meetings & Organizer & Teachers' discussion & Director's agenda \\
\hline 1 & $\begin{array}{l}4 \text { and 5-year- } \\
\text { oldclass team } \\
\text { meeting }\end{array}$ & $\begin{array}{l}\text { Selina } \\
\text { (Team } \\
\text { leader) }\end{array}$ & $\begin{array}{l}\text { Review of big event - } \\
\text { International Women's Day } \\
\text { celebration } \\
\text { Sharing class plans for the } \\
\text { upcoming parent meeting } \\
\text { Discussing project approach } \\
\text { documentation } \\
\text { Discussing how to write } \\
\text { "What next?" section }\end{array}$ & NA \\
\hline 2 & Staff meeting & Director & NA & $\begin{array}{l}\text { Teacher registration } \\
\text { Review of last week's parent } \\
\text { meeting } \\
\text { Monthly focus } \\
\text { Writing Learning Stories } \\
\text { Over-weight children. }\end{array}$ \\
\hline 3 & $\begin{array}{l}\text { International } \\
\text { classes } \\
\text { teachers' } \\
\text { meeting }\end{array}$ & Director & NA & $\begin{array}{l}\text { Review of the programme } \\
\text { Plan for next week's open class for } \\
\text { the prospective parents }\end{array}$ \\
\hline 4 & $\begin{array}{l}4 \text { and } 5 \text {-year- } \\
\text { old class team } \\
\text { meeting }\end{array}$ & $\begin{array}{l}\text { Selina } \\
\text { (Team } \\
\text { leader) }\end{array}$ & $\begin{array}{l}\text { Writing up Learning Stories, } \\
\text { Studying book "Young } \\
\text { Investigators" and discussing } \\
\text { project }\end{array}$ & $\begin{array}{l}\text { Suggested teachers to use the } \\
\text { developmental phases indicated in } \\
\text { the summative report while writing } \\
\text { learning stories } \\
\text { Thought the teachers needed to } \\
\text { enhance in-depth investigation } \\
\text { during the second phase of project }\end{array}$ \\
\hline 5 & Staff meeting & Director & NA & $\begin{array}{l}\text { Review of open class for parents } \\
\text { and fellow teachers } \\
\text { Plans for the upcoming parent- } \\
\text { teacher mid-term interview } \\
\text { Safety concerns } \\
\text { Use of parent-teacher interview } \\
\text { feedback forms }\end{array}$ \\
\hline
\end{tabular}




\begin{tabular}{|c|c|c|c|c|}
\hline 6 & $\begin{array}{l}4 \text { and 5-year- } \\
\text { old class team } \\
\text { meeting }\end{array}$ & $\begin{array}{l}\text { Selina } \\
\text { (Team } \\
\text { leader) }\end{array}$ & $\begin{array}{l}\text { Plan and preparation for } \\
\text { International Children's Day } \\
\text { celebration } \\
\text { Teacher-children interaction } \\
\text { strategies } \\
\text { Discussing parent-teacher } \\
\text { mid-term interview }\end{array}$ & NA \\
\hline 7 & $\begin{array}{l}\text { Preparation } \\
\text { meeting }\end{array}$ & $\begin{array}{l}\text { Director } \\
\text { Selina } \\
\text { participated }\end{array}$ & Not observed & $\begin{array}{l}\text { Preparing for treasure hunt as part } \\
\text { of International Children's Day } \\
\text { celebration }\end{array}$ \\
\hline 8 & Staff Meeting & Director & NA & $\begin{array}{l}\text { Series of activities for International } \\
\text { Children's Day celebration } \\
\text { Next open class focus: project } \\
\text { approach and maths activities } \\
\text { Work attendance and teachers } \\
\text { arrive later }\end{array}$ \\
\hline 9 & $\begin{array}{l}4 \text { and 5-year- } \\
\text { old class team } \\
\text { meeting }\end{array}$ & $\begin{array}{l}\text { Selina } \\
\text { (Team } \\
\text { leader) }\end{array}$ & $\begin{array}{l}\text { Review of open class to } \\
\text { parents and fellow teachers } \\
\text { Discussing the plan for } \\
\text { International Children's Day } \\
\text { celebration, deleted two } \\
\text { activities at the end. }\end{array}$ & $\begin{array}{l}\text { Asked the teachers to review the } \\
\text { feedback from parents } \\
\text { Questioned some of planned } \\
\text { activities for celebration }\end{array}$ \\
\hline 10 & $\begin{array}{l}\text { Math } \\
\text { teaching } \\
\text { training }\end{array}$ & $\begin{array}{l}\text { Director, } \\
\text { Teachers } \\
\text { who teach } \\
\text { math must } \\
\text { participate } \\
\text { Cherry did } \\
\text { not go }\end{array}$ & $\begin{array}{l}\text { Workshop led by an } \\
\text { experienced class teacher } \\
\text { Selina helped with workshop } \\
\text { preparation. }\end{array}$ & $\begin{array}{l}\text { Summarised the key information } \\
\text { from the workshop. }\end{array}$ \\
\hline 11 & $\begin{array}{l}4 \text { and 5-year- } \\
\text { old class } \\
\text { group } \\
\text { planning }\end{array}$ & $\begin{array}{l}\text { Six teachers } \\
\text { from three } \\
\text { classes }\end{array}$ & $\begin{array}{l}\text { Group planning for the } \\
\text { upcoming month's structured } \\
\text { teaching in different learning } \\
\text { areas. }\end{array}$ & NA \\
\hline
\end{tabular}

When observing these meetings, my impressions were:

- There were quite a lot of meetings.

- The teachers seemed to have a lot to say, but most of their thoughts were voiced during the 4 and 5 -year-old class team meetings when the director was not present.

- Most of the meetings were one-sided information-sharing.

- Parents did not participate in meetings but their presence could be strongly felt. 
- Children were at the centre of most discussions but how to understand them as individuals was not the emphasised topic.

- Learning how to write learning stories and how to lead projects were two major topics of teachers' discussions, as well as English and Maths teaching.

There was no doubt the director had put lots of effort into building a collaborative and supportive professional learning community for teachers by encouraging teachers to talk and discuss together. She knew the importance of reflection in teaching, learning, and management; hence, she was trying to avoid simple control of teachers' teaching by telling them what to do (interview, March 19, 2010). Instead, she encouraged teachers to actively reflect either individually or collectively. Hellner (2008) identified the critical attributes of a professional learning community as a place with shared and supportive leadership, shared value and visions, collective learning and collaboration, teachers sharing personal practice, and supportive conditions in terms of kindergarten structure, communication channels, and relationships. Some of these attributes could be found at Private Kindergarten; for instance, the shared philosophy of children foremost, collective learning, and sharing of personal practice during team meetings and group planning time. However, Selina and Cherry's participation in the meetings suggested their thoughts were only valued at the execution and practical level. The collaboration among teachers was dynamic but only around the chosen topics according to the kindergarten's agenda. Consequently, I rarely heard Cherry voicing her ideas voluntarily in meetings, while Selina had two voices: to represent the kindergarten during team meetings, and to represent the teachers at the management meetings. As will become apparent later, Selina did not feel comfortable about the two 
voices she had because of some disagreements with the kindergarten management.

In this sense, Cherry and Selina's agency, their reflection and collaboration with others were only partially valued.

\title{
Selina's Stories as Poems
}

\section{Childhood memory}

\author{
I went to kindergarten \\ around 3 years old. \\ I only remember \\ I was a slow eater. \\ Teachers blamed me. \\ Teachers favoured \\ some children. \\ Not me! \\ We \\ most of children \\ were at the corner \\ where teachers forgot.
}

\section{Choice of being a kindergarten teacher}

\author{
I thought \\ it would be a good idea \\ to try the teachers' training college \\ after middle school. \\ I could go to workforce \\ straight out of the college. \\ I was so scared of study \\ at that time! \\ Exams! \\ I was most afraid of \\ memorising stuff! \\ Math and physics were ok! \\ I was hoping to start work \\ as soon as possible! \\ Did not want to study anymore!
}


I did not have much idea of teaching at kindergarten.

Only felt

it should be quite comfortable

since teachers would

be working with young children!

Family members also said

it was good for the girls

to be teachers.

\section{Initial training}

Our learning at the training college

was passive.

Studied everything

by rote before exams

then forgot everything

afterwards.

What I had learnt were

Playing piano

Singing songs

Be more open!

I could still use these now!

I would never

be brave enough

to perform anything

on stage before.

At the training college

there was such a stage and

it changed my personality.

\section{After graduation}

During the practicum

I felt

teaching young children

was very troublesome.

I thought

I'd be better to teach

at primary school.

It should be easier!

I graduated in 1994

then taught grade one and two math at a primary school 
for four years.

I resigned in 1998

moved to South Africa

due to a change of

family circumstances.

I came back to Shanghai

after three years.

I stayed at home

taking care of the family.

Then I taught at

another private kindergarten

for one year.

One of the former colleagues

came here

asked me to join her.

So I did.

\section{Project approach}

If we notice children's interest

we would think

if this interest

is suitable for carrying out

as a project.

We would

make a "project prediction plan".

This approach emphasises

children's individual development.

It requires teachers

to pay attention

to every child's development

use different strategies

for each child's development.

I think

this curriculum model

is quite good.

It would be better

if we have less children

in the class.

We have 27 children.

It takes time

to follow up on each child.

It is very hard

to take account of everyone. 


\section{The dinosaur project}

\section{Children}

kept talking about dinosaur

initially.

But

we did not find a right angle

to start the project

so children could learn

through hands-on experience.

Children were interested in dinosaur

for a while.

Then they lost interest.

We had to wait for a while.

But

we also had to

fill in the project box

on the daily planning form.

It could not be blank.

Blank means

you did nothing.

You must do something.

We filled it up with

teachers' pre-planned activities.

Watch PowerPoint presentation.

Measure how long a dinosaur is.

How heavy a dinosaur would be?

We are required to

do two projects per term

regardless if you are able to

carry on with the project or not.

You must start from this week

and finished at a certain date.

But actually

It is out of our control.

Suddenly one day

a child brought in

a 3D dinosaur book.

He was very interested in this book wanted to make a book like this.

Others wanted to as well.

I said ok

and supported them.

Children 
made their dinosaur book

in many different ways.

The interest came back.

The project actually took off

from this dinosaur book.

I asked children to bring in

some 3D cards or 3D books

$3 \mathrm{D}$ craft material.

We added these materials

to the learning centres.

Children experienced

many problems

when making their books.

How to let the dinosaur

stand up in the right way?

I provided scissors

allowed them to

cut the 3D cards out

looked at them

compared the pictures

drew the pieces

glued them together.

They succeed!

We felt joy

during this series of activities.

Children liked activities too.

Following children's interest

motivates me!

\section{“No need for structured lessons!"}

Structured lessons include

English

Math

Chinese Language and Literacy

Music.

Structured lessons' orientation

is based on

the developmental goals of children.

We often go to

state-run kindergartens

to observe their lessons.

Usually observe an open-class lesson. 
It's supposed to be good.

But

sometimes we do not think so.

Their lessons

emphasise the group

not the individual child.

Everybody draws

same kind of pictures.

It restricts

children's development of creativity.

If we have a structured lesson

we would also have this restriction.

How to conduct a structured lesson

that matches with our philosophy?

This is very difficult!

If the class number

is not that big

I do not think it's necessary

to have lessons.

We can follow individual children

at learning centres.

Like math

we gather some children

at the math area

play with them.

We can know their development

when they manipulate the materials.

If there is enough time

we could provide further activities.

No need for a structured lesson.

Music lesson seems necessary.

Group teaching

can help children

to know their role

in a collective group environment.

But

we have circle time and assembly

they can help

solving this problem!

\section{"Selling dog meat as mutton"}

The ability to solve problems.

Interpersonal relationship.

How to make friends? 
How to learn from others?

Express one's inner feelings and thoughts.

They are very important.

At this age

it is not about

storing up

knowledge and skills.

We focus on

letting children learn

how to learn actively.

So

they can carry on learning

after leaving

parents

teachers

schools.

Some parents feel

it is more important

to store up knowledge

at this stage.

They focus on

how much knowledge children learnt

neglect ability

and children's emotions

whether they are happy!

There was a grandpa

kept asking me

why did you not teach Chinese characters

other kindergartens taught children a lot.

I told him

we did not require children

to learn a certain amount of characters.

Learning

hould be based on

children's interest.

We provided

prints or other materials in the class.

If children were interested

they would ask us

how to read and write these characters.

We could teach them naturally.

Then he told me

we were "selling dog meat as mutton".

He felt it was ambiguous.

Other people would tell him 
children would learn

500 characters

more or less.

I said they could learn

if they wanted.

If a child was not interested at all

he might not learn

one single character here.

The grandpa

was not happy

and said

did this mean

if they did not want to learn

then teachers did not teach!

Now I feel

our parents' thoughts

are slowly changing.

I talk to our parents

during the one-to-one interview.

By reviewing the project

discussing the learning stories

we share with the parents

children's learning process

activities they initiated

skills they developed.

\section{"To comprehend from the practice"}

There are

high professional requirements

of teachers here!

During my first year

I knew nothing.

Sometimes

when I really did not know

what to do in the class

the former director would

come in and tell me

what and how I should do.

She would say some focal points

main factors.

Such as

all I should do was

think how to help children develop.

The former director 
Led me to think more

led us to think through

on-going study and training.

There is a book called

Young Investigators ${ }^{11}$.

It proposes some questions

to lead teachers

undertaking projects.

However

it cannot solve

practical problems.

Therefore

I still have to

comprehend it

from practice

by myself.

I felt

this kindergarten

gave teachers

spaces to play.

You can have

some of your own thoughts

as long as you follow

the route of children's development.

\section{Being a teacher}

My professional development

really started and continued here.

I like the explorative curriculum here.

It is fun.

It is my interest.

So it really suits.

Children and teachers

are mutually complementary.

I observe their interests.

I support them.

They move forward

under my assistance!

Children follow my ideas

\footnotetext{
${ }^{11}$ Selina refers to the Chinese translation of the book Young investigators: the project approach in early years
} written by J. H. Helm and L. G. Katz (2001). 
during the structured teaching.

They play with

the materials I provided

for a long time.

I discover their interests.

These are the moments of

achievement and success!

The most difficult time

is when

children's safety is at risk.

This is the scariest thing!

There was an incident

in my teaching career.

A child jumped off

the window sill

into the reading area.

Another child

was reading there.

He landed on the other child's hand

broke the bones of the child's hand.

Some children

are very naughty

always bite

hit

push others

out of control.

We have no way

to deal with them.

I do not want to be a teacher

at those moments.

Too much trouble.

At that time

I wanted to

quit teaching.

This really was

a case involving human life

we cannot make fun of.

I was crying and very sad

after that incident.

I resigned.

But

it was not accepted.

The former director

talked me through it. 
I stay here

to absorb

better education philosophies.

They are helpful

when I educate my own children.

\section{The ideal and the real}

Our curriculum is not

the ideal curriculum

in my mind yet!

Our kindergarten

is at a transition period.

It may not have found

the balance yet.

So many lessons need to be taught.

Children actually

do not have much time

to play.

We have not paid enough attention to

social development

learning dispositions

integration capability.

Children in our class

may have not developed

the way we have anticipated

in some areas.

I think

Chinese early childhood education

should focus on

the essential things.

Every kindergarten

should pay more attention

to children.

Children foremost!

It is often said like this.

But

are children really treated

as the foremost?

Much of teachers' energy

should be put into

how to observe children better

follow up 
provide learning materials.

But in fact

it was not done like that

in practice.

I am like this too.

No energy and time indeed.

When it's time

to hand in something ${ }^{12}$

the management

expects you to do so.

Although people say

one needs to

better manage the time.

However

time is limited.

If many things like this

take up most of your time

you will not have time

to do what you're supposed to do.

According to our philosophy

we should regard children

as our friends

using respectful language

to them.

However

sometimes

we do not do things

the way our philosophy tells us.

Especially

when you are irritated

or something affects your emotion.

Ideal kindergarten is

an institution that

leads children and teachers'

development.

It requires

a leader.

She has clear ideas.

She needs to

lead the whole team

to move forward.

It also requires

a perfect system.

${ }^{12}$ Selina refers to the written work the teachers are required to do and hand in to the management. 
The former director

is now in charge of

all kindergartens of the organisation

she asked me about our curriculum

just recently.

I told her my thoughts.

But

regarding how to adjust

the curriculum in reality

is ... (their decision)

I do not know.

\section{Personal life, work, resigning and future}

This term

we do not have

a curriculum assistant.

As a team leader

I need to

take up quality management

help the director.

It would affect

the teaching quality of my class.

I have not found a way

to balance these roles.

I feel I am

in a chaotic situation.

Too many things.

I could not finish

all the work

the director asks me to do

during my eight working hours.

I could not handle all of them.

When I finish my work here

I go home

take care of my children

immediately.

I really admire

a former colleague.

She is very professional.

She gets along with people

deals with matters well.

She convinces people

with sound reasons. 
Carefree and lively.

Maintains high spirits everyday!

Looks after family very well too!

I have my thoughts of

ideal teaching.

However

it seems impossible right now.

I decide to give up.

Do not want to think about it anymore.

Family first!

Family is the most important!

\section{Cherry's Stories as Poems}

\section{Childhood memories}

My hometown

is a small place

in Sichuan province.

I started kindergarten

around 2 years old

in Inner Mongolia

when my dad was working there.

After a year

we moved back

to my hometown.

When I moved to

Inner Mongolia

I felt everything was novel.

Most impressive memory was

the kindergarten

it was like primary school.

Teachers would

dismiss us after lessons

and we played outside.

When it was time

for the next lesson

teachers would 
stand at the doorway

and sing "xxx class, time for the lesson!"

In that environment

it was quite fun!

Children at that time

were quite sensible.

When we were little

our life was not

as well-off as now.

I was very happy then.

Did not have the pressures

children nowadays have.

My parents did not put

many demands on us.

\section{Becoming a kindergarten teacher}

I studied

English education initially.

My parents suggested it to me.

I quite liked

to be a teacher then.

I felt

being a teacher I could

control many children.

Have power and pride.

I wanted to teach

after graduation.

My mum said

being a teacher

might affect my family life

since my husband was a sailor

and was not home most of the time.

So I worked at

the local bureau of personnel

for six years.

We moved to Shanghai.

My son

started kindergarten here.

I took my son

to kindergarten every day.

I would see teachers 
taking them to play outside.

I thought

it was so good

to be a teacher.

It was so much fun

watching them

singing and dancing.

There was another reason.

I was quite diffident

when I was young.

I did not have much contact

with many people.

Most of the time

I was quite passive.

I thought

doing this job

might make me

more active

talk more

communicate with people more

and be more open and cheerful.

I had

a general teacher's qualification certificate

after graduating from

my English education degree.

I needed to

pass the exams

to get

the early childhood teaching certificate.

I then enrolled in

a course

at a normal university.

The course

lasted for six months.

\section{First year of teaching at Private Kindergarten}

I was quite ignorant

at the beginning.

But

I followed a good teacher ${ }^{13}$.

Her initial training was

\footnotetext{
${ }^{13}$ Cherry refers to the master teacher of the class whom she worked with.
} 
teaching early childhood.

She had been teaching

for many years.

She was very warm hearted

willing to help others.

Initially

she did most of the work.

I was watching her.

Then I felt

quite embarrassed

and said to her

"let me do something".

I was modest

and always asking her

if I did ok.

\section{Project approach}

I feel it is very good.

Very new and unique.

In some areas

it follows children's interest

solves problems

through exploration.

Children's level of

excitement

interest

is high.

This is the display of

active learning.

This is the highlight.

Sometimes I find

children's success

is also mine.

When they developed

through the activities

I would feel

a sense of achievement.

I would be motivated

to support more explorations.

If teachers organise all the activities

I feel children are passive

so are we.

Then I would lose interest too. 


\section{Supporting project and learning centre activities}

When we provide materials

at the science learning centres

some children

may not play with them

or some just want to

play with the materials

but not learn through play.

Some girls never go there

stay at the art centre all the time.

How can we guide them

and switch their interests

to these activities?

When we were playing

float and sink with water

many children

just wanted to play with water.

They did not have

the sense of observing

what was sinking and floating.

The questions

came from them

but during play

they did not talk about

these questions.

How to let all children

or children who are not interested

participate better

in all learning centre activities?

How can teachers know

if children have grasped

the materials

at learning centres?

How to follow

all the learning centres closely?

During project exploration

teachers may focus on

the science centre.

Children's interaction and development

at the other centres

may be noticed

but will not be observed 
or attended to

in detail.

I do not know

how to balance and weigh

children's development

at each learning centres.

We do structured learning

in groups

plus English group lessons.

There are quite a lot of

structured learning times.

Comparatively speaking

children have less time

playing at learning centres

and free choices.

\section{Teaching structured music activity}

I started to

teach music activity

this year.

I do not know how to teach it.

Selina helped me once.

She played keyboard.

I organised the children.

It was good.

But

if just one teacher there

I find difficult to

arouse their enthusiasm

let them grasp

knowledge and skills

and get them to like the activity.

When teaching group structured lesson

since I do not have

much experience in teaching

I often look at

The curriculum guide.

Most of the time

I follow

the process

learning goals

and suggestions

written in the curriculum guide.

But find they do not match 
our class' situation.

How to make adjustments?

Sometimes

when I am planning the lesson

I imagine

the lesson would be good

if I do this and that.

However

it often does not achieve

the expected result.

Here we reflect.

Reflect how we can make changes

in the following lesson.

But apart from

the teacher making adjustments in teaching

I am confused by the questions of

how to follow up with children

how to let children adjust

in order to make up

what was lacking in the previous lesson.

\section{Learning story}

They ${ }^{14}$ have not decided on

the model of learning story yet.

They are still exploring.

They developed the forms

for writing up learning stories.

After using them for a while

we found

sometimes

the child had only demonstrated

significant learning

at some learning areas.

Other areas would be

blank on the form.

It is not good

to share the story with parents

that has blank areas on it.

The director

then required us

to fill up all boxes on the form.

They said

child's total development

\footnotetext{
14 "They" refers to the experts who develop the kindergarten's curriculum and the kindergarten management.
} 
involved all learning areas.

But in today's meeting

she changed her thoughts to we shouldn't write anything if certain area's development was not displayed.

\section{The ideal and the real}

Our curriculum looks

quite rational.

But

it has some disparity

to its philosophy in practice.

The philosophy says

Children Foremost!

It may require

children learn through play

most of the time.

But in reality

there are so many children

in the class.

Teachers' ability

parents' demands

limited this practice.

Consequently

we found it very difficult

to have more interaction

with children

after observing their development

at the learning centres.

I personally think

kindergarten shouldn't

emphasise too much

what children learn

but

how children learn.

Ideally

I hope

I can do everything

with high proficiency.

But

everyone will have to

go through a process 
from a beginner

to a mature stage.

From teacher's perspective

I hope

the kindergarten approves

the things we do.

The management from the top

could think from

teacher's perspective.

What would be beneficial

for teacher's and children's development?

I hope

children are happy

teachers are happy!

It is closely related to

the relationship between

teachers and children

teachers and teachers

and the integration of

teachers and the environment.

Ideal and reality

are too far apart.

\section{Child-teacher relationship}

I really like Harry and Jeremy

these kinds of children.

But

I have mixed feelings

towards them.

I like them very much

but I do not know

how to lead Jeremy.

Sometimes

we are in the situation of

bargaining/negotiation.

Jeremy

very naive

very cute

a real child.

But

in terms of

the awareness of rules 
he is distanced

from other children.

How to let him

be aware of the rules

also have own choices

or develop according to his interest.

This is challenging.

How to build a friendly relationship

that can guide children to follow the rules

but also have a good rapport with them?

If I get too close to some children

they would be indulged.

I am confused.

I want to

have a good relationship with them

have them follow the required rules

but not control them.

When children are happy

they like me very much

I would feel

it is so good to be a teacher.

If they are afraid of me

do not want to talk to me much

I feel distanced with children

and failing.

\section{Being a learner}

I learn from children.

I like observing them.

Observe how they

interact and communicate

how they apply learnt experience.

Like Harry

quite naughty

sometimes I would observe

how he interacts with others

and how other children respond to him

learn from this

I get to know children's minds.

I learn from the parents.

We interview parents

every term.

I need to prepare 
for the interviews.

During the conversation

I would learn

good methods

from the parents.

Sometimes I learn from

other teachers.

Sometimes

experts and professors

from the top

would come to train us

explain the curriculum goals to us.

We could ask questions.

When I educate my own child

I have many dilemmas and questions.

I often reflect

how to communicate with him

help him progress.

Come to this kindergarten

if something does not work well

when I interact with children

I would reflect too

then try out different methods.

\section{Being a teacher}

Sometimes

I am quite childish.

Play crazily with children

and get very excited.

When they are happy

I am happy too.

But actually

I am a serious person.

Being a kindergarten teacher

suits me.

But

I am not satisfied

with myself.

I do not have

a nice voice.

When I sing with my hoarse voice

I wonder

if children like to listen to it. 
I feel sorry for them.

But

I have tried my best.

I feel quite happy

when I am with children.

But sometimes

there are pressures

from the top.

Request for much work

to be done.

I like

just to work with children

interact with them

take my teaching seriously.

Why do we have to

take photos of whatever we see

write up as learning stories

document children's development

for each child?

Too many written tasks.

Cannot guarantee the quality.

We were told

since our work

was not quality enough

we needed ensure

quantity first.

Actually

we are in pursuit of

quantity now.

\section{Personal life, work and future}

Family harmony

health

are most important to me.

I am contented with

what I have now.

I am satisfied with my life.

I think

I may be working here

for several more years.

If I feel the job is

getting more tiring than now

I may go home 
and do something I like.

Also

our parents

will be older then

they may need me

to stay at home

and take care of them. 


\title{
Chapter 8: Analysis of Selina and Cherry's Stories
}

\section{Selina: "I have my thoughts of ideal teaching,}

\author{
however, ..."
}

Burke et al. (1987) argue that both personal and organisational environments impact upon careers. Selina's story illustrates this when she refers to some personal components such as relocation, personal values and inspirations, relationship between family and career, and her priorities and goals at different life stages. Selina's interactions with the organisational environment, more specifically the traditional Chinese culture of learning, the exam-orientated educational system, Private Kindergarten's curriculum, management and regulation, and societal expectation had also influenced her experiences of becoming and being an EC teacher.

In the following sections, my analysis of Selina's narratives focuses on:

- How Selina experienced the reality of teaching, which was about the disparity between the reality and the ideal teaching and learning she anticipated.

- How Selina learned from everyday practices and how the former director influenced her professional development. 
- How Selina balanced professional and personal life, which was about the positive and negative links between Selina's professional self and her personal self.

Selina's stories and my interpretation of them provide some insights into Chinese EC teachers' experiences of working in a dual-curriculum context where both the child-led and inquiry-based project approach and the structured teaching and learning are implemented, and the challenges of working with a project approach. Moreover, they also offer some ideas as to how teachers may feel and respond to a kindergarten management that takes technical and bureaucratic control of teachers.

\section{The reality of teaching}

\section{Positive experiences of project approach}

Selina felt positive about the explorative aspect of Private Kindergarten's dual-curriculum (more specifically the projects); "it is fun, it is my interest, so it really suits me". To Selina, working with the "explorative curriculum" meant to "observe" and "follow" children's interests to help them "move forward" with teacher's assistance. The poem, The dinosaur project, made the explorative curriculum explicit in practice:

- Teachers noticed "children kept talking about dinosaur initially".

- But teachers could not "find a right angle to start the project".

- Teachers had to "wait for a while" when children "lost the interest".

- When "a child brought in a 3D dinosaur book", teachers recognised and supported children's new interest by providing appropriate materials and 
allowing opportunities for children to explore how to make their own 3D dinosaur books.

- A sense of success and "joy" were experienced after teachers and children solved some problems.

This child-led teaching and learning process values children's agency, learning interest, problem solving and positive feelings. This new approach, advocated by the recent Chinese ECE reforms (Jimei Li, 2002), is unlike Selina's personal experience of traditional exam-orientated and knowledge-transmission learning as a student.

The explorative curriculum and the idea of following children's interest were not only practised through projects, but also during free-play time. In an unexpected scenario (below), I observed how Selina supported children's emergent interest of playing with an overhead projector that Cherry set up for a music lesson.

\section{Playing with the overhead projector (observation, March 18, 2010)}

Selina saw several children were switching on and off the projector, so the light was projected on and off the wall. She then put some laminated geometrical shapes by the projector. Three children immediately put them on the projector and watching the images on the wall with great excitement. Selina put down the refraction mirror that was on top of the projector. Selina asked children: "Where is the shadow?" Tom flipped up the refraction mirror. The image appeared on the wall again. Danny started to play with the refraction mirror, and observed the changes in the projected images on the wall.

Selina put her two fingers on the projector. Her finger shadow appeared on the wall. Selina said: "Rabbit, rabbit." Children joined in, making finger shadows and started to make up stories of the finger play. Some children added geometrical shapes too.

After a while, Selina went to get some transparent sheets and colour pens. She 
drew a fish on the sheet and put it on the projector. A fish image appeared on the wall. Children got excited again. They put some shapes near the fish and said: "Water drops!" Some children sat down and started to draw their own pictures on the transparent sheets and put them on the projector afterwards.

Selina reflected on this unexpected but "pedagogically meaningful and comprehensible" (van Manen, 1991, p. 45) learning moment, and stated:

"It feels so good to be able to observe what children do, analyse their needs, provide materials for them to explore, and guide them as a playmate. I feel proud." (Written comments on the observation notes, March 18, 2009)

Following and supporting children's emergent interests led Selina to realise children's central position in teaching and learning. It made the children foremost philosophy explicit in practice. It positioned Selina in an equal relationship with children as they were "mutually complementary". The child-led learning, equal and complementary teacher-child relationship echoed the recent Chinese ECE reform ideas of respecting children, active learning, and play-based teaching and learning (Yan Liu \& Feng, 2005). But they were quite different to young Selina's own experience of being forgotten and neglected at kindergarten.

While Selina was motivated to facilitate child-initiated learning, she also identified a number of difficulties:

- It was "very hard to take account of everyone" because "it takes time to follow up on each child", and 27 children in the class seemed too many.

- When there was a need to "wait" when children "lost interest" in dinosaurs, the kindergarten management still required teachers "to fill in the project box on the daily planning form".

- Teachers usually "filled it [daily planning form] up with teachers' pre-planned activities" that might not allow time for children to display their interests 
through play, and for Selina to "find their interests" emerging in play.

- Selina experienced a dilemma between the "two projects per term", the fixed timeframe for exploring each project, and the uncertainty of how long the child-interest-orientated projects might take.

- The statement "children do not have much time to play" reflected a major concern for Selina, and she wished to teach at a kindergarten where children would play most of the time, and teachers would facilitate children's learning through play (personal conversation).

- Assisting the director for curriculum management reduced Selina's contact with children significantly: for 9 of the 16 days of observation, Selina was either in meetings or doing curriculum work for 1 to 3 hours outside the classroom (an intern was in the class working alongside Cherry and the English teacher to cover for Selina). This may be why Playing with the overhead projector was the only scenario I observed where Selina supported children's emergent interests in free play.

Structural matters such as class size, centralised curriculum and planning process, time demands, and Selina's multiple roles and responsibilities seemed constraints on effective implementation of the project approach and following children's interests. Similar findings are reported by some Chinese primary and secondary school teachers when they were required to implement the studentcentred and inquiry-based teaching and learning (D. Y. Dai, Gerbino, \& Daley, 2011; D. Wang, 2011).

\section{Need "structured lessons" or not?}

Selina questioned the necessity for "structured lessons", an important aspect of Private Kindergarten's dual-curriculum. During data collection, Selina taught structured lessons with half of the class to introduce maths concepts, Chinese 
poetries and stories. Her question of "how to conduct structured lessons that matches with our philosophy" may reflect some tensions relating to:

- the modes of teaching: whether it should be group-orientated and structured or "follow individual children's development" through projects and learning centre activities

- the relationship between individual children and the collective group

- the position of creativity in child development.

Selina valued "individuality, inquisitive minds, and intellectual independence" (D. Y. Dai et al., 2011, p. 154) rather than formal structured group teaching and learning. This is not surprising. Acquiring knowledge and skills through drilling, lecturing and memorising were norms when Selina was a student. She recalled she was "afraid of" it and reported it had no long-term productivity as she "forgot everything afterwards". Selina's "scared" feeling of knowledge acquisition-focused learning even influenced her initial career choice. In short, the requirement to teach structured lessons at Private Kindergarten, Selina's personal philosophy valuing individual children's learning interests, and her negative experiences of structured learning may be some factors causing tensions in her teaching.

The parents' voice seems another factor influencing Selina's teaching. The critical incident of a grandfather challenging her illustrated different opinions of teaching and learning. It highlights a big question in education: What counts as quality teaching, and meaningful learning? Selina and the grandfather had different answers to the question that reflected their different conceptions of teaching and learning, and their different priorities for children's development (Stimpfl, Zheng, \& Meredith, 1997): 
- accumulating knowledge such as "learning Chinese characters" or developing higher order thinking and social skills such as "problem solving "and "relationship"

- short-term outcomes such as "learn 500 characters" or an emphasis on lifelong learning

- structured learning when "teachers taught" or emergent active learning when "children were interested" and teachers could "teach them naturally".

Selina and the grandfather firmly believed their own ideas, which represented the modern and traditional beliefs of teaching and learning respectively. Private Kindergarten's management was aware that some parents might have similar concerns to the grandfather's. Therefore, structured lessons were scheduled every day, but promoting active learning to the parents was a priority too. Learning stories was the medium the management asked teachers to use when communicating children's active learning process with parents, as it is a way of "foregrounding [children's] achievement" (Carr, 2001, p. 12) and can make each child's actual development and learning process visible. The visible learning process and its positive outcomes may address parents' and some teachers' concern over whether they can "entrust students to 'own' their own learning", and whether children have enough "knowledge and ability to handle the learning tasks without explicit teaching" (D. Y. Dai et al., 2011, p. 154).

\section{The ideal and the reality: "are children really the foremost?"}

Selina asked an important question for many ECE professionals: "are children really treated as the foremost" in our practice? She took a philosophical approach when seeking her own answers to the question. She aligned her own teaching, 
Private Kindergarten's curriculum, and management with the ideal children foremost philosophy and attempted to confront the particular teaching and learning reality she was part of. Selina pointed out:

- There was an imbalance in Private Kindergarten's dual-curriculum thus certain areas of child development had not been "paid enough attention".

- There was a time tension, which meant she often had to choose between spending time and energy on "how to observe children better, follow up, provide learning materials" or completing tasks assigned by the kindergarten management.

- She felt her negative feelings might affect the equal, respecting, and quality teacher-child interactions that the children foremost philosophy promoted.

- A kindergarten leadership with "clear ideas" and "a perfect system" were important for making the ideal children foremost philosophy a reality.

Through a process of critical thinking, Selina became more conscious of what she desired in teaching: to "pay attention to children", to value children's "social development, learning dispositions, integration capability", and to commit to friendlike and respectful teacher-children relationships. These narratives indicate that Selina's personal vision of kindergarten teaching was to teach towards freedom, democratic and humanistic values, and to prioritise children in teaching (Allender \& Allender, 2008; Ayers, 2004).

\section{Professional Learning}

\section{"Comprehend from the practice"}

Selina's professional learning at Private Kindergarten seemed an active, reflective, collaborative, and contextualised learning journey. Selina shared how she 
moved from "knew nothing" to learning to "solve practical problems" by taking ideas from the literature and incorporating them into her own teaching practice, which many other Chinese EC teachers have found difficult to do (J. Zhu \& Zhang, 2008).

Selina was able to notice and recognise unexpected situations such as Playing with the overhead projector and the possible learning opportunities during The dinosaur project through "sensitive observing and listening" (van Manen, 1991, p. 83). According to van Manen, being able to respond and participate in unexpected situations involves a complex thinking process that can be learnt through on-going interpretive thinking and searching for the meanings of actions, which Selina learnt through planning for projects and writing up learning stories. The three-phase project study plan recorded why, how, and what happened during children's investigation of certain topics. Writing learning stories allowed Selina to practise active listening and observation, and to think about how children learn and why the particular learning was worth recording. By practising these teaching approaches that valued children's involvement and inquiry (Katz \& Chard, 2000), Selina developed a set of repertoires that was different to the teacher-directed passive rote learning; for instance, to teach by activating her inquiring mind, and to focus on the children's interests and their interaction with the environment.

Projects and learning stories thus became pedagogical tools that helped Selina realise children's central position in her teaching. She gained pedagogical thoughtfulness from her "direct experience" (Ethridge \& Branscomb, 2009, p. 403) of observing, listening, and interacting with children. Through on-going reflection, Selina developed "a philosophical disposition" (Greene, 1973) that might enable her 
"to continue probing, learning, seeking connections and meanings" (p. 108) of teaching and learning.

\section{Positive influences of the former director}

Instead of talking about the current director's influence on her teaching and learning, Selina referred to the former director several times when sharing her experience with me. Selina shared the following examples:

- When Selina was a newcomer to Private Kindergarten and "knew nothing", the former director provided guidance. She did not focus on teaching Selina "what to do in the class". Rather, she led Selina to "think how to help children develop".

- When Selina experienced the crisis in her career that led her to resign, the former director cared for her, talked her through the incident, and convinced to stay in teaching.

- The former director sought Selina's opinion of Private Kindergarten's current curriculum and practices, and Selina openly shared with her.

Selina seemed to have a closer relationship with the former director than the current one. This may have been because the current director was newly promoted from being a classroom teacher and was a similar age to Selina. In contrast, the former director was part of the group who set up Private Kindergarten and had earned a lot of respect from teachers and parents. Moreover, the former director had acted as Selina's mentor, while the current director expected Selina to be a support person to assist her with curriculum management, kindergarten documentation, and training. The former director was able to "awaken a truth" (Palmer, 1998, p. 21) within Selina that was to focus on children and also encouraged the teachers to reflect on their practices. In this sense, the former 
director encouraged and supported a community that focused on understanding children, and promoted collaborative reflection rooted in solving practical problems and dilemmas. At the same time, the former director was caring, especially when Selina experienced crisis in her career. Under her leadership, there was a sense of trust and respect. These features are found to be important aspects in schools for "creating greater motivation, increased trust and risk taking, and building a sense of community and efficacy among its members" (Wahlstrom \& Louis, 2008, p. 467).

\section{Professional self and personal self}

\section{The most difficult time as a teacher: "when children's safety is at risk"}

An incident a few years earlier, when an "out of control" child broke the bone in another child's hand, almost led Selina to quit teaching. This critical incident was "totally unanticipated, unrehearsed, and uncontrolled" (Sikes et al., 1985, p. 230) but it seemed to have had a long-term affect, since Selina was still teary when sharing this story. Selina's strong reaction to the incident may reflect the high priority of keeping children safe in Chinese kindergartens as they are mostly a family's only child. By experiencing this incident, Selina became clearer that she had "no way to deal with" children who could be "very very naughty" and who might be potential threats to other children's safety. She could not "make fun of" the issue of children's safety, and felt dealing with naughty children and keeping children safe were "too much trouble" for her. She came to the conclusion that it could be "the scariest thing" for a kindergarten teacher if "children's safety is in risk".

There is a sense of self-doubt, pressure, exhaustion and fear revealed in Selina's narrative of the incident, which was quite different to the motivated, proud 
and confident image of Selina emerging in the earlier analysis. As informed by Palmer's (1998) discussion about fear and its influence on teachers, the negative emotions Selina experienced throughout the incident impacted on her capacity to connect with "naughty" children and her job. Only with the former director's support was she able to reconnect herself with children and the job. This supports Xing and Chen's (2009) finding that a director's trust, support and care influence Chinese EC teachers' decisions on whether or not to leave a job.

\section{Positive links}

Selina's narratives illustrated a dynamic relationship, both positive and negative, between her professional self and personal self. The positive links included:

- learning performing art at training college, which changed Selina's personality from "never be brave enough to perform anything on the stage" to "be more open"

- learning Private Kindergarten's "better education philosophies", which was helpful for Selina's parenting.

In this sense, Selina's professional growth was not only about becoming a better teacher, but also about becoming a "complex, multi-faceted" (Shapiro, 2010, p. 616) person.

\section{Negative links}

Negative links existed between Selina's professional self and personal self. Selina admired one of her former colleagues who was both "very professional" and looked after her family very well. She wanted to work out the relationship between her professional and personal self intellectually, socially, and emotionally like this 
colleague, which Day (2004) sees as being "at the core of being an effective teacher" (p. 54). This can be a challenging task as Confucianism encourages and honours selflessness (Lau, 1996). Therefore, Selina's personal needs are possibly subordinated to the professional needs required by society since "[t]here are rules, regulations, and priorities for every relationship leaving little room to manoeuver in one's mind" (ibid., pp. 361-362). These cultural ideas may have influenced the director's decision to promote "the spirit of devotion" at Private Kindergarten (interview, March 10, 2010). However, on top of her professional roles as a class teacher and team leader, Selina was also a mother of two young boys and a daughter of her hospitalised father who had a car accident during data collection. Not being able to cope with multiple roles placed Selina in "a chaotic situation". Consequently, she refused to attend an unplanned meeting after school and did not want to lead the math workshop when the director asked her to (observation, May 24, 2010). Selina prioritised her family over her career in these incidents.

According to the director, the reason for Selina's resignation in 2010 was that she shifted house to another district. This move did occur; however, Selina's narratives convey other reasons. Through our interviews and my observations, I understood how much the connection with children in the class meant to Selina, and how much effort she put into all the roles she was assigned. Sadly, her additional role as a supporter to the director had reduced her contact with children, although the management might consider it a promotion. Selina was also quite upset to receive an official warning issued by the management for arriving 1 or 2 minutes late on three mornings within one term. She felt her effort and days of working late were not recognised. These two critical incidents, Selina's additional 
management role and receiving a late arrival warning, may be the "secret stories" (Clandinin et al., 2006) behind her resignation, which revealed the tension between technical and bureaucratic control (Apple, 1995) and effective leadership in kindergarten management. Selina's stories thus suggest understanding teachers' intellectual and emotional needs is as important as understanding children's needs for kindergarten management, since "Teachers Matter" (Day, Sammons, Stobart, Kington, \& Gu, 2007).

\section{Cherry: "I learn from children"}

Cherry experienced several relocations because of changes in family circumstances. Her decisions on whether to teach as an English teacher after graduating from the university or as a kindergarten teacher after moving to Shanghai were influenced by several components of her personal environment: the expectation of her role as a sailor's wife for the family, her positive impression of kindergarten teaching, and her assessment of the possible changes kindergarten teaching might bring to her personality. Cherry's journey to becoming a kindergarten teacher was also influenced by the organizational environment: a shortage of qualified kindergarten teachers led the Chinese government to allow everyone holding a degree to enter kindergarten teaching as long as they passed the required examinations for obtaining an ECE certificate and registration (Yi Chen \& Wang, 2010). Like Cherry, many Chinese teachers started to teach in kindergarten classrooms with cross-disciplinary professional knowledge and short-term pre- 
service training. In Cherry's case it was six months. Private Kindergarten thus was not only a place where Cherry taught, but also a place she learned to teach.

My analysis of Cherry's poetic stories is structured around:

- How Cherry experienced the reality of teaching, which included Cherry's experiences of working with child-centred and play-based educational approaches, of teaching structured lessons, and of her relationship with children.

- How Cherry learned from experienced teachers, children and people around her.

- How Cherry felt about the relationships between her professional self and the personal self, family and career.

Cherry's stories and my analysis may provide some insights into the possible enabling and constraining factors influencing teachers' development of a childorientated view of teaching and learning in mind and in practice. It also provides insights into how a teaching career may shape teachers' personal self and life, and vice versa.

\section{The reality of teaching}

\section{Project approach and learning centres}

Cherry regarded project approach as "very good, very new and unique" since "in some areas, it follows children's interest, solves problems through exploration". Cherry understood a project as an active learning process that was different to passive learning when "teachers organise all the activities". Like Selina, for Cherry, being able to follow and support children's learning interests, and witness children's success and their development became a motivating force "to support more 
explorations". This suggests that the project approach created a reciprocal bond between Cherry and the children. Children's interests, their active involvement, achievements, and positive experiences with projects influenced Cherry's feelings of self-efficacy as a teacher (Day, 2004; Hargreaves et al., 2001).

When guiding children's projects, Cherry followed Private Kindergarten's three-phase planning and documentation process by working alongside Selina. The learning centres teachers set up in the classroom were where children's active exploration of a project would take place after a project was decided, children's questions about a project were gathered, and relevant materials were provided (mainly brought by children from home: water-play toys, togs, fire-engine toys and books etc.). Cherry intended to provide children with a learning process that came from children's interest, and engaged children's inquiring minds through participation and problem solving as Katz and Chard (2000) suggested. Cherry often checked to make sure children had done the relevant science experiments teachers provided and to see if children found answers to their questions. She also expected children to represent their questions or learning by "symbolising" (in her words); for instance, children drew pictures of their questions about fire engines. In other words, Cherry also intended to have "children [engaged] in the activities that teachers arranged" (Rao \& Li, 2008, p. 108) when facilitating children's exploration of particular projects.

Cherry experienced some practical dilemmas when supporting children's exploration of projects at different learning centres. Firstly, in Cherry's mind, the project approach could follow children's interests "in some areas" and the hands-on exploration process might lead teachers to "focus on the science centre", but some 
girls would "never go there" (the science centre). However, projects are not all science-focused. For example, the dinosaur project focused on art-craft and maths concepts. Therefore, Cherry experienced tension when trying to "balance and weigh children's development at each learning centres". This may reflect a question of what is more important in projects in terms of fostering holistic development: children's balanced and rotated participation in all activities provided as Cherry wished or children's active engagement in the activities selected by themselves?

Secondly, Danny's conversation with Cherry (below) suggests that not all children had questions or wanted to participate in the project approach as teachers expected:

\section{Observation Notes, March 18, 2010}

Danny did not want to draw his question about fire engine during the first phase of the project Fire Engine. Cherry asked: "Do you have any questions?" Danny shook his head. Cherry asked again: "Then what are you going to do at the fire station?" Danny said: "Just visit." Cherry kept asking: "Do you have any questions?" Danny was silent. Cherry led Danny to read questions on the Question List that recorded other children's during a class discussion in the morning. Danny still did not draw a picture.

Cherry did not force Danny to draw a picture; however, she shared with me that she was not prepared for this kind of conversation, and did not know what to do when encountering similar situations. When interacting with Danny, Cherry may have been swinging between the choices of being the expert to address Danny's deficiencies and make him learn through teacher-directed participation (Katz \& Chard, 2000), or respecting Danny as somebody who knew what he wanted and to "capitalize from his proficiency" (p. 13) based on active listening and observing. 
Thirdly, there was a question of what kind of play was desirable in "learning through play". Did it mean to play with rules, pre-set questions, and problems in mind, for example when Cherry expected children to talk about "sinking and floating" when playing with water; or was it children's spontaneous play when interacting with available resources which might lead to problem solving and further inquiries according to their immediate interests? Cherry and the children had different agendas during water-play, which raises a question of whose agenda should come first. Cherry seemed to value play with rules and pre-set questions/problems based on children's interests expressed several days earlier, despite the possibility children's questions and curiosity about certain topics might have changed over time.

Cherry's dilemmas reflect implicit cultural logic (Tobin et al., 2009) influencing her actual practices that she might not be aware of:

- Holistic development may be interpreted as balanced participation in all provided activities.

- Educative play should be instrumental, work-like and sober which is different to "real play" (Bai, 2005a), therefore, "learning through play" may be equivalent to learning through play with rules and the playful activities/games the teacher arranges.

- In-depth hands-on investigation and inquiry in a project is often associated with scientific experiments (D. Y. Dai et al., 2011).

A pedagogical tension between whether to value individual children's needs or teachers' intentional guidance during project studies emerged from Cherry's narratives. Teacher's intentional guidance seemed to be highlighted at Private Kindergarten through very detailed planning and documentation processes for each 
project, and the specific requirements for the quantity, length, and content of projects. Katz and Chard (2000) view children's in-depth investigation of projects under teachers' intentional guidance as complementary to children's spontaneous and informal learning. However, Katz and Chard made their claim based on the American preschool context where children's spontaneous play dominated the curriculum and thus project work could lend "coherence and continuity to their work together" (p. 8). Nevertheless, at Private Kindergarten project work was used as a way of changing the dominant teacher-directed teaching style by attending to children's interests. Cherry's experience of projects suggests that if teachers' intentions and control are highlighted, then the spontaneity and children's active participation may be weakened and thus the value of making changes to teacherdirected teaching and learning may be lost.

\section{Learning centres and spontaneous play}

At Private Kindergarten, the learning centres not only supported the projects, but also children's learning through spontaneous play. Private Kindergarten scheduled at least two 45-minute slots for learning centre activities every day that would allow children free choice play. Therefore, children should have had a good amount of time to learn through spontaneous play. But I did not observe any instances like Playing with the overhead projector in Cherry's teaching. Maybe the story of Jeremy exploring the stapler can provide some insights into why Cherry found it difficult to create and sustain such moments. 


\section{Jeremy exploring the stapler (observation notes, March 9, 2010)}

Cherry added some flower making material to the art-craft learning centre yesterday. She taught children who showed interest how to make a particular kind of flower individually.

This morning, some children were still interested in making the flower during learning centre playtime. Cherry was sitting with them and showing children how to make it. Jeremy was making the flower too, but found difficult to master it. Soon it was tidy up time, but Jeremy had not finished his flower. He was quite upset, cried, walked away and did not want to line up for outdoor-play that he was require to go.

Later, during the learning centre activity time between 10:00-11:00am, Cherry tried to help Jeremy finish his flower. However, Jeremy had changed his interest to the stapler that was provided as a tool on the art table. But it had run out of staples. Cherry put some staples in and Jeremy tried to staple a piece of paper. By then, Cherry was surrounded by other children who needed her help of making flower. Jeremy tried to use his hands to staple the paper while sitting on the chair, squatting on the floor, and even putting the stapler on chair and using his bum to make it work by sitting on the stapler. But he failed all attempts. He put the stapler and the paper on the floor, and stamped on the stapler. He failed too. Then he tried his bum again. Cherry was occupied with other children at the same table, but did not notice Jeremy's attempts.

Cherry had planned the flower-making activities beforehand and realised that the particular method she introduced was a bit difficult for the children. But some children's responses indicated their interests in the activity. Cherry thus provided her expertise to meet these children's needs through systematic instructions (Katz \& Chard, 2000). Nevertheless, she had to demonstrate and repeat the instructions step by step many times to different children. She was fully occupied by the flower-making process. Her sole goal at that time was to help 
children successfully make the flowers, and this made it difficult for her to actively observe and listen both to children who were making flowers and to Jeremy. In this sense, the flower-making activity became a skill acquisition process for producing certain product, rather than a process of letting children explore different materials and apply their skills in creating, designing and making their flowers by following their own ideas. Two different types of learning occurred at that moment: spontaneous and active child-initiated exploration by Jeremy, and structured learning by children who were learning how to make a particular kind of flower. Consequently, teacher-directed learning was at the centre of Cherry's interaction with children, and child-initiated learning was not noticed.

The preceding analysis of the relationship between learning centre activities, projects and children's spontaneous play may suggest that Cherry tended to take a structured, instructional and teacher-directed approach when interacting with children. This approach is rooted in the traditional Chinese culture of learning $(\mathrm{Hu}$, 2002). It may imply that Cherry emphasised knowledge, rules and control, which are teaching behaviours often seen in Chinese kindergarten teachers (Xiaoyi Gao \& Pang, 2006b).

\section{Structured teaching}

Structured teaching in Cherry's class included small group English lessons, Chinese lessons and maths lessons (when the class split into two groups), and the whole class music lesson (approximately 30 minutes long) that Cherry taught by herself. Cherry struggled to cope with the multitasking nature of the music lesson with "just one teacher there". The prescriptive "collective plans" for structured 
teaching and the anticipated "good" lessons pre-planned by Cherry seemed not to match with the actual class' situation and the uncertain teaching and learning processes occurring in the class. Therefore, Cherry's confusion and frustration may have been caused by the mismatch of the prescriptive and pre-set plans done in "exclusively rational ways" (Hargreaves et al., 2001, p. 47) and the uncertain teaching and learning process in reality. This kind of planning process may disconnect Cherry from children's interests and their active position in teaching and learning, and thus distance her actual teaching from the expected result. The structured big group music lessons were teacher-directed and highly reliant on children's cooperation gained through discipline, routine and order as Y. L. Li (2006) has argued in the Hong Kong ECE context. In short, teacher-child ratio, the uncertainty of implementing prescriptive and pre-set plans, and the teacherdirected group-orientated structured teaching may be reasons for the challenges Cherry faced when teaching music lessons.

\section{Children}

Children influenced Cherry's teaching, learning and the construction of her professional identity as she stated "I find children's success is also mine", "I learn from children", and "if they are afraid of me, do not want to talk to me much [sic] I feel distanced with children and failing". These narratives suggest a dynamic relationship between Cherry and children since sometimes children could be a source of motivation, learning, and positive emotion for Cherry, but at other times they could bring forth confusion, challenge and "mixed feelings" in her teaching. Cherry's position in the children's life also seemed dynamic as she viewed herself as 
"observer", "leader", "supporter", "playmate", "dialogist", "communicator", but preferred to be children's "friend" (interview, March 17, 2010). Cherry's dynamic relationship with children and her multiple roles seem to align with the democratic teacher-child relationship (Yan Liu \& Feng, 2005), the required change of teachers' role from expert to multiple roles, and the realisation of children's subjectivity (S. Li, 2006). Cherry's not wanting to "control them" further suggests the teacher-child relationship Cherry intended to build is totally different to "the traditional idea of obeying the teacher without arguing" (Rao \& Li, 2008, p. 114).

Cherry's mixed feelings towards children and some dilemmas while working with them were illustrated in her narratives about Jeremy. The first dilemma was about how to develop teacher-child relationships that would honour and support children's "own choices" and "interests" in the collective learning classroom regulated by rules. Working with this dilemma may require Cherry to choose between understanding the child self as individual from Western psychological perspectives or in relation to others within the social context according to traditional Confucian thinking (Lau, 1996). Secondly, Cherry was "confused" about how to take a less authoritative role such as a negotiator when she and children were "at the situation of bargaining", and of the appropriate distance with children for not only building "a friendly relationship" but also guiding them "to follow the rules". This may imply that Cherry experienced difficulty in having equal and dialogic interactions with some children who challenged her authority, which is also experienced by other Chinese EC teachers (J. Liu \& Elicker, 2005; Yi \& Pang, 2003). 


\section{The ideal and the real}

The ideal teaching and learning in Cherry's mind was guided by children foremost philosophy, and Cherry's interpretation of it were:

- Children should "learn through play".

- Teachers should focus on "how children learn".

- Teachers should "have more interaction with children after observing their development at the learning centres".

- Kindergarten should be a harmonious place where the management could "think from teachers' perspective" and approve the things teachers do.

These narratives indicate Cherry valued a relational and humanistic learning environment (Allender \& Allender, 2008). However, Cherry pointed out "the real and the ideal are too far apart" and Private Kindergarten's curriculum had "some disparity to its philosophy". Cherry identified some factors constraining the practices of the desired "learn through play" philosophy:

- "so many children in the class"

- "quite a lot structured learning"

- "teachers' ability"

- "parents' demands" of seeing "the end results" of children's learning.

Cherry's narratives echoed Selina's viewpoints and they experienced similar pedagogical tensions caused by teacher-child ratio, time, curriculum requirements, and different agendas of early childhood learning. Unlike Selina, Cherry thought teachers' ability to implement the curriculum was also part of the constraints.

Strong negative feelings as a result of coping with "pressures from the top" and "too many written tasks" can be identified in Cherry's narratives. The learning 
story debate around the topics of how to write up learning stories and quality versus quantity vividly illustrated the different voices and positions of the management and Cherry when disagreements occurred. At the centre of the debate around the learning story format were the questions of:

- What counted as children's holistic development?

- Who or what should determine the content of the learning story and in what ways - teacher's observation, children' learning, the management's requirement, the experts' anticipation, or the parents' expectation?

Private Kindergarten was still in the process of deciding how to make the learning story approach work in practice, and experiencing the power struggle between multiple stakeholders who might have conflicting priorities, values, and conceptions of teaching and learning. However, during the on-going learning, adjusting, and decision-making process, the people "from the top" had the final say based on their ideas, not on the teachers' ideas: and not building new ideas in "a shared endeavor" (Rogoff \& Toma, 1997, p. 471) among all people involved. Consequently, the teachers had to cope with the changing ideas of the people "from the top", and to pursue quantity rather than quality in actual practice. A vicious circle was apparent as a result of the power struggle between: the management's decision to "ensure the quantity first" because the teachers' work "was not quality enough", and the teachers' logic that there were "too many written tasks" so quality could not be guaranteed. Moreover, there was a sense of passiveness in Cherry's narrative since she only saw herself as someone who could help parents change their views of teaching and learning, but had no power to make her ideal kindergarten a reality since her voice seemed not to be heard. However, Cherry had 
the power to withdraw from Private Kindergarten "if the job getting [sic] more tiring" in the future. In short, the management's position as at the "top" and Cherry's passive position may reflect a hierarchical relationship and a big power distance between the management and Cherry, which contrasted with the "happy" social relations and an integrated kindergarten environment Cherry desired.

\section{Professional learning}

\section{"Followed a good teacher" as a beginning teacher}

As a new teacher and newcomer, Cherry "followed a good teacher" (her teaching partner) who was properly trained, experienced and "willing to help others". The follower position allowed Cherry to teach at a peripheral position in the classroom. This gave Cherry time and space to learn by "watching" how her teaching partner taught. However, Cherry "felt quite embarrassed" about her passive and peripheral position in the class, so she took an active approach by seeking opportunities to increase her participation, as well as seeking guidance and approval from her teaching partner. From the socio-cultural perspective, Cherry's professional learning as a beginning teacher could be understood as a process of "face-to-face interaction" and "side-by-side joint participation" (Rogoff, 1995, p. 142) with her teaching partner in everyday contexts. Cherry received sustained support and was integrated into the professional culture of Private Kindergarten, which were also found to be important aspects of new teachers' experiences in American schools (Kardos \& Johnson, 2007). 


\section{"Learning from children" and others}

Private Kindergarten was not just the place where Cherry taught but also "an educative setting" (Shulman, 1988/2004, p. 331) where she was learning by interacting with the people around her, including children, parents, other teachers, experts, and her own child. The foci of Cherry's professional learning were:

- to "know children's mind"

- to learn how to communicate with parents and to learn "good methods from the parents"

- to understand the "curriculum goals"

- to improve the quality of her interaction with children.

This analysis indicates Cherry's professional learning was orientated to children, the conceptions of teaching and learning, and communication with parents, instead of teaching techniques and skills. My observation of Cherry's teaching and learning also suggests Cherry's professional learning was mostly informal and situated through practical problem-solving in everyday contexts and by collaborating with Selina and other teachers. In short, Cherry's professional learning may be situated, active, and reflective in a collaborative context, which are key aspects of effective learning (Shulman, 1996/2004).

\section{Professional self and personal self}

\section{A teacher at kindergarten and a mother at home}

Cherry found some parallels between teaching and parenting, for instance, the importance of reflection when experiencing difficulty in communicating with her son and interacting with children in the classroom. Cherry also recalled a happy 
moment when she shared with the children an ancient Chinese poem she and her son learnt at home, which was received positively by the children (interview, March 17, 2010). It seemed Cherry's teacher role and mother role were interrelated and complementary.

\section{Interrelated professional and personal self}

When evaluating herself as a teacher, Cherry was "not satisfied". She felt "sorry" for children due to her "hoarse voice". In fact, she was suffering from a severe and on-going throat infection. Cherry tried to drink more water during the day but was fully occupied with children and hardly had time to do so. This may be a sign of an intensified working reality (Apple, 1986) that could affect her recovery. Cherry also identified her communication skill as requiring improvement due to her "quiet and passive" personality. In these examples, the professional self and the personal self were interrelated and influenced each other in terms of Cherry's health, personality, teaching practice, and professional ability.

\section{Family and career}

Cherry would think about quitting teaching when she experienced pressures "from the top" and was required to complete many written tasks (interview, March 17, 2010). These experiences were quite different to Cherry's initial understanding of kindergarten teaching as "fun" and "singing and dancing", which led her to reexamine her career choice. Cherry identified some material motives (Huberman et al., 1993) that kept her at Private Kindergarten, for instance the need to "make a living", the closeness to her home, and her familiarity with Private Kindergarten's ways of teaching and learning (interview, March 17, 2010). Like Selina, Cherry 
prioritised her family over her career. However, despite the challenges and dilemmas experienced when teaching and learning at Private Kindergarten, Cherry still expressed that she was "contented" and "satisfied" with her life. This may be due to the support she received from her extended family and the stable career stage (Lynn, 2002) she had reached.

\section{Summary}

Selina and Cherry's stories revealed that Private Kindergarten ran a dualcurriculum, project approach and structured lessons, to accommodate both childcentred and structured teaching and learning. Modern and traditional educational ideas seemed to have equal status at Private Kindergarten. Selina and Cherry developed child-oriented and observation-based beliefs and repertoires of practice by using child-centred pedagogical tools. The dual-curriculum thus facilitated the extension of Selina and Cherry's personal knowledge base, which "provide[d] the grounds for [their] choices and actions" (Shulman, 1987/2004, p. 243) in teaching.

Three common threads emerged in Selina and Cherry's stories. Firstly, while Selina and Cherry shared the excitement of practising the project approach, following children's interest, and learning through play, they also experienced difficulties in implementing this because of some structural constraints. Selina and Cherry reflected on the necessity and challenge of teaching structured lessons, and were concerned that children did not have enough time to play. Their concerns evoked the challenge of practising the dual teaching and learning approach 
informed by traditional Chinese and Western educational ideas. The contradictory characteristics of a child-centred project approach and teacher-directed structured lessons, and the teachers' ability and capability to practise the dual-curriculum created confusion, frustration, and disappointment for teachers.

Secondly, Selina and Cherry indicated that their professional learning started at Private Kindergarten, where reflection, collaboration and a shared philosophy were promoted. Teacher's agency and reflection, kindergarten leadership, being able to practice in a peripheral position as a beginning teacher, and a collaborative learning community seemed enabling factors in the development of their childoriented personal beliefs and conceptions of teaching and learning.

Thirdly, Selina and Cherry talked about how they embraced the professional self and the personal self, and the challenges of coping with their responsibilities as a kindergarten teacher and a family member. They also conveyed their frustration at being directed by impersonal bureaucratic rules. Their experiences suggest that the director may need to look into the kindergarten structure and management styles at all levels, and to analyse the potential stress that the teachers-in-context may have (Pattie, 2009). It may also be important to take a collaborative approach and to involve the teachers in curriculum decision-making processes within a shared sociocultural endeavour (Rogoff, 1994). 


\title{
Chapter 9: Summer and Cecilia from
}

\author{
International Kindergarten
}

\section{International Kindergarten Context}

Summer and Cecilia were two Chinese teachers from International Kindergarten in Beijing. Unlike the other four participants, Summer and Cecilia were not teaching partners. Each was partnered with a Western co-teacher. Summer was teaching in a 2-year-old class with 12 children on the roll during the first round of data collection in December 2009 and 15 on the roll for the second round in April 2010, while Cecilia worked with 3 and 4-year-old children, with 19 children on the roll in December 2009 and 21 in April 2010. Summer and Cecilia were both in their third year of teaching at International Kindergarten, and both had about 10 years previous work experience before joining International Kindergarten, and they were both in their early thirties.

International Kindergarten was the ECE service of an English-Chinese bilingual international school. The school served 2 to 18 years-old students from the expatriate community in Beijing and was only permitted to accept students with foreign passports and whose parents/legal guardians were working in China. The parents/legal guardians were mostly internationals in China for business or 
diplomatic purposes. The students came from over 40 countries. Staff were recruited worldwide and they represented more than 15 nationalities. The international school followed the British education system and International Kindergarten offered Early Years Foundation Stage (EYFS) curriculum to children aged from 2 to 5 years. The kindergarten occupied the ground floor of a threestorey building with an indoor piazza and a well-equipped outdoor play area. It comprised 4 classes with approximately 70 children enrolled at International Kindergarten during data collection.

\title{
Funding
}

International Kindergarten was funded and managed by a private education organisation running chained international schools in China. School fees paid by parents were International Kindergarten's main source of income, and the tuition fees were approximately CNY $¥ 150,000 / N Z D \$ 28842$ per annum, five times more than Private Kindergarten's and eleven times more than Public Kindergarten's. "This is NOT the real world!" was how International Kindergarten's Western director (who was in charge of the daily operation of the kindergarten) described the school context. She shared:

\author{
They (children) are \\ in a privileged setting. \\ Here (at this school) \\ most people or all people \\ have got money. \\ All people \\ have got a passport. \\ They are travelled. \\ Children \\ have all got \\ more than two languages
}


probably three or four or five.

Here is a privileged situation

for this particular programme.

This is not the real world!

According to the director, International Kindergarten was privileged in terms of funds, resources, and its multicultural community. Although the physical size of each classroom and their outdoor play area were the smallest of the three kindergartens, International Kindergarten had more outdoor play equipment, art supplies, and teaching resources for different learning areas. It was the only kindergarten where teachers and children had access to a well-resourced library with English and Chinese books published worldwide. The six parents I interviewed reported that the kindergarten's English and Chinese bilingual curriculum and the learning through play approach attracted them. With qualified Western and Chinese teachers co-teaching all day in each class, children at International Kindergarten would learn English and Chinese through their interactions, mainly spontaneously, with the co-teachers.

\section{Curriculum}

According to its website, International Kindergarten provided global education to children, with a vision to help children grow up as balanced and responsible citizens of the global community. "Combine the best of Eastern and Western" was its interpretation of global education in practice. Supported by local and international resources, International Kindergarten's philosophy and objectives were to promote a child-centred, play-based, non-prescriptive, and integrated programme through teachers' developmentally appropriate practice. Teachers were required to adapt the Practice Guidance of Early Years Foundation Stage (Crown, 
2008) to the local context. "Following children's interest" was the phrase often used by the teachers to explain their teaching. The promoted goal of teaching and learning was to develop the whole child, rather than to implement the curriculum. Teaching in this sense was according to the individual needs of children.

International Kindergarten's programme handbook further stated: “[children's] active role is realised by the teacher's continuous attention to children's interest, their wonders and curiosities, their on-going experiences in their life, and their spontaneous explorations that are made possible by their classroom teachers". This required the teachers to attend to children's emergent learning and spontaneous play rather than teachers' agendas and planned activities. Thus everyday teaching and learning at International Kindergarten started from teachers' observations of children. Teachers set up classrooms every morning based on their observations of children's play during the previous day, which were recorded on their daily observation-reflection sheets. Co-teachers could decide to extend or shorten children's playtime on the spot according to their observations of children's play. The project plan was to be based on children's current interests and was a work in progress; prescribed long-term planning was discouraged. Teachers had the power to propose changes to the programme and any decisions were made collectively either between co-teachers or among the whole team during staff meetings. The assessment and reporting system was a combination of formative and summative approaches through children's individual digital portfolios documenting children's learning in all areas over the year. To align with the whole school's reporting practice, International Kindergarten also used one-page reports to summarise each child's learning and development twice a year. 
International Kindergarten promoted its child-centred philosophy in different forms to diverse audiences:

- The school's educational philosophy was framed and hung on the wall at the entrance.

- A detailed explanation of the educational philosophy for early childhood teachers was displayed in the staff room.

- Big posters promoting child-initiated and play-based learning to parents were made by the teachers and presented in the piazza (multifunction hall).

- Specific notes on how to encourage children to be independent in self-care were posted in the sleep room to guide the Ayis' (who helped with the nap time duty) interaction with children.

- Documentation of child-centred learning with photos and teachers' interpretation could be found in the wall displays and children's portfolios.

These artefacts that articulated child-centred teaching and learning could be regarded as cultural scripts, since they specified how "the people should appropriately participate in an event, the social roles they play, the objects they use, and the sequence of actions and causal relations that apply" (Cole, 2000, p. 126). These promoted scripts thus might shape Summer and Cecilia's teaching and learning at International Kindergarten.

Western educational ideas and child-led emergent teaching and learning approaches guided International Kindergarten's curriculum and practice. The Chinese traditional teacher-led, structured and group orientated teaching and learning was not promoted in everyday practices at all. However, as will become apparent in later analyses, these traditional ideas and practices as embodied cultural repertoires of practice were still implicitly influencing Summer and Cecilia's teaching. 


\section{Co-teaching}

To ensure the equal status of English and Chinese languages and cultures in the school, the international school had one Chinese and one Western co-principal responsible for the school's overall operation. During data collection, International Kindergarten had a full-time Western director as well as a Chinese classroom teacher who was given the Chinese coordinator title to assist the Western director's work. In the classroom, International Kindergarten used a co-teaching model to strengthen the bilingual programme by having one Western and one Chinese teacher work side-by-side every day. Co-teaching was believed to be not only a sharing of time and responsibility, but also a process of developing partnership. The school's Chinese co-principal shared her view of their co-teaching practice in the following poem.

\section{Equal relationship}

between

Western and Chinese co-teachers

means agree with disagreement.

It is a process.

Chinese teachers

do not have

a very high level of English.

They have never

taught in

a foreign cultural context.

They come to

teach the students

who come from

many different cultural backgrounds.

They experience

cultural shock

as much as

the Western teachers do. 


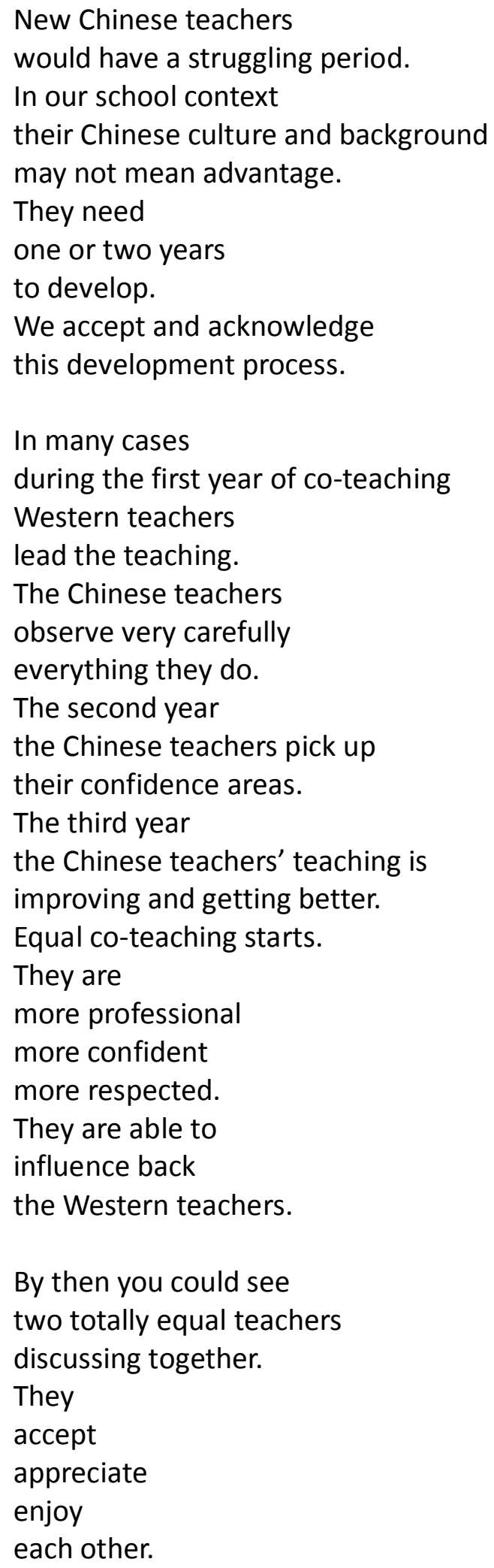

According to the Chinese co-principal, communication, understanding, and giving teachers time to develop a professional and equal relationship were 
important aspects of a successful co-teaching partnership. As Summer and Cecilia's narrative will reveal, being able to work with a Western co-teacher in the class every day was a very important aspect of their professional learning, especially when they were newcomers to the teaching community. However, teaching disagreements between Western and Chinese teachers could occur because of cultural differences and the Chinese teachers' growing understanding and confidence in their teaching, as will become apparent.

\section{Teamwork}

International Kindergarten's Western director talked about the importance of equal voices, respect and teamwork for International Kindergarten from a department leader's point of view in the following poem.

Ensuring equality of voices understanding of both cultures were important.

We came a long way to let the Chinese teachers have the confidence.

It's not to say they cannot do it. It's having the confidence to say

"I am as powerful, I am just as knowledgeable I have as much input". Western people appear to have a lot more confidence about how it should be. I think the Chinese teachers are getting a lot better at voicing concerns.

I believe in team approach.

It is my way

my style of 


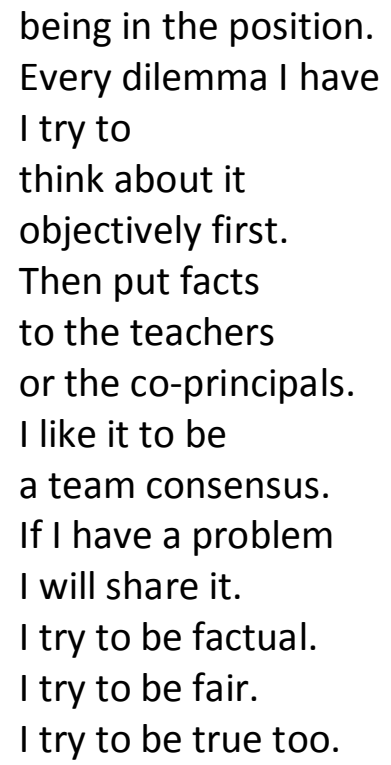

The director was trying to remove the barriers between the Chinese and Western teachers' different cultural ways of being, and building internal leadership by distributing power to the teachers, allowing multiple levels of participation, and by being open to different perspectives and voices. Ensuring the Chinese teachers' voices were heard seemed a priority for the director. This may reflect Wenger et al.'s (2002) argument that the process of building a successful community of practice "must give practitioners a chance to gain a reputation as contributors to the community's practice" (р. 40). For example, all teachers volunteered to take on extra responsibilities to serve the whole department. For instance, Summer was in charge of the cooking ingredients order for the department and Cecilia was on the school's lunch committee to monitor the children's lunch menu and the food catering service. They were also involved in contributing to staff meeting agendas, resource ordering, policy reviewing, and newsletter producing etc.

\section{Professional learning}

Before the start of each term, the kindergarten would organise an in-service 
training programme for all the teachers during teacher-only-days. During the year, the director would post information about relevant external training courses in the staff room. Teachers could apply for any of the courses that interested them and the director would decide whether to approve teachers' applications based on their professional development needs and the budget. The ECE superintendents (one Chinese and one Western), who were working with all ECE services of the entire education organisation, would visit International Kindergarten several times a year to provide professional guidance, consultation, workshops, or seminars to the teachers as requested by the director or the teachers. The Chinese ECE superintendent visited International Kindergarten for a week during the first round of data collection. She observed the classroom teaching, chatted with the teachers, attended a staff meeting and provided a seminar for the Chinese teachers after school one day. The seminar was about how to support children learning Chinese at International Kindergarten. The teachers seemed to have many questions for the superintendent; therefore, the discussion continued after the seminar and carried on to the dinner table. The Chinese teachers would also meet once a week, led by the Chinese coordinator, to share their teaching practices, questions, and ideas with each other. It seemed that International Kindergarten's professional learning was loosely organised rather than systematic like Public Kindergarten's and Private Kindergarten's. As will become apparent, Summer and Cecilia's experiences of this loosely organised but contextualised informal professional learning approach were very positive. 


\section{Summer and Cecilia's daily routine}

Summer and Cecilia both shared the overall responsibilities of care, teaching, and learning in the class with their Western co-teachers. Table 9.1 shows how the Chinese (CHN) and Western (WST) co-teachers worked together every day.

\section{Table 9.1}

The daily schedule of Summer and Cecilia's classes

\begin{tabular}{|c|c|c|}
\hline Time & Schedule & Teachers on Duty \\
\hline 7:30-7:45 & Classroom Preparation & CHN and WST co-teachers \\
\hline 7:45-10:00 & $\begin{array}{l}\text { Free choice play; Morning tea; Morning } \\
\text { circle time; Library visit (once a week) }\end{array}$ & CHN and WST co-teachers \\
\hline 10:00-11:00 & Outdoor play & $\begin{array}{l}\text { One class teacher on duty } \\
\text { Another teacher on preparation }\end{array}$ \\
\hline 11:00-11:30 & $\begin{array}{l}\text { Group learning time (music and movement } \\
\text { or story time); Walk in the nearby park } \\
\text { (once a week) }\end{array}$ & CHN and WST co-teachers \\
\hline $11: 30-12: 15$ & Lunch time; Nap time preparation & $\begin{array}{l}\text { One class teacher on duty } \\
\text { Another teacher on lunch break }\end{array}$ \\
\hline 12:15-2:00 & Nap Time & $\begin{array}{l}\text { Each teacher on duty twice a week } \\
\text { Other days on preparation }\end{array}$ \\
\hline 2:00-3:00 & $\begin{array}{l}\text { Get up; Afternoon tea; Free choice play; } \\
\text { Group games }\end{array}$ & CHN and WST co-teachers \\
\hline 3:00-3:15 & Group time; Preparation for going home & CHN and WST co-teachers \\
\hline $3: 15-3: 30$ & Children leave school; Chat with parents & CHN and WST co-teachers \\
\hline 3:30-4:30 & $\begin{array}{l}\text { ECE staff meetings (once a week) } \\
\text { Preparation }\end{array}$ & CHN and WST co-teachers \\
\hline
\end{tabular}

Every morning, all teachers arrived at the kindergarten at 7:30 a.m. and the co-teachers would discuss a brief plan for the day. One teacher would then be in charge of setting up the classroom for the free-choice play in the morning, and the other would greet the children and parents. As the daily schedule shows, the co- 
teachers worked together in the classroom most of the time, and took turns supervising outdoor play, lunch-time, and afternoon nap-time. Planning was done after children went home around 3:15 p.m. and before 4:30 p.m. Co-teachers would discuss their observations of children and record them on daily observationreflection sheets (each child had their own box on every sheet for the teachers to record their observations), as well as the planning for the next day or so. Children's digital portfolios were saved on the shared folder on the computer, and the coteachers would work on the same Power-Point file for each child to document their learning. Co-teachers would also discuss and complete the one-page report together twice a year. In short, the Western and Chinese co-teachers at International Kindergarten were working closely together in everyday practices.

\section{Summer's Stories as Poems}

\section{My kindergarten}

My kindergarten teachers

all liked me.

At that time

there were

lots of opportunities

for me to perform.

I could perform well.

The teachers

really liked me.

They took me seriously.

I felt

I was the best. 


\title{
Choice of being a kindergarten teacher
}

\author{
When I finished \\ my junior secondary school \\ my mum suggested \\ I study at the training college. \\ I did not have a clear idea of \\ kindergarten teacher and teaching. \\ I felt \\ being a teacher \\ should be a good thing. \\ My mum always said that \\ teachers' words \\ were an imperial decree. \\ My mum meant \\ teachers had \\ higher status than parents.
}

\section{The training college}

\author{
What we had learnt \\ at the training college was \\ not relevant \\ not practical \\ in real kindergarten. \\ At the training college \\ the teachers \\ wanted you to \\ write up the teaching process \\ step by step \\ in great detail. \\ At kindergarten \\ the process was \\ not that important. \\ Only the bullet points of 123 \\ were needed. \\ I had to learn everything \\ at the kindergarten again.
}

\section{First day of teaching}

Real teaching

was different to

what I had expected.

I was nineteen.

Quite young 
and nervous.

I did not know

what I should do.

At the training college

I felt

I only needed to teach the lesson.

When the lesson finished

I finished my job.

But in real classroom teaching

there were many things

needed to be done.

Lessons were not

the most important things.

That's why the real thing

was different to

what I had expected.

\section{Influential teachers}

My first teaching partner

helped me a lot.

She was older.

She could

control children.

Of course

we do not control children

now.

But back then

I admired her.

She could

control children very well.

When somebody

came to observe her teaching

children would be

active or quiet

according to her needs.

\section{"I did not change much"}

I did not change much

during my first ten years

of teaching.

I walked along

a prescribed path.

Thinking back

I did not know how I taught. 
For the first three years

I knew nothing.

Just a young girl

do whatever I was told.

Gradually

I learnt more things.

I knew how to organise activities.

I knew what I should do.

After four years of teaching

I decided to

study another profession

piano tuning.

I did not

like early childhood education anymore.

I did not

want have anything to do with it.

I just wanted to

find something that I liked

that I could learn!

Towards the end of my ten years

I was very confident (in teaching).

All major activities

were led by me.

I felt

I had control

of what I was doing.

I was taken seriously

by everyone there.

But

I did not enjoy teaching.

I was just

doing what I was told.

I did not want to

be a teacher any more.

I did not like

the complex interpersonal relationship.

I did not like

the big class

(45 children in my class).

There was pressure

on teachers

to keep children safe.

I did not think 
I could do so much

with children back then.

However

I did and still do like children.

When I was with children

I felt

I was like their mum

they needed me

they trusted me

this made me feel good.

I was needed!

Therefore

I stayed (in teaching)!

\section{First impression of International Kindergarten}

Firstly

it was

children running wildly outside.

Teachers

were not afraid of them

falling down.

Children

were running

very fast.

If it was at my previous kindergarten

we would be

worried and afraid

that they would hurt themselves.

But the teachers here said

the more children ran

the less chance

they would hurt themselves.

since they had lots of practice

of running and balancing.

Secondly

it was

all the children here

looked messy

by the time of going home.

The clothes were dirty.

Faces were dirty.

Paints everywhere.

I thought about children

at my previous kindergarten 
their clothes would be

clean all week

kept very clean.

Reflecting on that

I realise

it was because

they were not busy.

They did not have chance

to try out messy play.

So they would not get dirty.

\title{
"Children choose what they want to learn"
}

\author{
Before \\ learning was like \\ learn what the teachers teach us. \\ We noted down \\ what teachers said \\ and then memorised it. \\ Now \\ it is completely different. \\ What children want to know \\ we tell them. \\ It is not like \\ you have to learn \\ what I tell you to learn. \\ I think \\ this is the biggest difference! \\ Before \\ 'take children as the centre' \\ was clearly stated \\ in the curriculum documents. \\ From my personal opinion \\ it was because \\ whoever developed the curriculum \\ had put children \\ at the centre \\ of their considerations \\ when they wrote the documents. \\ In everyday practices \\ I need to plan my teaching \\ according to the curriculum. \\ There was \\ suggested curriculum content \\ for teachers to follow.
}


The teachers chose

what activities

what content

to teach children.

Now

my understanding is

if it is something

that comes from

children's interests

children

would be more eager

to explore.

Children choose

what they want to

learn

know.

This should be

what

take children as the centre

really means.

Before

children may just learn

surface knowledge and skills.

Now

we encourage children

to be interested

to concentrate.

It is not about

learning the skills.

It is about

letting them develop

an attitude of

being curious

being positive.

I think

this is something different.

\section{"Lessons are too trivial to mention"}

Before

I understood teaching activities

as 45 minutes of lesson time.

(in the five to six years old classes). 


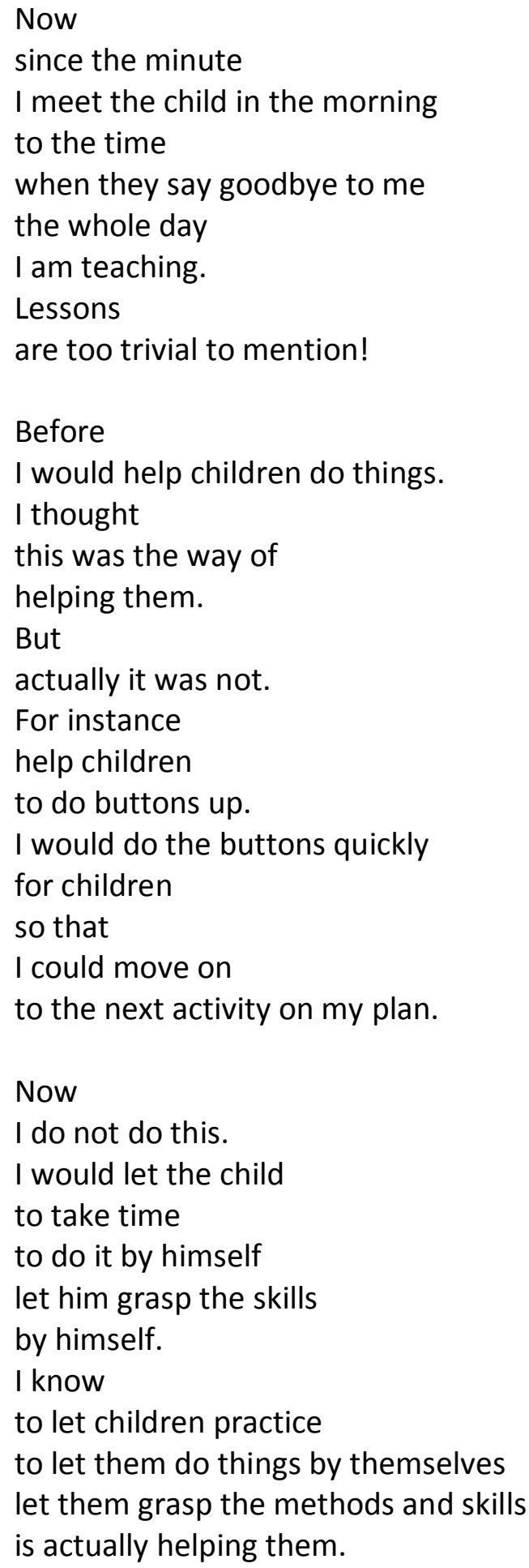

\section{"They are angels"}

There was a child

at my previous kindergarten

who I can still remember now.

He had a very difficult

settling in period 
when he first came to my class.

Every morning

he would

cry extremely loudly

refuse to come into the classroom

kick the door frame

nobody could calm him down

even the kindergarten director.

He had to be removed

from the classroom.

He was an extreme case.

I was very frustrated.

I did not know what to do.

I can remember

my thoughts towards him

were something like

'he is so difficult'

'he will not listen'

'he hits other people'

'he hides under the table'

and even the kindergarten director

blamed him for breaking our door frame.

Now

I would think about him

differently.

I would ask myself

why he would cry like that first.

Maybe I could ask his parents

if he had any group learning experiences.

Maybe that was because

he was in a

new environment

he did not know

any other children.

He came in the middle of the year.

He might

be afraid of this situation

so that he used cry

to let out his frustration.

I would think more

to find out

why he was so stressed

and had such extreme behaviour

and then to look for some ways

to solve the problem. 
Teaching here

I do not think

there are good and bad children.

Each one of them

is very cute.

All children

are great and lovely.

They are angels!

All the nice words

should be used to describe these children.

The perplexities are around ...

In our kindergarten

the whole educational philosophy and ideas

are advanced.

But

it was quite difficult

for the teachers like me

who were not trained

this way.

Our view and understanding

have slowly changed.

But

we still need to

learn it in depth.

I need to

learn more theories.

How to support children's learning?

There was a time

when we were all asked to use

project approach.

We did not know how to do it

in our 2-year-oldsclass.

My co-teacher and I

could only try.

Project approach

wanted children to

propose their questions.

Our 2-year-old children

could not express their questions clearly.

This led me

to a state of perplexity. 
My co-teacher and I

came to a conclusion

it was not suitable for our class.

We shared our thoughts

with the Chinese ECE superintendent.

She agreed with us.

We then decided not to do it.

Last term

we had a small ...

it shouldn't be called

theme activity.

It was just something about holiday.

Came back from Christmas holiday

children were

really interested in holiday activities

such as getting on the plane.

They also took holiday photos to the class

such as riding on the elephants.

We were thinking

how we could extend this.

But we got lost.

I am not clear

how to support children's learning

through themes or projects.

Shall we provide activities?

Like for the holiday interests

We pretended to

take them on the plane

look at photos.

Or shall we just let them go.

If they are interested in it today then they play.

If they are not interested tomorrow

and do not play around this theme

we do not remind them?

\section{How to define "curriculum"?}

When I was teaching

at the previous kindergarten

curriculum was about

stages and age groups.

Each stage had

its prescribed content

and what we must do.

This was set.

Each area had goals 
that we needed to achieve.

There were things we needed to do

in order to achieve those goals.

This was the curriculum to me

at that time.

Now

Curriculum is our goals.

No

they are not goals

they are guidance.

It goes back to

children's interests.

We provide support to them.

That should be our curriculum.

I do not know

how to define curriculum.

I feel

the activities

that accumulate children's experience

is curriculum.

Curriculum (the word/concept)

feels limiting.

I just feel

children gain experience

anytime

anywhere.

But I cannot say

It is a curriculum.

It is limiting.

\section{Happy, but not very confident}

Working here

has been a very happy thing.

However

I am not very confident

of my own teaching now.

There are many things

I need to learn here.

Many things

children want to know

but I do not know

how to support them.

So many cases like that 
made me less confident now.

The only thing I can do

is learn.

Learn from the teachers around me.

\section{"I was observing other teachers"}

When I first came here

there were many little things

I did not know how to do.

Could they run outside?

Shall I help children

when they put their clothes on?

Shall I talk to the child now?

I had no idea what to do

at the beginning.

I was

observing other teachers.

asking other Chinese teachers

talking to them

watching what my co-teacher did.

I have learnt more

in the past three years here

than the last ten years.

That is because

there are

many good teachers

around me here.

I can learn from them.

Before

there were

many classroom observations

meetings

discussions

courses

provided to the teachers.

But

I did not think

I could learn much from them.

I have learnt more about

how to think about children

and understand children here.

But back then

it was all about 
teaching techniques.

How to conduct a good and effective lesson?

How to let children listen to you,

interact with you

and achieve the lesson goals?

At this school

influenced by the teachers around you

I know

I should pay attention

to children's interests

provide children the support they need.

What children want to learn

is the most important thing.

This is something really different.

\section{"I become less agreeable to ..."}

During my first year of teaching here

I was learning from others

completely.

I thought

all of them were excellent.

Their strategies

were excellent.

Maybe because

I had developed more

knew children better

especially this age group

I became more confident of

working with children now.

I became less agreeable to

some of my co-teacher's approaches.

Not long ago

during Lucas' first week in our class

my teaching partner

had kept him in the classroom

before home time

since he did not put any effort into

putting his shoes on.

Lucas was crying.

His mum was peeping through

the window on the door.

If it was before

I would go with

what my co-teacher did. 
But this time

because you were there

I thought about it more.

Lucas

a lovely child

the youngest in the class

was new to the class

did not understand

both Mandarin and English.

I did not interfere

when she was dealing with the child.

But

when we were talking about

this afterwards

I told her

how I felt about this incident.

The next day

I dealt with Lucas.

He did put his shoes on

by himself

with my support.

He was too young.

His fine motor skills

were quite poor.

I was teaching him

how to hold the shoes

how to put them on.

I told him not to worry.

And he did.

This incident

has given me

great confidence.

If the same sort of moment

happens again

I would know

how to communicate

with my co-teacher.

My co-teacher would

accept my ideas

if I am right.

I need to

communicate more.

I do not express my thoughts enough. 


\section{"I want to share ..."}

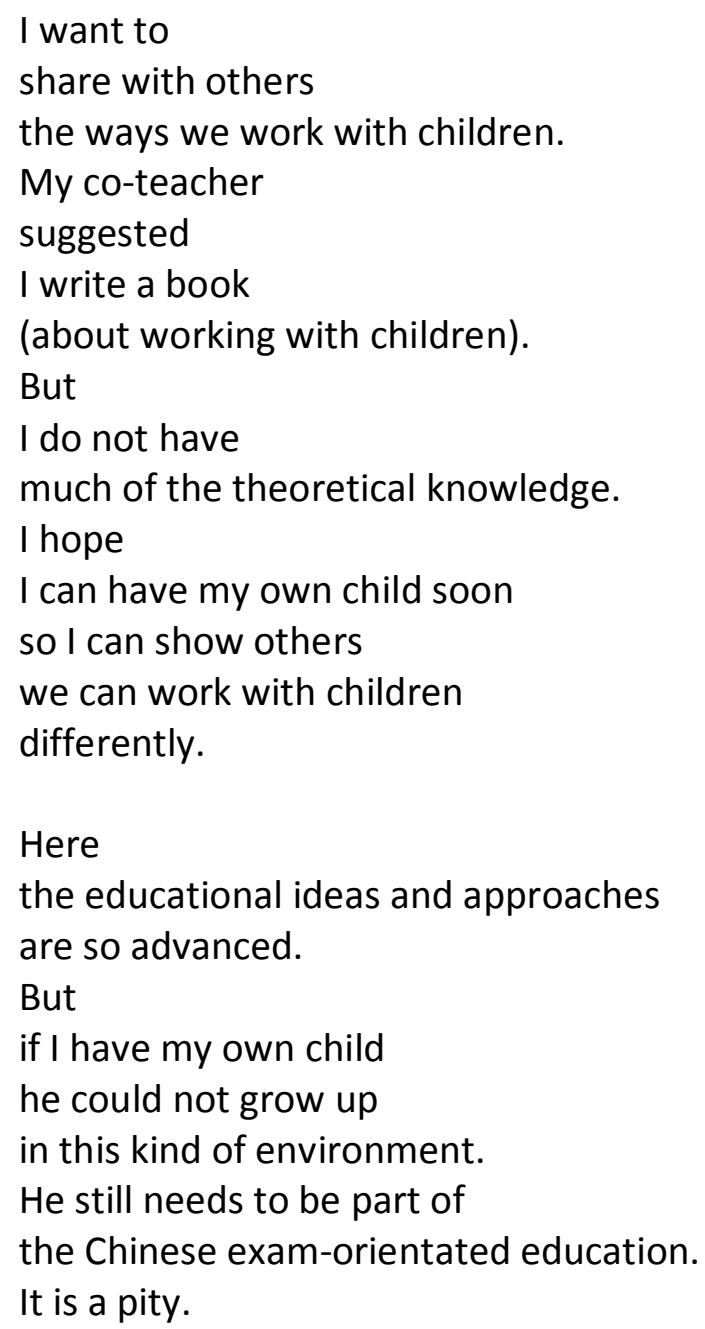

\section{To be a mum; Look for a new world!}

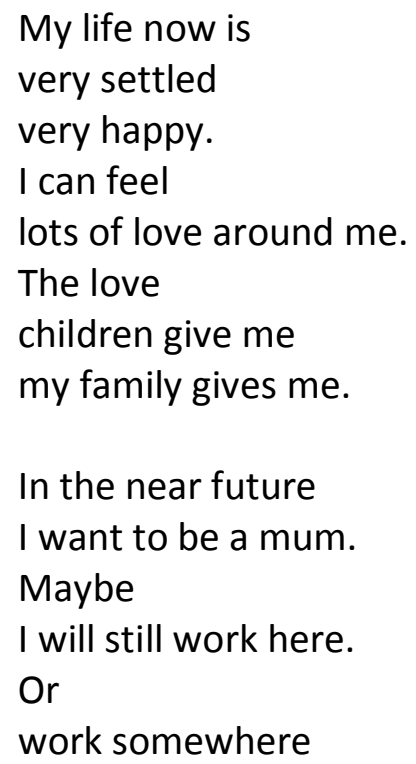


with a better environment.

An environment

can take me

to a different world.

When I changed

from my previous kindergarten

to here

it already

opened my eyes

showed me a new world.

Maybe

there is

another world somewhere.

To be a mother.

Look for a new world

to see if I could do something more.

They are two parallel tasks

for my future!

\title{
Cecilia's Stories as Poems
}

\section{Childhood memory}

\author{
I was born and grew up \\ in Inner Mongolia. \\ My extended family \\ looked after me \\ since I was nine months old. \\ I went to \\ a boarding kindergarten \\ for two years. \\ I was at the kindergarten \\ most of the time. \\ It was ok \\ since I was \\ a carefree girl. \\ I was quite naughty \\ at kindergarten. \\ Wet beds every night.
}


Did naughty things

to other children.

I would be

sent to the toilet

by the teachers

as punishment

almost every day.

I can only remember

one teacher.

She was nice to me.

She would praise me

when I did something good.

Other teachers

NO!

I had quite strong personality.

I wouldn't do the things

that I did not like.

My early childhood

was a happy time for me.

I was able to

live the way I wanted.

I was able to

be naughty.

But I was still

loving and caring.

If somebody fell down

or was not feeling well

I would care for them.

We moved to Beijing

before I went to primary school.

My mum then said

a girl

should not be

raised in this way.

She started to

discipline me.

As a result

I changed

from being open and cheerful

to an introvert girl. 


\section{Choice of being a kindergarten teacher}

To be a kindergarten teacher

was not my intention

initially.

I wanted to be

a music teacher.

But I did not pass

the entrance examine

for the music teacher programme.

So I chose

the early childhood teacher's

training programme.

I could still learn music.

I did not have any idea of

the differences between

being a music teacher and an EC teacher.

I just loved music!

We followed the textbooks.

Not many opportunities

to practice.

Teachers

passed on

what was written in the textbooks

provided some examples.

We did not have

real practical experiences.

Only one month practicum

before graduation.

We could not really apply

the theories from the textbooks

to the real practice

in just one month.

What I had learnt

at the dance classes

was most useful and practical.

We learned

how to create

choreography for children.

It was creative

and spontaneous.

We could dance

whatever we wanted.

It is useful even now. 
At the training college

being a teacher was about ...

teaching the lessons

you had planned

passing on the planned knowledge

to children.

In reality

there were

20 or more than 30 children

in front of you.

They would have

many unexpected problems.

They would

catch me on the wrong foot.

When we were facing children

it was completely different to

what we had learnt

at the training college!

\section{"Observe and follow all rules and regulations"}

I had been teaching

at a local kindergarten

for the first five years of my teaching.

I felt happy

when I saw children

when I was with them.

But

the educational philosophy

and other aspects

of that kindergarten

made me wonder

if teaching at kindergarten

was the career

that I would be

passionate about.

I was about to quit teaching

back then.

I and other teachers

did not agree with

the director's

philosophy of management

and education.

She treated us as prisoners. 
We were not allowed

to sit with children

even sit with other teachers.

Many things

were not allowed.

Too many restrictions.

This made you feel

there was no freedom there!

I was passive.

I had no desire to learn.

Others

pressured you to learn.

Six months before my resignation

there was a PhD student

came to the kindergarten.

Her research project was about

taking children

as the main subject

teaching around their interests.

At that time

I made an Olympic Wall display.

The idea emerged from

children's discussions.

They discussed

among themselves.

All the displays

were made

by children.

She was very interested.

She spent

quite a lot of time

with me.

Talking to me.

I found a little bit of interest

in teaching.

I thought to myself

Oh, I could teach like this!

My first five years of teaching

was like

doing things by

observing and following

all rules and regulations.

No creativity.

No desire. 
No motivation.

Not enjoyed.

I still liked children.

But

the whole work environment

did not make me

enjoying teaching.

I was

weary and tired

every day!

\title{
"Catch the white wolf with empty hands"
}

\author{
It was very hard \\ to adjust \\ to the way of teaching here \\ (International Kindergarten) \\ at the beginning.
}

From the time

when we were students

to the time

when we were teachers

the educational philosophy

was the same.

It was very difficult to change.

We did not really

put children at the centre

of our education

in China.

It was teachers

and kindergarten

at the centre.

It was 'spoon-fed' type of education.

Here

it is children

at the centre.

Everything follows

children's interests.

What we are doing

is guided by children.

This is the approach

both children

and the teachers

would enjoy 
and be happy about

what we do!

I liked

the educational philosophy

here.

I thought I could teach

in this way.

But in fact

it was really difficult.

I had many puzzling

and confusing moments.

Feeling I was trying to

catch the white wolf with empty hands.

What I am doing here?

I thought

I was an ok teacher

I knew how to teach children.

But here

I was useless.

Did not know how to teach!

When trying to

communicate with children

they would not

follow my ideas.

They wanted me

to follow them.

It was a real challenge

for me.

I had doubts about myself.

Could I still do this job?

It put your knowledge to test.

I felt I knew nothing!

\section{"Slowly, slowly learning and changing my philosophy"}

The western co-teacher

I am working with now

has accelerated

my changes of mind/heart.

Through the on-going communication

she shares with me

her educational philosophy

her thoughts

her rationale 


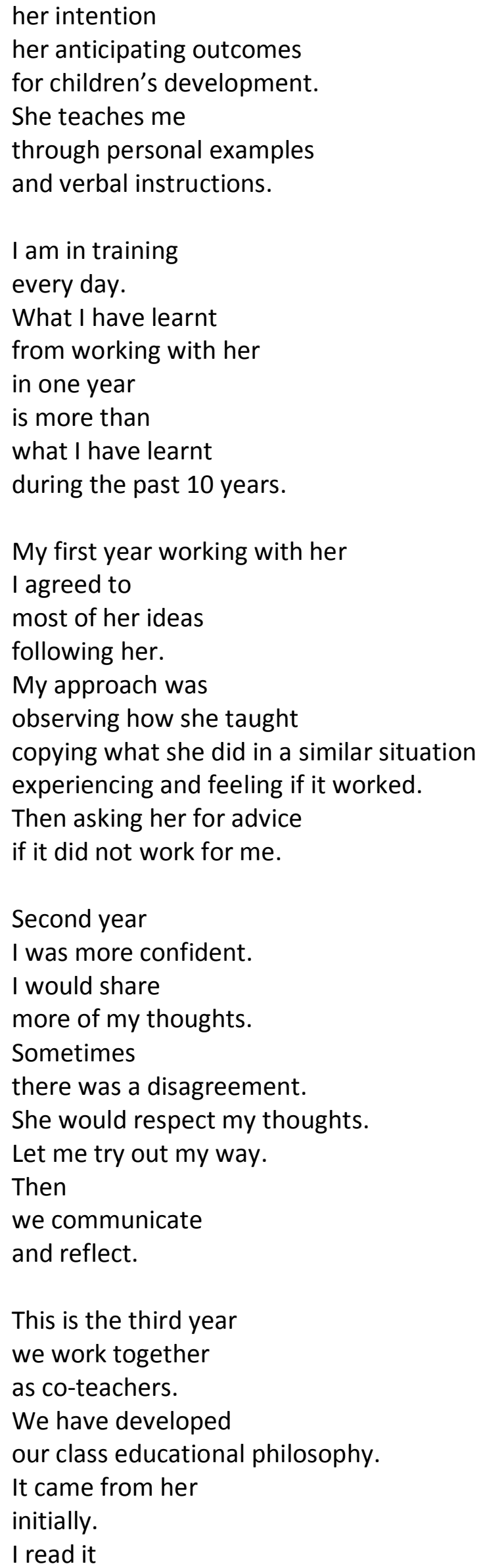


and agreed to it.

Then we practise it.

I also learn from other colleagues.

Like other Chinese teachers.

We meet once a week

share our practices

and philosophy.

This is a collective wisdom.

When an expert

(the ECE superintendent)

comes

talks to us

answers our questions

offers guidance for

what could be done next

I feel suddenly enlightened.

Realise that

we are actually

doing it this way

for this reason.

We just do not know

how to

summarise

theorise

what we are doing.

We had many training sessions

at my previous kindergarten.

But

in real practice

the things you learnt

from the training

sometimes did not link to

the real practice.

They could not be used.

Here

I learn by myself

most of the time.

Try to digest by myself.

Self-development

begins with thinking/self-reflection.

We cannot just use

other people's 'stuff'.

Need to think first. 
Here

nobody tells you

what to do

with children.

Only gives you a direction

and the learning outcomes.

You need to

think by yourself.

It is a relaxed

and open environment.

I feel relaxed.

But

at the same time

I also feel the tension.

I need to

learn more

do more

to do a better job.

\section{"A complete change of heart"}

\section{Educational philosophy}

Firstly

it is the change

in my educational philosophy.

A complete change of heart!

Now

my educational philosophy

is to put children

and their interests

at the centre.

Support children's

individual development

to be global citizens

to get to know different cultures

learn to tolerate and accept

develop social skills and

to be independent.

At the previous kindergarten

it was the teacher

who led the process.

Weekly Plan would be done

prior to the week. 
I did not pay close attention to

children's interests.

Only focused on

what I should teach.

How to achieve my teaching goals.

What had the curriculum content indicated

that children should learn / know?

These were done according to

teacher's subjective consciousness.

I did not really consider

children's development.

At this school

I had to change

my philosophy.

I must put children

at the centre.

You (teacher) are only

an observer

a supporter/facilitator

to support children's development.

You cannot

let children

walk with teacher's thinking.

It must be

a cultural difference.

From the Chinese perspective

the adults or seniors think

you should learn this

then you must learn it.

Nobody cares

whether you like it or not.

I ask you to learn this

then you need to learn

Because

I know it is good for your future.

Actually

this approach

did not let children

develop by themselves

and being independent.

\section{Feelings towards teaching}

Secondly

It was a change

in my feeling towards teaching. 
Now

I would try to do things that

both children and I

would want to do.

I would change different ways

and do something new every day.

This is a very enjoyable process.

I feel happy

when I think of children.

Want to be with them.

Want to talk to them.

Because they always

surprise me.

I have found

fun with children.

I can be silly or crazy

sometimes.

Children like to see

this side of you.

If you follow this interest

they would like it.

Many sparks would occur

between you and children.

This might not be permitted

according to

the old educational philosophy.

The crazy words or craziness

would be considered bad.

But in fact

these moments

let you get closer to children.

My ability in responding to

children's spontaneous learning

has improved.

I can feel the fun

working with children

at any time.

As well as

supporting children's development.

It is not static.

Having some changes every day

is fun. 
Children's sense of achievement

in their own development

gives us (teachers)

a sense of achievement!

I never thought

being a teacher

could be this happy!

\section{View of challenging children}

Before

I found children

with strong personalities

were very challenging.

They did not

follow instructions.

They would cause some

unexpected incidents.

Here

all children

have very strong personalities.

But

I do not find them

challenging.

It is because

the environment

allows them

to display personality.

They can do

what they want

at any time.

\section{Understanding curriculum}

We do not have lessons.

No curriculum here.

Actually

our curriculum

is embedded in everyday life.

It's spontaneous.

Skills are learnt

during free play time

according to

children's different abilities.

Children learn through play.

We do not have 
pre-set goals for children's play.

Children lead their own play.

Children initiate their play.

We teachers would

initiate some group games.

Such as music games.

P.E. games.

But children's play

is led by children

from their own interest.

The group games the teachers lead

are for children's information

modelling and sharing

teachers' experience.

If children

are inspired

by the games

we introduce to them

they would use them

in their own play.

Curriculum

this word

has almost disappeared

from my dictionary.

It means something

boring

limiting

pre-planned

with clear goals.

\section{Some Challenges}

The most challenging part is

to teach according to

individual children's needs.

How to really help

children's individual development?

How to follow

children's interest?

I feel frustrated

if I have no idea of

how to support children's play

cannot offer them ideas or resources

to support and extend their play. 
I also have many questions.

When to talk to children?

When to be involved in children's play?

How to support child-initiated play

and make sure I do not take over the learning?

How to communicate with children

who do not like to speak Chinese?

How to connect to children

who do not talk much?

How to understand children?

Why they do not follow my(your) instruction?

Why they do not like me(you) or some activities?

Sometimes

the parents

would have different priorities

in children's development.

Some mums were very angry

because the teachers

did not make children

put their coats on

before outside play (in winter).

We did suggest to children.

But

it was the child's decision to

not wear the coat.

Children needed to learn

to think and make decisions

independently

bearing the consequences.

However

the parents had different ideas.

They were afraid of

children being sick.

I understood the parents' concern.

My western co-teacher insisted

it should be

children's responsibility.

Not the teachers'.

I was torn.

\section{Thinking big and dreaming a dream}

The whole Chinese education system

needs a change.

From its foundation.

Start with the teacher education. 
The future teachers

need to be

global citizens themselves.

If they do not

change their philosophy

children will not be global citizens.

So the whole education system

needs to change.

We teachers

can influence children.

We could only influence

a small amount of children.

The real influence

should come from

their parents

the educational philosophy of

the whole education system.

My dream is to share

what I know about

the educational philosophy

and approaches

what is good for children

that can help them

become global citizens.

To summarise some theoretical stuff.

My dreams is

to present

to promote

try my best

to influence more people.

Parents and teachers.

Maybe we cannot change

the government's policy.

But

we may be able to

change some people's behaviour.

Influence them.

Change them.

Then they could

influence their children.

Make changes

in the notion of parenting.

This is my dream! 


\section{Chapter 10: Analysis of Summer and Cecilia's Stories}

\section{Summer: "Think back, I did not know how I taught before"}

"I feel sorry for children I taught before" (observation notes, October 26, 2009) was what Summer shared with me in tears on the first morning of my observation in her class. This was her immediate response to my question of whether she worked with children at the previous kindergarten in the same way as she taught at International Kindergarten. Summer's negative emotion about her past teaching and the many times she used the words different/difference/differently may imply a disconnection between her past and present teaching and learning experiences, which were mainly concerned with:

- How Summer experienced the impact of the change from a teacher-directed to a child-centred teaching approaches in reality.

- How Summer learned from two different professional learning approaches at her previous and current kindergartens.

- How Summer changed her feelings of being a teacher over time, and why she seemed so confident now when talking about the unknown future.

Summer's stories and my analysis provide some insights into how teachers may work with disconnected past and current knowledge and experiences, and become empowered in an "ideal" kindergarten context. 


\section{The reality of teaching}

Summer's teaching at International Kindergarten started from observing children's learning and noticing "children running widely outside", "teachers were not afraid of them falling down", and children "looked messy" every day. These observations contrasted with Summer's previous teaching practices where safety was prioritised and messy play seemed non-existent. Other teachers' practices made the International Kindergarten's guiding educational ideas and approaches explicit to Summer, which helped her understand the possible changes she needed to make. Reflection is also believed important for teachers who are learning to change (Hargreaves et al., 2001). In Summer's case, recognising the differences between her past practices and the International Kindergarten's ways of teaching led her to explore the rationale behind such differences, and become aware of different conceptions of learning; for instance, learning through practice and mistakes, and learning being about busy and active participation. In this sense, active observation and reflection on other teachers' practices in relation to her own experiences seemed conducive to Summer when she was being enculturated into International Kindergarten's teaching approach.

\section{Teaching approach: "children choose what they want to learn"}

Summer experienced a change of teaching approach from "to plan according to the curriculum" and "[teachers] chose what activities, what content to teach children" at the previous kindergarten, to "children choose what they want to learn" at International Kindergarten. I observed many examples of children choosing "what they want to learn" when Summer was teaching. For instance, children could ask for 
the songs and stories they wanted to dance to and listen to, and decide how often, choose what activities they wanted to participate in and to try out their own ways of solving problems.

The following story provides a glimpse of Summer's child-orientated way of thinking and practice when interacting with Miles.

\section{Miles talking to Jane (the researcher) on Summer's mobile phone}

(interview, June 22, 2010)

Summer: "Yesterday, Miles gave me the toy phone and told me that it was Jane (the researcher) on the phone wanting to talk to me. I was then pretending talking to you on the phone. At that time, I thought to myself that I should really ring you because it would be a very special experience for Miles. Children played with the toy phone every day. But it was not real, they could only pretend. If he could ring you, it would be really special for him. Miles and you had also developed a very special relationship when you were doing classroom observation, so it was a way to communicate our feelings and emotions. However, we did not have enough time yesterday, it happened just before tidy up time. Today, you should see the big happy smile on Miles's face when he was talking to you on the real phone. He was nodding, talking and smiling. It was very special and I wanted to give him such a surprise."

Summer's teaching was based on her observation and understanding of Miles' seemingly repetitive behaviour (talking on a toy phone almost every day) and the special relationship Miles had with me. Summer demonstrated her pedagogical thoughtfulness which led her to plan and provide a meaningful and comprehensible learning experience (van Manen, 1991) for Miles. The most important agenda in this situation for Summer was Miles and how she felt she could most effectively support his interest. This may suggest Summer honoured the individual child in the 
classroom over the curriculum guide, and taught according to children's interests rather than prescriptive learning content as she did at her previous kindergarten.

International Kindergarten's child-centred school scripts (Blank, 2009) and observation-based planning process promoted and supported Summer's childorientated teaching and learning. However, some contrasting traditional cultural scripts may have implicitly influenced Summer's teaching, for instance, the teacherdirected, knowledge and skills-driven pedagogy. The following vignettes recorded Summer's attempts to support children's interests in spiders/insects, and may reveal ways the traditional cultural scripts influenced her teaching.

\section{Observation note, October 26, 2009}

During morning play, Summer spotted a little bug crawling on the drawing that was stuck on the carpet, "Look, it is crawling." Several children gathered around and looked at the bug with Summer, but some children ran away. Summer and children observed and talked about the bug for a while.

Summer and her Western co-teacher talked about this scenario after school. They thought children were interested in the bug, and decided that they could search for some insect video clips on YouTube, look for some games and add some bug toys or other related resources to the classroom. Then they could observe how children respond to these resources. Summer went to find some bug toys and a big hanging spider web from the ECE resource cupboard. She hung a big spider web in the classroom and put the toys on the science table. Summer then went to borrow some spider/insect related books from school library.

\section{Observation note, October 27, 2009}

Tim noticed the big spider web and was learning how to say 'spider web' in Chinese during morning play. Summer introduced the spider web and the spider 
toys to children during circle time. On the way to the school library, children and Summer found a big photo of a spider from the secondary students' photo gallery. They stopped walking, talked about the photo. During morning tea time, a video clip about bugs was played on the classroom computer. Children were watching while having their morning tea. At the primary school playground, Summer found a little spider and children gathered around to look at it and talked about it.

\section{Observation note, November 2, 2009}

Summer told me that children did not make any spiders last Friday as they expected. (Summer and her co-teacher had put out some collage material on the art table.)

Noticing children's interest and their different reactions to the bug, Summer intended to develop it to an exploratory learning project by providing spider/insect related resources and activities. Summer quickly gathered relevant resources and introduced them to children. However children did not respond to the activities as enthusiastically as Summer had anticipated. Summer later reflected, "I do not know how to support their interests in spider further" (written comments on the observation notes). What is interesting to me is the approach Summer took when she realised a potential project. She quickly started a top-down, teacher-directed, and activity-orientated planning process, instead of the bottom-up listening, observing and interpreting process that she often used when responding to children on the spot. This may be why she found it difficult to predict the possible development of the educational project as it should have been informed by the information gathered from children (Rinaldi, 2006). During the top-down planning and decision-making process, the traditional teacher-directed scripts implicitly 
played in Summer's mind. Therefore, Summer felt torn between whether she "should provide activities" to keep the existing project alive in the class or "just let them go" and leave children to decide whether they wanted to learn something about the project on a daily basis.

\section{Focus in teaching: "lessons are too trivial to mention"}

Another change in Summer's teaching related to the question of when teachers teach. At the training college, Summer learnt as a teacher she "only needed to teach the lesson". At the previous kindergarten, Summer understood teaching as something that happened during "45 minutes of lesson time". These lessons were often called learning (xuéxí) activities in the recent ECE reform contexts and were formally organised.

In contrast, Summer considered every minute she spent with children at International Kindergarten as teaching, and stated "lessons are too trivial to mention". Play was the most important aspect of Summer's everyday teaching. Her planning and the class' daily schedule did not include lessons or learning activities. Instead, there were group activities such as group greetings in the morning, group story-time before tidy-up time and in the library, group music and movement time, and show and tell time for children who wanted to participate. These group activities were teacher-directed, but short, flexible and based on the teachers' observation of children's interest. Also, it was quite hard to distinguish four kinds of activities that Shanghai's common curriculum promoted - learning, sports, play, and everyday life - in Summer's planning and teaching. The class daily schedule and the

daily reflection and planning sheets did not use these categories of activities, but 
orientated Summer to plan for individual children's learning based on their interests rather than to plan for teaching different kinds of activities.

The changing focus in Summer's teaching reflected two different views of curriculum:

- a narrow view of curriculum as purposefully selected and planned formal teaching and learning experiences including "prescribed content" to cover and "goals" to be achieved

- a broad view of curriculum as including everything that happened in the kindergarten, which highlighted the spontaneous and emergent aspects of teaching and learning.

These contrasting views co-existed in Summer's professional knowledge system but at different levels. The narrow view of curriculum dominated Summer's conceptualisation of curriculum, but was not relevant for explaining her current child-centred and emergent teaching practices. Therefore, Summer was perplexed and questioned whether there was such thing as curriculum since the term itself sounded "limiting". In the end, Summer defined curriculum in her own terms based on her professional practical knowledge (Clandinin, 1985) as "the activities that cumulate the children's experience" and "the children gain experience anytime anywhere". Summer's description of curriculum resonated with the broad definition stated in the Curriculum Guidance for the Foundation Stage (Qualifications and Curriculum Authority, 2000) as "everything children do, see, hear or feel in their setting, both planned and unplanned" (p. 2). In short, the different ideas of curriculum from her past and current teaching, the gap between her theoretical knowledge and her practical knowledge, and her lack of confidence in articulating her practice at the conceptual level contributed to the tension Summer experienced 
when defining curriculum.

\section{Image of the child: "they are angels"}

Several images of the child were illustrated in Summer's narratives. The young Summer, who was able to "perform well" and liked by her teachers, represented a child-image as being obedient and mature which was highly valued as an ideal child in the Confucian doctrine (Bai, 2005a). The obedient image of child was also reflected in Summer's mother's view of a kindergarten teacher and in her first teaching partner's practices that implied an order-giving and obedient-listening teacher-child relationship.

Summer relived a "critical incident" (Sikes et al., 1985) from her previous teaching experience that vividly illustrated the image of a troublesome child who displayed some disruptive behaviours when settling into her class. Summer recalled she then defined the child as "so difficult", "will not listen", "hit other people", and this child was obviously nowhere near the child that Summer and her colleagues thought he ought to be. When dealing with this "extreme case", Summer tended to blame the child. This blaming of the child may have been caused by the mismatch between the child's actual needs and Summer's expectations of him, and this led her to a state of frustration and helplessness.

Summer had a positive, loving and accepting attitude towards children at International Kindergarten. She regarded all children as "angels", and stated "I do not think there are good and bad children", "each one of them is very cute", and "all children are great and lovely". Guided by her current views of children, Summer claimed that now she would work differently with the child she previously found 
challenging. She would accept his behaviour rather than blaming him, would try to understand his feelings by connecting with the child's inner world and his family, and would "look for some ways to solve the problem" rather than simply removing him from the class.

The three different images of child as - obedient, troublesome and being unique individuals - may reflect the differences in how children have been defined over time in different cultural and kindergarten contexts. The obedient image of child suggests that children may be defined "in relation to other" and "in the hierarchy of relationship" (Lau, 1996, p. 360). The troublesome image of some challenging children implies that children may be defined in the social context and according to the norms, rules and regulations of the collective group. Confucian thinking has hugely influenced the construction of the obedient and troublesome images. In contrast, Western culture and the child-centred philosophy practised at International Kindergarten has shaped Summer's current view of the children as unique individuals to be accepted for who they are.

\section{A sense of regret: "I feel sorry for the children I taught before"}

Summer criticised and rejected many educational ideas and practices she previously accepted, for instance:

- She used to admire her first teaching partner who "could control children", but she stated "of course, we do not control children now".

- She now thought her past teaching had focused on children's "surface knowledge and skills" after realising the importance of developing children's dispositions. 
- She used to do things for children so she could "move on to the next activity" on her plan. In contrast, at International Kindergarten she was able to give children time to do things by themselves and understood this was an important aspect of their learning.

- She viewed all children at International Kindergarten as "great and lovely", which was different from the troublesome and deficit views of children she used to hold in the previous kindergarten context.

The contrasting views and practices created conceptual and pedagogical tensions for Summer when she first came to International Kindergarten, which left her in a situation of having "no idea of what to do" as an mature and experienced teacher. Now Summer regarded International Kindergarten as her ideal kindergarten as it had a "flexible environment, many people and good colleagues to learn from, small classes and correct educational philosophy" (interview, November 5, 2009). Summer's stories suggest particular kindergarten contexts play crucial roles in the construction of teachers' knowledge, understanding, repertoire, and emotion (BenPeretz, 2011; Day et al., 2007; Skaalvik \& Skaalvik, 2009).

\section{Professional learning and growth}

\section{Professional learning in the past: teaching techniques and lesson-focused}

The previous kindergarten provided "many classroom observations, meetings, discussion, courses" for teachers. It seemed Summer's professional learning at the previous kindergarten should have been effective, since two factors identified by Rogoff (1995) as being influential in learning culturally appropriate teaching practice can be identified in Summer's narrative: 
- being able to interact with more experienced teachers

- learning collaboratively with others by connecting with the wider professional community.

However, Summer criticised this teaching-techniques and lesson-focused professional learning and stated "I did not learn much". In contrast, her current professional learning focused on "how to think about children and understand children". Summer felt she benefited from this child-focused professional learning as it helped her understand “children's interests, provide children the support they need". Summer's critique was insightful because recent studies about Chinese teachers' professional learning and development have not identified the professional learning foci as a factor that may influence teachers' actual teaching and learning. Rather, the identified influential factors have been mostly around the kindergarten environment, teachers' attitudes and motivations for seeking professional growth, and effectiveness of the professional learning approaches $(\mathrm{Mu}$, 2010; B. Peng \& Xie, 2009).

\section{Professional learning over three years: "I was observing other teachers"}

Summer's narratives, "influenced by the teachers around you, I know . . ." and "I was learning from others completely", indicated that being able to work with "many good teachers" was the most important aspect of Summer's professional learning. Through observing and interacting with other teachers, and her growing participation in International Kindergarten's child-centred pedagogy in everyday contexts (Lave \& Wenger, 1991), Summer was able to learn informally. 
Shulman's (1996/2004) four aspects of effective learning - learner's activity, reflection, collaboration, and community - could be identified in Summer's current professional learning experience. Firstly, most of her professional learning occurred during the process of solving practical dilemmas she faced by actively interacting with her co-teacher (e.g., whether the project approach was suitable for their class), with other Chinese teachers, and with the visiting experts. Secondly, Summer constantly reflected on others' and her own teaching practices by connecting to her previous teaching and learning experiences. Thirdly, the Western and Chinese teachers often exchanged their observations and thoughts about children and planned possible teaching opportunities either casually during non-contact time or during meetings. They also provided support to each other when needed. For instance, all the Chinese teachers put together a short play "Little bear goes to the dentist" in Chinese to support a 4 and 5-year-old class' project on teeth. In short, Summer's positive professional learning experiences were shaped by the context in which her active learning, reflection and collaboration were enabled.

\section{Professional growth: "I become less agreeable to ..."}

The narrative about helping Lucas put on his shoes vividly illustrated Summer's professional growth. Summer disagreed with how her Western coteacher (Asian descent) interacted with Lucas, and tried to voice her opinion to her co-teacher. However, voicing her disagreement was a big step out of Summer's comfort zone. She respected her co-teacher very much as her co-teacher had taught her almost everything about teaching at International Kindergarten. Therefore, Summer initially kept quiet. This approach may reflect Summer's tendency to avoid 
conflict, since harmony is highly valued in relationships in Chinese culture (D. Zhang, 2003). Summer only communicated with her co-teacher after she had shared her thoughts with me and I had asked her "did you tell your co-teacher how you felt?" It seemed my presence as a researcher and a fellow Chinese teacher motivated and supported Summer to voice her thoughts. The positive responses Summer received from both Lucas and her co-teacher made this critical incident an important event in her development, since it became part of the process of discovering her voice, redefining herself in her relationship with her co-teacher, and becoming more confident of her ability to understand children.

\section{Feelings and professional identity}

\section{Changing identity and feelings}

Summer felt what she learnt at the training college about teaching was "not relevant, not practical in real kindergarten". This left Summer in a "knew nothing" state as a beginning teacher. Furthermore, the discrepancy between anticipating that she "only needed to teach the lesson" and the reality of "lessons were not the most important things" created a "reality shock" (Veenman, 1984, p. 143) for her. At the previous kindergarten, Summer became a "confident" teacher who "had the control" of her teaching. However, she did not enjoy her teaching because of the complex social relations, big classes, and safety requirements. Summer's status as a confident, able and mature teacher did not seem to bring her positive feelings towards teaching - rather, she was losing heart. The "prescribed path" Summer walked may have contributed to her negative feelings about teaching, as it led her to honour the external world but lose contact with her inner world (Palmer, 1998). 
In the end, Summer chose to reconnect with her inner world and so realised her commitment to children. However, changing her teaching community seemed a necessity.

Summer felt "happy" but "not confident" when teaching at International Kindergarten. However, her lack of confidence was no longer a threat; rather, she saw it as an opportunity for further learning. With the support of her colleagues and the increasing connection between Summer and children, the negative feelings of uncertainty, tensions, and lack of confidence became motivating forces, rather than disconnecting her from children and the community. Moreover, the Western coordinator's team-building approach, the valuing of equality, and the integrating of the Chinese teachers' voices and contributions into decision-making and day-to-day management may have been enabling factors influencing Summer's positive experiences of teaching and learning at International Kindergarten.

\section{A sense of empowerment}

Both a professional and personal life were equally important for Summer. I could feel the happiness and see the sparkle in Summer's eyes when she was talking about the future, and she seemed ready and confident to take on new challenges. This was so different to the tearful emotion she had shown when recalling her past teaching experience on the first day of my classroom observation. Summer was living in a dual context, the Western culture-dominated community at International Kindergarten and the Chinese society outside the school campus. Summer thought she was equipped with "advanced" educational philosophy and felt confident in her Western values-informed practical knowledge. Hence, she identified herself as someone who knew how to work with children in a non-Chinese traditional way, 
and who could bring some advanced approaches to Chinese society that might benefit Chinese children. Therefore, Summer was willing to make contributions to the development of a better society, which Day (2004) views as an ultimate goal of teaching.

Quinn and Spreitzer (1997) argue that an empowered person would have a sense of self-determination, meaning, competence and impact. Summer demonstrated her development of these characteristics over time, and she credited the change of teaching community for her transformation. This view supports Rogoff's (2003) argument that culture and environment play important roles in teaching, learning and development, and Vescio et al.'s (2008) view that certain types of communities can have positive impacts on teachers' teaching and learning experience. However, the question of empowering teachers has not featured in models and research on professional development in the Chinese ECE context. The main focus of Chinese EC teachers' professional development has been on helping teachers to understand and implement promoted educational ideas and curriculum (Dan, Wang, \& Wu, 2006; Huo, 2010), rather than helping individual teachers to become empowered members of a particular kindergarten community.

\section{Cecilia: "A complete change of heart!"}

Cecilia is Mongolian, the only minority participant in this project. However, once Cecilia went to primary school in Beijing, she received education in Mandarin, in a setting that was predominantly Han Chinese. Cecilia taught at a local Chinese 
kindergarten for five years after her initial teacher training. She then went to teach at another international school in Beijing for five years, first as a teacher assistant and then as an admission officer. However, the work experience during that period did not seem significant to Cecilia since she only mentioned it briefly and did not make any reference to it when talking about her teaching and learning.

Cecilia's narratives revealed that her personal and professional development and growth were shaped by different personal and organisational environments (Burke et al., 1987) in which she was embedded. Like Summer, Cecilia made references to her past teaching and learning experiences many times when making sense of International Kindergarten's ways of teaching. In fact, in many respects, Cecilia's narratives were very similar to Summer's around the three emerging themes:

- How Cecilia experienced the impact of the change from a teacher-directed to a child-centred teaching approaches in reality.

- How Cecilia learned in two different professional learning approaches at her previous and current kindergartens, and how her Western co-teacher influenced her professional development over a three-year period.

- How Cecilia changed her feelings of being a teacher over time, and became so eager to make some contributions in parenting.

In particular, Cecilia's stories and my analysis provide some insights into the importance of aligning espoused educational philosophy with the kindergarten scripts, planning methods, daily schedule, and teachers' actual teaching practice, and the important role colleagues and management play in professional learning and in empowering teachers. 


\section{The reality of teaching}

\section{Educational philosophy: "put children and their interests at the centre"}

Cecilia believed the biggest change in her teaching after joining International Kindergarten related to educational philosophy. In fact, the phrase "educational philosophy/philosophy" was mentioned 19 times in Cecilia's narratives, which reflected the two kinds of education she had experienced. Firstly, it was an educational philosophy that placed "the teachers and the kindergarten at the centre" and resulted in a passive "spoon-fed type of education". This teacher-centred educational philosophy dominated the Chinese education system and Cecilia experienced it in the local Chinese context. In contrast, the second educational philosophy placed "children at the centre". Cecilia understood the child-centred teaching and learning as:

- being led by children

- valuing spontaneous learning and learning through play

- accepting children's different personalities

- valuing the individual child's development of social skills, independence, and positive emotions.

Like Summer, the irrelevance and disconnections between Cecilia's past and present teaching experiences were apparent, and the co-existence of teachercentred and child-centred educational ideas created challenges for her. One challenge Cecilia experienced was that children "would not follow" her ideas, but wanted her to "follow them". This reflected the tension between Cecilia's repertoire of practice as teacher-led and lesson-focused, and International Kindergarten's 
child-centred and play-based spontaneous teaching and learning. However, the disconnections were merely at the practical level, not the conceptual level. Cecilia's narratives about her own childhood, her initial teacher training and her teaching at local kindergarten suggested that she had always valued individual needs, creativity, spontaneity, and freedom in teaching and learning. The match between Cecilia's personal beliefs and International Kindergarten's educational philosophy and practices could be considered as a prerequisite for Cecilia's change process (Whitaker, 1993).

My observations suggested that the child-centred educational ideas of "everything follows children's interests" were realised not only in Cecilia's mind but also in her practice. They guided her teaching including setting up the classroom and interacting with children during play, group activities and everyday routines etc.

\section{Change the classroom layout (observation, November 18, 2009)}

This morning, when I entered the classroom, the classroom had changed its layout completely. The teachers told me that they had noticed that children did not use the science area often over last two weeks. So they had moved the science table to a more visible spot in the classroom. They wanted to promote the science table, family area and the blocks. Now the family area was in the middle of the room instead of being put at one side the room. The teachers wanted to see how children respond to the changes and the curriculum would be driven by their responses.

\section{The Often House Café (observation, April 22, 2010)}

The layout of the classroom was the same as yesterday's, just added a 'door' (made by two high standing-up mirrors that could block off the 'café' and 'car play' area at the far end of the classroom). The idea of having a café came from Paige during yesterday's morning play. The name of the café "The Often House 
Café" was given by Paris and was written on top of the "mirror door". Some paper was stuck on both "mirror doors", so Cecilia and her co-teacher could write English and Chinese menu on them.

As these observations showed, children's interests and needs and a focus on enabling children to learn through play were at the centre of Cecilia's considerations. International Kindergarten's observation-based planning process and flexible daily schedule allowed Cecilia to make changes in her teaching whenever there was a need. Cecilia regarded this kind of teaching as "a very enjoyable process". This was not surprising since it acknowledged both children's and teachers' agency in teaching and left "greater scope for teachers to exercise professional judgment and discretion" (Hargreaves et al., 2001, p. 9).

The realisation of child-centred philosophy in practice was also evident in Cecilia's self-positioning in teaching not just as "an observer" but also "a supporter" who should not "let children walk with teacher's thinking". I observed Cecilia roleplaying a dog crawling around the classroom and following the instructions given by her owner Hanna, and as a pregnant lady giving birth so children/doctors could operate on her (observation, November 19, 2009). When interacting with children, Cecilia's main concerns were how she could support children's play and learning, whether children enjoyed their interactions with her, and whether she could "get closer to children", which highlighted her focus was on children's needs rather than her teacher status. Cecilia reflected later that her "silly or crazy" play with children might "be considered bad" and "not be permitted according to the old educational philosophy". The "silly or crazy" image of teacher was different to the Chinese traditional image of teacher as authoritative and a knowledge giver (Ho, 2001). Such 
child-led playful interactions were not often observed in Chinese kindergarten, where teachers initiated most of the interactions and were "the dominating participants of the interaction" (J. Liu \& Elicker, 2005, p. 138).

In summary, International Kindergarten's child-centred teaching approaches encouraged Cecilia to attend to individual children's needs and the spontaneous learning embedded in everyday life. Cecilia's narratives "we do not have lessons" and the word curriculum has "almost disappeared from my dictionary" implied individual children were more prominent in Cecilia's thoughts than curriculum or lessons. I observed:

- children could decide what stories they wanted to listen to and what games/music/movement they wanted to play by counting children's votes

- children could choose the areas they wanted to tidy up

- children had opportunities to learn to take responsibility for their own eating by having a buffet lunch together every day.

Letting children/learners lead the teaching and learning, acknowledging individual choices and valuing independent thinking and decision making even during group activities such as tidy-up time, were vividly illustrated in Cecilia's practices. Cecilia encouraged children to be free thinkers and active learners in ways that would enable them to make decisions independently, and so she tended to emphasise freedom and democracy (Ayers, 2004).

Although Cecilia was committed to the child-centred educational philosophy and tended to follow children's interests on almost every occasion, the traditional teacher-centred educational philosophy that valued the teachers' contribution was "difficult to change". The following dialogue suggests this created tension for Cecilia. 


\section{Put art activity out or not (observation, April 28, 2010)}

Cecilia's western co-teacher had been absent for the last two days. This morning, Cecilia shared her two days of work and observation with the coteacher. Cecilia then put six different colours of paints in six paint pots on a rectangle shape table. Each pot had a fine paintbrush in it. Children could choose the paper they wanted to use from the nearby paper shelf. Cecilia said that she would like to see how children use these paints.

While putting the paints out, Cecilia shared with me that she had argued with her Western co-teacher before about whether the teachers should put different art materials on the table. The Western teacher believed that all material should be available for children to use all the time whenever they wanted to. Teachers should not determine what children should use for their artwork. But Cecilia thought that the teachers should introduce different art activities and materials to children, because the 3 and 4-year-old children did not have many experiences in using different art materials. At the end, her co-teacher told her she could do what she wanted to do.

In this scenario, Cecilia was trying to contribute some of her ideas into children's learning and to find a balance between teacher's guidance and children's choices. But challenges to this included:

- How much guidance teachers should offer while working with the idea of "everything follows children's interest"?

- How big a role should children's personal choices play in teaching and learning?

- How should Cecilia work with disagreements between herself and her Western co-teacher, especially when she felt able to challenge her?

When dealing with these challenges, Cecilia learnt to modify the contradictions to accommodate the teacher-led ideas alongside the preferred child- 
centred ones, which echoed Blank's (2009) discussion of how teachers work with contradictory school scripts. For instance, Cecilia put the paints out but did not force children to use them and did not limit children's choices of paper, colour, how and what to paint. The scenario highlighted the two different value systems Cecilia was working with:

- a system valuing collective learning and teacher guidance she learnt from her past experience

- a system valuing children's initiative and individual development practised at International Kindergarten.

These two value systems were also embodied in Chinese and Western teachers' conceptions of teaching, and the teachers' and the parents' priorities of child development. As a teacher who understood both value systems, Cecilia sometimes was "torn". The "torn" feeling was revealed in an incident when the parents and her co-teacher had different answers to the question of whether the teachers should put the coats on for children. Working with conflicting educational ideas could be complex and challenging because Cecilia needed to constantly "find the workable compromises and discriminate juxtapositions" (Blank, 2009, p. 257).

\section{View of children: "I do not find them challenging"}

Reflecting on her own childhood, Cecilia thought her strong personality and naughty behaviour as a child were not accepted by most of her kindergarten teachers. When teaching at the previous kindergarten, Cecilia "found children with a strong personality were very challenging" since they might be troublesome, "did not follow instructions" and "would cause some unexpected incidents". It seems Cecilia's previous view of children was defined by external rules and expectations, 
rather than accepting the child's self. When teaching at International Kindergarten, Cecilia stated "here, all children have very strong personality", but "I do not find them challenging". These statements imply she accepted all children for who they were; even the children whose behaviour was challenging.

Cecilia's story further suggests her experience of two different kindergarten communities had led her to view children differently:

- a kindergarten community that valued obedience and harmony might lead teachers to prioritise group interests

- a kindergarten community that valued children's independence, personality, and self-expression might encourage teachers to respect and accept individual differences.

To respect every child, including challenging children, is required by the recent ECE reforms (Hsueh \& Tobin, 2003). However, unlike Cecilia who reflected on teachers' respect for children by focusing on contextual influences, Chinese ECE professionals have tended to discuss it at the theoretical and personal levels (Hsueh, 2010; Yan Liu et al., 2007). Their foci have mainly been on why, what, and how the teachers may respond to challenging behaviour, rather than examining the influence of the particular kindergarten community and its structure on the construction of teachers' views of children in an everyday context.

Cecilia never once mentioned the word "discipline" when talking about her current teaching. Cecilia said children in her class could really "do what they want at any time". My observations suggested that this was partially true. Children were not allowed to do certain things according to their classroom rules. Cecilia and her coteacher proposed the rules and discussed them with children. The bilingual version 
of the class rules was posted in the classroom so that all children and parents knew about them. Everyone (including the teachers) was expected to follow them in everyday context. Cecilia saw the implementation of the following rules (in Italics) as learning opportunities for children:

- We use quiet voices inside: Learning to consider other people's feelings and activities.

- When one person speaks, the others listen: Learning to respect others.

- Everyone helps at tidy-up time: To develop awareness of taking responsibility.

- This is a 'No Hitting' place: Learning to use appropriate strategies to communicate with others and solve problems.

- We use walking feet inside: To develop safety awareness.

(interview, June 21, 2010)

Discipline and classroom management were a shared effort among the children, teachers and parents (some of them asked for the photocopy version of the rules and wanted to implement them in the family context) with the foci on the children, the environment and the curriculum. Discipline and classroom management were worked out in relationships and in contexts, and were no longer maintained by simply using behaviour management techniques. Cecilia's approach to discipline echoes Ayers' (2001) argument that a technique-focused discipline approach may turn teachers' attention in the wrong direction and may result in passive classrooms where "children's hearts, souls, and minds are being silently destroyed in the name of good management" (p. 11). 


\section{Professional learning}

\section{"I am in training everyday"}

As a newcomer, Cecilia was "following", "observing", "copying" her Western co-teacher's practice, and asking her for advice. Therefore, her co-teacher acted not only as Cecilia's teaching partner, but also a source of knowledge about childcentred teaching and learning who made the abstract philosophy explicit in the everyday context. Having a Western co-teacher who was willing to share her thinking process behind her teaching, and being able to work alongside her for three years, meant Cecilia had access to constant daily mentoring. Informed by Rogoff (1995), Cecilia's professional learning could be seen as situated in everyday practices, in her interactions with her co-teacher, through on-going reflections, and by modifying her practices. As it was for Summer, Shulman's (1996/2004) four aspects of effective learning could be found in Cecilia's professional learning at International Kindergarten. However, International Kindergarten's supportive community seemed to contradict Cecilia's narrative "here, nobody tells you what to do with children". What Cecilia really meant was nobody gave her prescriptive plans or solved practical problems for her, which gave her space and opportunities to actively learn, think and digest others' ideas, then find her own solutions. Reflection was extremely important and Cecilia pointed out "self-development begins at thinking/self-reflection". Cecilia collaborated with other colleagues, especially the Chinese teachers who shared similar educational backgrounds, so that she could access a safe and non-threatening knowledge community (Craig, 2004) and "collective wisdom". The relaxed and "open" kindergarten environment supported 
Cecilia's learning in a loose and informal way. This professional learning approach was quite different to Cecilia's previous formal and controlled professional learning, packed with planned workshops and training that "sometimes did not link to the real practice" and thus "could not be used".

Cecilia's three-year professional learning at International Kindergarten could be seen as a process of "developing capacity to change" (Hargreaves et al., 2001, p. 131) through "communication and coordination during participation in shared endeavors" (Rogoff, 2003, p. 285). Cecilia was active in her own learning, which was situated in a professional learning context where management allowed her time, access to more knowledgeable others and opportunities to explore the kindergarten's ways of teaching. Furthermore, Cecilia's constant reflection on her past and current teaching, and her collaboration with others may enable her to connect the meaning-making process with her personal practical knowledge, children's learning, and the colleagues' ideas. These are the features of satisfying learning experience for teachers (Craig, 2010b).

\section{Feelings and professional identity}

\section{"I never thought being a teacher could be this happy"}

"No passion", "no freedom", "no desire to learn" were phrases Cecilia used to describe her feelings about teaching at the previous local kindergarten. In Cecilia's description, the local kindergarten had a dominant-subordinate management style with the director treating the teachers as "prisoners" which left Cecilia with a feeling of lost freedom. It had a prescriptive curriculum, and strict rules and regulations that placed Cecilia in a "passive" position and required her to 
do things by "observing and following all rules and regulations". The local kindergarten seemed to honour social order, curriculum reproduction, and external power rather than "humanist values like freedom, reason, autonomy, reciprocity" (Blacker, 1998, p. 350). Cecilia's "weary and tired everyday" feelings may have been the negative effects of contextual constraints that could result in emotional exhaustion, depersonalisation and reduced personal accomplishment (Skaalvik \& Skaalvik, 2009).

However, it was not only negative feelings that Cecilia experienced at the local kindergarten. Cecilia said she "felt happy" when she was with the children, and "found a little bit interest in teaching" when actively exploring an emergent learning project when making "an Olympic wall display" with the children. These narratives suggest children, and the active roles teacher and children played in teaching and learning were the real motivators for Cecilia's teaching, which may also explain why Cecilia was committed to the child-centred pedagogy at International Kindergarten.

Cecilia reflected on her struggles when she first joined International Kindergarten with the words "it was hard to adjust", "I was useless", and "did not know how to teach". Through these phrases, Cecilia painted a self-portrait of a newcomer as a de-skilled and unequipped teacher who had lost control of her teaching. The negative feelings may be a result of "culture shock" (Rogoff, 2003, p. 13) due to the different educational ideas Cecilia encountered as a newcomer, which I have discussed earlier.

"Enjoyable", "happy", and "fun" were how Cecilia described her current feelings about teaching. These positive feelings may come from Cecilia's close relationships with children. They were also influenced by the moral, professional 
and physical aspects of teaching: the shared purposes of learning through the activities that "both children and I would want to do", the reduced professional power distance through some "silly or crazy" moments, and the physical closeness between Cecilia and children through hugs, sharing snacks with children every day and being involved in children's play. Moreover, the child-centred classroom ethos and emergent learning approach was creative and active rather than "static". Cecilia recognised her growing ability in "responding to children's spontaneous learning", and experienced "a sense of achievement" when observing children's development. Hargreaves (2001) argues, teachers' emotions are closely related to the sociocultural, moral, physical, professional, and political distances with not only children, but also parents, colleagues, and management. My interviews with the parents indicated they respected, praised, and appreciated the teachers' work. Moreover, my earlier discussions about the support Cecilia received from her co-teacher and the Chinese teachers, and the kindergarten director's management approaches show the closeness of the relationships among Cecilia, her colleagues, and management. In this sense, the close social relations Cecilia had with the people around her may have been an enabling factor for her positive feelings about teaching.

\section{Professional identity: knower, unknown, knower}

Cecilia's professional identity seemed invisible and hidden in the narratives about her time at the previous kindergarten, but started to emerge in the International Kindergarten context. As a newcomer, she regarded herself as "an OK teacher" who "knew how to teach children" based on her previous teaching 
experience. But migrating to a new teaching community made Cecilia a stranger in this new community of practice who "knew nothing" about the International Kindergarten's child-centred pedagogy. The change of teaching community required Cecilia to embrace the unknown and the changes with curiosity and open mind (Greene, 1973). As I discussed earlier, Cecilia's three-year professional learning helped her understand child-centred educational ideas both theoretically and practically. Thus Cecilia became a knower again of "what is good for children".

\section{A sense of empowerment: wanting to "share" and "influence more people"}

Like Summer, a sense of confidence and empowerment emerged in Cecilia's narratives. When anticipating the future, Cecilia said she wanted to share what she knew about Chinese and Western educational ideas and practices, and to "influence more people". Cecilia's attention to parenting may be influenced by her own childhood experiences, as her mother's discipline changed her personality. With growing confidence and firmly believing in what she knew about ECE, Cecilia started to criticise the Chinese education system and dream about the possibility of making changes "in the notion of parenting". Cecilia's critiques and the articulation of her dream can be seen as a hope emerging from her "concrete relationships with [the] students, [her] willingness to be there for them and to not be defined by the accountability culture that now saturates schools" (Edgoose, 2010, p. 403). Moreover, the director's management style of ensuring the "equality of voices" allowed Cecilia autonomy and freedom, and enabled her to actively "exercise the talents and capacities that the new conceptions of teaching require" (Shulman, 1988/2004, p. 313). These enabling factors may lead Cecilia to becoming an 
empowered person, who is self-determined, cares about what she is doing, is confident about her ability, and knows the possible impact she may make on others (Quinn \& Spreitzer, 1997).

\section{Summary}

International Kindergarten's philosophy, management and practices represented foreign/Western cultural values, democracy, liberty, and individuality. Child-centred educational ideas guided its curriculum, planning, practice, and the social relations within the kindergarten structure. These cultural values and guiding educational ideas were represented consistently and cohesively in the kindergarten scripts for Summer and Cecilia to draw on. They also became catalysts for Summer and Cecilia's transformation because they made International Kindergarten's vision and identity visible and explicit (Blank, 2009). However, despite the dominance of Western educational ideas, some traditional educational ideas still acted as an implicit cultural logic (Tobin et al., 2009) in Summer and Cecilia's thinking and practices. Summer and Cecilia experienced tensions in their teaching approach because of the change of teaching community and irrelevance of their previous repertoires of teaching practice. But they seemed to have worked out most of the challenges and tensions over the three years, supported by some unique features of International Kindergarten's structure and professional learning approaches; for instance: 
- teaching alongside a Western teacher

- being supported by the Chinese teacher group

- having two to three years to increase their participation and contribution in the community

- flexible daily schedule

- practising child-centred and observation-based ways of planning and teaching

- informal and contextualised professional learning structure.

Therefore, collaboration with a more experienced teacher, being accepted by and integrated into a safe community, time and space for the teachers to learn actively in practice, and relevant pedagogical tools emerged as enabling factors in Summer and Cecilia's transformation. Similar findings have also been reported in Western school and professional development contexts in recent years (Craig, 2004; Dehli \& Fumia, 2008; Morrell, 2003; Nuttall et al., 2009; Scherff, 2008).

Three common themes emerged from Summer and Cecilia's stories. Firstly, both of them accepted, committed to, and firmly advocated for the child-centred educational philosophy, which was aligned in their everyday practices. Understanding, connecting, and supporting the individual child in front of them was the most important agenda for them, which changed their overall experiences of teaching.

Secondly, Summer and Cecilia experienced a change of feelings from their previous to their current situations, from losing their heart in teaching to feeling happy and satisfied. With the support of International Kindergarten's management and their colleagues, Summer and Cecilia embraced the emotional and intellectual 
challenges that they experienced in learning the unfamiliar Western-valuesdominated kindergarten culture and pedagogy, working with the Chinese and Western educational ideas, and relating to their co-teachers with growing confidence.

Thirdly, there was a strong sense of empowerment in Summer and Cecilia's narratives. My analysis indicated that International Kindergarten's management, structure, and professional learning played a crucial role in the teachers becoming empowered; each of them had changed their conforming position in the previous situations to now being accepted as an equal and valuable member of the community. This led Summer and Cecilia to realise their agency, become confident in their ability, and feel satisfied with their teaching and learning. Summer and Cecilia's stories may thus provide some hope for other Chinese teachers - that there is a positive way through the complexities with which they are currently struggling, if teachers can teach in a child-centred, reflective, and collaborative teaching community with on-going professional development embedded in everyday practices, and if each class can have two teachers co-teach most of the time each day with small class numbers. 


\section{Chapter 11: Conclusion}

The overarching research question of this study was to understand the tensions six Chinese EC teachers experienced in their teaching and learning. I analysed the teachers' stories in the three-dimensional narrative inquiry space (Clandinin \& Connelly, 2000), and examined them in the light of relevant literature in order to understand why and how the experienced tensions influenced the teachers. Through individual teachers' poetic stories and my analysis, I found that:

- In the contemporary Chinese ECE context where an ideological shift from traditional to modern occurred, the teachers were working with multiple and contradictory educational ideas and practices that created multiple truths of teaching and learning.

- Intellectual, pedagogical, socialisation/enculturation, and personal tensions were identified in all six teachers' everyday teaching and learning experiences.

- Four factors within kindergartens - the kindergarten culture, the organisational structure, the curriculum and the professional learning approach - were significant in shaping the teachers' experiences of and responses to traditional Chinese and modern educational ideas and practices, and the teachers' practices.

In this concluding chapter, I discuss the interrelationships between the findings identified in the analysis of the three paired narratives in Chapters 6,8 , and

10. Nuances between the multiple and contradictory ideas and practices are 
examined, along with the tensions teachers experienced in their teaching and learning. These tensions emerged from the uncertain and ambiguous moments when the teachers tried to make sense of teaching and learning at the intellectual, pedagogical, social, and personal levels. I also analyse enabling and constraining factors that have shaped the teachers' experiences. I argue that the situated teaching and professional learning context contributes greatly to Chinese EC teachers' teaching and learning experiences in the contemporary urban Chinese context. Implications are identified in several areas that I believe could contribute to teachers being better supported in teaching and professional learning. Directions for future research, validity issues and limitations of this study are also discussed.

\section{Co-existence of Multiple Educational Ideas}

As described earlier, the co-existence of multiple and contradictory educational ideas is obvious in the teachers' narratives, curriculum documents and kindergarten scripts. In this section, I explore the nuances between multiple truths of teaching and learning revealed in the teachers' stories.

\section{About images of the child}

To respect children and to cater for individual children's learning and development needs are two leading educational philosophies outlined in the Chinese government's ECE regulations (M. Zhu, 2002). This is a big change from traditional Chinese culture where the concept of self does not really exist, and the 
self is often defined according to the group/society's agendas (Lau, 1996). The multiple images of the child revealed in the teachers' narratives reflect this change. In this section, I talk about the main constructions and images of the child, and will later draw on this discussion in describing the pedagogical tensions the teachers experienced.

The traditional Chinese image of the obedient and disciplined child is revealed in all six teachers' childhood memories but their experiences of this cultural image of the child (Bai, 2005a), influenced by Confucian thinking, were different. Some of them, like Angela and Summer, remembered it positively but others responded to it negatively as revealed in Selina and Cecilia's stories. This is possibly because of disconnections between the individual child's personality and the cultural views of the ideal child as obedient and disciplined.

The disconnection between the individual child's personality and the cultural image of the child may create a challenge for discipline and classroom management for the teachers. At Public Kindergarten where group teaching and pre-set and structured activities dominated everyday teaching and learning practices, this challenge concerned Linda and Angela greatly. However, it was not mentioned in Summer and Cecilia's narratives of teaching at International Kindergarten where the kindergarten structure, curriculum, teaching approach, and daily schedule were flexible and oriented to individual children's interests and needs.

Some developmental psychology theories have identified normative developmental trends and stages that may be applied to all children. These theories illustrate a universal image of the child, which was highlighted in the Public Kindergarten director's narratives as she expected the teachers to use children's 
general developmental characteristics to guide the pre-set planning process - the only planning approach practised at Public Kindergarten. The universal image of the child was also revealed in the narratives of the Private Kindergarten teachers, Selina and Cherry, about the use of "developmental goals" or "learning goals" in their teaching and learning. However, Selina and Cherry tended to use the universal image of the child to help them understand individual children's development better, rather than to guide the choices of teaching content and instruction. The teachers' stories suggest that different curricula, teaching approaches, the school scripts that the particular curriculum and kindergarten context created, and the pedagogical tools (for instance planning sheets and assessment tools) teachers utilized influenced the pedagogical images of the child in the teachers' mind.

All the teachers expressed the need to respect and observe children in everyday teaching. This reflects the modern views of the child that emphasise the child's central position in teaching and learning. However, only the teachers teaching at Private Kindergarten and International Kindergarten mentioned following a child's interests. This may be because child-centred and observationorientated teaching approaches were implemented at both kindergartens: for instance, the project approach (Katz \& Chard, 2000) at Private Kindergarten, and the emergent play-based curriculum at International Kindergarten.

The teachers' experiences of working with the child and how they view children may be influenced by whether the kindergarten's daily schedule and curriculum are flexible and value individual children's voices, and whether the class size and the teacher-child ratios allow the teachers to pay close attention to individual children. This influence is evidenced in the teachers' different personal 
views of children when working at their respective kindergartens. At International Kindergarten, Summer regarded all children as "angels" and Cecilia felt children in her class were not challenging at all. As I have discussed in Chapter 10, they accepted children as who they were and as unique individuals rather than expecting them to conform to the group, which enabled them to develop a positive view of every child, including some "challenging" children who may be understood "on the basis of their deficits" (Ayers, 2004, p. 142). In contrast, the teachers at Public Kindergarten and Private Kindergarten expressed mixed feelings towards children. The teachers saw children nowadays as clever and assertive with strong personalities. But in contexts where there were disconnections between the individual child's agendas and the group's needs, some children could be difficult to handle. This caused frustrations and negative feelings for the teachers working with them. It seems that whether the teachers tend to define the child as a unique individual or according to the group needs and requirements determines how they see children, and this view is in turn influenced by factors such as the particular kindergartens' structure, curriculum, and daily schedule.

The preceding discussions provide some support for Ebbeck and Warrier's (2008) argument that the construction of different images of the child is influenced by "an image of child within us" (p. 247) based on our own experience of childhood and our work with children. However, it is also clear that external factors such as public opinion, dominant school scripts, and kindergarten structures also shape teachers' views of children. 


\section{About pedagogy}

The recent Chinese ECE reform initiatives promote children's active and central position in teaching and learning in order to change the traditional teachercentred approaches. Teacher-centred, child-centred, and teacher-child-dualsubjectivity are three pedagogies revealed in the teachers' stories. Teacher-centred pedagogy is influenced by the traditional Chinese education that values a hierarchical but harmonious teacher-child relationship in which the teacher holds authority and power in teaching and learning (Hofstede, 1986; Hu, 2002). All the teachers experienced teacher-centred pedagogy as students themselves. They all regarded teacher-centred pedagogy as a traditional approach, in contrast to childcentred pedagogy. Child-centred pedagogy is a Western approach rooted in progressive education and the Western cultural context. This "naturalised, individualised model of childhood" (Burman, 2008, pp. 261-262) is quite different to the traditional Chinese collective cultural values and teacher-centred pedagogy. Therefore, Chinese scholars promote the idea of teacher-child double-subjectivity as a way of balancing the teacher-centred and the child-centred pedagogies in Chinese kindergartens. Previous chapters revealed the teachers had different experiences of these pedagogies in particular kindergarten contexts.

Public Kindergarten's teachers used three different phrases - child-centred, child-development-orientated, and teacher-child-dual-subjectivity - when talking about the child's position in teaching and learning. However, these terms weren't clearly defined in practice as my analysis showed Public Kindergarten's curriculum, planning and daily schedule reflected a prescriptive and teacher-centred pedagogy. 
This may explain why a common thread emerging in Linda and Angela's stories was that they wanted to have a close relationship with children but felt constrained. At Private Kindergarten, both teacher-centred and child-centred pedagogies were practised within their dual-curriculum approach through child-led projects and structured subject-based teaching. Selina and Cherry expressed their frustrations at working in this dual-curriculum model since they anticipated an ideal child-centred pedagogy would guide all their teaching practices, but the strong influence of the teacher-centred pedagogy prevented this in reality. International Kindergarten, which was entirely independent and did not have to follow any of the Chinese ECE reforms, had a clear focus on promoting child-centred, emergent and play-based pedagogy. These values were represented consistently and cohesively in the kindergarten scripts for Summer and Cecilia to draw on. While they both felt positive about this child-centred pedagogy, teacher-directed pedagogy still implicitly influenced their thinking and decision-making.

The three kindergartens differently translated and incorporated modern educational ideas promoted through either the reforms or a Western curriculum like EYFS into their practices. Teacher-centred pedagogy is embodied in the teachers' and some kindergarten's repertoires of practice. Child-centred pedagogy is no longer foreign to Chinese teachers and is regarded as an ideal pedagogy by some teachers. A balance between teacher-centred and child-centred pedagogies is sought in the local Chinese kindergartens (H. Li, 2005). However, as the analysis of the teachers' stories showed in Chapters 5 to 10 , the teachers experienced some pedagogical tensions when trying to find a balance. This will be discussed more fully in the section about pedagogical tensions. 


\section{About play}

Play, in Chinese as yóuxì, is regarded as children's basic activity at kindergarten in the Chinese ECE reform context (Ministry of Education in People's Republic of China, 1996). Promoting play in ECE contradicts the traditional Confucian view of an ideal child, as being obedient and controlled rather than free and playful. This view is critiqued in the modern context as failing "to recognize the nature of children and attributes of childhood" (Bai, 2005a, p. 11). One purpose of promoting play/yóuxì in ECE is therefore to change the teacher-centred and lessonbased formal educational approach (M. Zhu, 2002).

The teachers' stories referred to two kinds of play in actual teaching free/spontaneous play (wán) and edu-play (yóuxì). International Kindergarten's curriculum and everyday practices were based on children's free/spontaneous play. Edu-play was emphasised at Public Kindergarten through multiple planned sessions for different kinds of play - social-dramatic play, construction/block-Lego play and learning-centred activities - in their daily schedule. Free/spontaneous play only occurred during transition times. Private Kindergarten's dual-curriculum valued both free/spontaneous play and edu-play. For instance, projects emerged from children's interests that teachers observed during free/spontaneous play, but the activities teachers planned for structured teaching and to extend the projects were either edu-plays or activities organised by the teachers. Selina and Cherry's comments that children did not have much time to play may indicate that the actual teaching practice at Private Kindergarten emphasised edu-play and structured teaching more than free/spontaneous play. Valuing edu-play in teaching and learning echoes the 
Confucian view of play being to "serve self-cultivation in moral practice" (Bai, 2005a, p. 12), and tends to lead the teachers to focus on their own role of making the play educative. In contrast, valuing free/spontaneous play highlights children's leading role in teaching and learning, ahead of the prescriptive curriculum, pre-set planning, and teachers' instructions.

\section{About teaching, learning and everyday life}

Another influential modern educational idea is that children learn and develop through their interactions with the surrounding environment, which is in contrast to the traditional teacher-centred and lesson-subject-based teaching and learning (M. Zhu, 2002). This idea requires teachers to develop a broader view of curriculum rather than just understanding it as lessons in the class. Teaching in this sense does not mean just teaching lessons but also integrating everyday life into teaching and learning. However, should this integration be the integration of different subjects/learning areas, or the integration of learning content and children's interests/experiences, or the integration of every possible learning opportunity with everything happening in the kindergarten? Should the integration be achieved through a structured approach or a flexible, emergent, and unstructured approach?

Learning and everyday life were integrated differently in the three kindergartens. At Public Kindergarten, the obvious evidence of integrating learning and everyday life was that Everyday Life Activities (shēnghuó huódòng) were included in planning and teaching. However, inserting Everyday Life Activities into daily kindergarten life did not mean the integration of learning and everyday life, 
rather it was more like a new subject to learn. Angela's story also showed the broad view of curriculum seemed to be realised only at the theoretical level and not in actual practice. At Private Kindergarten, the integration of learning and everyday life wasn't clearly articulated by Selina and Cherry. However, it happened when the teachers were supporting children's spontaneous play, and children's projects emerged from interests experienced in their daily life in the kindergarten. At International Kindergarten, different kinds of activities emerged from children's everyday life in a spontaneous way. Practical decisions, such as whether lunch should be buffet style or not, were educational decisions as a result of weighing up multiple learning opportunities. The integration of learning and everyday life was achieved through the flexible and unstructured daily schedule, attention to everyday learning opportunities throughout the day, and a mind-set reflected in Summer's words "the whole day I am teaching".

\section{Tensions Experienced in Teaching}

Informed by Deweyan and socio-cultural views of learning as experiential, situated, relational and multifaceted (Bruner, 1986; Dewey, 1938; Rogoff, 2003; Shulman, 1996/2004), my analysis of the teachers' stories revealed that the teachers experienced tensions in four interrelated and equally important aspects of their teaching and learning: 
- intellectual tensions when (re)conceptualising teaching and learning

- pedagogical tensions when relating to and interacting with children

- socialisation and enculturation tensions when becoming and being a member of a particular teaching community

- personal tensions when balancing their professional personal life.

The teachers experienced tensions when trying to position themselves in the lives of children, kindergarten, community, contemporary urban Chinese early childhood context and their personal and family lives. The tensions were greater when there were imbalances, conflicts and disconnections for the teachers between:

- prior learning and current practice

- the ideal teaching and the reality

- personal beliefs and kindergarten requirements

- their personal sense of agency and the particular kindergarten structure they were embedded in

- their personal and professional lives.

Similar disconnection was also identified by Meng and Yu (2007) in their study of a young Chinese EC teacher's thoughts of leaving teaching, but not the possible disconnection between teachers' personal sense of agency and the particular kindergarten structure. The six teachers' stories told in the current study further suggest that the tension between a teacher's agency and the particular kindergarten structure seem more significant than other aspects, as it is reflected in all four kinds of tensions - intellectual, pedagogical, socialisation/enculturation, and personal - the teachers experienced. The teachers' responses to the tensions varied. Sometimes a teacher's experience of the tensions would lead her to resign 
and/or leave teaching as Linda and Selina did. At other times a teacher might use the opportunity to work with tensions as a catalyst for the development of her own educational philosophy, belief, practice, identity, and agency as Summer and Cecilia's stories revealed. Therefore, it is worthwhile analysing what, why, and how the tensions were reflected in the six teachers' stories, and the factors that seemed to influence how the teachers responded to the tensions.

\section{Intellectual tensions}

Intellectual tensions were revealed through the multiple practical dilemmas that the teachers shared in their stories, for instance:

- decision of content: whether to teach according to children's aptitude and the prescribed content or children's interest

- priority of teaching: whether it is more important to execute lesson plans and achieve pre-set learning goals or to respond to children's emergent thinking and extend their learning beyond the lessons

- method of learning: whether young children should learn through play, through inquiry, or through structured formal teaching, or a combination of all of them

- method of teaching: whether knowledge should be transmitted, constructed or co-constructed

- form of teaching and learning: whether to teach and learn in big groups, small groups or individually

- role of curriculum: whether curriculum is a context-free and prescribed manual for teaching, a guide for understanding children, teaching and learning, or broad and emerging from everyday life at kindergarten? 
These practical dilemmas make earlier discussions about the co-influence of traditional and modern educational ideas explicit in everyday teaching contexts. The wide range of educational ideas and concepts also reflects the complexity and multifaceted nature of teaching $(H$. Li, 2005). Among these ideas, some can be regarded as public theory promoted by the experts and the reform initiatives; and others are private theory grounded in the teachers' personal experience to help them make meaning of the world (Bullough Jr. \& Gitlin, 1995). On the one hand, the specific kindergarten's curriculum and daily practice provided the teachers with certain experiences, concepts, and understandings of teaching and learning (Apple, 1990; K. Hall \& Murphy, 2008) that were public and authoritative. On the other hand, the teachers' conceptions of teaching could be rooted in their personal practical knowledge, obtained from their experiences of teaching and learning both as a student and a teacher over time (Brilhart, 2010; Connelly \& Clandinin, 1988) and this might be private and intuitive. The teachers' narratives showed that the way ideas were introduced and experienced might influence a teacher's implementation of the ideas in practices. The situated kindergarten curriculum context, a teacher's personal practical knowledge, her personal responses towards the multiple truths of teaching and learning, and how experienced she was as a teacher were four interconnected aspects that might influence her experience of intellectual tensions.

Summer and Cecilia's experiences of teaching and learning at International Kindergarten provides an example of learning new ideas and teaching approaches in context and in practice. They learned Western educational ideas mainly through “intent participation" (Rogoff, Paradise, Arauz, Correa-Chávez, \& Angelillo, 2003, p. 176) by observing and listening to on-going child-centred activities in the shared 
endeavour when working alongside Western co-teachers and practising the project approach. This active and contextualised way of learning made the unfamiliar Western educational ideas explicit to them, and Hargreaves et al. (2001) believe this is important in allowing teachers to imagine possible changes in their teaching.

Summer and Cecilia struggled to define and explain the role of curriculum when teaching at International Kindergarten. This is perhaps because of the mismatch of their theoretical knowledge learnt from previous experiences of prescriptive curriculum and their current emergent and negotiated teaching at International Kindergarten. Other teachers did not mention this struggle. The Private Kindergarten teachers expressed more challenges around the teaching methods and finding the balance between learning through play and structured lessons than about other aspects of learning. This can be seen as a consequence of teaching in a dual-curriculum context and their effort to accommodate multiple but contrasting concepts in practice. At Public Kindergarten, Linda and Angela, a beginning teacher and a newcomer to the community, reported their uncertainties about content, methods of teaching and learning, discipline, and class management.

Linda and Angela, teaching at Public Kindergarten, experienced more practical dilemmas than other teachers. This may be because the teacher-directed and developmental-goals-orientated teaching approach in Public Kindergarten's practice had a stronger influence than the child-led and emergent learning promoted by the reform initiatives and Public Kindergarten's curriculum. There may be three reasons causing this situation. Firstly, the teachers' stories suggest there is a cultural tension about the topic of valuing children's interest or aptitude. Many Chinese kindergarten teachers do not consider children's interests first. Unlike 
American teachers who put children's interests at the top of their priority list, Chinese kindergarten teachers often prioritise developmental stages, goals, and children's abilities in planning and teaching (J. Wang, Mao, \& Elicker, 2007). This may reflect one of the fundamental ideas of Chinese contemporary educational philosophy, inherited from traditional Chinese education (M. Gu, 2006), to teach according to children's aptitude rather than children's interest.

Secondly, the teachers' stories suggest there is a practical tension about when children's interests and individual children's learning should be supported. Individual children's interests were mainly recognised and supported during learning centre activities at Public Kindergarten. Learning centre activities were classified as individualised activities orientated to children's interests, as opposed to the teacherdirected group activities that follow pre-set themes and prescriptive plans. However, Linda's narratives showed that children's interests would emerge "whenever and wherever", both inside and outside the scheduled learning centre activities. Moreover, teaching solitarily for most of their time in the class may also have created challenges for the teachers and inhibited their attention to individual children's interests and learning, as they had to cope with both the group and the individual children's needs on their own.

Thirdly, Public Kindergarten's director chose to focus on teacher-directed group teaching for professional learning rather than understanding individual children and individualised learning, since "it could be prepared and pre-set". This, in her opinion, might be easier for the teachers to grasp than supporting "children's individual activity which requires teachers to have multiple skills and ability due to its emergent and instant nature" (interview, December 23, 2009). The teachers were 
being taught about child-initiated and constructivist learning in a very didactic topdown way, rather than in a way that responded to and/or emerged from teachers' interests or needs. It seems that the child-led and emergent learning was not articulated explicitly and cohesively in Public Kindergarten's professional learning and curriculum. This may have hindered the teachers' understanding, commitment, and development of their capacity and ability to transform their practices from teacher-led to child-led.

This analysis supports some Chinese scholars' (Y. Peng, 2009; Yi \& Pang, 2005) argument that personal experience, promoted educational ideas, and the specific kindergarten culture can influence Chinese EC teachers' conceptualisation of teaching and learning. The teachers' stories have also vividly illustrated how these factors influenced their teaching.

\section{Pedagogical tensions}

The teachers reported some tensions concerning the teacher-child relationship and interaction: should it be teacher-directed, or child-led, or teacherchild-dual-subjectivity pedagogies? As I have mentioned at various points throughout this thesis, traditionally, Chinese teachers would adopt a scholastic pedagogy influenced by the Confucian doctrine that prioritises knowledge transmission, teacher's control of learning contents, and teacher authority in discipline and teacher-student interactions (M. Gu, 2006). The teachers' childhood stories and their stories of learning at the training college revealed the long-lasting legacy of scholastic pedagogy in Chinese education. Their cultural repertoire of teaching practice (Gutierrez \& Rogoff, 2003) embodied this traditional teacher- 
directed educational pedagogy, which is difficult to change as Cecilia pointed out in Chapter 9. The traditional teacher-directed scholastic pedagogy is obviously different to the relational pedagogy or humanistic pedagogy that advocates for children's central position in curriculum. It also values the learning process more than achieving pre-set learning outcomes (Ayers, 2004; van Manen, 1991). The authoritative role of traditional Chinese teachers is also different to the Chinese ECE reforms' requirement of teachers being "the supporter, the partner and the guide" in children's learning (Ministry of Education in People's Republic of China, 2001). Therefore, pedagogical tensions arise when teachers like Linda and Angela encounter the promoted child-centred pedagogical relationship that they are struggling to put into practice, and the teacher-directed Chinese traditional scholastic pedagogy that is embodied in their inner learning landscapes at the same time. This analysis may help to explain why teacher-directed pedagogy has continued to influence the teachers' practical decision-making processes.

The teachers experienced pedagogical tensions differently, and their different experiences closely related to the particular kindergarten's pedagogical position as expressed in their philosophy and curriculum, and kindergarten culture and structure. The three kindergartens used different phrases to highlight their particular version of child-centred learning:

- "child-development-orientated" at Public Kindergarten

- "children foremost" at Private Kindergarten

- "everything follows children's interest" at International Kindergarten. 
These guiding philosophies can be regarded as cultural tools (Cole, 2000) that may mediate the kindergarten's operation, curriculum and everyday practices. However, only the "following children's interest" phrase suggests a teacher's follower position when working with children. The other two phrases convey less obvious pedagogical implications for teacher-child relationships in actual teaching. In fact, "child-development-orientated" implies a developmental-goals-centred pedagogy. This may be why Linda and Angela prioritise achieving their planned teaching goals, rather than meeting children's emerging interests. Private Kindergarten's "children foremost" philosophy may sound a bit broad and vague to inform pedagogy and practice, but it does place children before the teachers. Moreover, the project approach and observation-based learning stories reflect a child-centred pedagogical position that Selina and Cherry valued.

Another factor contributing to pedagogical tensions may be how the individual child is acknowledged in teaching. Is it the individual child in front of the teachers in the class who guides the teaching and learning process, or the cultural image of the child, or the pedagogical image of the child? Linda, Angela, Selina, and Cherry's stories suggest cultural and pedagogical images of the child seem more visible at Public Kindergarten and Private Kindergarten. At International Kindergarten, the individual child is the most visible of the three images of the child. International Kindergarten's emergent play-based curriculum directed the teachers to pay attention to the individual child's interest on a daily basis. Knowing clearly what image of the child they were working with, and adopting a teaching approach consistent with the promoted image seemed part of the reasons why Summer and Cecilia experienced fewer pedagogical tensions. Moreover, Summer and Cecilia 
learned to accept all children for who they were, rather than defining them in a hierarchical relationship determined by rules and regulations influenced by Confucianism (Lau, 1996). This may explain why discipline and class management did not concern Summer and Cecilia but caused great challenges for Linda and Angela.

The teachers from Public Kindergarten and Private Kindergarten reported pedagogical tensions around the relationships between:

- prescriptive planning and children's interests

- the group's needs and individual child's needs

- the accustomed teacher-directed practice and the anticipated change towards child-centred practice.

There is a difference though. Selina and Cherry reported that their childcentred educational stance emerged from their positive experience of the project approach at Private Kindergarten, while Linda and Angela from Public Kindergarten struggled to find an appropriate educational stance to exemplify the promoted but vaguely explained notion of teacher-child-double-subjectivity pedagogy in practice.

\section{Socialisation and enculturation tensions}

Teachers are not only individual professionals but also members of specific teaching communities that define and regulate their practices (Shulman, 1998/2004). When being socialised into the different kindergarten communities, either from the training college or from a previous kindergarten, the teachers shared some tensions that were caused by the conflicts between: 
- the individual teacher's teaching and the others'/exemplified teaching

- the teacher's autonomy and the particular kindergarten's requirements and control

- the teacher's idealistic views and the reality of everyday teaching and learning

- the teacher's relationships with their inner world and the external forces.

The teachers' stories evoke the important role of the particular kindergarten's work culture, for instance, the kindergarten's management style, the types of control, the curriculum form, and the power relations, that may influence the teachers' socialisation into the new teaching communities. In particular, the three kindergartens were all different in their choices of whether to prioritise kindergarten structure and control or teacher agency and autonomy, prescriptive curriculum or children's emerging interests, and hierarchical power relations or equal voices and shared understanding. If these characteristics were put on a continuum, Public Kindergarten would be placed at the end that values structural and tight control, and where the execution of curriculum seemed paramount and power was exercised through a hierarchical management structure. International Kindergarten would be at the other end with an emphasis on teachers' agency, autonomy, individual children's needs, and shared power among the members of the community. Private Kindergarten might be in-between since it adopted collaborative and reflection-based curriculum management strategies while taking "technical and bureaucratic" (Apple, 1995, p. 128) and centralised control of the teachers. The teachers' feelings about teaching vary: Summer and Cecilia were very positive but Linda and Selina felt so negative about teaching at their respective 
kindergartens that they resigned. This finding supports Apple's argument that although work culture is often invisible to the outsiders, it has great influence on (re)skilling, and deskilling or intensifying teachers and teaching.

The teachers explained that as a newcomer they learned how to teach from more experienced teachers around them. In the Chinese kindergartens, the more experienced teachers are often regarded as role models, exemplars, or master teachers with authoritative advice who can pass on their experiences to the novice (Mu et al., 2008). But the knowledge they pass on is only from their own vantage point and this can be confusing when multiple truths co-exist, and "one situation might have multiple ways to deal with it" as Angela stated. Instead of simply conforming to the more experienced teachers' knowledge and their ways of teaching when they first arrived at International Kindergarten, Summer and Cecilia seemed to connect the more experienced teachers' knowledge with their own past experiences, observation of children and contexts, through a process of active reflecting, comparing, and meaning-making. This inward-outward approach of learning to become and be a member of the community is contextualised, informal, active and critical, which Hargreaves et al. (2001) believe is important for developing teachers' capacity for higher-order thinking. It seems that the learning from more experienced teachers can be a double-edged sword for teachers depending whether the more experienced teachers transmit the knowledge to the others in formal, structured and authoritative ways, or are able to share, negotiate and construct new meanings of teaching and learning collectively with others in a community that values shared leadership and regards everyone as a knower. Public Kindergarten's professional learning structure tended to reflect the former approach while the 
latter approach seemed visible at International Kindergarten.

\section{Personal tensions}

Teachers' professional role cannot be separated from their multifaceted personal self (Shapiro, 2010). Therefore, teachers may experience tensions when their professional life overtakes their personal life, and when their inner learning landscape is irrelevant to the situated professional knowledge landscape. This tension may reflect the teachers' struggles between the inner self and the external world: the self and the structure, the teacher's agency and the external requirements and control, being an individual and being a professional teacher in ways that the particular kindergartens and society expect.

In China the teaching profession is traditionally understood as being altruistic (G. Li, 2009). Chinese teachers are often praised for living a life like a silkworm or a candle that contributes everything and brings light to the world by sacrificing themselves. This may be why professional life overtaking personal life seems to be the norm for many Chinese EC teachers. It is only in recent years that Chinese EC teachers' emotions and feelings have become a topic of research (J. Liu et al., 2007). Researchers have found many Chinese EC teachers are living their life with heavy workloads and packed with professional learning and research activities, experiencing dictatorial or poor management, and suffering from a lack of self-value and satisfaction (Lai, 2011b; Liang \& Feng, 2004; Yuming Zhang, 2004).

The teachers from Public Kindergarten and Private Kindergarten expressed their struggles to meet their particular kindergarten's requirements and keep themselves happy and satisfied. Linda, Angela, Selina, and Cherry's stories painted a 
picture of a busy and intense work environment where working late, taking work home, structured professional activities and meetings, and not even having time to go to the toilet seemed normal. Similar feelings were also expressed in Summer and Cecilia's narratives about their previous teaching. In contrast, Cecilia described International Kindergarten as a "relaxed and open" environment that gave teachers freedom and autonomy to exercise their knowledge and talent. Such differences may reflect the individual kindergartens' strategies of managing teachers' time as Hargreaves (1994) argues "time is the enemy of freedom" (p. 95). Public Kindergarten and Private Kindergarten tended to define and control teachers' time by setting up detailed and structured daily schedules, preparation, planning, meetings, and professional learning activities etc. However, International Kindergarten tended to give "more responsibility and flexibility to teachers in the management and allocation of their time, and to offer them more control over what is to be developed within that time" (p. 114). Therefore, Summer and Cecilia no longer suffered high work intensity and tight control. They were given educationally meaningful tasks to do with their time and these tasks were immediately connected to their daily work, such as observing, understanding, interacting with children and creating enabling environments for children's learning.

The tight or loose control of curriculum and teaching may imply a dilemma for policy-makers and kindergarten directors about whether to trust in teachers and allow autonomy in teachers' teaching and learning, or to trust in the process. Directors or policy makers' responses to this dilemma may reflect that their priorities are to either foster more meaningful social relationships in the community, or to invest in abstract systems as "a condition of [teacher's] existence" (Hargreaves, 
1994, p. 252). The teachers' stories reveal that in some Chinese kindergartens, the kindergarten structure, prescriptive curriculum and planning, pre-set developmental goals and learning outcomes often dominate the teachers' attention, time and energy. The teachers thus become the managers of the curriculum and the class (Apple, 1995), rather than "the supporter, the partner and the guide" in children's learning as the promoted ideal (Ministry of Education in People's Republic of China, 2001). The teachers' agency may be weakened in Public Kindergarten's controlled planning process, with the many written tasks Private Kindergarten's management required the teachers to do, since they may be "caught up in the spiral of intensification, bureaucratically driven initiatives to exert tight control" (Hargreaves, 1994, p. 144).

Summer and Cecilia's contrasting experiences of teaching and learning from their previous kindergartens to the current one may provide some insights into how to reduce the intensity of teachers' work, increase their feeling of self-worth and make them visible in their own teaching and learning. International Kindergarten's structure and everyday practices recognised and valued the teachers' personal knowledge and connection with their inner selves. Instead of totally abandoning the irrelevant cultural repertoires of practice learnt in the past, Summer and Cecilia reflected on their past experience critically. Moreover, they were allowed time to develop new repertoires of practice through "intent participation" (Rogoff et al., 2003 , p. 176) and collaboration with others in the shared endeavour. This may have helped them overcome the tensions caused by the disconnection between their past and current practices and developed their ability and capacity for problem solving and pedagogical decision-making (van Manen, 1991). Summer and Cecilia's 
future dreams and their willingness to share suggest that they have become empowered by a community that values non-judgmental understanding, listening and trust.

Summer and Cecilia's stories convey that teachers' past experiences and knowledge often seemed irrelevant, but they can be regarded as personal practical knowledge and can form the inner landscape constituting teachers' exploration of the new and promoted knowledge (Palmer, 1998). Valuing teachers' personal practical knowledge rather than seeing it as something needing to be changed and abandoned may be the turning point for changing some Chinese EC teachers' passive stance, and negative self-image. Moreover, acknowledging what teachers know, and guiding them to think about what and how they know about teaching and learning may help them become more active and reflective in their own learning (Shulman, 1996/2004).

\section{Teaching and Learning in Context}

\section{Teachers in context}

This study emerged from my own teaching and learning experience as a Chinese EC teacher in different social, cultural and curriculum contexts. Reflecting on my own teaching and learning experiences, I realised the power of culture and context in shaping my understanding of teaching and learning, practice and agency. Supported by the theoretical framework that I outlined in Chapter 2, my inquiry into 
six Chinese EC teachers' teaching and learning illustrated how different kindergarten cultures, structures, curricula and professional learning approaches may influence teachers' teaching and learning. This is represented in Figure 11.1.

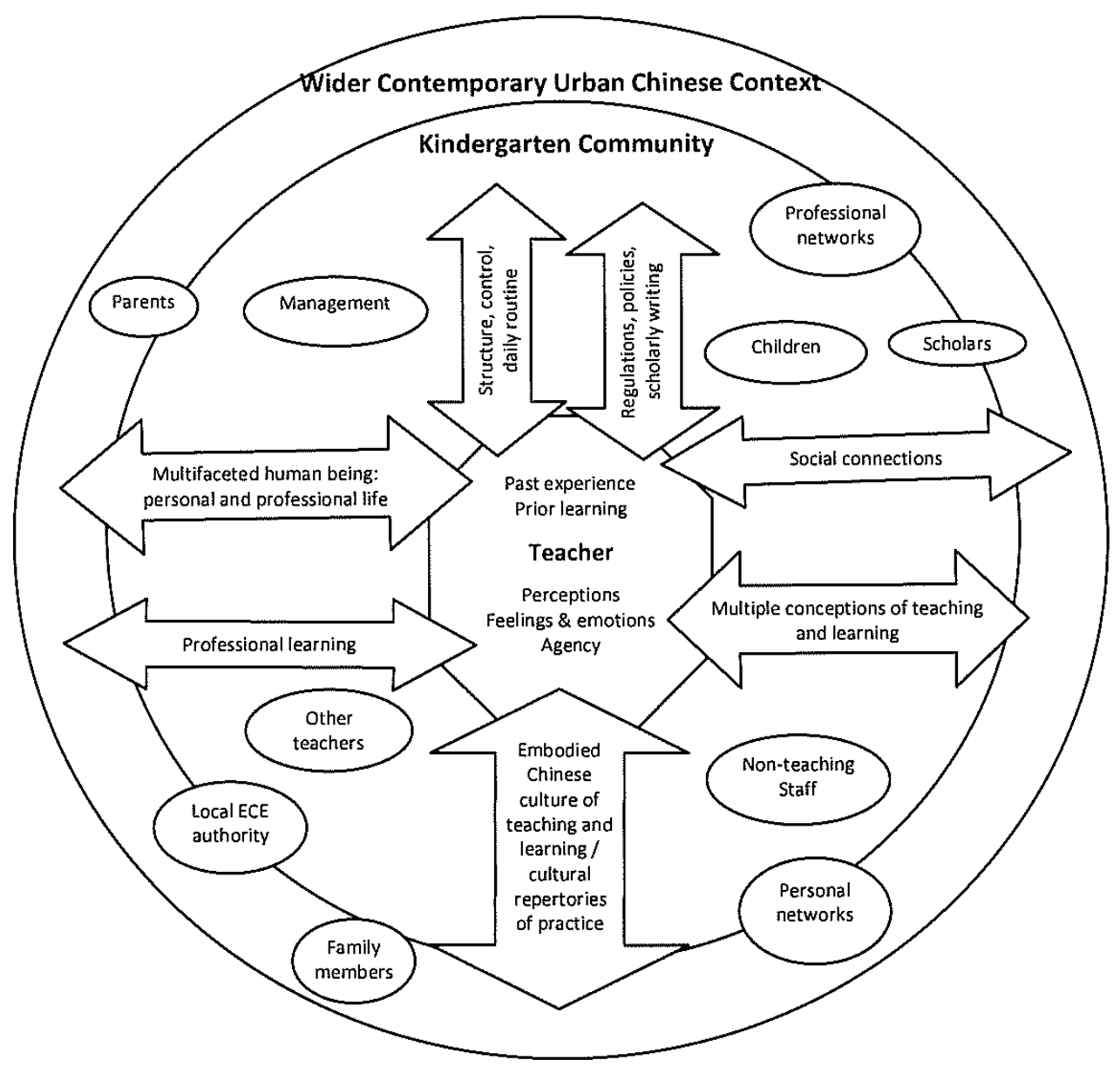

Figure 11.1 Context of Chinese early childhood teachers' teaching and learning

The kindergartens were three unique teaching communities with distinctive cultures, structures, curricula and professional learning approaches. They provided different cultural tools, official knowledge, and culturally organised activities that might shape the teachers' teaching and learning, the curriculum, the children and the environment around them. However, there were common cultural and structural matters influencing the teachers' teaching and professional learning. 
These are represented in the two-way arrows in Figure 11.1. I place the teacher in the centre, and emphasise the teacher's relationship and interaction with children and others, with the inner self, and with the embedded kindergarten community and wider Chinese context (Clandinin \& Connelly, 2000; Dewey, 1938).

The teachers' stories suggest that the situated kindergarten communities may shape teachers' experience of working with multiple educational ideas, searching for their positions in children's and others' lives, getting in touch with their inner selves, and being empowered with increasing capacity and agency as a teacher. Teachers may be empowered if:

- the external world - work culture, structure, and professional learning approaches - allow and support collaboration, reflection and teacher autonomy

- the cultural tools such as the culturally organised daily activities and curriculum are cohesive and consistently represent clearly defined kindergarten identity, values and guiding educational ideas

- the personal practical knowledge that connects the mind and the practice is valued and used as the starting point for the construction of new understanding and knowledge

- the teacher's personal and internal world, their inner landscape and agency are valued and connected with the external world.

However, the study of cultural and contextual influences, more specifically the particular kindergarten community, on teachers' teaching and learning has not been explored extensively in China. In Jimei Li's $(2006,2008)$ reviews of implementing Guidelines for Kindergarten Education (Trial) (Ministry of Education in People's Republic of China, 2001), she outlines the changes made and needed for the development of future government policies and for teachers, but does not 
discuss potential changes at the kindergarten level. Many Chinese scholars have paid attention to the introduction of new approaches and ideas into Chinese kindergartens, such as kindergarten-based research, involving teachers in curriculum development, building up a learning community, and so on (Huo, 2010; Ketizu, 2006; Z. Zhao, 2007). What have been missing are the inward study of the culture and identity of particular kindergarten communities, and the collective review of a community's values, structure, knowledge strategies, social relations and practices (Wenger et al., 2002). Informed by Wenger and his colleagues, this inward exploration of a particular kindergarten community may be started by examining whether the community creates values and promotes educational philosophies in consistent and cohesive ways by connecting personal development, teacher identity, and kindergarten priorities. Other aspects, such as whether knowledge is managed as an object or "lived in human act of knowing" (p. 8) and whether social relations foster the building of trust, shared leadership and knowledge, may also be explored. Furthermore, the review of whether "the community validates and endorses new submissions as accepted communal knowledge" (p. 40) in practice is also necessary since it may encourage the emergence of new understandings and knowledge.

Yet, the inward evaluation should not stop there. It is important for the teacher to connect with their inner self - who I am, what I know, why and how I know what I know, and beyond - since "[t]eaching, like any truly human activity, emerges from one's inwardness, for better or worse" (Palmer, 1998, p. 2). In fact, it is both the teaching self and the situated context that should be explored at the same time through on-going inward and outward explorations. 


\section{Kindergarten culture and ideological shift}

The ideological shift from teaching according to Chinese traditional ideas to teaching according to modern Western ideas is prioritised and legitimised in the contemporary Chinese context. However, the modern conceptions cannot be simply substituted for the traditional in real life as they do in the government's policies and the curriculum guidance. Therefore, the three kindergartens' and six teachers' stories of working with both traditional and modern educational ideas are also stories of ideological shift. The range of ways the kindergartens and teachers coped with multiple educational ideas reflects Apple's (1993) claim that ideological shifts "occur through the presentation of novel combinations of old and new elements" ( $p$. 20).

Different kindergartens' exploration of old/traditional and new/modern ideas in context and in practice may reflect how kindergarten culture accommodates multiple and contrasting ideas. However, the relationship between a kindergarten's culture and teachers' ideological shift has not been explored extensively in the Chinese ECE context. Discussions of teachers' responses to the ideological shift are mainly at the personal and intellectual level (Xiaoyi Gao \& Pang, 2006a; Y. Peng, 2009), rather than the cultural and kindergarten structural level. This study has addressed some gaps that have existed in this area. I argue that it is important to examine the presence of traditional and modern educational ideas represented and interpreted in specific kindergartens, as well as the particular kindergarten's approach of selecting and managing available knowledge and the teachers' experience of multiple truths of teaching and learning. 


\section{Implications}

Narrative inquiry has given me entry into six Chinese EC teachers' everyday teaching life and their voices through rich and contextualised data. This may be a useful approach to guide kindergartens' and teachers' inward and outward studies of the self and context. Teachers' narratives can be used to understand and create new knowledge of teaching and learning through "putting forward interpretations in dialogue and for contestation" (Rinaldi, 2006, p. 3). Therefore, I now draw out some implications from the teachers' stories that may lead to better understanding of and support for Chinese EC teachers' teaching and learning.

\section{Underpinning ideas}

Nowadays, Chinese EC teachers and kindergarten directors encounter multiple truths of teaching and learning influenced by both traditional Chinese and Western educational ideas. Different teachers and kindergartens incorporate these ideas into their everyday practices differently, and how they incorporate these ideas into practices may influence teachers' teaching and learning experiences. Therefore, it is important to analyse the underpinning ideas of teaching and learning in kindergarten curricula, in teachers' and directors' personal practical knowledge, and in the wider Chinese ECE context, and to ask what is affected by drawing on certain ideas in particular kindergarten contexts and why. Teachers and directors may also need to reflect on teachers' positions in their relationships with the wider world, and to gain a critical understanding of the multiple educational ideas that are 
available. Further explorations of how to make promoted theories and educational ideas visible in kindergarten scripts and in kindergartens' everyday practices cohesively and consistently may be needed.

\section{Pedagogical position}

The teachers in this study worked with children differently in different kindergarten contexts. One possible influential factor for such differences was the different pedagogical positions kindergartens and teachers took. The experience of the teachers at International Kindergarten suggests the importance of having a clear and consistent expression of a kindergarten's pedagogical position in its philosophy and curriculum structure. Having a thorough understanding of the different images of the child that exist in curriculum and in practice, either visibly and/or invisibly, is also crucial. Therefore, it may be necessary for teaching teams to collaboratively and creatively explore a particular kindergarten's pedagogical position, as well as making explicit the valued pedagogical position and image of the child in all aspects of the kindergarten's operation and practice.

\section{Teachers' personal knowledge}

The teachers experienced disconnections and a sense of irrelevance between personal knowledge learnt from their past experiences, and the current promoted educational ideas and practices in their teaching and learning. In some cases, teachers' irrelevant past experiences and personal knowledge were viewed as something that needed to be changed or abandoned. However, they can also be viewed as cultural resources teachers draw on when learning new knowledge and 
adapting to new environments. Therefore, it is important that teachers and kindergarten directors recognise, respect, and reflect on teachers' personal knowledge, and help teachers make the connections between their past and present, and to personally reconceptualise teaching and learning.

\section{Professional learning}

Teaching and learning have become increasingly complex in the contemporary Chinese context, a context that is diverse, dynamic, and everchanging. Professional learning is viewed as being essential to help teachers cope with the demands of teaching nowadays. However, the teachers' stories show that kindergartens may adopt different professional learning approaches: formal, structured, director-led and technique-focused; or informal, contextualised, teacher-initiated and child-focused. The teachers' experiences of different professional learning approaches highlight the importance of valuing teachers' agency in deciding what and how they want to learn, and the search of an inner learning landscape when learning new ideas and approaches. Shulman's (1996/2004) notion of effective learning may help kindergarten directors to review their kindergartens' professional learning approaches by analysing four interconnected aspects of learning - active/agency, reflection, collaboration, and community/culture.

\section{Culture, structure and teacher agency}

Kindergarten culture and structure have a great impact on teachers' teaching and learning experiences and the construction of their professional identity. A 
teacher may have contrasting feelings about teaching in different kindergartens, as both Summer and Cecilia had experienced. Therefore, kindergarten directors may need to attend to the close relationship between kindergarten culture, structure, and teacher agency. Specifically, directors may want to review the positioning of kindergarten management and teacher, the styles of control, the work that teachers are required to do, and teachers' autonomy in teaching and learning.

Summer and Cecilia both stated that International Kindergarten was the ideal kindergarten for them as a teacher, and their positive experiences of teaching at International Kindergarten seem to support their claims. Nevertheless, is International Kindergarten an aspirational goal for Chinese kindergartens? It may not be. The director stated that International Kindergarten was not a "real" world. Its privileged position as an outsider to the mainstream Chinese education system allowed the kindergarten freedom and autonomy to develop its international visionorientated educational philosophy, curriculum, and teaching approaches. It also had money and access to worldwide resources. The situated world of the local kindergartens seemed quite different. A fear of losing Chinese culture and identity (H. Li, 2007), a shortage of funding and personnel, and a lack of appropriate resources (Chinese Early Childhood Education Practitioners, 2008) seemed common concerns among Chinese scholars, kindergarten directors, parents, and teachers. Therefore, I do not intend to promote the International Kindergarten's model and approaches in the real Chinese context. Rather, I view it as an alternative kindergarten community with alternative interpretations of kindergarten teaching and learning. What is happening at International Kindergarten may provide some insights to catalyse further discussions among those who are interested in 
constructing an enabling environment for Chinese EC teachers in the contemporary Chinese context.

So far, the discussed implications addressed kindergarten teachers and directors at the micro level. However, teachers and kindergartens are embedded in the wider Chinese ECE context. Policy-makers and scholars also influence teachers' teaching and learning, but implicitly through reforms, regulations, funding, literature, and training etc. They have the power to create dominant discourses and determine the direction of future development in Chinese ECE. Therefore, it is important for policy-makers and scholars to understand how teachers respond to the promoted ways of teaching and learning so that they can embed future Chinese ECE development in actual practices instead of the past idea-input and top-down model of reform (Yan Liu \& Feng, 2005). The telling and re-telling of the six teachers' stories in this thesis may help policy-makers and scholars with this. Moreover, policy-makers may wish to analyse educational bureaux management structures, search for new systems and approaches that will allow individual kindergartens autonomy, and develop a trusting and collaborative network to support individual kindergartens' interpretations of the reform educational ideas being promoted.

For future research, I suggest there is a need for in-depth exploration of the cultural aspects of Chinese EC teachers' teaching and learning. It is also important to study the influences of diverse professional learning programmes on teachers' professional and personal development, and on the construction of teachers' knowledge, conceptions, and practices as well as their professional identity and feelings about being a kindergarten teacher. The use of narrative inquiry in investigating Chinese EC teachers' teaching and learning may be another area 
requiring further attention, as it is a useful research tool and a medium not only for research, but also for professional development (Conle, 2000).

\section{Legitimacy of this Narrative Study}

Narrative inquirers use words and stories to explore human experiences within the three-dimensional narrative inquiry space (Clandinin \& Connelly, 2000), to represent "the meaning life events have for people" (Polkinghorne, 2007, p. 479), and to make "claims about how people understand situations, others, and themselves" (p. 476). Good narratives have qualities such as being explanatory, inviting, authentic, adequate, and plausible (Clandinin \& Connelly, 2000) that can help narrative inquirers establish "the authenticity and trustworthiness of their findings" (Pinnegar \& Daynes, 2007). However, there is always a danger of narrative research reports being fictional rather than viable research. To avoid this, I have tried to represent my and the participants' feelings, and intentions, truthfully using the teachers' own words, detailed observation notes, and contextual information. I gathered multiple resources as narrative data to acquire multiple voices and stories not only from the teachers, but also from parents and school management. Therefore, what I describe can be regarded as true, and the teachers' authentic and contextualised personal experiences can be interwoven into the entire story.

I invited the teachers to connect their actions and meanings within particular contexts through our interviews and by commenting on my observation records. I have been very cautious about the possible impact this study may have on 
individual teachers and kindergartens, and have communicated with the teachers and written this thesis in a non-judgemental way. Moreover, my analysis of teachers' stories dug deep into the teachers' experiences while remaining conscious of the complexity of experienced meanings and felt meanings, and the possible resistance to self-exploration and revealing true feelings (Polkinghorne, 2007). This was particularly true when they were sharing their negative experiences, e.g. resigning from the job and having negative feelings about their role. The participants' voices were valued, their stories were listened to with care, their rights were protected, and their feelings were attended to in the ways outlined in Chapter 4.

\section{Limitations}

One of the limitations of this small-scale study relates to the particularity of individual teachers' experiences, and the fact that teachers' stories are connected with the situated contexts and particular phase of their teaching and learning journey. For instance, Linda was a beginning teacher and Angela was a newcomer to the Public Kindergarten community during data collection. However, while I have been writing up this thesis, they will have gained two more years' experience of Public Kindergarten's culture, curriculum, and teaching. Moreover, the Public Kindergarten context may have changed. During a phone conversation with the director in early 2011, I learned that the local early childhood education authority had requested that they remove all afternoon group learning times to give children more time to play. In these ways, Linda and Angela's teaching and learning 
experiences may have changed over the past two years as a result of changes in government policies, reform innovations, new interpretations of early childhood teaching and learning, the different career stages they are now at, and events in their personal lives.

Similar changes may apply to Selina who is now teaching at another privately run kindergarten in Shanghai, to Cherry who will now be more experienced in teaching at Private Kindergarten, to Summer who is now a proud mother of a beautiful baby girl, and to Cecilia who has experienced an unexpected tragedy in her family. Therefore, I do not intend to make any broad generalised claims beyond presenting these stories of teachers teaching and learning in a context of change. My hope is that they will stimulate more discussions of teaching and learning among teachers, kindergarten directors, scholars and policy makers in the contemporary Chinese ECE context.

Although I have made some comparisons of the teachers' experiences across the three kindergartens, I do not intend to compare the six teachers' teaching practices and abilities. Not only are they all at different stages of their teaching careers, but also the focus of this study is not on comparing their teaching ability: rather, it is on the cultural and contextual influences on teachers' teaching and learning. Therefore, my comparisons of the teachers' stories are about the influence of enabling and constraining factors on their teaching.

Another limitation is related to the subjectivity of the narratives, as my interpretations of the teachers' stories are from my own vantage points and epistemological standpoints. Other readers may connect with the teachers' experiences differently, which is why I have included the teachers' narratives and 
represented them in poetic format. This is important so that readers find "new shades of meaning" (Clandinin, 1993, p. 2) in their own teaching and learning experiences by reinterpreting the teachers' stories from their own vantage points.

Besides, there are many other Chinese EC teachers' stories waiting to be heard and understood, for instance, the "good teachers" whom Linda and Angela have been looking up to, and the teachers who teach in rural Chinese areas. How do other teachers teach and learn in different curriculum and structural contexts? Do other teachers experience similar tensions? What may be done for developing an enabling and empowering teaching and learning environment for the Chinese EC teachers in the contemporary Chinese context?

Finally, but importantly, my difficulty in recruiting teachers for this study may reflect the need to review how narrative inquiry is viewed in the Chinese ECE community and used in researching Chinese EC teachers' teaching and learning experiences. My study may make a small contribution to the development of narrative inquiry - a less familiar research perspective - in China.

\section{Final Thoughts}

The six teachers that I was fortunate to know through this study were all hard working teachers, and had different experiences of modern educational ideas and approaches in different kindergarten contexts. Their stories support Hargreaves's (1994) argument that teaching and being a teacher is an intellectual, emotional, and multifaceted career that is challenging and difficult. Also, teachers' 
teaching and learning experiences are greatly influenced by the structure, culture, and interpersonal relationships within a particular community and wider society, and "always end in an act of personal knowing" (Apple, 1993, p. 14). Therefore, I argue that the situated teaching and professional learning context contributes greatly to how Chinese kindergarten teachers conceptualise teaching and learning, how they define and construct their pedagogical positions and strategies, how they learn and develop appropriate and relevant repertoires of practices, and how they feel about being a teacher and understand who they are in children's lives. With this in mind, teachers should not just be expected to learn, to develop, and to transform their teaching as required by the government or other stakeholders. They deserve an enabling environment to support their teaching and learning; in Shulman's (1988/2004) words, teachers should not be treated "in a manner inconsistent with the ways in which we treat students" (p. 314). Consequently, teaching and learning in an enabling environment may mean that teachers are respected for who they are, are provided with appropriate and relevant cultural tools, have their voices listened to, their feelings acknowledged, and given time and space to develop their own understanding of teaching and learning in theory and in practice. 


\section{References}

Allender, J. S., \& Allender, D. S. (2008). The humanistic teacher: First the child, then curriculum. Boulder: Paradigm.

Andrews, M., Squire, C., \& Tamboukou, M. (Eds.). (2008). Doing narrative research. Los Angeles; London: Sage Publications.

Apple, M. W. (1986). Teachers and texts: A political economy of class and gender relations in education. New York: Routledge \& Kegan Paul.

Apple, M. W. (1990). Ideology and curriculum (2nd ed.). New York: Routledge.

Apple, M. W. (1993). Official knowledge: Democratic education in a conservative age. New York: Routledge.

Apple, M. W. (1995). Education and power (2nd ed.). New York: Routledge.

Apple, M. W. (2001). Educational and curricular restructuring and the neo-liberal and neoconservative agendas: Interview with Michael Apple. Currículo sem Fronteiras, 1(1), i-xxvi.

Apple, M. W. (2004). Ideology and curriculum (3rd ed.). New York: RoutledgeFalmer.

Atkinson, P., \& Delamont, S. (2006). Rescuing narrative from qualitative research. Narrative Inquiry, 16(1), 164-172.

Aultman, L. P. (2009). A story of transition: Using poetry to express liminality. Qualitative Inquiry, 15(7), 1189-1198.

Avalos, B. (2011). Teacher professional development in Teaching and Teacher Education over ten years. Teaching and Teacher Education, 27(1), 10-20.

Ayers, W. (1989). The good preschool teacher: Six teachers reflect on their lives. New York: Teachers College Press.

Ayers, W. (2001). To Teach: The journey of a teacher (2nd ed.). New York: Teachers College.

Ayers, W. (2004). Teaching toward freedom: Moral commitment and ethical action in the classroom. Boston: Beacon.

Bai, L. (2005a). Children at play: A childhood beyond the Confucian shadow. Childhood, 12(9), 9-32.

Bai, L. (2005b). Shaping the ideal child: Children and their primers in late imperial China. Hong Kong: The Chinese University Press.

Bamberg, M. G. W. (2007). Introductory remarks. In M. G. W. Bamberg (Ed.), Narrative - State of the art (pp. 1-6). Amsterdam: John Benjamins Pub.

Basic Education Department of Ministry of Education (Ed.). (2002). Youeryuan jiaoyu zhidao gangyao (shixing) jiedu [Interpreting Guidelines for Kindergarten Education (trial)]. Nanjing: Phoenix Publishing and Media Network \& Jiangsu Jiaoyu Chubanshe. 
Baskerville, R. F. (2003). Hofstede never studied culture. Accounting, Organizations and Society, 28, $1-14$.

Ben-Peretz, M. (2011). Teacher knowledge: What is it? How do we uncover it? What are its implications for schooling? Teaching and Teacher Education, 27(1), 3-9.

Benson, S. P. (1986). Counter cultures: Saleswomen, managers, and customers in American department stores, 1890-1940. Illinois: University of Illinois Press.

Bhabha, H. K. (1994). The location of culture. New York: Routledge.

Biggs, J. B., \& Watkins, D. (1996). The Chinese learner in retrospect. In D. Watkins \& J. B. Biggs (Eds.), The Chinese learner: Cultural, psychological, and contextual influences (pp. 269-285). Hong Kong Camberwell, Melbourne, Vic.: CERC; ACER.

Blacker, D. (1998). Intellectuals at work and in power: Toward a Foucaultian research ethic. In T. S. Popkewitz \& M. Brennan (Eds.), Foucault's challenge: Discourse, knowledge and power in education (pp. 348-368). New York: Teachers College Press.

Blank, J. (2009). Situated in school scripts: Contextual early childhood teaching. Teaching and Teacher Education, 25(2), 251-258.

Bradley, V. L. (2004). "What if we are doing this all wrong?": Sequestering and a community of practice. Anthropology \& Education Quarterly, 35(3), 345-367.

Bredekamp, S. (Ed.). (1997). Developmentally appropriate practice in early childhood programs (revised ed.). Washington, DC: National Association for the Education of Young Children.

Brilhart, D. (2010). Teacher conceptualization of teaching: Integrating the personal and the professional. Journal of Ethnographic \& Qualitative Research, 4, 168-179.

Britzman, D. (2007). Teacher education as uneven development: Toward a psychology of uncertainty. International Journal of Leadership in Education, 10(1), 1-12.

Bruner, J. S. (1986). Actual minds, possible worlds. Cambridge, Mass.: Harvard University Press.

Bullough Jr., R. V., \& Gitlin, A. (1995). Becoming a student of teaching: Methodologies for exploring self and school context. New York: Garland.

Burke, P. J., Christensen, J. C., Fessler, R., McDonnell, J. H., \& Price, J. R. (1987). The teacher career cycle: Model development and research report. Paper presented at the Annual Meeting of the American Educational Research Association, Washington, D.C.

Burman, E. (2008). Deconstructing developmental psychology (2nd ed.). London: Routledge.

Carr, M. (2001). Assessment in early childhood settings: Learning stories. London: Paul Chapman Publishing.

Chen-Hafteck, L., \& Xu, Z. (2008). Pulling the river: The interactions of local and global influences in Chinese early childhood music education. Art Education Policy Review, 109(3), 9-16.

Chen, Y. [Youqing]. (2006). Experience and its generation. Frontiers of Education in China, 1(1), 10-19.

Chen, Y. [Yan]., Jiang, Y., \& Wang, H. (2010). Fansi dui youer jiaoshi zhuanye chengzhang zuoyong de gean yanjiu [A case study on a kindergarten teacher's professional development based on reflection]. Studies in Preschool Education(2), 37-40. 
Chen, Y. [Yi]., \& Wang, C. (2010). 60 nian lai woguo youeryuan jiaoshi jiaoyu de fazhan licheng ji zhanwang [Review of 60 years development of Chinese kindergarten teacher education and future anticipations]. Early Childhood Education (Educational Sciences)(6), 6-11.

Cheng, K.-m., \& Wong, K.-c. (1996). School effectiveness in East Asia: Concepts, origins and implications. Journal of Educational Administration, 24(5), 32-49.

Cherrington, S. (2011). Early childhood teachers' thinking and reflection within their communities of practice. PhD in Education Thesis, Victoria University of Wellington, Wellington. Retrieved from http://hdl.handle.net/10063/1893

Cherubini, L. (2009). Reconciling the tensions of new teachers' socialisation into school culture: A review of the research. Issues in Educational Research, 19(2), 83-99.

Chinese Early Childhood Education Practitioners. (2008). An open letter to Premier Wen Jiabao. Chinese Education and Society, 41(2), 71-76.

Clandinin, D. J. (1985). Personal Practical Knowledge: A study of teachers' classroom images. Curriculum Inquiry, 15(4), 361-385.

Clandinin, D. J. (1993). Teacher education as narrative inquiry. In D. J. Clandinin, A. Davies, P. Hogan \& B. Kennard (Eds.), Learning to teach, teaching to learn: Stories of collaboration in teacher education (pp. 1-15). New York: Teachers' College Press.

Clandinin, D. J., \& Connelly, F. M. (1996). Teachers' professional knowledge landscapes: Teacher stories -- stories of teachers -- school stories -- stories of schools. Educational Researcher, 25(3), 24-30.

Clandinin, D. J., \& Connelly, F. M. (2000). Narrative inquiry: Experience and story in qualitative research (1st ed.). San Francisco: Jossey-Bass Publishers.

Clandinin, D. J., Huber, J., Huber, M., Murphy, M. S., Orr, A. M., Pearce, M., \& Steeves, P. (2006). Composing diverse identities: Narrative inquiries into the interwoven lives of children and teachers. London and New York: Routledge.

Clandinin, D. J., Murphy, M. S., Huber, J., \& Orr, A. M. (2010). Negotiating narrataive inquires: Living in a tension-filled midst. The Journal of Educational Research, 103(2), 81-90.

Clandinin, D. J., \& Rosiek, J. (2007). Mapping a landscape of narrative inquiry: Borderland spaces and tensions. In D. J. Clandinin (Ed.), Handbook of narrative inquiry: Mapping a methodology (pp. 35-76). Thousand Oaks, Calif.: Sage Publications.

Clark, R., \& Gieve, S. N. (2006). On the discursive construction of 'the Chinese learner'. Language Culture and Curriculum, 19(1), 54-73.

Cohen, A. (2009). Many forms of culture. The American Psychologist, 64(3), 194-204.

Cole, M. (2000). Cultural psychology: A once and future discipline. Cambridge: The Belknap Press of Harvard University Press.

Conle, C. (2000). Narrative Inquiry: Research tool and medium for professional development. European Journal of Teacher Education, 23(1), 49-63. 
Conle, C. (2001). The rationality of narrative inquiry in research and professional development. European Journal of Teacher Education, 24(1), 21-33.

Connelly, F. M., \& Clandinin, D. J. (1988). Teachers as curriculum planners: Narratives of experience. New York: Teachers College Press, Columbia University.

Connelly, F. M., \& Clandinin, D. J. (1990). Stories of experience and narrative inquiry. Educational Researcher, 19(5), 2-14.

Connelly, F. M., \& Clandinin, D. J. (Eds.). (1999). Shaping a professional identity: Stories of educational practice. New York: Teachers College Press.

Cortazzi, M., \& Jin, L. (2001). Large classes in China: 'Good' teachers and interaction. In D. Watkins \& J. B. Biggs (Eds.), Teaching the Chinese learner: Psychologycial and pedagogical perspectives (pp. 115-134). Hong Kong \& Melbourne: Comparative Education Research Centre \& The Australian Council for Educational Research.

Craig, C. (1997). Telling stories: Accessing beginning teacher knowledge. Teaching Education Journal, 9(1), 61-67.

Craig, C. (2004). Shifting boundaries on the professional knowledge landscape: When teacher communications become less safe. Curriculum Inquiry, 34(4), 395-424.

Craig, C. (2007). Story constellations: A narrative approach to contextualizing teachers' knowledge of school reform. Teaching and Teacher Education, 23(2), 173-188.

Craig, C. (2010a). Change, changing, and being changed: A study of self in the throes of multiple accountability demands. Studying Teacher Education, 6(1), 63-73.

Craig, C. (2010b). Coming full circle: From teacher reflection to classroom action and places inbetween. Teacher and Teaching: Theory and Practice, 16(4), 423-435.

Crown. (2008). Practice guidance for the Early Years Foundation Stage. Nottingham: Department for Children, Schools and Families.

Dai, D. Y., Gerbino, K. A., \& Daley, M. J. (2011). Inquiry-based learning in China: Do teachers practice what they preach, and why? Frontiers of Education in China, 6(1), 139-157.

Dai, H., \& Zheng, Z. (2009). Youer jiaoshi kecheng jiazhi quxiang de zhuanxing [On shift the preschool teacher's value orientation of curriculum]. Studies in Preschool Education(12), 41-44.

Dan, F., Wang, H., \& Wu, L. (2006). Gao suzhi youer jiaoshi de peiyang yu jiaoshi de zhuanyehua fazhan [Teacher training to the high quality children teachers with the development of teacher specialization]. Teacher Development and Teacher Education(4), 43-45.

Davies, B. (1990). Agency as a form of discursive practice: A classroom scene observed. British Journal of Sociology of Education, 11(3), 341-361.

Day, C. (2004). A passion for teaching. New York: RoutledgeFalmer.

Day, C., Sammons, P., Stobart, G., Kington, A., \& Gu, Q. (2007). Teachers matter. Maidenhead: Open University Press. 
Dehli, K., \& Fumia, D. (2008). Teacher's informal learning, identity and contemporary education reform. In K. Church, N. Bascia \& E. Shragge (Eds.), Learning through community: Exploring participatory practices (pp. 143-167). Dordrecht; London: Springer.

Denzin, N. K., \& Lincoln, Y. S. (2008). Introduction: The discipline and practice of qualitative research. In N. K. Denzin \& Y. S. Lincoln (Eds.), Collecting and interpreting qualitative materials (3rd ed., pp. 1-44). Thousand Oaks, Calif.: Sage Publications.

Dewey, J. (1933). How we think: A restatement of the relation of reflective thinking to the educative process. Lexington: D.C. Health and Companry.

Dewey, J. (1934). Art as experience. New York: Minton, Balch \& Company.

Dewey, J. (1938). Experience \& Education. New York: Touchstone.

Dimmock, C. (1998). Restructuring Hong Kong's schools: The applicability of Western theories, policies and practices to an Asian culture. Educational Management \& Administration, 26(4), 363-378.

Dimmock, C., \& Walker, A. (1998). Towards comparative educational administration: Building the case for a cross-cultural school-based approach. Journal of Educational Administration, 36(4), 379-401.

Dollase, R. H. (1992). Voices of beginning teachers: Visions \& realities. New York: Teachers College Press.

Ebbeck, M., \& Warrier, S. (2008). Image of the Singapore child. Early Childhood Education Journal, 36(3), 247-251.

Ebbs, C. A. (1996). Qualitative research inquiry: Issues of power and ethics. Education, 117(2), 217222.

Edgoose, J. (2010). Hope in the unexpected: How can teachers still make a difference in the world? Teachers College Record, 112(2), 386-406.

Edwards, S., \& Nuttall, J. (2009). Introduction. In S. Edwards \& J. Nuttall (Eds.), Professional learning in early childhood settings (pp. 1-8). Rotterdam: Sense.

Esposito, N. (2001). From meaning to meaning: The influence of translation techniques on non English focus group research. Qualitative Health Research, 11(4), 568-579.

Ethridge, E. A., \& Branscomb, K. R. (2009). Learning through action: Parallel learning processes in children and adults. Teaching and Teacher Education, 25(3), 400-408.

Evans, L. (2002). What is teacher development? Oxford Review of Education, 28(1), 123-137.

Fang, T. (2003). A critique of Hofstede's fifth national culture dimension. International Journal of Cross Cultural Management, 3(3), 347-368.

Feiman-Nemser, S. (2001). From preparation to practice: Designing a continuum to strengthen and sustain teaching. Teachers College Record, 103(6), 1013-1055.

Feng, T., He, X., Gui, Z., \& Yan, C. (Eds.). (2001). Zhonghua wenhua cidian [A glossary of Chinese culture]. Wuhan: Wuhan University Press. 
Fessler, R. (1985). A model for teacher professional growth and development. In P. J. Burke \& R. G. Heideman (Eds.), Career-long teacher education (pp. 161-193). Springfield, IL: Charles C. Thomas.

Fleet, A., \& Patterson, C. (2009). A timescape: Personal narratives - perfessional spaces. In S. Edwards \& J. Nuttall (Eds.), Professional learning in early childhood settings (pp. 9-25). Rotterdam: Sense.

Gao, X. [Xuesong]. (2008). Teachers' professional vulnerability and cultural tradition: A Chinese paradox. Teaching and Teacher Education, 24(1), 154-165.

Gao, X. [Xiaoyi]., \& Pang, L. (2006a). Youer jiaoshi jiaoyu guannian de zhuangbian: Guocheng yu jiben celue [The change of preschool teachers' educational beliefs: Process and basic ways]. Teacher Development and Teacher Education, 12, 41-43.

Gao, X. [Xiaoyi]., \& Pang, L. (2006b). Youer xuexi guochengzhong de jiaoshi jiaoyu xingwei yanjiu [The study of teachers' behaviors in children's learning process]. Education Science, 22(5), 71-74.

Gao, X. [Xiaoyi]., \& Pang, L. (2009). Youer jiaoshi ertong xuexiguan de zhixing fenxi [Qualitative analysis of kindergarten teachers' beliefs on children's learning]. Teacher Education Research, 21(1), 36-40.

Gardner, H. (1983). Frames of mind: The theory of multiple intelligences. New York: Basic Books.

Gilrane, C. P., Russell, L. A., \& Roberts, M. L. (2008). Building a community in which everyone teaches, learns, and reads: A case study. The Journal of Educational Research, 101(6), 333-349.

Glesne, C. (1997). That rare feeling: Re-presenting research through poetic transcription. Qualitative Inquiry, 3(2), 202-221. doi: 10.1177/107780049700300204

Goldstein, L. S. (1999). The role of caring relationships in the co-construction of mind. American Educational Research Journal, 36(3), 647-673.

Goodman, R. A., Phillips, M. E., \& Boyacigiller, N. A. (2003). Culture, passion, and play. In N. A. Boyacigiller, R. A. Goodman \& M. E. Phillips (Eds.), Crossing cultures: Insights from master teachers (pp. 3-9). New York: Routledge.

Goodnough, K. (2010). Teacher learning and collaborative action research: Generating a "knowledgeof-practice" in the context of science education. Journal of Science Teacher Education, 21, 917-935.

Goodson, I., \& Choi, P. L. (2008). Life history and collective memory as methodological strategies: Studying teacher professionalism. Teacher Education Quarterly, 35(2), 5-28.

Gravani, M. N. (2007). Unveiling professional learning: Shifting from the delivery of courses to an understanding of the processes. Teaching and Teacher Education, 23(5), 688-704.

Graven, M. (2004). Investigating mathematics teacher learning within an in-service community of practice: The centrality of confidence. Educational Studies in Mathematics, 57, 177-211.

Greene, M. (1973). Teacher as stranger: Educational philosophy for the modern age. Belmont, Calif.: Wadsworth.

Greene, M. (1978). Landscapes of learning. New York: Teachers College Press. 
Gu, M. (2006). Analysis of the impact of traditional Chinese culture on Chinese education. Frontiers of Education in China, 1(2), 169-190.

Gu, M. (2010). A blueprint for educational development in China: A review of "The National Guidelines for Medium- and Long-Term Educational Reform and Development (2010-2020)". Frontiers of Education in China, 5(3), 297-309.

Gu, R., Qin, Y., Zheng, R., \& Cheng, Y. (2007). Cong xinshou laoshi dao zhuanjia: Youer jiaoshi zhuanye chengzhang yanjiu [From novice ot expert: A study on early childhood teachers' professional development]. Beijing: Beijing Normal University Press.

Gutierrez, K. D., \& Rogoff, B. (2003). Cultural ways of learning: Individual traits or repertoires of practice. Educational Researcher, 32(5), 19-25.

Hall, D. L., \& Ames, R. T. (1995). Anticipating China: Thinking through the narratives of Chinese and Western culture. Albany: State University of New York Press.

Hall, K., \& Murphy, P. (2008). Introduction. In K. Hall, P. Murphy \& J. Soler (Eds.), Pedagogy and practice: Culture and identities (pp. viiii-xiv). Los Angeles; London: Sage Publications; The Open University.

Hargreaves, A. (1994). Changing teachers, changing times: Teachers' work and culture in the postmodern age. London: Cassell.

Hargreaves, A. (1998). The emotional practice of teaching. Teaching and Teacher Education, 14(8), 835-854.

Hargreaves, A. (2001). Emotional geographies of teaching. Teachers College Record, 103(6), 10561080.

Hargreaves, A., Earl, L., Moore, S., \& Manning, S. (2001). Learning to change: Teaching beyond subjects and standards. San Francisco: Jossey-Bass.

He, M. F. (2002a). A narrative inquiry of cross-cultural lives: Lives in Canada. Journal of Curriculum Studies, 34(3), 323-342.

He, M. F. (2002b). A narrative inquiry of cross-cultural lives: Lives in China. Journal of Curriculum Studies, 34(3), 301-321.

He, M. F. (2002c). A narrative inquiry of cross-cultural lives: Lives in the North American academy. Journal of Curriculum Studies, 34(5), 513-533.

He, R. (1998). Youer jiaoshi xuexi fangshi de diaocha he sikao [A study on early childhood teachers' learning style]. Shanghai Research on Education(8), 29/10.

He, Y. (2005). Shanghai xueqianjiaoyu erqi kegai wunian huimou [Review of the second phase of Shanghai early childhood education reform over the last five years]. Early Childhood Education(1), 20-21.

Hedges, H. (2007). Funds of knowledge in early childhood community of inquiry. PhD in Education Thesis, Massey University, Palmerston North. Retrieved from http://hdl.handle.net/10179/580

Hellner, J. (2008). The professional learning community. Kairaranga, 9(1), 50-54. 
Ho, I. T. (2001). Are Chinese teachers authoritarian? In D. Watkins \& J. B. Biggs (Eds.), Teaching the Chinese learner: Psychologycial and pedagogical perspectives (pp. 99-114). Hong Kong \& Melbourne: Comparative Education Research Centre \& The Australian Council for Educational Research Ltd.

Hofstede, G. (1980). Culture's consequences: International differences in work-related values. Beverly Hills, California: Sage Publications.

Hofstede, G. (1986). Cultural differences in teaching and learning. International Journal of Intercultural Relations, 10(3), 301-320.

Hofstede, G. (1997). Cultures and organizations: Software of the mind. New York: McGraw-Hill.

Holt, B. S. (2011). Creating interpretive visual texts. International Journal of Qualitative Studies in Education. doi: 10.1080/09518398.2010.539580

Hopper, T., \& Sanford, K. (2008). Using poetic representation to support the development of teachers' knowledge. Studying Teacher Education, 4(1), 29-45.

Hsieh, M.-F. (2004). Teaching practices in Taiwan's education for young children: Complexity and ambiguity of developmentally appropriate practices and/or developmentally inappropriate practices. Contemporary Issues in Early Childhood, 5(3), 309-329.

Hsueh, Y. (2010). Zhongguo xueqian jiaoyu gongzuozhe dui ertong de zunzhong [Chinese preschool education workers' respect to children]. Early Childhood Education(11), 5-9.

Hsueh, Y., \& Tobin, J. J. (2003). Chinese early childhood educators' perspectives: On dealing with a crying child. Journal of Early Childhood Research, 1(1), 73-94.

Hsueh, Y., Tobin, J. J., \& Karasawa, M. (2004). The Chinese kindergarten in its adolescence. Prospective, 34(4), 457-469.

Hu, G. (2002). Potential cultural resistance to pedagogical imports: The case of communicative language teaching in China. Language Culture and Curriculum, 15(2), 93-105.

Hua, A. (2007). Dui zhongguo xueqian jiaoyu gaige ruogan wenti de wenhuaxing sikao [Cultural reflections on several problems of Chinese early childhood education reform]. In J. Zhu (Ed.), Zhongguo shiye xia de xueqian jiaoyu [Early childhood education from the Chinese persepective] (pp. 64-77). Shanghai: East China Normal University Press.

Huang, J. (1998). Dui bawei youxiu youer jiaoshi neiyin jiaoyu xingwei de yanjiu [A study on eight good early childhood teachers' tacit teaching behaviour]. Shanghai Research on Education(12), 37-42.

Huang, J., Du, H., Yang, Z., Zhe, G., \& Wang, Z. (1999). Dui bawei youxiu youer jiaoshi waixian jiaoyu xingwei de yanjiu [A study on eight good early childhood teachers' explicit teaching behaviour]. Studies in Preschool Education(3), 17-20.

Huang, Q. (2012). Dang "jiti jiaoxue" huodong meitian zhisheng yijie [When there is only one "group teaching and learning" activity]. Shanghai Tuoyou. Retrieved from Age06 website: http://www2.age06.com/Age06.Web/Detail.aspx?CategoryID=27a61e63-2c0a-412c-a02cee1395f42902\&InfoGuid=a68a5f11-ba45-42e5-ac96-0bc2c6c27977 
Huberman, M., Grounauer, M.-M., \& Marti, J. (1993). The lives of teachers (J. Neufeld, Trans.). New York: Teachers College Press \& Cassell.

Huo, L. (2010). Xueqian jiaoyu kecheng gaige huhuan youer jiaoshi de zhuanye fazhan [Early childhood education reform calls for early childhood teachers' professional development]. Journal of Edcuational Development(February/2nd), 4-6.

Jin, L., \& Cortazzi, M. (2006). Changing practices in Chinese cultures of learning. Language Culture and Curriculum, 19(1), 5-20.

Jordan, B. J. (2003). Professional development making a difference for children: Co-constructing understandings in early childhood centres. Doctor of Philosophy in Education, Massey University, Palmerston North.

Josselson, R. (2006). Narrative research and the challenge of accumulating knowledge. Narrative Inquiry, 16(1), 3-10.

Josselson, R. (2007a). The ethical attitude in narrative research: Principles and practicalities. In D. J. Clandinin (Ed.), Handbook of narrative inquiry: Mapping a methodology (pp. 537-566). Thousand Oaks, Calif.: Sage Publications.

Josselson, R. (2007b). Narrative research and the challenge of accumulating knowledge. In M. G. W. Bamberg (Ed.), Narrative - State of the art (pp. 7-16). Amsterdam; Philadelphia: John Benjamins Pub. Co.

Jurasaite-Harbison, E., \& Rex, L. A. (2010). School cultures as contexts for informal teaching learning. Teaching and Teacher Education, 26(2), 267-277.

Kable, E. (2001). Making sense of a new curriculum text within competing discourses and complex contexts. Contemporary Issues in Early Childhood, 2(3), 321-335.

Kardos, S. M., \& Johnson, S. M. (2007). On their own and presumed expert: New teachers' experience with their colleagues. Teachers College Record, 109(9), 2083-2106.

Katz, L. (1972). Developmental stages of preschool teachers. The Elementary School Journal, 73(1), 50-54.

Katz, L., \& Chard, S. (2000). Engaging children's minds: The project approach (2nd ed.). Stamford: Ablex.

Kelly, P. (2006). What is teacher learning? A socio-cultural perspective. Oxford Review of Education, 32(4), 505-519.

Kennedy, J. E. (2005). Grey matter: Ambiguities and complexities of ethics in research. Journal of Academic Ethics(3), 143-158. doi: 10.1007/s10805-006-9011-7

Ketizu. (2006). Jianshe yige shijianxing de xuexi gongtongti: Mianxiang weilai de jichu xuexi yanjiu [Building a practical learning community: Researching basic education for the future]. Explore Education Development(7A), 18-23.

Kirkman, B. L., Lowe, K. B., \& Gibson, C. B. (2006). A quarter century of "Culture's Consequences": A review of empirical research incorporation Hofstede's cultural values framework. Journal of International Business Studies, 37(3), 285-320. 
Kose, B. W., \& Lim, E. Y. (2010). Transformative professional development: Relationship to teachers' beliefs, expertise and teaching. International Journal of Leadership in Education, 13(4), 393419.

Kroeber, A. L., \& Kluckhohn, C. (1952). Culture: A critical review of concepts and definitions. Cambridge: Harvard University Press.

Labmson, D. (2010). Novice teachers learning through participation in a teacher study group. Teaching and Teacher Education, 26(8), 1660-1668.

Lai, D. (2011a). Beijingshi youer jiaoshi canjia zhuanye fazhan huodong de xianzhuang, xuqiu, dongyin ji yingxiang yinsu fenxi [A study on Beijing early childhood teachers' participation of professional development activities]. The Science and Education Article Collects(3), 12-16.

Lai, D. (2011b). Beijingshi youer jiaoshi gongzuo yali diaocha yanjiu [A study on Beijing early childhood teachers' working pressure]. China Electric Power Education(10), 31-33.

Lantolf, J. P. (2000). Introducing sociocultural theory. In J. P. Lantolf (Ed.), Sociocultural theory and second language learning (pp. 1-26). Oxford: Oxford University Press.

Latta, M. M., \& Kim, J.-H. (2010). Narrative inquiry invites professional development: Educators claim the creartive space of praxis. The Journal of Educational Research, 103(2), 137-149.

Lau, S. (1996). Self-concept development: Is there a concept of self in Chinese culture. In S. Lau (Ed.), Growing up the Chinese way (pp. 357-374). Hong Kong: The Chinese University Press.

Lave, J. (1993). The practice of learning. In S. Chaiklin \& J. Lave (Eds.), Understanding practice: Perspectives on activity and context (pp. 3-34). Cambridge, U.K.: Cambridge University Press.

Lave, J., \& Wenger, E. (1991). Situated learning: Legitimate peripheral participation. Cambridge, U.K.: Cambridge University Press.

Lawton, D. (1975). Class, culture and the curriculum. London; Boston: Routledge \& K. Paul.

Le Maistre, C., \& Pare, A. (2010). Whatever it takes: How beginning teachers learn to survive. Teaching and Teacher Education, 26(3), 559-564.

Lee, I.-F., \& Tseng, C.-L. (2008). Cultural conflicts of the child-centred approach to early childhood education in Taiwan. Early Years: An International Journal of Research and Development, 28(2), 183-196.

Lee, W. O. (1996). The cultural context for Chinese learners: Conceptions of learning in the Confucian tradition. In D. Watkins \& J. B. Biggs (Eds.), The Chinese learner: Cultural, psychological, and contextual influences (pp. 25-42). Hong Kong Camberwell, Melbourne, Vic.: CERC; ACER.

Lefstein, A., \& Snell, J. (2011). Professional vision and the politics of teacher learning. Teaching and Teacher Education, 27(3), 505-514.

Levine, T. H., \& Marcus, A. S. (2010). How the structure and focus of teachers' collaborative activities facilitate and constrain teacher learning. Teaching and Teacher Education, 26(3), 389-398.

Lewis, T. (1998). Official knowledge and vocationalism: A reply to Michael Apple. Curriculum Inquiry, 28(3), 361-368. 
Li-Chan, W. (2006). When the West meets East: Issues of context defining and meaning making in the world of globalization. Paper presented at the American Educational Research Association Annual Conference, San Francisco.

Li, G. (2009). Yihua yu chongjian: Shixi youer jiaoshi de shengming [Alienation and reconstruction: On the kindergarten teacher's life]. Contempoary Education Management(10), 70-72.

Li, H. (2005). Youeryuan kecheng gaige: Zai ertong zhudao yu jiaoshi zhudao zhijian xunzhao pingheng [Kindergarten curriculum reform: Finding the balance between child-directed and teacher-directed]. Early Childhood Education(7-8), 4-6.

Li, H. (2007). Pubianlun yihuo xiangduilun: Zhongguo xueqianjiaoyu gaige zhi wenhuaxue fansi [Universalism or relativism: Cultural reflection on Chinese early childhood education reform]. In J. Zhu (Ed.), Zhongguo shiye xia de xueqian jiaoyu [Early childhood education from the Chinese persepective] (pp. 53-63). Shanghai: East China Normal University Press.

Li, J. [Jimei]. (2002). "Youeryuan jiaoyu zhidao gangyao (shixing)" jiexi [Brief analysis of Guidelines for Kindergarten Education (trial)]. In Basic Education Department of Ministry of Education (Ed.), Youeryuan jiaoyu zhidao gangyao (shixing) jiedu [Interpreting Guidelines for Kindergarten Education (trial)] (pp. 41-55). Nanjing: Phoenix Publishing and Media Network \& Jiangsu Jiaoyu Chubanshe.

Li, J. [Jimei]. (2006). Women gaibian le shenme? Women haineng gaibian shenme? - Zai quanguo dierci shishi <gangyao> jingyan jiaoliuhui shang de baogao [What have we changed? What can we change more? - Speech at the second national conference of implementing Guidelines for Kindergarten Education (trial)]. Early Childhood Education(10), 6-10.

Li, J. [Jimei]. (2008). Guanyu youer jiaoshi zhuanye fazhan de ruogan wenti chuyi [On some problems of early childhood teachers' professional growth]. Early Education(2), 12-14.

Li, J. [Jin]. (2009). Learning to self-perfect: Chinese beliefs about learning. In C. K. K. Chan \& N. Rao (Eds.), Revisiting the Chinese Learner: Changing contexts, changing education (pp. 35-69). Hong Kong: Springer \& Comparative Education Research Centre The University of Hong Kong.

Li, R. (2010). Yizhoushi youer jiaoshi jixu jiaoyu xianzhuang de diaocha yanjiu [A survey on Yizhoushi early childhood teacher's continuing education]. Education and Teaching Research(September), 169-171.

Li, S. (2006). Xueqian jiaoyuxue (xiudingban) [Pre-school education (Revised edition)]. Shanghai: East China Normal University Press.

Li, X. (2005). A Tao of narrative: Dynamic splicing of teacher stories. Curriculum Inquiry, 35(3), 339365.

Li, Y. L. (2004). The culture of teaching in the midst of western influence: The case of Hong Kong kindergartens. Contemporary Issues in Early Childhood, 5(3), 330-348.

Li, Y. L. (2006). Classroom organization: Understanding the context in which children are expected to learn. Early Childhood Education Journal, 34(1), 37-43. 
Li, Z., Yang, X., \& Yin, J. (2009). Youeryuan yuanben kecheng kaifa de lilun yu shijian [Theory and practice of developing kindergarten-based curriculum]. Beijing: People's Education Press.

Liang, H., \& Feng, X. (2004). Beijingshi youer jiaoshi zhiye juandai de zhuangkuang ji chengyin yuanjiu [A study on career burn-out of early childhood teachers in Beijing]. Studies in Preschool Education(5), 32-35.

Lin, K. (2010). Youer jiaoshi jiaoxue fansi zhong wenti guiyin de xianzhuang yu tedian fenxi [A study on early childhood teachers' problem attribution in reflection]. Curriculum and Teaching(9), 36-47.

Little, J. W. (2003). Inside teacher community: Representations of classroom practice. Teachers College Record, 105(6), 913-945.

Liu, J., \& Elicker, J. (2005). Teacher-child interaction in Chinese kindergartens: An observational analysis. International Journal of Early Years Education, 13(2), 129-143.

Liu, J., Sun, Y., \& Wang, L. (2007). 1996 2006 nian woguo xueqian jiaoyu lingyu guanyu "jiaoshi xuanti" de yanjiu zhuangkuang yu fenxi [A survey of research condition concerning 'teacher' of preschool education in 1996-2006: Based on three universities' masters and doctors' dissertation research]. Studies in Preschool Education(10), 13-25.

Liu, L. (2009). Personal knowledge in education autobiography: An investigation on "good teachers". Frontiers of Education in China, 4(1), 123-132.

Liu, X. (2002). Wei Duwei "ertong zhongxinlun" bianhu [Defending Dewey's "child-centred" notion]. Studies in Preschool Education(02), 25-29.

Liu, X. (2007). Shilun zhongguo xueqian jiaoyu gaige de fangxiang [An essay on the direction of Chinese early childhood education reform]. In J. Zhu (Ed.), Zhongguo shiye xia de xueqian jiaoyu [Early childhood education from the Chinese persepective] (pp. 1-17). Shanghai: East China Normal University Press.

Liu, Y. [Yan]., \& Feng, X. (2005). Kindergarten educational reform during the past two decades in mainland China: Achievements and problems. International Journal of Early Years Education, 13(2), 93-99.

Liu, Y. [Yun]., \& Gu, R. (2008). Yangyu shijian yingxiang youeryuan jiaoshi zhuanye chengzhang zhi geren yinsu fenxi [An analysis of personal factors of influence of nurturing incidents upon preschool teachers' professional development]. Early Childhood Education (Educational Sciences)(9), 26-31.

Liu, Y. [Yan]., Pan, Y., \& Sun, H. (2007). Zhongguo dalu jin ershinian lai youer jiaoyu gaige de licheng huigu yu xianzhuang fenxi [Review of the twenty years early childhood education reform in mainland China]. In J. Zhu (Ed.), Zhongguo shiye xia de xueqian jiaoyu [Early childhood education from the Chinese persepective] (pp. 18-40). Shanghai: East China Normal University Press. 
Liu, Y. [Yongcan]., \& Xu, Y. (2011). Inclusion or exclusion?: A narrative inquiry of a language teacher's identity experience in the 'new work order' of competing pedagogies. Teaching and Teacher Education, 27(3), 589-597.

Lu, Q. (2006). Youer jiaoshi xinli jiankang zhuangkang de diaocha yanjiu [The investigation of psychological health of infants' teachers]. Xu Teli Research (Journal of Changsha Normal College)(4), 21-25.

Lynn, S. K. (2002). The winding path: Understanding the career cycle of teachers. The Clearing House, 75(4), 179-182.

Lyotard, J. F. (1984). The postmodern condition: A report on knowledge. Minneapolis: University of Minnesota Press.

Marcos, J. M., Sanchez, E., \& Tillema, H. H. (2011). Promoting teacher reflection: What is said to be done. Journal of Education for Teaching, 37(1), 21-36.

Marton, F., \& EDB Chinese Language Research Team. (2009). The Chinese learner of tomorrow. In C. K. K. Chan \& N. Rao (Eds.), Revisiting the Chinese learner: Changing contexts, changing education (pp. 133-167). Hong Kong: Springer \& Comparative Education Research Centre The University of Hong Kong.

McNaughton, K., \& Krentz, C. (2007). The construction site project: Transforming early childhood teacher practice. Theory Into Practice, 46(1), 65-73.

Mears, C. L. (2008). Gateways to understanding: A model for exploring and discerning meaning from experience. International Journal of Qualitative Studies in Education, 21(4), 407-425.

Meighan, R., \& Harber, C. (2007). A sociology of educating (5th ed.). London; New York: Continuum.

Meng, K., \& Yu, S. (2007). Qingnian youer jiaoshi lizhi yuanwang de xushi yanjiu [A narrative research on the willing of a young preschool teacher's leaving her job]. Journal of Jiangxi Radio \& TV University(4), 74-76.

Ministry of Education in People's Republic of China. (1989). Youeryuan gongzuo guicheng (shixing) [Kindergarten Work Regulations and Procedures (Trial)]

Ministry of Education in People's Republic of China. (1996). Youeryuan gongzuo guicheng [Kindergarten Work Regulations and Procedures] Retrieved October 10th, 2008, from http://www.bjchy.gov.cn/affair/zfyj/law/15365.htm

Ministry of Education in People's Republic of China. (2001). Youeryuan jiaoyu zhidao gangyao (shixing) [Guidelines for kindergarten education (Trial)] Retrieved October 10, 2008, from http://www.edu.cn/20011126/3011708.shtml

Mitchell, J., Riley, P., \& Loughran, J. (2010). Learning professional learning in schools: Emotion in action. Teacher Development, 14(4), 533-547.

Morrell, E. (2003). Legitimate peripheral participation as professional development: Lessons from a summer research seminar. Teacher Education Quarterly, 30(2), 89-99. 
Mu, Y. (2010). Youeryuan gugan jiaoshi zhuanye chengzhang de yingxiang yinsu fenxi [Analysis of the influential factors of backbone preschool teacher's professional growth]. Early Childhood Education (Educational Sciences)(11), 39-43.

Mu, Y., Shen, J., \& Luo, L. (2008). Cong "shifu" de jiaodu jiedu youeryuan shituzhi jiaoshi zhuanye chengzhang moshi [Unscramble the master-prentice mode of preschool teacher's professional development from the angle of masters]. Studies in Preschool Education(06), 15-17.

Noddings, N. (1988). An ethic of caring and its implications for instructional arrangements. American Journal of Education, 96(2), 215-230.

Nolen, A. L., \& Putten, J. V. (2007). Action research in education: Addressing gaps in ethical principles and practices. Educational Researcher, 36(7), 401-407.

Null, W. (2011). Curriculum: From theory to practice. Plymouth: Rowman \& Littlefield.

Nuttall, J., Coxon, L., \& Read, S. (2009). Structure, agency, and artefacts: Mediating professional learning in early childhod education. In S. Edwards \& J. Nuttall (Eds.), Professional learning in early childhood settings (pp. 97-113). Rotterdam: Sense.

O'Sullivan, M. C. (2002). Action research and the transfer of reflective approaches to in-service education and training (INSET) for unqualified and underqualified primary teachers in Namibia. Teaching and Teacher Education, 18(5), 523-539.

O'Connor, K. E. (2008). "You choose to care": Teachers, emotions and professional identity. Teaching and Teacher Education, 24(1), 117-126.

Olson, M. R., \& Craig, C. (2009). "Small" stories and meganarratives: Accountability in balance. Teachers College Record, 111(2), 547-572.

Paine, L. (1986). Traditions and reforms. Science, 232(4753), 1011-1012.

Palmer, P. J. (1998). The courage to teach: Exploring the inner landscape of a teacher's life (1st ed.). San Francisco, Calif.: Jossey-Bass.

Pan, Y., \& Liu, Y. [Yan]. (2008). A comparison of curricular practices in Chinese kindergartens: the influence of curriculum reform. International Journal of Early Childhood, 40(2), 33-48.

Pattie, L. Y. Y. (2009). Teachers' stress and a teachers' development course in Hong Kong: Turning 'deficits' into 'opportunities'. Professional Development in Education, 35(4), 613-634.

Peng, B., \& Xie, M. (2009). Yingxiang youer jiaoshi zhuanye chengzhang de guanjian yinwu diancha [On the key factors of kindergaren teachers' professional growth]. Studies in Preschool Education(10), 47-50.

Peng, C. (2010). Traveling theory: The dissemination and transformation of educationl narrative inquiry in China. US-China Education Review, 7(1), 41-50.

Peng, Y. (2009). Youeryuan jiaoshi geren jiaoyu guannian xingcheng de gean xushi yanjiu [A narrative case study on formation of preschool teacher's personal view of education]. Early Childhood Education (Educational Sciences)(9), 36-40. 
Peterson, E. E., \& Langellier, K. M. (2006). The performance turn in narrative studies. Narrative Inquiry, 16(1), 173-180.

Pinnegar, S., \& Daynes, J. G. (2007). Locating narrative inquiry historically: Thematics in the turn to narrative. In D. J. Clandinin (Ed.), Handbook of narrative inquiry: Mapping a methodology (pp. 3-34). Thousand Oaks, Calif.: Sage Publications.

Polanyi, M. (1962). Tacit knowing: Its bearing on some problems of philosophy. In M. G. Grene (Ed.), Knowing and being: Essays by Michael Polanyi (pp. 159-180). London: Routledge \& K. Paul.

Polkinghorne, D. E. (1988). Narrative knowing and the human sciences. Albany: State University of New York Press.

Polkinghorne, D. E. (1995). Narrative configuration in qualitative analysis. Qualitative Studies in Education, 8(1), 5-23.

Polkinghorne, D. E. (2007). Validity issues in narrative inquiry. Qualitative Inquiry, 13(4), 471-486.

Popkewitz, T. S., \& Brennan, M. (1998). Restructuring of social and political theory in education: Foucault and a social epistemology of school practices. In T. S. Popkewitz \& M. Brennan (Eds.), Foucault's challenge: Discourse, knowledge, and power in education (pp. 3-38). New York: Teachers College Press.

Qi, W., \& Tang, H. (2004). The social and cultural background of contemporary moral education in China. Journal of Moral Education, 33(4), 465-480.

Qualifications and Curriculum Authority. (2000). Curriculum guidance for the foundation stage. London: Qualifications and Curriculum Authority.

Quinn, R. E., \& Spreitzer, G. M. (1997). The road to empowerment: Seven questions every leader should consider. Organizational Dynamics, 26(2), 37-49.

Rao, N., \& Li, H. (2008). "Eduplay": Beliefs and practices related to play and learning in Chinese kindergartens. In I. Pramling-Samuelsson \& M. Fleer (Eds.), Play and learning in early childhood settings: International perspectives (pp. 97-116). Dordrecht ; London: Springer.

Rao, N., NG, S. S. N., \& Pearson, E. (2009). Preschool peddagogy: A fusion of traditional Chinse beliefs and contemporary notions of appropriate practice. In C. K. K. Chan \& N. Rao (Eds.), Revisiting the Chinese learner: Changing contexts, changing education (pp. 255-279). Hong Kong: Springer \& Comparative Education Research Centre The University of Hong Kong.

Renard, L. (2003). Setting new teachers up for failure or success. Educational Leadership, 62-64.

Richardson, L. (2000). Writing: A method of inquiry. In N. K. Denzin \& Y. S. Lincoln (Eds.), The handbook of qualitative research (2nd ed., pp. 923-948). Thousand Oaks, Calif.: Sage Publications.

Richardson, L. (2003). Analytic strategies of interviews. In J. F. Gubrium \& J. A. Holstein (Eds.), Postmodern interviewing (pp. 187-202). Thousand Oaks: Sage Publications.

Richter, D., Kunter, M., Klusmann, U., Ludtke, O., \& Baumert, J. (2011). Professional development across the teaching career: Teachers' uptake of formal and informal learning opportunities. Teaching and Teacher Education, 27(1), 116-126. 
Rinaldi, C. (2006). In dialogue with Reggio Emilia: Listening, researching and learning. New York: Routledge.

Rippon, J., \& Martin, M. (2006). Call me teacher: The quest of new teacher. Teachers and Teaching, 12(3), 305-324.

Rochon, T. R. (1998). Culture moves: Ideas, activism, and changing values. Princeton, New Jersey: Princeton University Press.

Rogoff, B. (1994). Developing understanding of the idea of communities of learners. Mind, Culture, and Activity, 1(4), 209-229.

Rogoff, B. (1995). Observing sociocultural activity on three planes: Participatory appropriation, guided participation, and apprenticeship. In J. V. Wertsch, P. del Rio \& A. Alvarez (Eds.), Sociocultural studies of mind (pp. 139-164). Cambridge: Cambridge University Press.

Rogoff, B. (1998). Cognition as a collaborative process. In W. Damon (Ed.), Handbook of child psychology (5th ed., Vol. 2). New York: John Wiley.

Rogoff, B. (2003). The cultural nature of human development. Oxford: Oxford University Press.

Rogoff, B., Baker-Sennett, J., Lacasa, P., \& Goldsmith, D. (1995). Development through participation in sociocultural activity. New Directons for Child and Adolescent Development(67), 45-65.

Rogoff, B., Matusov, E., \& White, C. (1996). Models of teaching and learning: Participation in a community of learners. In D. R. Olson \& N. Torrance (Eds.), Handbook of education and human development (pp. 387-414). Oxford: Blackwell.

Rogoff, B., Paradise, R., Arauz, R. M., Correa-Chávez, M., \& Angelillo, C. (2003). Firsthand learning through intent participation. Annual Review of Psychology, 54(1), 175-203.

Rogoff, B., \& Toma, C. (1997). Shared thinking: Community and institutional variations. Discourse Processes, 23(3), 471-497.

Sawyer, R. (2002). Unresolved tensions in sociocultural theory: Analogies with contemporary sociological debates. Culture \& Psychology, 8(3), 283-305. doi: 10.1177/1354067X0283002

Scherff, L. (2008). Disavowed: The stories of two novice teachers. Teaching and Teacher Education, 24(5), 1317-1332.

Schmidt, M., \& Datnow, A. (2005). Teachers' sense-making about comprehensive school reform: The influence of emotions. Teaching and Teacher Education, 21(8), 949-965.

Schön, D. A. (1983/1991). The reflective practitioner: How professionals think in action. Aldershot, Hants: Ashgate.

Schön, D. A. (1987). Educating the reflective practitioner: Toward a new design for teaching and learning in the professions (1st ed.). San Francisco: Jossey-Bass.

Schulz, R., Schoroeder, D., \& Brody, C. M. (1997). Collaborative narrative inquiry: Fidelity and the ethics of caring in teacher research. International Journal of Qualitative Studies in Education, 10(4), 473-485.

Schwab, J. (1983). The practical 4: Something for curriculum professors to do. Curriculum Inquiry, 13(3), 239-265. 
Shanghai Municipal Education Commission. (1999). Shanghai xue qian jiao yu gang gao [Shanghai early childhood education framework] Retrieved January 4th, 2011, from http://www.age06.com/Age06Public/SPEAuditing/PostPreview.aspx?view\&Contentld=3842 9

Shanghai Municipal Education Commission. (2004). Shanghai xue qian jiao yu ke cheng zhi nan (shi xing ban) [Curriculum guidelines for Shanghai early childhood (Trial)]. Shanghai: Shanghai Education Publishing House.

Shanghaishi jiaoweijiaoxueyanjiushi youjiaozu. (2001). Shanghaishi youeryuan xinkecheng de lilun sikao yu shijian tansuo [Theoretical reflection and practical exploration of Shanghai's new kindergarten curriculum]. In Y. He (Ed.), Youeryuan kecheng [Kindergarten Curriculum] (pp. 19-37). Beijing: Beijing Normal University Press.

Shao, G., \& Gu, L. (2010). Zhongxue jiaoshi jiaoxue fansi xianzhuang de diaocha fenxi yu yanjiu [A survery on middle school teachers' reflection]. Teacher Education Research, 22(2), 66-70.

Shapiro, S. (2010). Revisiting the teachers' lounge: Reflections on emotional experience and teacher identity. Teaching and Teacher Education, 26(3), 616-621.

Shi, L. (2006). The successors to Confucianism or a new generation? A questionnaire study on Chinese students' culture of learning English. Language Culture and Curriculum, 19(1), 122147.

Shu, C., Gao, Y., \& Li, F. (2006). Shiluo yu huigui: Dui youer jiaoshi zhuanye zizhuquan de sikao [On preschool teachers' autonomy rights in their profession]. Studies in Preschool Education(2).

Shu, C., Ke, Q., \& Du, Y. (2006). Jiaoshi zhuanye chengzhang jieduan jiqi yingxiang yinsu tanxi [An analysis of stages and influencing factors of preschool teachers' professional development]. Early Childhood Education (Educational Sciences)(7/8), 55-60.

Shu, J. (2010). Return of the ghost: To discipline or/and to teach? Asia Pacific Journal of Education, 30(1), 105-120.

Shulman, L. S. (2004). Knowledge and teaching: Foundations of the new reform. In S. M. Wilson (Ed.), The wisdom of practice: Essays on teaching, learning, and learning to teach (pp. 217-248). San Francisco: Jossey-Bass. (Original work published 1987)

Shulman, L. S. (2004). Teaching alone, learning together: Needed agendas for the new reforms. In S. M. Wilson (Ed.), The wisdom of practice: Essays on teaching, learning, and learning to teach (pp. 309-334). San Francisco: Jossey-Bass. (Original work published 1988)

Shulman, L. S. (2004). Just in case: Reflections on learning from experience. In S. M. Wilson (Ed.), The wisdom of practice: Essays on teaching, learning, and learning to teach (pp. 461-482). San Francisco: Jossey-Bass. (Original work published 1996)

Shulman, L. S. (2004). Theory, practice, and the education of professionals. In S. M. Wilson (Ed.), The wisdom of practice: Essays on teaching, learning, and learning to teach (pp. 521-544). San Francisco: Jossey-Bass. (Original work published 1998)

Sikes, P. J., Measor, L., \& Woods, P. (1985). Teacher careers: Crises and continuities. London: Falmer. 
Skaalvik, E. M., \& Skaalvik, S. (2009). Does school context matter? Relations with teacher burnout and job satisfaction. Teaching and Teacher Education, 25(3), 518-524.

Sparkes, A. C., Nilges, L., Swan, P., \& Dowling, F. (2003). Poetic representation in sport and physical education: Insider perspectives 1. Sport, Education and Society, 8(2), 153-177.

Spector-Mersel, G. (2010). Narrative research: Time for a paradigm. Narrative Inquiry, 20(1), 204-224.

Stenhouse, L. (1967). Culture and education. London: Nelson.

Stimpfl, J., Zheng, F., \& Meredith, W. (1997). A garden in the motherland: A study of a preschool in China. Early Childhood Development and Care, 129(1), 11-26.

Taras, V., Kirkman, B. L., \& Steel, P. (2010). Examining the impact of Culture's Consequences: A threedecade, multilevel, meta-analytic review of Hofstede's cultural value dimensions. Amercian Psychological Association, 95(3), 405-439. doi: 10.1037/a0018938

Tobin, J. J. (2011). Implicit cultural beliefs and practices in appraoches to early childhood education and care. Asia-Pacific Journal of Research in Early Childhood Education, 5(1), 3-22.

Tobin, J. J., Hsueh, Y., \& Karasawa, M. (2009). Preschool in three cultures revisited. Chicago: The University of Chicago Press.

Tobin, J. J., Wu, D. Y. H., \& Davidson, D. H. (1989). Preschool in Three Cultures: Japan, China and the United States. New Haven: Yale University Press.

van Manen, M. (1991). The tact of teaching: The meaning of pedagogical thoughtfulness. Ontario: The Althouse Press.

Veenman, S. (1984). Perceived problems of beginning teachers. Review of Educational Research, 54(2), 143-178.

Vescio, V., Ross, D., \& Adams, A. (2008). A review of research on the impact of professional learning communities on teaching practice and student learning. Teaching and Teacher Education, 24(1), 80-91.

Victoria University of Wellington. (2007). Human ethics policy. Wellington: Victoria Univeristy of Wellington.

Vygotsky, L. S. (1987). Thinking and speech (N. Minick, Trans.). In R. Riber \& A. Carton (Eds.), L. S. Vygotsky, Collected works (Vol. 1, pp. 39-285). New York: Plenum (Original works published in 1934, 1960).

Vygotsky, L. S. (1997). Interaction between learning and development. In M. Gauvain \& M. Cole (Eds.), Readings on the development of children (pp. 29-36). New York: W. H. Freeman and Company. (Reprinted from: Mindy and Society, pp. 79-91, 1978, Harvard University Press).

Wahlstrom, K. L., \& Louis, K. S. (2008). How teachers experience principal leadership: The roles of professional community, trust, efficacy, and shared responsibility. Educational Administraion Quarterly, 44(4), 458-495.

Wang, D. (2011). The dilemma of time: Student-centered teaching in the rural classroom in China. Teaching and Teacher Education, 27(1), 157-164. 
Wang, H. (2008). Translating Chinese classics in a colonial context: Janes Legge and his two versions of the Zhongyong. Bern: Peter Lang.

Wang, J., Elicker, J., McMullena, M., \& Mao, S. (2008). Chinese and American preschool teachers' beliefs about early childhood curriculum. Early Child Development and Care, 178(3), 227249.

Wang, J., Mao, S., \& Elicker, J. (2007). Zhongmei liangguo youer jiaoshi kechengguan bijiao [On Chinese and American preschool teachers' curriculum beliefs]. Studies in Preschool Education(1), 46-50.

Wang, Y. (2010). Woguo youer jiaoshi zhuanye chengzhang yanjiu zongshu [Summary of the research on Chinese early childhood teacher's professional development]. Journal of Education Development(April (2)), 8-11.

Ward, A. R. (2007). Students with disabilities talk about their friendships: A narrative inquiry. PhD in Education Thesis, Massey University, Palmerston North.

Weber, K. (2010). Professional learning between past experience and future work. Frontiers of education in China, 5(3), 329-346.

Wenger, E. (1998). Communities of practice: Learning, meaning and identity. Cambridge: Cambridge University Press.

Wenger, E., McDermott, R., \& Snyder, W. M. (2002). A guide to manage knowledge: Cultivating communities of practice. Boston: Harvard Bussiness School Press.

Wertsch, J. V. (1991). Voices of the mind: A sociocultural approach to mediated action. London: Harvester Wheatsheaf.

Whitaker, P. (1993). Managing change in schools. Buckingham: Open University Press.

Williams, A. (2003). Informal learning in the workplace: A case study of new teachers. Educational Studies, 29(2/3), 207-219.

Wu, D. (2009). Reflection on prosperity: Localization of pedagogy in China. Frontiers of Education in China, 4(3), 453-465.

Wu, Z. (2010). Youer jiaoshi xuexi xiaonenggan xianzhuang jiqi peiyang celue yanjiu [A study of early childhood teacher's sense of effective learning and cultivating strategies]. Fujian Tribune (Social Science Education Edition)(10), 63-65.

Xing, Q., \& Chen, Z. (2009). Zuzhi qifen yu youer jiaoshi lizhi qingxiang de guanxi yuanjiu [The corelation beteween organizational ethos and kindergarten teachers' turnover intention]. School Management and Development(3), 12-17.

Yang, C., \& Pang, L. (2009). Youer jiaoshi kexue jiaoyu zhishi de leixing jiqi tezheng [Study of types and properties of kindergarten teachers' pedagogical content knowledge for science]. Studies in Preschool Education(7), 25-28.

Yang, S. (2008). Narrative of a cross-cultural language teaching experience: Conflicts between theory and practice. Teaching and Teacher Education, 24(6), 1564-1572. 
Yang, X., \& Zhai, Y. (2006). Zhuanye rentong dui youeryuan jiaoshi zhuanye fazhan yingxiang de gean yanjiu [A case study: The influence of professional identity on preschool teachers' professional development]. Early Childhood Education (Educational Sciences)(2), 32-35.

Yi, L., \& Pang, L. (2003). Youer jiaoshi quanwei de shiluo yu chongsu [Losing and remoulding early childhood teacher's authority. Journal of the Chinese Society of Education(11), 47-50.

Yi, L., \& Pang, L. (2005). Zai qinli zhong chengzhang: Yige youer jiaoshi geren jiaoyu guannian de xushi yanjiu [Develop from one's own experience: A narrative research on the forming of a preschool teacher's personal educational concepts]. Studies in Preschool Education, 2, 40-43.

Yue, Y. (2010). Youer jiaoshi geren zhishi guanli celue fazhan guocheng jiqi jieduan tezheng [Strategies, development and characteristics of early childhood teacher's personal knowledge management]. Journal of Education Development, May(2).

Zeichner, K. M., \& Liston, D. P. (1996). Reflective teaching: An introduction. Mahwah, N.J.: L. Erlbaum Associates.

Zhang, C., \& Zong, M. (2010). Youer jiaoshi zhuguan xingfugan, xinli jiankang yu yingdui de fangshi [The correlation between subjective well-being, mental health and coping style of the preschool teachers]. Health Research, 30(3), 194-197.

Zhang, D. (2003). Key concepts in Chinese philosophy (E. Ryden, Trans.). New Haven: Yale University Press.

Zhang, H. (2006). On the essence of knowing in teaching/learning. Frontiers of Education in China, 1(2), 226-257.

Zhang, Y. [Yuming]. (2004). Dui yize BBS tie de yanjiu: Youer jiaoshi zhiye juantai chengyin xi [On a BBS post: Understanding kindergarten teachers' job burnout]. Studies in Preschool Education(4).

Zhang, Y. [Yani]. (2009). Youer jiaoshi zhuanye fazhan gean yanjiu: Wo de chengzhang gushi [Case study on the professional development of preschool teacher: My growing story]. Education and Teaching Research, 23(6), 101-103.

Zhao, G. (2010). Chinese cultural dynamics and childhood: Towards a new individuality for education. Frontiers of Education in China, 5(4), 579-595.

Zhao, N., \& Qin, J. (2007). Youer jiaoshi zhiye shengya zhouqi de zhiye juandai yanjiu [A study on early childhood teacher's job burnout during at career stages]. Teacher Education Research, 19(3), 72-76.

Zhao, Z. (2007). Cong zhiliang huayu dao yiyi shengcheng huayu de zhuanbian: Yuanben jiaoyan yu chuantong jiaoyan de shengtaixue shijiao bijiao [From quality terms to meaning-emerging terms: Contrast between kindergarten-based teaching research and traditional teaching research]. Studies in Preschool Education(11), 9-12.

Zhu, J., \& Zhang, J. (2008). Contemporary trends and developments in early childhood education in China. Early Years, 28(2), 173-182. 
Zhu, M. (2002). Zhongguo youer jiaoyu fazhan de huigu yu zhanwang [Review and Anticipate the development of Chinese early childhood education]. In Basic Education Department of Ministry of Education (Ed.), Youeryuan jiaoyu zhidao gangyao (shixing) jiedu [Interpreting Guidelines for Kindergarten Education (trial)] (pp. 15-28). Nanjing: Phoenix Publishing and Media Network \& Jiangsu Jiaoyu Chubanshe.

Zhu, X. (Ed.). (2008). Youer jiaoshi fansi nengli yanjiu peiyang [A study on cultivating early childhood teacher's ability to reflect]. Beijing: Educational Science Publishing House.

Zinchenko, V. P. (1985). Vygotsky's ideas about units for the analysis of mind. In J. V. Wertsch (Ed.), Culture, communication and cogintion: Vygotskian perspectives (pp. 95-118). Cambridge, NY: Cambridge University Press. 


\section{Appendices}

\section{Appendix A: Information Sheets}

(I combined the separate information sheets for Kindergarten Directors, Teachers and Parents here. The original information sheets that I sent out were all English and Chinese bilingual documents.)

Points $1-3$ are the same for Kindergarten Directors, Teachers and Parents

\section{Title of the study}

Stories of Chinese early childhood teachers' teaching and learning experiences in contemporary China

\section{Researcher's self-introduction}

My name is xxx. I am an early childhood teacher who has more than fifteen years of early childhood teaching experience in Shanghai, Beijing and Wellington. I have a Master degree in Education (Early Childhood) from Victoria University of Wellington (New Zealand) and I am undertaking this research project as the requirement for my $\mathrm{PhD}$ dissertation.

\section{Introduction of the research project}

The purpose of this study is to tell the stories of Chinese early childhood teachers' contextualized teaching and learning experiences in contemporary China through a narrative inquiry process. I will focus on Chinese early childhood teachers' experiences of working with the tension between Chinese traditional educational discourses and Western influenced early childhood educational approaches and curriculum. Central to this study is to hear Chinese early childhood teachers' voices and reveal their stories of their teaching and learning experiences. I will work closely with the participating Chinese early childhood teachers, invite them to articulate and reflect their practices to help teachers, kindergarten directors and interested early childhood professionals better understand early childhood teaching and learning in contemporary China. I would also like to talk to the parents, the children in their classes and the kindergarten directors. 


\section{Information about data collection \\ For Kindergarten Directors}

This research will have two phases, September -December 2009 will be the first phase, and March-June 2010 will be the second phase. I will need two volunteering class teachers from the same class from your kindergarten to participate in my study (six teachers from three different kindergartens in total). I will go to your kindergarten two or three days per week for one month during each phase. When I am in your kindergarten, I will observe, take notes, and talk to the children and the teachers. I would also like to interview the participating teachers, yourself and some interested parents (probably six parents). During the second phase, I would like to form a network for all six participating teachers to meet (three meetings) and share experiences. I will also keep in touch with the participating teachers through weekly e-mails and phone calls. Participating teachers can share their stories with me either orally or in a written form, for instance, e-mails, letters or journal. I will also need your permission to gather relevant documents from your kindergarten that will inform my research, for instance, policies, curriculum planning and evaluation; and to attend staff meetings.

\section{For Teachers}

This research will have two phases, September -December 2009 will be the first phase, and March-June 2010 will be the second. I would like to come to the participating class and be part of it as a teacher assistant two or three days per week for one month during each phase. When I am in the classroom, I will observe, take notes, talk to children and teachers, and also assist teachers with the matters that relate to safety and hygiene. I will interview the participating teachers three times during the first phase of the study and the fourth interview will be conducted at the end of the phase two. During the second phase, I would like to form a network for all six participating teachers to meet (three meetings) and share experiences. I will also keep in touch with the participating teachers through weekly e-mails and phone calls. Participating teachers can share their stories with me either orally or in a written form, for instance, e-mails, letters or journal. I will also interview some parents (probably six) of children in the participating class to seek their perception of early childhood education in China.

\section{For Parents}

My research has two phases, September -December 2009 will be the first phase, and MarchJune 2010 will be the second. Although the research focus is the teachers, I will need to observe teaching and learning in the class where children will be involved as well. I will observe teaching in the classrooms eight days during each phase. I will act as a teacher 
assistant when observing in the classroom, and I will talk and interact with children during the observation. I will also interview some interested parents to seek their perception of Chinese early childhood education for my research.

\section{Ethical Considerations}

\section{For Kindergarten Directors}

Participation in this research is entirely voluntary. The participants have the right to decline and withdraw from the study at any point of time during the data collection period. The participants can refuse to answer any particular questions and to ask questions at any time during participation. Neither the names of the kindergartens nor teachers, parents nor children's real name will be used in my writing. All participants will choose a 'research name' for them to use throughout the research process. A summary report of findings will be available to the participants when the study is concluded.

\section{For Teachers}

Participation in this research is entirely voluntary, and it has to be a group decision that is agreed by all teachers who are teaching in the same class. Please also discuss this with the teacher aid in the class as she/he may be part of the scene of my observations. The participants have the right to decline and withdraw from the study at any point of time during the data collection period. The participants can refuse to answer any particular questions and to ask questions at any time during participation. Neither the name of the kindergarten nor teachers' real names will be used in my writing. All participants will choose a 'research name' to use throughout the research process. A summary report of findings will be available to the participants when the study is concluded.

\section{For parents}

Participation in this research is entirely voluntary. Parents can choose whether they want their children to be part of the research. For children whose parents do not give the consent for participation, I will make sure that I do not take any notes of these children. The parents also have the right to withdraw from the research at any time during the data collection process, and ask me any questions at any time. Neither the names of the kindergartens and the teachers nor the parents' or children's real names will be used in my writing. All participants will choose a 'research name' for them to use throughout the research process.

\section{Information below is the same for Kindergarten Directors, Teachers and Parents}

Interviews will be audio-recorded (taped) and transcribed. Interview transcripts will be checked by the interviewees. The electronic files and documents will be saved on the 
password protected computer (only the researcher can access it), and any related memory sticks, audio tapes and written materials will be stored in lockable cabinets. The audio recordings (either digital files or tapes) will be returned to the participants or destroyed/deleted from the computer upon the participants' wishes at the completion of the study. Other data such as interview notes, observation notes and journals will be stored in a secure situation for five years and will then be destroyed. By implementing these practices, I will try to ensure that the participants' anonymity and confidentiality are assured. However, I cannot guarantee this as the early childhood education sector in Beijing is a relatively small community.

No other person besides me, my supervisors - Judith Loveridge and Alison Stephenson, will see the original data. The participants will be able to access the data that relates to them. I will use the collected data in the writing of my $\mathrm{PhD}$ dissertation, and the dissertation will be submitted for marking to the School of Educational Psychology and Pedagogy, Victoria University of Wellington, and deposited in the university library. The data will also be used in writing academic articles for publication purposes and for presentations at academic conferences.

This research is assessed and approved by Victoria University College of Education Ethics Committee. I would like to ask your support in order to make this research possible. If you have any questions or would like to receive further information about this research project, please do not hesitate to contact me or my supervisors.

The researcher and her supervisors' contact information in English and Chinese

Address ...

Email ...

Phone... 


\section{Appendix B: Consent Forms}

(Only minor differences in wording in consent forms for Kindergarten Directors and Teachers; original consent forms were English and Chinese bilingual documents)

\section{Title of the study: Stories of Chinese early childhood teachers' teaching and learning experiences in contemporary China}

$\square \quad$ I have read the Information Sheet of this study and have had the details of this study explained to me. My questions have been answered to my satisfaction, and I understand that I may ask any questions at any time.

$\square$ I understand that I have the right to withdraw from the research at any time during the data collection phases.

$\square$ I agree to provide information to the researcher on the understanding that my name and the name of our kindergarten will not be used. I know the information will remain confidential.

$\square$ I agree to be part of the study under the conditions set out in the Information Sheet.

$\square \quad$ I agree to the researcher observing in my classroom.

$\square \quad$ I know my name and the names of children will not be used.

$\square$ I agree to be interviewed and the interviews can be audio-recorded. I understand that I have the right to ask for the audio-recording to be stopped at any time during the interviews. I also understand that I can decline to answer any particular questions. I know that I will have the opportunity to check and make changes to the interview transcripts.

I agree to be part of the participating teachers' network to meet up with other participants.

$\square \quad$ I agree to keep contact with the researcher during the research process. I understand that the oral and written forms of our communication and my journal may be used as research data to inform the study. I know that I have the right to determine what information I want to be used in the research.

$\square \quad$ I understand that the information will only be used for this research, and for publications and presentations arising from this research project.

Signed:

Name:

Kindergarten:

Date: 


\title{
Appendix C: Consent Form for Parents
}

\author{
(Original consent form was an English and Chinese bilingual document)
}

Title of the study: Stories of Chinese early childhood teachers' teaching and learning experiences in contemporary China

$\square \quad$ I have read the Information Sheet of this study and have had the details of this study explained to me. My questions have been answered to my satisfaction, and I understand that I may ask any questions at any time.

$\square \quad$ I agree to being observed by the researcher. I know that the researcher will talk, interact with my child, and use my child's work during the research process.

$\square \quad$ I understand that I have the right to withdraw my child from the research at any time during the data collection phases.

I understand that my name, my child's name and the name of the kindergarten will not be used. I know the information will remain confidential.

$\square$ I understand that the information will only be used for this research, and for publications and presentations arising from this research project.

$\square$ I agree to let my child be part of the study under the conditions set out in the Information Sheet.

Interview with parents (please indicate)

$\square$ I agree to be interviewed and the interviews can be audio-recorded. I understand that I have the right to ask for the audio-recording to be stopped at any time during the interviews. I know that I can decline to answer any particular questions.

$\square$ I know that I will have the opportunity to check and make changes to the interview transcripts.

Signed: Name: Date: 


\section{Appendix D: Sample of Observation Notes}

Date $\cdots$

$8: 50$

Summer 回来后, 在沙发上坐下, A 也是, 坐到她身边。

A 请 Summer 帮她把气球绳绑在她的右手手腕上。

Summer 接过绳子, 没有马上帮她绑, “那你洗手时怎么办? ”

A 想想，拉起袖子，“就这样”

Summer: “那一会儿如果洗手时, 你不方便, 我再帮你解下来。”

A 点点头。

Summer 绑她把绳子系在右手手腕上, 可是还是不方便, 因为 $\mathrm{A}$ 的手老 动。

Summer: “我还是帮你系在这里吧（背带裙肩带上）。”

A: “好。”

Summer 给她系上。系完, Summer 捋着绳子, 手往上升, “A, 气球会把 你带着飞上天吗？”

A: “不会。”笑。

$\mathrm{A}$ 很满意, 坐在沙发上开始看书。

$9: 00$

WT 摇铃。

Kids stop playing, went to the science table, sat on the floor in front of it. Summer 开始读故事《啊, 蜘蛛》。

Summer 开始先和孩子一起观察封面和扉页图片, 然后开始讲。

WT and Ayi put away the things are on the tables (Lego, crayons, paper and table cloths).

Tidy up time, the children pick up the things on the floor and mat, and sort them out to different containers.

$9: 15$

收完玩具, 洗手, 吃点心。

A 自己要求把气球拿下来, 怕弄湿了。

Summer: “我把它放到你的书包柜里, 行吗? ”

A: “好。”

Summer 帮助 A 解开绳子, 和 A 一起去放入书包柜, 系在 A 昨天带来的 “喜羊羊” 玩偶上, 放在书包柜上面了。 


\section{Appendix E: Interview Schedules for Teachers}

\section{Interview One: As an auto-biographer}

1. Did you go to kindergarten when you were young? What can you remember about your kindergarten and your teachers? How do you think about these memories now?

2. When did you decide to become an early childhood teacher? What did your decision mean to you at that time? What was it about teaching young children that interested or attracted you?

3. What role, explicitly or implicitly, did your family play in your decision to teach? Do you remember any early experiences that affected your decision to teach and your actual teaching practices?

4. What was your formal teacher education like? Did it prepare you for the realities of teaching? Is teaching pretty much what you expected? When you first taught were there any colleagues or mentors who influenced you? How?

5. Are there differences between the way you were taught when you were a student and the way you are teaching now? If yes, what are the differences? What do the differences contribute to your teaching?

6. Can you describe the central teaching ideas that guide your work, and how you came to adopt them?

7. Do you feel comfortable as a teacher, confident with your own philosophy and practical knowledge?

8. How many kindergartens have your taught? Why do you choose to teach in this kindergarten?

9. Have you changed as a teacher over the years? How?

\section{Interview Two: As an early childhood teacher}

1. Tell me about the curriculum, planning and teaching approach of your kindergarten.

2. Are there any challenges and dilemmas for you in practice? If yes, what are the challenges and dilemmas that you have experienced? What are the main causes of these challenges and dilemmas in your opinion? Can you please give me an example?

3. How do you deal with these challenges and dilemmas?

4. What do you like most about teaching? What are the rewards for you?

5. When do you feel best as a teacher? What are your favourite moments?

6. What is most difficult about teaching? Do you ever feel like leaving the profession? Why? Why do you stay? If you could, what things would you change in your work?

7. What other teachers do you admire? Why? 
8. What's your goal for the children? Are there any conflicts between your goals, parents' goals and the kindergarten's goals? Society's goals? If so, what are they and how do the conflicts affect your teaching and the children' learning and development?

9. What is your observation of early childhood education in contemporary China?

10. In your mind, what is important in early childhood education and what kind of kindergarten is ideal for Chinese children?

11. How do you describe your role as an early childhood teacher in the children's early childhood development?

\section{Interview Three: As a whole person}

1. What is important to you in your life? How do you see your life now?

2. What concerns you most about children and families today in China?

3. What are your interests outside of teaching? How are they important to you?

4. What have you experienced/read recently that was significant to you?

5. What do you imagine you'll be doing in five years? In ten years?

\section{Final Interview}

About teaching and learning:

1. Ask teachers to read other two kindergartens' daily schedule and ask them to comment. Hopefully the discussion around teacher-directed learning and child-initiated learning can emerge.

2. Present one little story (a messy classroom after the free play) to the teachers and ask them to comment. Hopefully I can lead the discussion to the topic of class rules and why these rules are important.

3. What kinds of children often require more of your attention? Why? What sort of attention you may give to her/him? Why?

4. Do you find some children are challenging to deal with? Why do you feel they are challenging?

5. How would you define 'curriculum'? What are the metaphors/adjectives would you use to describe curriculum, you, children and the bigger context?

6. How would you describe the children in your class as learners?

7. Do you consider yourself a learner? How would you describe yourself as a learner?

8. In your opinion, what kind of environment / context would enhance learning for both children and teachers?

About the research:

9. How do you feel about participating in this research project?

10. What are the suggestions that you have for me in terms of the research process, my behaviour etc.? 


\section{Appendix F: Interview Schedule for Kindergarten Directors}

1. What is your kindergarten's vision and mission? Could you please explain them to me?

2. What is your kindergarten's curriculum, methods of planning and teaching approach?

3. What's the aspiration for children in your kindergarten? As a kindergarten director, how do you think you are doing / can do to achieve these?

4. Do you personally think that the programme your kindergarten runs is an ideal early childhood programme? Why?

5. How do you think your teachers respond to this kind of curriculum, planning and teaching approach?

6. How about the parents?

7. Are there any challenges and dilemmas in practice for you and your teachers? If yes, what are the challenges and dilemmas that you and your teachers have experienced? What are the main causes of these challenges and dilemmas in your opinion?

8. What would you and your teachers do when they face challenges and dilemmas?

9. How do you support your teachers' when dealing with the challenges and dilemmas?

10. Are there any other professional development opportunities for your teachers that can support their teaching and learning?

11. What is your observation of early childhood education in contemporary China?

12. In your mind, what is important in early childhood education and what kind of kindergarten is ideal for Chinese children?

13. How do you describe the role of kindergarten in the children's early childhood development? 


\section{Appendix G: Interview Schedule for Parents}

1. What's your aspiration for your child? How do you think you are doing / can do to achieve these?

2. Who looks after your child at home? What are the weekends like in your family?

3. Did/do your child attend other early childhood programmes? If yes, why do you enrol your child in these programmes? Does your child like these programmes?

4. Why do you choose this kindergarten? What do you expect from this kindergarten?

5. Do you know what your child does and learns at the kindergarten? How do you get the information?

6. How about teaching? What do you think is important in early childhood teaching and learning?

7. Do you personally think that this kindergarten runs an ideal early childhood programme for your child? Why?

8. What is your opinion on parent-teacher relationship and parents' involvement in the kindergarten activities?

9. Was your own childhood or early childhood education experiences similar to your child's now? Can you please describe to me what the differences and similarities are comparing your own childhood experiences to your child's life now?

10. What is your biggest challenge or dilemma as a parent now? How do you deal with the challenges and dilemmas?

11. What is your observation of early childhood education in contemporary China?

12. In your mind, what is important in early childhood education and what kind of kindergarten is ideal for Chinese children?

13. How will you describe your role as a parent in your child's early childhood development? 


\section{Appendix H: Simplified Letter and Consent Form for Public Kindergarten's Parents (in Chinese only)}

尊敬的家长/监护人:

您好！

我叫 $\mathrm{xx}$, 是一名幼儿园教师，有着十五年教龄，曾经在上海、北京（中国）和惠灵顿 (新西兰) 的多家幼儿园任教。现在我正在新西兰维多利亚大学继续攻读博士学位, 并为我的 博士论文课题进行相关研究。

我的博士论文课题是《当代中国幼儿教师教学经验和学习经验的叙事研究》。我对中 国幼儿教师的教学和学习经验感兴趣的最重要原因是, 我也是她们中的一员。在当代中国这个 充满变化和日益全球化的大时代背景下, 我发现我们幼儿教师是站在中西教育理念交汇点上教 学和学习。倾听中国幼儿教师的声音, 讲述她们的故事, 可以帮助感兴趣的幼教专业人士更好 地理解当代中国幼儿教师的教学和专业学习。

我已经联系了您孩子幼儿园的园长和班级老师, 她们将参与我的研究活动。虽然这个 课题主要研究的是幼儿教师的教学和学习, 但是因为我要在班里进行观察, 您的孩子也有可能 参与到。在观察的过程中, 我会以助教的身份, 和孩子交谈、互动。在研究过程我所收集到 的有关孩子学习发展和教师教学的信息将仅被此研究使用, 这些信息不会用来对儿童进行发展 评价和教师的教学评估。

是否参与课题研究完全取决于您的意愿。请您填写附表，告知我您是否希望您的孩子 参与这个课题研究。对于家长不同意参与研究的孩子, 在研究期间, 我不会观察这些孩子, 也 不会做相关记录。同意参与研究的家长和孩子也有权利在我进行实地调研, 收集研究信息的过 程中随时退出研究。家长也可以随时向我提出与课题研究相关的问题。

我热切期待着您的理解和支持！如果您对我的研究课题感兴趣, 请跟我联系。我的电 话是 $\mathrm{xxxx}$ (上海) 或 $\mathrm{xxxx}$ (北京), 您也可以发邮件到 $\mathrm{xxxx}$ （中英文）或者到 $\mathrm{xxxx}$ (英文)。 谢谢关注!

此致

敬礼

姓名 
请填写以下表格告知我您是否希望您的孩子参加课题研究。谢谢!

口我同意我的孩子 (孩子姓名) 参与课题研究。

口我不同意我的孩子 (孩子姓名) 参与课题研究。

家长/监护人签名:

姓名:

幼儿园:

日期: 


\section{Appendix I: From interview transcripts to pomes}

\section{Step 1: Selecting content from the raw interview transcript in Chinese}

Interview with Cecilia on November 11, 2009 - about Cecilia's kindergarten teachers

$\mathrm{J}:$ 那你对上幼儿园时候的幼儿园和老师有什么记忆和印象吗?

C: 我对幼儿园的印象就是我们幼儿园是两层楼, 我是住在一层的靠东边的那间教室, 记忆深 刻就是每天会尿床, 早上起床, 老师都不用问, 拿起被子就出去晾。

$\mathrm{J}$ : 你说的是全托, 那时候是吗?

$\mathrm{C}$ : 对。更多的记忆就是被罚站则所啦, 然后淘气呀这些。

$\mathrm{J}$ : 为什么会罚站则所?

$\mathrm{C}$ : 我淘气，所以老师基本每天都会让我去则所罚站。

$\mathrm{J}:$ 淘气是不听话, 还是打别人?

$\mathrm{C}$ : 比如说, 前面小朋友的头发挺长的, 我坐在她后头, 就把她的头发绑在椅子上, 然后她起 来回答问题, 就 “嫩”一下，老师都不用问，“去，则所”，然后就去则所。这是大块的 记忆, 然后小块的记忆, 就是, 表演个节目, 还挺爱表演, 但是, 到了表演最后也得捣一 下乱，人家都往右走，我就往左走。

$\mathrm{J}$ : 你现在自己回想起来, 你觉得自己当初这么做的目的是什么呀? 为什么会这么做呀?

$C$ : 可能就是想淘气, 就是不想听, 因为, 我还是相对挺个性的, 你如果做的事儿是我不感兴 趣的事儿, 我就去会做我感兴趣的事儿了, 可能大部分都是我不感兴趣的, 你知道都很教 条的, 坐椅子要手背后, 然后不让动, 我不行, 我控制不了我自己。但是我只对一个老师 相对有印象, 就是短短的卷发, 右嘴角上有一个黑色的痣, 老师好像叫图雅, 我记忆当中 我觉得这个老师对我最好, 所以我也对她的印象特别深。

$\mathrm{J}$ : 她罚过你吗？她怎么对你好？

$\mathrm{C}$ : 想不起来了。我记忆中她好像对我比较好, 可能她会很温柔的跟我说话呀, 或者是 偶尔我 做的好的时候会给我一些小奖励呀，而其它老师我一点点印象也没有了!

(Interview was interrupted by an Ayi who came to the room to ask Cecilia something.)

$\mathrm{J}$ ：继续吧，说那个老师，对你很温柔，对你有奖励。

C: 我对其他老师一点印象都没有, 其他老师估计老罚我, 老说我, 对我是没有鼓励的那种, 所以我不喜欢他们, 所以就不记得他们。

Step 2: Rearrange the transcripts into poetic form in Chinese, delete repeated words, stammer words and very detailed descriptions; highlight and annotate kindergarten experience that may be influential.

对幼儿园的印象

就是我们幼儿园是两层楼

我是住在一层的靠东边的那间教室

记忆深刻就是每天会尿床

早上起床

老师都不用问

拿起被子就出去晾

是全托

更多的记忆就是 


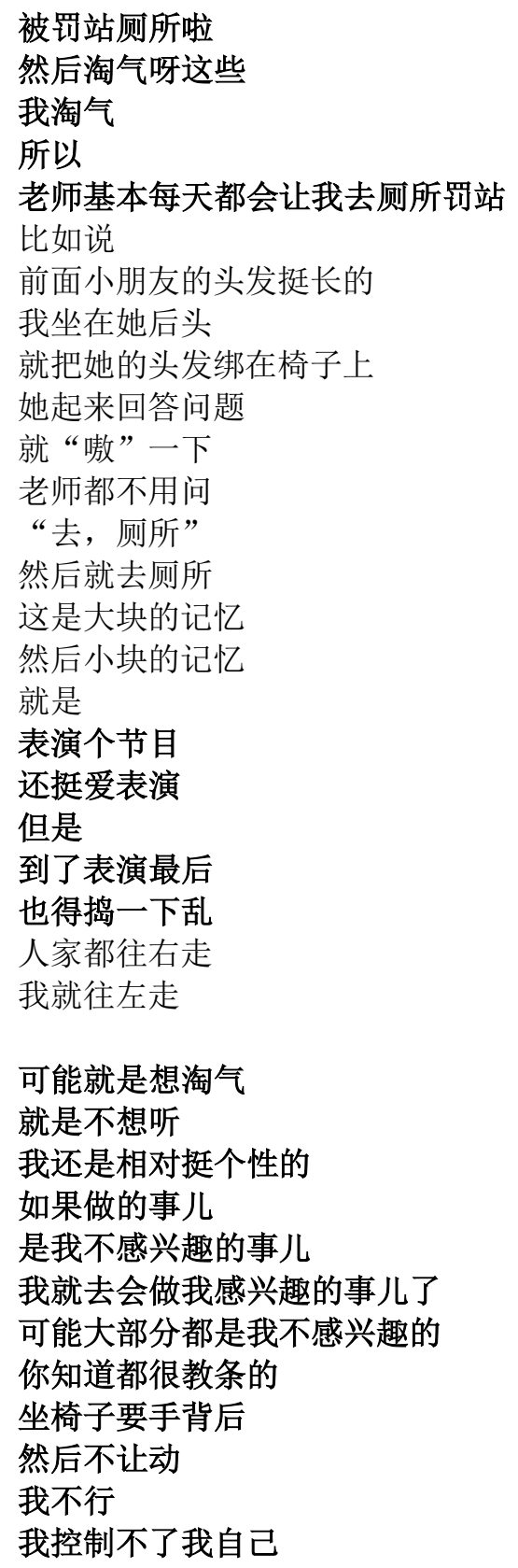

Annotation: Cecilia's reflection on who she was when she was a little girl in the kindergarten and why she was like that and how the teachers responded to her behaviour.

我只对一个老师相对有印象

就是短短的卷发

右嘴角上有一个黑色的痣

老师好像叫图雅

记忆当中

我觉得这个老师对我最好

所以我也对她的印象特别深

想不起来了

我记忆中 


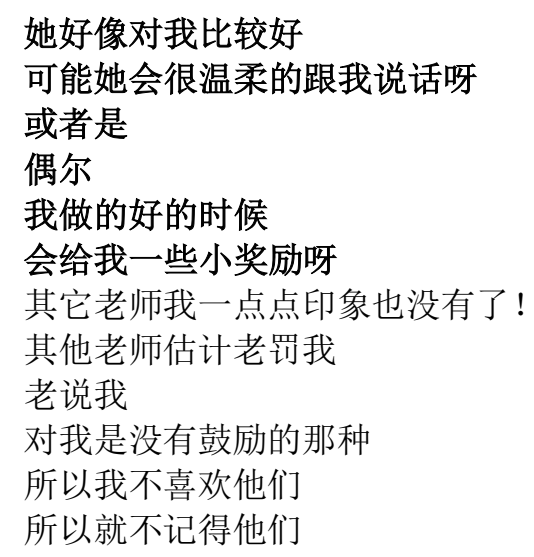

Annotation: The only kindergarten teacher that Cecilia remembered since she was nice to her and sometimes gave her some little prizes.

Step 3: Deleting the materials that don't relate to the research questions and the foci of this while translating them into English, and rearrange the texts to a temporary poem.

I was quite naughty at kindergarten.

Wet beds every night.

Do naughty things to other children.

I would be sent to the toilet by the teachers

as punishment.

Almost every day.

When there was a performance

I could do well.

I would do things different to other children.

Like walking off the stage from a different direction.

I could only remember one teacher.

She was nice to me.

She would praise me when I did something good.

Other teachers

NO!

I did not know why I was like that.

Maybe I just wanted to be naughty.

I had quite strong personality.

Won't do the things that I did not like.

Step 4: Select more relevant parts of these poems, rearrange and fit them into the final poem Childhood Memory with other relevant temporary poems that have been arranged through the same process.

I was quite naughty

at kindergarten.

Wet beds every night.

Do naughty things

to other children.

I would be 
sent to the toilet

by the teachers

as punishment

almost every day.

I could only remember

one teacher.

She was nice to me.

She would praise me

when I did something good.

Other teachers

NO!

I had quite strong personality.

I won't do the things

that I did not like. 


\section{Appendix J: Sample of Analytical Memo - Cecilia}

\begin{tabular}{|c|c|c|c|c|c|}
\hline \# & Poems & Code & Cultural/Community Lens & Interpersonal Lens & Personal Lens \\
\hline 1 & Childhood memory & $\begin{array}{l}\text { Views } \\
\text { child and the } \\
\text { community }\end{array}$ & $\begin{array}{l}\text { Community based child rearing } \\
\text { Gendered view of rearing a girl }\end{array}$ & $\begin{array}{l}\text { Interactions with teachers and mum } \\
\text { Cecilia's position } \\
\text { Finding her ways to get what she } \\
\text { wanted }\end{array}$ & $\begin{array}{l}\text { Personality vs. Teachers/parents' expectations } \\
\text { Shaped feelings and changes } \\
\text { Importance of the self }\end{array}$ \\
\hline 2 & $\begin{array}{l}\text { Choosing and } \\
\text { studying at training } \\
\text { college }\end{array}$ & $\begin{array}{l}\text { Being a teacher - choice } \\
\text { TPL - T prep. }\end{array}$ & & $\begin{array}{l}\text { Disconnection between training } \\
\text { college and kindergarten }\end{array}$ & $\begin{array}{l}\text { Interested in music } \\
\text { Value practical, creative and spontaneous learning } \\
\text { Segregated view of professional learning }\end{array}$ \\
\hline 3 & $\begin{array}{l}\text { Observe and follow } \\
\text { all rules and } \\
\text { regulations }\end{array}$ & $\begin{array}{l}\text { Being a teacher }- \text { first } \\
\text { five years of teaching }\end{array}$ & $\begin{array}{l}\text { Local kindergarten } \\
\text { Restricted by rules and } \\
\text { regulations, prescribe curriculum } \\
\text { Personal and institutional values } \\
\text { clash }\end{array}$ & $\begin{array}{l}\text { Finding her ways to increase her } \\
\text { autonomy and satisfaction in } \\
\text { teaching, to balance prescriptive } \\
\text { curriculum and children's interests }\end{array}$ & $\begin{array}{l}\text { Like children } \\
\text { Disagree to educational philosophy and management style } \\
\text { Very negative emotions } \\
\text { Critical incident (positive)- interaction with a researcher - } \\
\text { emergent teaching and learning } \\
\text { Critical incident (negative) - inspections }\end{array}$ \\
\hline 4 & $\begin{array}{l}\text { Empty hand capture } \\
\text { white wolf }\end{array}$ & $\begin{array}{l}\text { TPL - change of } \\
\text { community }\end{array}$ & $\begin{array}{l}\text { Different educational } \\
\text { philosophies in different contexts }\end{array}$ & & $\begin{array}{l}\text { Disconnection between past and present experience } \\
\text { Dealing with old/new, ideal/practical educational philosophies } \\
\text { Powerless: doubting, unknown, }\end{array}$ \\
\hline 5 & $\begin{array}{l}\text { Slowly, slowly } \\
\text { learning and } \\
\text { changing my } \\
\text { philosophy }\end{array}$ & TPL-situated learning & Informal, loosely controlled & $\begin{array}{l}\text { Learning from teaching partners, } \\
\text { colleagues, and experts - } \\
\text { communication, collaboration and co- } \\
\text { construction }\end{array}$ & $\begin{array}{l}\text { Learning through self-study - observation, participation and } \\
\text { reflection } \\
\text { Active, responsible for own learning }\end{array}$ \\
\hline 6 & $\begin{array}{l}\text { Educational } \\
\text { philosophy }\end{array}$ & $\begin{array}{l}\text { TPL - understand } \\
\text { philosophical changes }\end{array}$ & & $\begin{array}{l}\text { Learning from teaching partners } \\
\text { through participation }\end{array}$ & $\begin{array}{l}\text { "Have to change" attitude } \\
\text { Articulating personal educational philosophy - child centred, } \\
\text { disposition orientated } \\
\text { Drawing on practical knowledge and cultural knowledge } \\
\text { Highlighted children's interests and independent thinking }\end{array}$ \\
\hline 7 & $\begin{array}{l}\text { The feelings towards } \\
\text { teaching }\end{array}$ & $\begin{array}{l}\text { TPL - emotional } \\
\text { geographies }\end{array}$ & & $\begin{array}{l}\text { Motivation - better interaction with } \\
\text { children }\end{array}$ & Positive emotions - realizing confidence, control and agency \\
\hline 8 & $\begin{array}{l}\text { Understanding the } \\
\text { curriculum }\end{array}$ & $\begin{array}{l}\text { TPL-Theorizing } \\
\text { View }\end{array}$ & $\begin{array}{l}\text { Curriculum context - flexible and } \\
\text { spontaneous, child-centred }\end{array}$ & & View of curriculum - broad, situated, child-centred, play-based \\
\hline 9 & $\begin{array}{l}\text { Challenges } \\
\text { accompanying the } \\
\text { changing process }\end{array}$ & $\begin{array}{l}\text { TPL }- \text { tensions } \\
\text { Being a teacher }- \text { self } \\
\text { image }\end{array}$ & Different value systems & $\begin{array}{l}\text { Different agendas among different } \\
\text { groups of people }\end{array}$ & $\begin{array}{l}\text { Inner tensions and contradictions } \\
\text { Uncertainty } \\
\text { Identity: Un-knower in front of children } \\
\text { Knowing self as a learner }\end{array}$ \\
\hline 10 & $\begin{array}{l}\text { Thinking big and } \\
\text { dreaming a dream }\end{array}$ & $\begin{array}{l}\text { Being a teacher - } \\
\text { identity, contribution }\end{array}$ & $\begin{array}{l}\text { Understanding the different } \\
\text { cultural contexts }\end{array}$ & & $\begin{array}{l}\text { Identity: Knower in the Chinese context with different cultural } \\
\text { knowledge, who has a big dream! }\end{array}$ \\
\hline
\end{tabular}


